\title{
IDENTIFICATION OF COMPOSITE COMBINATIONS: KEY TO VALIDATE GOLDBACH CONJECTURE
}

\author{
Manish Khare \\ Assistant Professor in Physics, MIT Academy of Engineering, Alandi(D),Pune \\ India-412105 \\ Email: mnshkhare@gmail.com, mrkhare@esci.maepune.ac.in
}

Kalyanlakshmi Chitta

Manager, Union Bank of India, Alandi(D),Pune India-412105

Email: kalyanilakshmichitta@gmail.com 


\section{Abstract:}

This paper discusses a possible approach to validate the Goldbach conjucture which states that all even numbers can be expressed as a summation of two prime numbers. For this purpose the paper begins with the concept of successive-addition-of-digits-of-an-integer-number (SADN) and its properties in terms of basic algebraic functions like addition, multiplication and subtraction. This concept of SADN forms the basis for classifying all odd numbers into 3 seriesthe S1, S3 and S5 series- which comprise of odd numbers of $\operatorname{SADN}(7,4,1), \operatorname{SADN}(3,9,6)$ and $\operatorname{SADN}(5,2,8)$ respectively and follow a cyclical order. The S1 and S5 series are of interest in the analysis since they include both prime and composite numbers while the S3 series exclusively consists of composite numbers. Furthermore, the multiplicative property of SADN shows why composites on the S1 series are derived as products of intra-series elements of the S1 and S5 series while composites on the S5 series are derived as products of inter-series elements of the S1 and S5 series. The role of SADN is also important in determining the relevant series for identifying the combination of primes for a given even number since it shows why such combinations for even numbers of $\operatorname{SADN}(1,4,7)$ will be found on the S5 series while those for even numbers of $\operatorname{SADN}(2,5,8)$ will lie on the $\mathrm{S} 1$ series and both the series have a role to play in identifying the prime number combinations for even numbers with $\operatorname{SADN}(3,6,9)$. Thereafter, the analysis moves to calculating the total number of acceptable combinations for a given even number that would include combinations in the nature of two composites $(\mathrm{c} 1+\mathrm{c} 2)$, one prime and one composite $(\mathrm{p}+\mathrm{c})$ and two primes $(\mathrm{p} 1+\mathrm{p} 2)$. A cyclical pattern followed by even numbers is also discussed in this context. Identifying the $\mathrm{c} 1+\mathrm{c} 2$ and $\mathrm{p}+\mathrm{c}$ combinations and thereafter subtracting them from the total number of combinations will yield the number of $\mathrm{p} 1+\mathrm{p} 2$ combinations. For this purpose the paper discusses a general method to calculate the number of composites on the S1 and S5 series for a given number and provides a detailed method for deriving the number of $\mathrm{c} 1+\mathrm{c} 2$ combinations. The paper presents this analysis as a proof to validate the Goldbach conjecture.

Since even numbers can be of SADN 1 to 9 and the relation between nTc (i.e. total number of acceptable combinations) and nc(i.e. number of composites) for all even numbers can either be of $n T c>n c$ or $n T c \leq n c$, the paper shows that the Goldbach conjecture is true for both these categories of even numbers. In this manner this analysis is totally inclusive of all even numbers in general terms and since the analysis of every even number is common in methodology but unique in compilation, apart from being totally inclusive, it is also mutually exclusive in nature.

This proves that the Goldbach conjecture which states that all even numbers can be expressed as atleast one combination of two prime numbers holds true for all even numbers, across all categories possible. Additionally this approach proves that the identification of $\mathrm{p} 1+\mathrm{p} 2$ combinations which would validate the Goldbach conjecture lies in the identification of $\mathrm{c} 1+\mathrm{c} 2$ combinations.

Keywords: Goldbach conjecture, Goldbach problem, Primes, Distribution of Primes, Primes and integers, Additive questions involving primes 


\section{Structure of the paper}

1. Introduction- Statement of Goldbach conjecture and attempts discussed to address it

2. SADN - definition and properties

3. SADN of prime numbers

4. (A) Classifying odd numbers into 3 series based on their SADN

(B) Why S3 is of only composites whereas S1 and S5 comprises of primes and composites

5. (A) Method for calculating total number of composites on the S1 and S5 series

(B) Number of unique composites for a given even number

6. Possible combinations of $\mathrm{p} 1+\mathrm{p} 2$ for even number of particular SADN and a particular last digit

7. Why components of $p_{1}+p_{2}$ combinations for an even number of:-

- $\operatorname{SADN}(5,2,8)$ lie on $\mathrm{S} 7$ series?

- $\operatorname{SADN}(7,4,1)$ lie on S5 series?

- $\operatorname{SADN}(6,3,9)$ lie on both $\mathrm{S} 5$ \& S1 series?

8. Cyclic-Series-Element (CSE) of even numbers (defined as $2 \mathrm{k}$ )

9. Identifying total number of acceptable combinations(i.e. nTC) for a given even number (2k) depending on SADN and CSE

10. Identifying combinations of type $\mathrm{p}_{1}+\mathrm{p}_{2}$ for even number $2 \mathrm{k}$ :-
(A) If $\mathrm{k}=$ prime
(B) If TC $\geq$ number of composites
(C) If TC < number of composites

11. Identifying number of unique combinations of type $\mathrm{c} 1+\mathrm{c} 2$ for a given $2 \mathrm{k}$ :-

(A) Step1:- $\quad \mathrm{c} 1+\mathrm{c} 2$ derived from $\mathrm{k}$

(B) Step2:- $\quad \mathrm{c} 1+\mathrm{c} 2$ derived from last digit of $2 \mathrm{k}$

(C) Step3:- $\quad \mathrm{c} 1+\mathrm{c} 2$ derived from $6 \mathrm{p} 1 \mathrm{p} 2$ where $\mathrm{p} 1$ and $\mathrm{p} 2$ are primes such that $6 \mathrm{p} 1 \mathrm{p} 2$ $\leq 2 \mathrm{k}$

(D) Deriving total number of $\mathrm{c} 1+\mathrm{c} 2$ combinations for a given even number (2k): Some illustrations

(E) PYTHON Codes used to compute for verification in case of any given even number $(2 \mathrm{k})$ of $\operatorname{SADN}(5,2,8), \operatorname{SADN}(7,4,1)$ or $\operatorname{SADN}(6,3,9)$

12. Number of $\mathrm{c} 1+\mathrm{c} 2$ combinations: minimum required theoretically vis-à-vis actual number of $\mathrm{c} 1+\mathrm{c} 2$ combinations :

- Concepts of minimum number of $\mathrm{c} 1+\mathrm{c} 2$ combinations and actual number of $\mathrm{c} 1+\mathrm{c} 2$ combinations for even numbers if $\mathrm{nTC}<\mathrm{nc}$

- Behaviour of actual number of $\mathrm{c} 1+\mathrm{c} 2$ combinations and minimum number of $\mathrm{c} 1+\mathrm{c} 2$ over a range of even numbers

- Zeno's Achilles and Tortoise paradox

- Relation between actual and minimum number of $\mathrm{c} 1+\mathrm{c} 2$ and derivation of $\mathrm{p} 1+\mathrm{p} 2$ combination

13. Conclusion: Implications for Goldbach conjecture

1 [Structure of the paper] 


\section{Introduction}

\section{Statement of Goldbach conjecture \& methodology discussed to address it}

On $7^{\text {th }}$ of June, 1742, a Prussian amateur mathematician and historian Christian Goldbach, wrote a letter to Leonard Euler, the content of which is later understood to have lead to saying 'at least it seems that every even number that is greater than 2 is the sum of two primes' $[1,2]$. In 1938 Nils Pipping showed that the Goldbach conjecture is true for even numbers up to and including 100,000 [3]. It has been established, using a computer search, that it is true for even numbers up to and including 4,000,000,000,000,000,000 [4]. The unproven Goldbach conjecture enjoyed the dual importance of being one of such theorems which were easy enough to be guessed by any fool and yet not proven [5]. It is generally because of these paradoxical properties attached with Goldbach conjecture that British Mathematicians G.H.Hardy and J.E.Littlewood attempted to prove it using partition functions and resulted in bringing this problem into contact with the then recognised methods of the Analytic Theory of Numbers [6,7] and the problem was found worthy of being included as selected problems in number theory [8]. Interestingly ternary Goldbach conjecture, also an offshoot of the abovementioned exchange of letters between Euler and Goldbach, has been proved by Helfgott to be true for odd numbers greater than 5 [9]. In this context, although the attempts by Pogorzelski have not received any objections, they have not been accepted either, till date $[10,11]$.

Watanabe observes that the number of prime \& prime combinations for even numbers would be less in case if half of even number in consideration is a prime as compared to number of prime \& prime combinations in case if half of even number in consideration is composite [12]. In present work a logical and conclusive derivation is presented for this observation as well.

The present paper's approach is to validate the Goldbach conjucture which states that all even numbers can be expressed as a summation of two prime numbers. For this purpose the paper begins with a brief discussion of the concept of successive-addition-of-digits-of-an-integernumber (SADN) and its properties in terms of basic algebraic functions like addition, multiplication and subtraction. This concept of SADN forms the basis for classifying all odd numbers into 3 series-the S1, S3 and S5 series- which comprise of odd numbers of SADN $(7,4,1),(3,9,6)$ and $(5,2,8)$ respectively and follow a cyclical order. The S1 and S5 series are of interest in the analysis since they include both prime and composite numbers while the S3 series exclusively consists of composite numbers except the number ' 3 '. Furthermore, the multiplicative property of SADN shows why composites on the S1 series are derived as products of intra-series elements of the S1 and S5 series while composites on the S5 series are derived as products of inter-series elements of the S1 and S5 series. The role of SADN is also important in determining the relevant series for identifying the combination of primes for

1 [Section 1] 
a given even number since it shows why such combinations for even numbers of SADN 1,4 and 7 will be found on the S5 series while those for even numbers of SADN 2,5 and 8 will lie on the $\mathrm{S} 1$ series and both the series have a role to play in identifying the prime number combinations for even numbers with SADN 3,6 and 9. Thereafter, the analysis moves to calculating the total number of acceptable combinations for a given even number that would include combinations in the nature of two composites $(\mathrm{c} 1+\mathrm{c} 2)$, one prime and one composite $(p+c)$ and two primes $(p 1+p 2)$. A cyclical pattern followed by even numbers is also discussed in this context. Identifying the $\mathrm{c} 1+\mathrm{c} 2$ and $\mathrm{p}+\mathrm{c}$ combinations and thereafter subtracting them from the total number of combinations will yield the number of $\mathrm{p} 1+\mathrm{p} 2$ combinations. For this purpose the paper discusses a general method to calculate the number of composites on the S1 and S5 series for any given even number and provides a detailed method for deriving the number of combinations of type $\mathrm{c} 1+\mathrm{c} 2$. The paper thereafter introduces the concept of minimum required number of combinations of type $\mathrm{c} 1+\mathrm{c} 2$ to identify a combination of type $\mathrm{p} 1+\mathrm{p} 2$; for any given even number. The relation between minimum required number of $\mathrm{c} 1+\mathrm{c} 2$ combinations and actual number of $\mathrm{c} 1+\mathrm{c} 2$ combinations forms the basis for identifying the possibility of existence of combination of type $\mathrm{p} 1+\mathrm{p} 2$. The paper presents this analysis as a proof to validate the Goldbach conjecture. 


\section{Successive Addition of Digits of a Number (SADN)}

\section{Definition and Properties:}

- What is SADN?

- What are the properties of SADN?

- Proof of the properties of SADN

The function of SADN stands for Successive Addition of Digits of (integer) Number. SADN function exhibits following properties:-

i. Idempotence

ii. Range of SADN function

iii. Distribution over addition

iv. Distribution over multiplication

v. Additive Identity for SADN function

vi. Interchangeability of non-positive SADN and positive SADN

vii. Distribution over subtraction

viii. Multiplicative Identity for SADN function

\section{i. Property of Idempotence:-}

SADN stands for successive-addition-of-digits-of-number. Addition is an operation which is operated upon multiple operands and not defined in case of a single operand alone. Here the term 'successive' implies that the digits of the number are to be added as long as the operation of addition is defined. It implies that to determine SADN of any given number, its digits are to be successively added until a single digit is obtained. This single digit is termed as SADN of the given number.

Example: Suppose the given number is 546289 . Addition of its digits $=5+4+6+2+8+9=34$

Successive addition of digits $=3+4=7$

In our example, SADN of (546289)=7

In general terms: SADN of $(\mathrm{x})=\mathrm{SADN}$ of $(\operatorname{SADN}$ of $(\operatorname{SADN}$ of $(\ldots \mathrm{SADN}$ of $(\mathrm{x}))))$ which says that SADN function is an idempotent function.

\section{ii. Range of SADN function:-}


The property of idempotence implies that the value of SADN function for any non-zero integer number would be a single digit integer only ranging from 1 to 9.

$1 \leq \mathrm{SADN}$ of $(\mathrm{x}) \leq 9$ implies that $\mathrm{SADN}$ of $(\mathrm{x})=\{1,2,3,4,5,6,7,8,9\}$

\section{iii. Property of distribution over addition:-}

Present paper identifies the phenomenon of SADN as analogous to 'valency of an atom'. In case of an atom, its inner shell gets filled by as much number of electrons as suggested by the octet rule and the outermost shell is known as valence shell. Electrons occupying the valence-shell are called as valence-electrons. Just as valence-electrons are responsible for the properties exhibited by the corresponding atom, the current-row(as discussed below) plays a central role in portraying the properties of SADN of an integer.

Consider the natural numbers written in matrix form where number of rows is nine [as 9 is the maximum possible value of SADN of any integer] and number of columns goes on increasing. Upon writing in this form, we get a sample matrix M1 for natural numbers from one(1) to fifty(50) as following:-

$\begin{array}{lllllll}\text { Row(1) having elements of } \operatorname{SADN}(1): & 1 & 10 & 19 & 28 & 37 & 46 \\ \text { Row(2) having elements of } \operatorname{SADN}(2): & 2 & 11 & 20 & 29 & 38 & 47 \\ \text { Row(3) having elements of } \operatorname{SADN}(3): & 3 & 12 & 21 & 30 & 39 & 48 \\ \text { Row(4) having elements of } \operatorname{SADN}(4): & 4 & 13 & 22 & 31 & 40 & 49 \\ \text { Row(5) having elements of } \operatorname{SADN}(5): & 5 & 14 & 23 & 32 & 41 & 50 \\ \text { Row(6) having elements of } \operatorname{SADN}(6): & 6 & 15 & 24 & 33 & 42 \\ \text { Row(7) having elements of } \operatorname{SADN}(7): & 7 & 16 & 25 & 34 & 43 \\ \text { Row(8) having elements of } \operatorname{SADN}(8): & 8 & 17 & 26 & 35 & 44 \\ \text { Row(9) having elements of } \operatorname{SADN}(9): & 9 & 18 & 27 & 36 & 45\end{array}$

\section{Matrix M1}

Through this matrix M1, we discuss about SADN as follows:

In order to determine the SADN of an integer ' $n$ '; we write numbers, starting from one(1), till the integer ' $n$ '. The column in which the integer ' $n$ ' exists, is called as current column. All columns filled before the current column are known as complete columns. For determining SADN of 'n'; we don't bother about the number of complete columns and count the number of rows of the current column. Number of row in which integer(n) exists; is termed as SADN of the integer(n). 
In this way, the current column in case of SADN is similar to what valence-shell is in case of an atom.

\section{Distributive over addition:}

$\operatorname{SADN}$ of $(x+y)=\operatorname{SADN}$ of $(x)+\operatorname{SADN}$ of $(y)$

SADN function is distributive over addition.

\section{Proof:-}

SADN of integers $x$ and $y$ denotes the number of rows of current columns corresponding to $\mathrm{x}$ and $y$ as mentioned in matrix M1. In case of addition: Suppose SADN of $x$ is given as $x$ ' and SADN of $y$ is given as y'. Here $x$ ' and y' would be natural numbers such that the value of $x^{\prime}$ and y' cannot exceed the number 9; as there are only 9 rows in matrix M1. Either $x$ ' $+y$ ' would be $<=9$ (i.e. first case) or it would be $>9$ (i.e. second case) but can never be greater than 18 , which is the case if both $x^{\prime}$ and $y^{\prime}$ attain their maximum possible values; i.e. 9.

\section{In first case when $x^{\prime}+y^{\prime}$ would be $<=9$ :-}

If we write numbers upto $\mathrm{x}$ as per matrix $\mathrm{M} 1$ and call this arrangement as matrix $\mathrm{M} 1 \mathrm{x}$, we may get some number of complete columns alongwith $x$ ' rows in current column and upon writing numbers upto $\mathrm{y}$ and call it matrix M1y, we may get some number of complete columns alongwith y' rows in current column. Now if we write numbers upto $\mathrm{x}+\mathrm{y}$ as matrices $\mathrm{M} 1 \mathrm{x}$ and M1y standing side by side, the number of complete columns remains as summation of number of complete columns of M1x and M1y. In present case the summation of number of filled rows (i.e. $x^{\prime}$ ) in current column of M1x and that of in M1y gives us $x^{\prime}+y^{\prime}$. As $x^{\prime}+y^{\prime} \leq 9$, it implies that no extra complete column is generated upto the integer $\mathrm{x}+\mathrm{y}$.

Hence SADN of $(x+y)=\operatorname{SADN}$ of $(x)+\operatorname{SADN}$ of $(y)$ in first case.

\section{In second case when $x^{\prime}+y^{\prime}$ would be $>9$ :-}

If we write numbers upto $\mathrm{x}$ as per matrix $\mathrm{M} 1$ and call this arrangement as matrix $\mathrm{M} 1 \mathrm{x}$, we may get some number of complete columns alongwith x' rows in current column and upon writing numbers upto $\mathrm{y}$ and call it matrix M1y, we may get some number of complete columns alongwith y' rows in current column. Now if we write numbers upto $\mathrm{x}+\mathrm{y}$ as matrices M1x and M1y standing side by side, the number of complete columns remains, (till now) as addition of number of complete columns of M1x and M1y. In present case the summation of number of filled rows (i.e. $x^{\prime}$ ) in current column of M1x and that of in M1y gives us x'+y'. As x'+y' >9, it implies that one extra complete column is generated if we write numbers upto the integer $\mathrm{x}+\mathrm{y}$ as arranged in matrix M1. As number of rows in this extra, newly generated, complete column would be 9 only; number of filled rows of current column would become $x^{\prime}+y^{\prime}-9$. As in present case, $9<x^{\prime}+y^{\prime} \leq 18$; there will be total of 9 subcases, corresponding to $x^{\prime}+y^{\prime}$ equals to either 10 
or 11 or 12 or 13 or 14 or 15 or 16 or 17 or 18 . In these subcases the corresponding row number of current column would be 1 or 2 or 3 or 4 or 5 or 6 or 7 or 8 or 9 respectively.

As 1 to 9 are SADN of 10 to SADN of 18 respectively i.e. 10 is the $1^{\text {st }}$ number after removing initial 9 numbers and similarly 18 is the $9^{\text {th }}$ number after removing initial 9 numbers. Hence in this case as well, if numbers upto $\mathrm{x}+\mathrm{y}$ are arranged in terms of matrix M1 and this arrangement is denoted as M1 $(x+y)$, then SADN of $(x+y)$ is summation of individual SADNs of the integers $x$ and $\mathrm{y}$.

Hence SADN of $(x+y)=$ SADN of $(x)+$ SADN of $(y)$ in second case as well.

Abovementioned analysis allows us to say that in any of the possible cases:

SADN of $(x+y)=\operatorname{SADN}$ of $(x)+\operatorname{SADN}$ of $(y)$

i.e. SADN function is distributive over addition.

Example: SADN of $(28)+$ SADN of $(541)=$ SADN of $(28+541)=$ SADN of $(569)$

Under property of idempotence $\mathrm{SADN}$ of $(569)=\mathrm{SADN}$ of $(20)=2$

\section{iv. Property of distribution over multiplication:-}

SADN of $(x . y)=\operatorname{SADN}$ of $(x) \cdot \operatorname{SADN}$ of $(y)$

SADN function is distributive over multiplication.

\section{Proof:}

Suppose SADN of $\mathrm{x}$ is given as $\mathrm{x}^{\prime}$ and SADN of $\mathrm{y}$ is given as $\mathrm{y}^{\prime}$.

Since $\operatorname{SADN}$ of $(\mathrm{x} . \mathrm{y})=\mathrm{SADN}$ of $(\mathrm{x}+\mathrm{x}+\mathrm{x}+\ldots \mathrm{y}$ times $)=$ SADN of $\mathrm{x}+\mathrm{SADN}$ of $\mathrm{x}+\ldots \mathrm{y}$ times $=\mathrm{y} \cdot[\mathrm{SADN}$ of $(\mathrm{x})]=\mathrm{y} \cdot \mathrm{x}$ [by property of distribution over addition, as discussed above]

Implies that $\mathrm{SADN}$ of $(\mathrm{x} . \mathrm{y})=\mathrm{y} \cdot \mathrm{x}$ ' [equation 1]

Property of idempotence of SADN function says that:-

$\operatorname{SADN}$ of $(\mathrm{x} \cdot \mathrm{y})=\mathrm{SADN}$ of $[\operatorname{SADN}$ of $(\mathrm{x} \cdot \mathrm{y})]=\mathrm{SADN}$ of $\left(\mathrm{y} \cdot \mathrm{x}^{\prime}\right)=\mathrm{x}^{\prime} \cdot \mathrm{y}^{\prime}$ i.e. [SADN of $\left.(\mathrm{x})\right]$. [SADN of $(\mathrm{y})]$ [applying equation 1]

Implies that SADN of $(x . y)=[\operatorname{SADN}$ of $(x)] .[\operatorname{SADN}$ of $(y)]$ 
Example: As shown below: SADN of (12). SADNof (15)= SADNof (12x15)=SADNof (180)

SADN of $12=3 ;$ SADN of $15=6$;

$[\mathrm{SADN}$ of 12].[SADN of 15$]=3 \times 6=18=9 \ldots \ldots$ [property of idempotence $]$

SADN of $(12 \times 15)=\operatorname{SADN}$ of $(180)=9 \quad \ldots \ldots$. [property of idempotence $]$

\section{v. Additive Identity for SADN function:-}

As SADN is primarily a type of addition operator, additive identity zero(0) acts as an additive identity for SADN as well.

Apart from zero, the number nine(9) also acts as an additive identity for SADN function.

\section{Proof:}

The reason of 9 being an additive identity for SADN function is as follows:-

In context of arranging the integers as per the matrix M1, SADN of any integer is identified by the number of row in which that integer lies in current column. Placing the digit 9 anywhere in an integer changes the integer in such a way that the new integer has more number of complete columns of 9 numbers but the number of filled rows in current column remains unchanged. As the number of filled rows of current column denotes the SADN of integer, hence introduction of digit 9 within the integer doesn't affect the SADN of that integer. This drives us to conclude that the number 9 acts as additive identity for SADN function.

Example: $\operatorname{SADN}$ of $(52)=\mathrm{SADN}$ of $(529)=\mathrm{SADN}$ of $(5092990)=7$

vi. Interchangeability of non-positive SADN and positive SADN:-

Properties of distribution over addition and identity of SADN function leads to following equivalence between nonpositive and positive values of SADN

\begin{tabular}{|l|l|l|l|l|l|l|l|l|l|}
\hline $\begin{array}{l}\text { Positive SADN } \\
\text { digit }\end{array}$ & 1 & 2 & 3 & 4 & 5 & 6 & 7 & 8 & 9 \\
\hline $\begin{array}{l}\text { Equivalent non- } \\
\text { positive SADN } \\
\text { digit }\end{array}$ & -8 & -7 & -6 & -5 & -4 & -3 & -2 & -1 & 0 \\
\hline
\end{tabular}

Table 2.1: Equivalence between nonpositive and positive values of SADN

5 [Section 2] 
Both numbers of same columns are considered to be identical and replaceable substitutes of one another if need arises to consider non-positive digit for SADN.

This above-mentioned table- 2.1 of interchangeability relates negative and positive SADN as follows:

$$
\operatorname{SADN} \text { of }(-\mathrm{a})=-\operatorname{SADN} \text { of }(\mathrm{a})
$$

\section{vii. Distribution over subtraction:-}

Under application of Table-2.1 and property of distribution over addition:-

SADN of (x)-SADN of $(y)=\operatorname{SADN}$ of $(x)+\operatorname{SADN}$ of $(-y)=\operatorname{SADN}$ of $(x-y)$

SADN of $(x)-\operatorname{SADN}$ of $(y)-\operatorname{SADN}$ of $(z)=$ SADN of $(x-y-z)=$ SADN of $(x)-\operatorname{SADN}$ of $(y+z)$

Example1: $\quad$ SADN of $(724-452)=$ SADN of $(724)-$ SADN of $(452)=S A D N$ of $(4)-S A D N$ of $(2)=\operatorname{SADN}$ of $(2)=2$

OR $\quad \mathrm{SADN}$ of $(724-452)=\mathrm{SADN}$ of $(724)-\mathrm{SADN}$ of $(452)=\mathrm{SADN}$ of $(4)-\mathrm{SADN}$ of $(2)=$ $\mathrm{SADN}$ of $(4)+\mathrm{SADN}$ of $(-2)=\mathrm{SADN}$ of $(4)+\mathrm{SADN}$ of $(7)=\mathrm{SADN}$ of $(11)=2($ refer table 1$)$

and $\mathrm{SADN}$ of $(724-452)=\mathrm{SADN}$ of $(272)=\mathrm{SADN}$ of $(2)=2$

Example2: $\quad$ SADN of (121-24) $=$ SADN of (121) - SADN of (24)=SADN of (4)-SADN of (6) $=-2=7($ refer table 2.1$)$

OR SADN of (121-24) = SADN of (121) - SADN of (24) = SADN of (4) - SADN of (6) = SADN of (4) + SADN of $(-6)=$ SADN of $(4)+$ SADN of $(3)=$ SADN of $(7)=7($ refer table 2.1$)$

And SADN of $(121-24)=\operatorname{SADN}$ of $(97)=7$

\section{viii. Multiplicative Identity for SADN function:-}

Apart from SADN(1) as multiplicative identity for every SADN function; following are multiplicative identities as special cases:-

$\operatorname{SADN}(4,7,1)$ acts as multiplicative identities for $\operatorname{SADN}(3,6)$

$\operatorname{SADN}(1,2,3,4,5,6,7,8,9)$ or $\operatorname{SADN}(n)$ act as multiplicative identity for SADN(9) 


\section{SADN of prime numbers}

\section{SADN of prime numbers}

Prime numbers are a particular type of subset of natural numbers. Any prime number would be divisible by itself and by the number 1 (one) only. Primes cannot be divided by any other natural number except themselves and 1. In terms of SADN function, the divisibility test of 3 says that any natural number would be divisible by 3 only if its SADN is 3, 6 or 9. It leads to conclude that any natural number whose SADN is 3,6 or 9 would be a composite as it would be divisible by the number 3 , hence SADN of primes can never be 3,6 or 9 (only exception to this would be the number ' 3 ' itself). This discussion in conjunction with the properties of range of SADN says that $\mathrm{SADN}$ of primes may be $1,2,4,5,7$ or 8 .

If ' $p$ ' represents a prime number, then $\operatorname{SADN}$ of $(p)=\{1,2,4,5,7,8\}$ 


\section{4(A).}

\section{Classifying odd numbers into 3 series based on their SADN}

\section{Classifying odd numbers into 3 series based on their SADN}

Set of natural numbers $\mathrm{N}=\{1,2,3,4,5,6,7,8,9,10,11, \ldots \ldots .$.

$\mathrm{N}=\mathrm{E}+\mathrm{D}$

Where $\mathrm{E}$ is set of even numbers, $\mathrm{E}=\{2,4,6,8,10, \ldots\}$

And $\mathrm{D}=$ set of odd numbers $=\{1,3,5,7,9,11, \ldots\}$

All elements of the set of even numbers ' $E$ ' are composites (with exception of the number 2) whereas elements of the set of odd numbers ' $\mathrm{D}$ ' may be prime or composite.

Now consider the following three series of odd numbers:-

$\mathrm{S} 1=\mathrm{a} 1+6 \mathrm{n}$ where $\mathrm{a} 1$ is 1 and $\mathrm{n}$ is a natural number implying

$\mathrm{S} 1=1+6 \mathrm{n} ; \mathrm{n} \in\{\mathrm{N}\}$

$\mathrm{S} 1=\{7,13,19,25,31,37,43,49,55,61,67, \ldots .$.

SADN of (element of $\mathrm{S} 1)=\{7,4,1\}$ in cyclic order

SADN of $(a 1+6 n) \in S 1$ implies that SADN of $(1+6 n) \in \mathrm{S} 1$

$\mathrm{S} 3=\mathrm{a} 3+6 \mathrm{n}$ where $\mathrm{a} 3$ is 3 and $\mathrm{n}$ is a natural number including zero implying

$\mathrm{S} 3=\{3,9,15,21,27,33,39,45,51,57,63,69, \ldots .$.

SADN of (element of $S 3)=\{3,9,6\}$ in cyclic order

$\operatorname{SADN}(a 3+6 n)$ e S3 implies that $\operatorname{SADN}(3+6 n)$ e S3

$\mathrm{S} 5=\mathrm{a} 5+6 \mathrm{n}$ where a5 is 5 and $\mathrm{n}$ is a natural number including zero implying

$\mathrm{S} 5=6 \mathrm{n}-1 ; \mathrm{n} \in\{\mathrm{N}\}$

1 | [Section 4: 4A] 
$\mathrm{S} 5=\{5,11,17,23,29,35,41,47,53,59,65,71, \ldots$.

SADN of (element of S5) $=\{5,2,8\}$ in cyclic order

SADN of $(a 5+6 n) \epsilon$ S5 implies that SADN of (5+6n) $є$ S5 implies that SADN of (6n-1) $€$ S5

\begin{tabular}{|l|l|}
\hline SADN of (n) :- & $\mathrm{n} \epsilon:-$ \\
\hline $7,4,1$ & S1 \\
\hline $3,9,6$ & S3 \\
\hline $5,2,8$ & S5 \\
\hline
\end{tabular}

Table 4A.1: SADN of odd numbers determines its Series out of S1, S3, S5

Set of natural numbers $N=\{1,2,3,4,5,6,7,8,9,10,11, \ldots \ldots .$.

Now we say that $\mathrm{N}=\mathrm{E}+\mathrm{D}=\mathrm{E}+\{1\}+\mathrm{S} 1+\mathrm{S} 3+\mathrm{S} 5$

Where $\mathrm{E}$ is set of even numbers, $\mathrm{E}=\{2,4,6,8,10, \ldots\}$

And $\mathrm{D}=$ set of odd numbers $=\{1\}+\mathrm{S} 1+\mathrm{S} 3+\mathrm{S} 5=\{1,3,5,7,9,11, \ldots\}$

An additional explanation for classifying odd numbers into the above-mentioned three series is discussed in Appendix 1. 


\section{4(B).}

\section{Why S3 is of only composites whereas S1 and S5 comprises of primes and composites}

\section{Why S3 is of only composites whereas $\mathrm{S} 1$ and S5 comprises of primes and composites}

Such segregation of odd numbers in term of three series S1, S3 and S5 leads to segregation of primes. As series $S 3$ consists of elements of $6 n+3$ type or $3 x(2 n+1)$ type, so all elements of S3 will be multiples of the number 3. This leads to conclude that series S3 consists of composites and no prime (number ' 3 ' being the only exception). A similar logic is that as all elements of S3 are having SADN as 3,6 or 9 leading to S3 elements beings multiples of 3 and hence being composites.

Hence prime numbers may belong to only S1 and S5. Additionally as mentioned above, series $S 1$ has elements of type $6 n+1$ and series $S 5$ has elements of type $6 n-1$. So this segregation of S1, S3 and S5 series also segregates the primes of types $6 n+1$ and $6 n-1$.

All $6 n+1$ type primes (and composites) will be only on series $\mathrm{S} 1$.

All 6n-1 type primes (and composites) will be only on series S5. 


\section{5(A).}

\section{Method for calculating total number of composites on the S1 and S5} series

\section{Method for calculating total number of composites on the S1 and S5 series}

SADN function is distributive over multiplication. An application of this property is the following table which leads to the condition for the elements of series S1 and S5.

\begin{tabular}{|c|c|c|c|c|c|}
\hline $\begin{array}{l}\text { Serie } \\
\text { s }\end{array}$ & $\begin{array}{l}\text { SADN } \\
\text { of } \\
\text { elemen } \\
\text { ts of } \\
\text { series }\end{array}$ & \multicolumn{4}{|c|}{$\begin{array}{l}\text { Possible combinations of SADN of divisors to yield the } \\
\text { composite number of particular SADN of series S1 or S5 }\end{array}$} \\
\hline S1 & SADN1 & $\begin{array}{l}\text { SADN1xSAD } \\
\text { N1 }\end{array}$ & $\begin{array}{l}\text { SADN2xSAD } \\
\text { N5 }\end{array}$ & $\begin{array}{l}\text { SADN4xSAD } \\
\text { N7 }\end{array}$ & $\begin{array}{l}\text { SADN8xSAD } \\
\text { N8 }\end{array}$ \\
\hline S1 & SADN7 & $\begin{array}{l}\text { SADN1xSAD } \\
\text { N7 }\end{array}$ & $\begin{array}{l}\text { SADN2xSAD } \\
\text { N8 }\end{array}$ & $\begin{array}{l}\text { SADN4xSAD } \\
\text { N4 }\end{array}$ & $\begin{array}{l}\text { SADN5xSAD } \\
\text { N5 }\end{array}$ \\
\hline S1 & SADN4 & $\begin{array}{l}\text { SADN1xSAD } \\
\text { N4 }\end{array}$ & $\begin{array}{l}\text { SADN2xSAD } \\
\text { N2 }\end{array}$ & $\begin{array}{l}\text { SADN5xSAD } \\
\text { N8 }\end{array}$ & $\begin{array}{l}\text { SADN7xSAD } \\
\text { N7 }\end{array}$ \\
\hline S5 & SADN5 & $\begin{array}{l}\text { SADN1xSAD } \\
\text { N5 }\end{array}$ & $\begin{array}{l}\text { SADN2xSAD } \\
\text { N7 }\end{array}$ & $\begin{array}{l}\text { SADN4xSAD } \\
\text { N8 }\end{array}$ & Xxxxxx \\
\hline S5 & SADN2 & $\begin{array}{l}\text { SADN1xSAD } \\
\text { N2 }\end{array}$ & $\begin{array}{l}\text { SADN4xSAD } \\
\text { N5 }\end{array}$ & $\begin{array}{l}\text { SADN7xSAD } \\
\text { N8 }\end{array}$ & Xxxxxx \\
\hline S5 & SADN8 & $\begin{array}{l}\text { SADN1xSAD } \\
\text { N8 }\end{array}$ & $\begin{array}{l}\text { SADN2xSAD } \\
\text { N4 }\end{array}$ & $\begin{array}{l}\text { SADN5xSAD } \\
\text { N7 }\end{array}$ & Xxxxxx \\
\hline
\end{tabular}

Table 5A.1: Series and SADN of series-elements alongwith possible combinations of divisors

Comparison of Table 4A.1 and Table 5A.1 concludes that:-

(a) Composites of SADN1 can be obtained by product of $\operatorname{SADN}(1 \times 1)$ or $\operatorname{SADN}(2 \times 5)$ or $\mathrm{SADN}(4 \mathrm{x} 7)$ or $\mathrm{SADN}(8 \mathrm{x} 8)$. In this case the only four possible combinations of both the divisor elements ( 1 and 1 OR 2 and 5 OR 4 and 7 OR 8 and 8) are always elements of a single series ( $\mathrm{S} 1$ or S5) 
(b) Composites of SADN7 can be obtained by product of SADN(1x7) or SADN(2x8) or $\operatorname{SADN}(4 \times 4)$ or $\operatorname{SADN}(5 \times 5)$. In this case the only four possible combinations of both the divisor elements ( 1 and 7 OR 2 and 8 OR 4 and 4 OR 5 and 5) are always elements of a single series ( 11 or S5)

(c) Composites of SADN4 can be obtained by product of $\operatorname{SADN}(1 \times 4)$ or $\operatorname{SADN}(2 \times 2)$ or $\operatorname{SADN}(5 \times 8)$ or $\operatorname{SADN}(7 \times 7)$. In this case the only four possible combinations of both the divisor elements (1 and 4 OR 2 and 2 OR 5 and 8 OR 7 and 7) are always elements of a single series ( 1 1 or S5)

(d) Composites of SADN5 can be obtained by product of SADN(1x5) or SADN(2x7) or $\operatorname{SADN}(4 \times 8)$. In this case the only three possible combinations of both the divisor elements (1 and 5 OR 2 and 7 OR 4 and 8) are always elements of $\underline{\text { two }}$ different series (S1 and S5)

(e) Composites of SADN2 can be obtained by product of SADN(1x2) or SADN $(4 \times 5)$ or $\operatorname{SADN}(7 \mathrm{x} 8)$. In this case the only three possible combinations of both the divisor elements (1 and 2 OR 4 and 5 OR 7 and 8) are always elements of two different series ( $\mathrm{S} 1$ and $\mathrm{S} 5$ )

(f) Composites of SADN8 can be obtained by product of $\operatorname{SADN}(1 \times 8)$ or $\operatorname{SADN}(2 \times 4)$ or $\operatorname{SADN}(5 \times 7)$. In this case the only three possible combinations of both the divisor elements (1 and 8 OR 2 and 4 OR 5 and 7) are always elements of two different series (S1 and S5)

Regarding seriesS1: The first three ( $a, b$ and $c$ )of above conclusions suggest that composite numbers of series $\mathrm{S} 1$ are either intra-series products of elements of series S1 or intra-series products of elements of series S5.

Regarding series S5: The next three (d, e and f) of above conclusions suggest that composite numbers of series S5 are always inter-series products of elements of S1 and S5.

\section{Pattern of formation of composite numbers on the S1 and S5 series:}

In context of Composites on $\mathrm{S} 1$ series:-

As composites contained in S1 are products of intra-series elements of S1 or S5, say products of intra-series elements of S1 are denoted by $\mathrm{C} 1$ and that of S5 are denoted by C5:- 
$\mathrm{C} 1=\left[(6 n+1) \cdot(6 n+1)+(6 n+1) \cdot 6 n^{\prime}\right] ;$ for each and every $n \epsilon\{N\}$, there exists $n$ ' $\epsilon\{0, N\}$

Or $C 1=(6 n+1) \cdot\left[6\left(n+n^{\prime}\right)+1\right]$; for each and every $n \in\{N\}$, there exists n' $\epsilon\{0, N\}$

Implies that $\mathrm{C} 1=\{49,91,133,175, \ldots\} \quad+\{91,169,247,325,403, \ldots\}$ $+\{133,247,361,475, \ldots\}+\{175,325,475,625, \ldots\}+\ldots+\{\}+\ldots$ infinite sets of infinite elements in each set

And C5 $=[(6 n-1) \cdot(6 n-1)+(6 n-1) \cdot 6 n ']$; for each and every $n \in\{N\}$, there exists n' $\epsilon\{0, N\}$

Or C5 $=(6 n-1) \cdot\left[6\left(n+n^{\prime}\right)-1\right]$; for each and every $n \in\{N\}$, there exists n' $\epsilon\{0, N\}$

Implies that $\mathrm{C} 5=\{25,55,85,115, \ldots\}+\{55,121,187, \ldots\}+\{85,187,289, \ldots\}$ $+\{115,253,391, \ldots\}+\ldots+\{\}+\ldots$ infinite sets of infinite elements in each set

From above discussion:

\section{Primes on series $\mathrm{S} 1=\mathrm{S} 1-$ composites of $\mathrm{S} 1=\mathrm{S} 1-\mathrm{C} 1-\mathrm{C} 3$}

In context of Composites on S5 series:-

As composites contained in S5 are products of interseries elements of S1 and S5, say interseries products of S1 and S5 are denoted by $\mathrm{C} 15$,

$C 15^{\prime}=\left[5(6 n+1)+(6 n+1) .6 n^{\prime}\right]$; for each and every $n \in\{N\}$, there exists $n ' \epsilon\{0, N\}$

$C 15^{\prime}=(6 n+1) .\left(5+6 n^{\prime}\right)$; for each and every $n \in\{N\}$, there exists n' $\epsilon\{0, N\}$

$\mathrm{C}^{\prime} 5^{\prime}=\{35,77,119,161,203, \quad\}+\{65,143,221,299, \ldots\}+\ldots .+\{\}+\ldots$ infinite sets of infinite elements in each set

\section{Primes on series S5 = S5- composites of S5 = S5 - C15'}

The pattern of formation of composite numbers on the S1 and S5 series as mentioned above has been confirmed both graphically (for limited number of integers) and also through a computer program (again, for limited but rather large number of integers). 


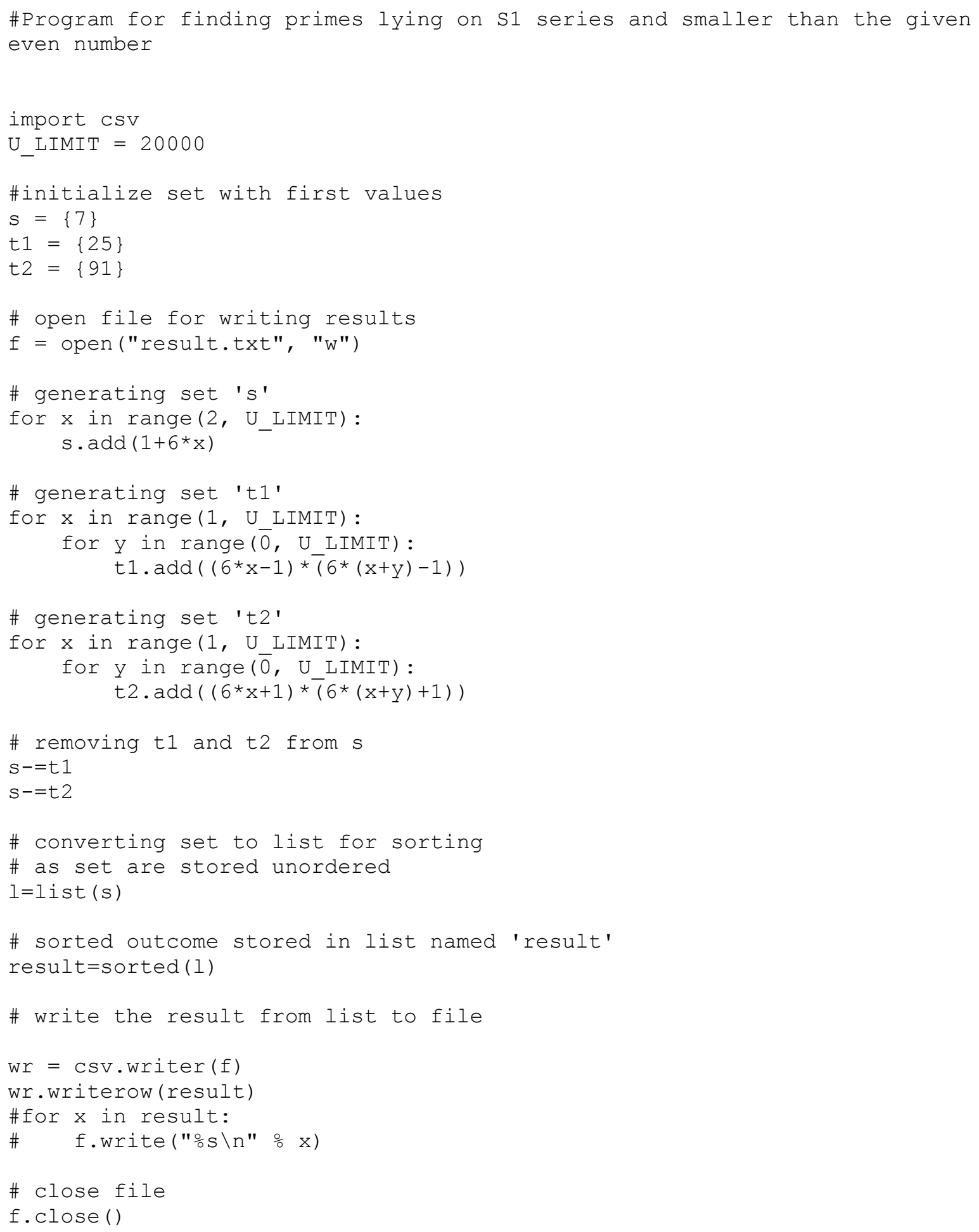




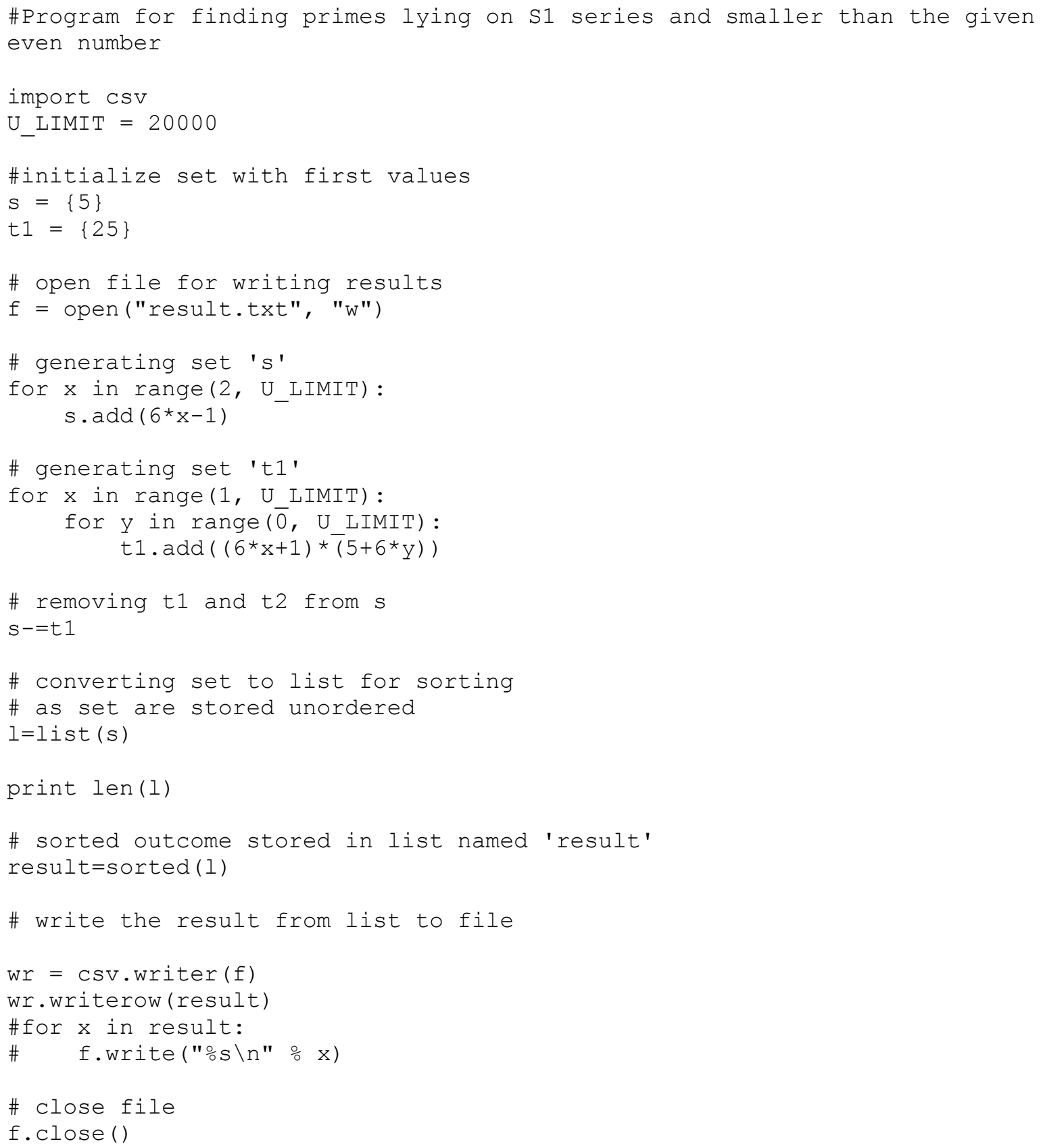




\section{5(B).}

\section{Number of composites for a given even number $2 k$}

\section{Number of composites for a given even number $2 k$}

\section{For S1 series:-}

For deriving number of unique composites on S7 series:-

Composites on S7 series are derived as intra-series products of elements of the S5 and S7 series.

In order to calculate the total number of composites formed on S7 series, following steps may be followed:-

1 Deriving composites on S7 series that are formed as intra-series products of S5 series

Unique composites of S7 series formed by elements of S5 series

Step 1:-Here we first find out the total number of composites formed by a particular prime element of the S5 series. This can be done by the following formula:-

Floor function of $[1 / 6\{$ floor function of $(2 \mathrm{k} /(6 \mathrm{n}-1))\}]=\mathrm{I}$

$\mathrm{ff}(2 \mathrm{k} / \mathrm{N})$ will tell us that how many numbers on a natural number line are such that their product with 'N' would be less than or equal to $2 \mathrm{k}$. Since elements of S5 series are denoted as $6 n-1$, hence if we wish to arrive at number of such numbers, we divide $2 k$ by $6 n-1$. Hence we get $f f\{2 k /(6 n-1)\}$. Now as there is a gap of 6 numbers between any two consecutive elements of S5 series, we further divide ff $\{2 \mathrm{k} /(6 \mathrm{n}-1)\}$ by 6 and consider its ff to ensure that we end up at an element of S5 series only. This is denoted as 'I' here.

Hence $\mathrm{I}=$ Floor function of [1/6\{floor function of $(2 \mathrm{k} /(6 \mathrm{n}-1))\}]$

Consider the floor function 'I'. This integer ' $\mathrm{I}$ ' indicates the total number of composites of which $6 \mathrm{n}-1$ is a factor and values of all these composites are less than $2 \mathrm{k}$. As the biggest number also needs to be on S5 series, so biggest number that is smaller than $6 \mathrm{I}$ is given as $6 \mathrm{I}-1$.The biggest such number of which $6 \mathrm{n}-1$ is a factor and whose value is less than $2 \mathrm{k}$ can be derived as

$$
(6 \mathrm{n}-1) \mathrm{x}(6 \mathrm{I}-1)
$$

For the first element of the S5 series, ' $\mathrm{I}_{1}$ ' will be the total number of unique composites due to first element. When we move to the second element of the S5 series, ' $\mathrm{I}_{2}$ ' will again indicate the total number of composites due to second element but not necessarily the total number of unique composites since there may be some composites that are common to both these first and second elements. The number of such composites needs to be identified and subtracted from ' $I_{2}$ ' to avoid double 
addition and thereby over-stating of the number of total composites. The conditions to be satisfied by such composites are as follows:-

- Such a composite should be divisible by both prime numbers; $6 n-1$ under consideration and 6n'-1 which is a previous prime element.

- Such a composite should lie on S7 series.

For example; while identifying the common composites formed by 5 and 11; the first such composite would be $11 \times 5$ since it has already been derived as $5 \times 11$ while considering composites formed by 5 .

Thereafter the product of 11 with every $5 \times 6$ th $\left(\right.$ or $30^{\text {th }}$ ) element of S5 series would satisfy the above condition. This is because for any particular element $6 \mathrm{n}-1$ of S5 series, the periodicity of obtaining common composites would be $6 x(6 n-1)$ because of the difference of 6 between any two consecutive elements of S5 series.

In general terms, these common composites can be identified as follows:-

$(6 n-1) x[(6 n '-1)+6 m(6 n '-1)]<=(6 n-1) .\left(6 I_{2}-1\right)$; for any n; $1<=$ n' $<$ n; m belongs to set of natural numbers including zero.

where $6 n-1$ is the current element, $6 n$ '- 1 is the previous prime element.

Number of possible values of $m$ may be arrived as:-

Number of such composites $=$ Number of possible values of ' $m$ ' $=q=\left[\left\{\left(6 \mathrm{I}_{2}-1\right)-(6 \mathrm{n}\right.\right.$ '-1) $\} / 6(6 \mathrm{n}$ '-1) $]+$ 1

\section{Unique composites for the $2^{\text {nd }}$ element of the $S 5$ series can be derived as:- $\mathbf{N}($ u.c.2S5 $)=\mathbf{I}_{2}-\mathbf{q}$}

Number of Unique Composites (UC) for nth element of S5 can be derived as: $N($ u.c. $n$ S5 $)=I_{n}-\sum_{n} n_{1}$ to n-1 $\left.\left[\left\{\left\{6 I_{2}-1\right)-\left(6 n^{\prime}-1\right)\right\} / 6 .\left(6 n^{\prime}-1\right)\right\}+1\right]$; such that $\left(6 n^{\prime}-\right.$ 1) is prime

From the $3^{\text {rd }}$ element (i.e. 17) onwards an additional step needs to be followed. This is because while identifying and subtracting composites already derived by earlier numbers, there may be some composites that are common to more than one earlier element number of S5. Just as it is important to avoid multiple/double counting of composites to avoid over-stating the total number of unique composites, it is equally important to identify those common composites and add the number of such composites to avoid multiple/double subtraction and thereby under-stating the total number of unique composites. This may be done as follows:-

Such composites need to satisfy the following two conditions:

If we denote such composites as ' $A$ ' then:-

- 'A' should be divisible by $\mathrm{p} 1$ and $\mathrm{p} 2$ and $6 \mathrm{n}-1$. Here $\mathrm{p} 1$ and $\mathrm{p} 2$ are any two prime elements on $\mathrm{S} 5$ series lying prior to $6 \mathrm{n}-1$ under consideration.

- 'A' divided by $6 \mathrm{n}-1$ under consideration, would be a composite number on the $\mathrm{S} 5$ series of which $\mathrm{p} 1$ and $\mathrm{p} 2$ are factors.

Considering $\mathrm{p} 1<\mathrm{p} 2$; the product of $\mathrm{p} 1^{2}$ (which would lie on the $\mathrm{S} 7$ series)and $\mathrm{p} 2$ (which lies on the S5 series) would give the first composite that lies on the S5 series which is divisible by both $\mathrm{p} 1$ and $\mathrm{p} 2$. The product of this composite with $6 \mathrm{n}-1$ under consideration would lie on S7 series and would be a composite that had been identified while calculating $\mathrm{q}$ for both $\mathrm{p} 1$ and $\mathrm{p} 2$. Since $\mathrm{q}$ would be subtracted from $\mathrm{I}_{3}$, 
to arrive at the number of unique composites for $6 \mathrm{n}-1$ under consideration, this composite would be subtracted twice if not identified and adjusted for. Thereafter every $(6 \mathrm{p} 1 \mathrm{p} 2)$ th number would also satisfy these conditions as long as their value remains less than corresponding 6I-1. In general terms, the composites common to $\mathrm{p} 1$ and $\mathrm{p} 2$ can be identified as follows:

$\mathrm{p} 1 \mathrm{p} 2\left(\mathrm{p} 1+6 \mathrm{~m}^{\prime}\right) \leq 6 \mathrm{I}_{3}-1 ;$ where $\mathrm{m}^{\prime}=\{0, \mathrm{~N}\}$

Number of such composites $=$ Number of possible values of $m^{\prime}=q^{\prime}=\sum\left[\left\{\left(6 I_{n}-1\right)-p 1^{2} p 2\right\} / 6 p 1 p 2\right]+1$

where $\mathrm{p} 1$ and $\mathrm{p} 2$ are prime elements of the S5 series prior to the number $6 \mathrm{n}-1$ under consideration and $\mathrm{p} 1<\mathrm{p} 2$. Also, all possible pairs of $\mathrm{p} 1$ and $\mathrm{p} 2$ that lie on the S5 series prior to $6 n-1$ under consideration need to be considered.

For example if $6 \mathrm{n}-1=17, \mathrm{p} 1$ and $\mathrm{p} 2$ would be 5 and 11 respectively

If $6 \mathrm{n}-1=23$, then $\mathrm{p} 1$ and $\mathrm{p} 2$ pairs would be $5 \& 11,5 \& 17$ and $11 \& 17$ subject to the condition that $\mathrm{p} 1^{2} \mathrm{p} 2 \leq 6 \mathrm{I}-1$

Unique composites for the $3^{\text {rd }}$ (and onwards) elements of S5 series would be derived as follows:-

$$
\mathbf{N}(\text { u.c.3S5 })=\mathbf{I}_{3}-\sum\left(\mathbf{q}-\mathbf{q}^{\prime}\right)
$$

In general terms, unique composites due to elements of S5 series would be derived as follows:-

Number of U.C. due to $(6 \mathrm{~m}-1)=I_{m}-\sum_{n=1}$ to $m-1$ floor function of $\left.((6 \mathrm{Im}-1) / 6(6 \mathrm{n}-1))+1\right\}+$ $\pi_{\mathrm{p} 1 \mathrm{p} 2(\mathrm{p} 1+6 \mathrm{n})<=(6 \mathrm{Im}-1)} \mathrm{p} 1 \mathrm{p} 2(\mathrm{p} 1+6 \mathrm{n})$

Deriving composites on S7 series that are formed as intra-series products of S7 series

Unique composites of S7 series formed by elements of S7 series

Here again we first calculate the total number of composites of a particular element number $6 \mathrm{n}+1$ (which belongs to $\mathrm{S7}$ series) as follows:-

$$
\text { Floor function of }[1 / 6\{\text { floor function of }(2 \mathrm{k} /(6 \mathrm{n}+1))\}]=\mathrm{I} \text {, }
$$

Consider the floor function I' which will indicate the total number of composites of which the $6 n+1$ number under consideration is a factor and whose value is less than $2 \mathrm{k}$. The biggest number would be $6 \mathrm{I}^{\prime}+1$ i.e. $(6 \mathrm{n}+1) \mathrm{x}(6 \mathrm{I}+1)$ would be the biggest composite of which this number $6 \mathrm{n}+1$ is a factor and whose value is less than $2 \mathrm{k}$

While deriving unique composites of S7 series formed by elements of S7 series, two types of repetitions are possible. First those composites those have been already derived by elements of S5 series and second those composites that have been derived by prior elements of $\mathrm{S} 7$ series. These can be identified as follows:-

(a) Identifying composites which have been already derived by elements of S5 series:- 
The composite number whose product with $6 n+1$ under consideration has already been derived while calculating composites formed by the elements of S5 series need to satisfy following conditions:-

The composite no should lie on the $\mathrm{S} 7$ series

It should be divisible by $6 \mathrm{n}-1$ number for which composites already derived are being identified. The first such composite number on the S7 series formed by the elements of S5 series that have not been derived earlier by prior elements of S5 series would be the square of the $6 n-1$ whose composites are being identified.

e.g., $11^{2}$ would be the first composite on $\mathrm{S} 7$ series of which 11 is a factor and has not been derived by earlier element of S5 series i.e. ' 5 '. ' $6 \mathrm{n}+1$ ' multiplied by 'this composite number' would be the first composite on S7 series that is common to both $6 n+1$ and $6 n-1$ under consideration. Thereafter every $6 x(6 n-1)$ would satisfy the above condition. All 6n- 1 numbers under consideration should be prime because if its composite then they would have been already counted while considering composites formed by its prime factors.

$$
\mathrm{r}=\sum_{\mathrm{n}}: 1 \text { to }\left(6 \mathrm{n}^{\prime}-1\right) \cdot\left(6 \mathrm{n}^{\prime}-1\right)<6 \mathrm{I}+1\left[\left[\left\{\left(6 \mathrm{I}^{\prime}+1\right)-\left(6 \mathrm{n}^{\prime}-1\right)^{2}\right\} / 6\left(6 \mathrm{n}^{\prime}-1\right)\right]+1\right]
$$

This will give the total number of such composites that have already been formed by elements of S5 series.

However, here again there may be some composites that are common to more than one elements of the S5 series. To account for such composites, following conditions may be identified:-

- The composite should be on the S7 series

- It should be divisible by any two prime elements of S5 series and the first element of $\mathrm{S} 7$ series, i.e. '7'.

The first such composite that satisfies the above conditions would be $7 \mathrm{p} 1 \mathrm{p} 2$ where $\mathrm{p} 1$ and $\mathrm{p} 2$ are prime elements of S5 series. Thereafter every $6 \mathrm{p} 1 \mathrm{p} 2$ th element would satisfy the above condition. In general terms such composites may be identified as :-

$$
\mathrm{r}^{\prime}=(6 \mathrm{n}+1) \mathrm{p} 1 \mathrm{p} 2(7+6 \mathrm{n}) \leq(6 \mathrm{n}+1)\left(6 \mathrm{I}^{\prime}+1\right)
$$

or number of possible values of r'; $n\left(r^{\prime}\right)=\left[\left\{\left(6 I^{\prime}+1\right)-7 p 1 p 2\right\} / 6 \mathrm{p} 1 \mathrm{p} 2\right]+1$;

where $\mathrm{p} 1$ is the number $6 \mathrm{n}-1$ for which $\mathrm{r}$ is being calculated, $\mathrm{p} 2$ is prior element of the S5 series that lie before $\mathrm{p} 1$, and 7 is the first element of the $\mathrm{S} 7$ series. This can also be written as :-

$$
\mathrm{n}\left(\mathrm{r}^{\prime}\right)=\left[\left\{\left(6 \mathrm{I}^{\prime}+1\right)-7 \mathrm{p} 1 \mathrm{p} 2\right\} / 6 \mathrm{p} 1 \mathrm{p} 2\right]+1
$$

Note: while compiling $r$ ' only those numbers are to be considered that are $>(6 n-1)^{2}$ (i.e. $\left.p_{1}^{2}\right)$ and $<6 I^{\prime}+1$. This is because numbers prior to $(6 n-1)^{2}$ have already been subtracted while calculating $r$

Once $r$ and r' have been computed, r-r' will give the unique composites that have been already derived by elements of the S5 series and are now being repeated while calculating unique composites for the S7 series elements. 
Now we turn to identify the composites already formed by prior elements of the S7 series that need to be identified and subtracted to avoid multiple counting of the same composite number.

For the first element of the $\mathrm{S} 7$ series (i.e. 7),

$$
\text { I' }-\sum\left(r-r^{\prime}\right)
$$

will give the number of unique composites for the number 7. From the second number 13 (i.e. 7+6) onwards, an additional step needs to be followed wherein composites already formed by 7 have to be identified and subtracted to avoid multiple counting of the same composite.

For this we follow the following steps:-

The conditions to be satisfied by such composites are as follows:-

- Such a composite should be divisible by both $6 n+1$ under consideration and $6 \mathrm{n}+1$ which is a previous prime element of S7 series.

- Such a composite should lie on S7 series.

The first such composite would be $13 \times 7$ since it has already been derived as $7 \times 13$. Thereafter every $7 \times 6$ th (or $42^{\text {nd }}$ ) element of 57 series would satisfy the above condition. This is because for any particular element $6 n+1$ of S7 series, the periodicity of obtaining common/non-degenerate composites would be $6 x(6 n+1)$ because of the difference of 6 between any two consecutive elements of S7 series.

In general terms, these common composites can be identified as follows:-

$(6 n+1) x\left[\left(6 n^{\prime}+1\right)+6 m^{\prime}\left(6 n^{\prime}+1\right)\right]<=(6 n+1) .\left(6 I_{2}{ }^{\prime}+1\right) ;$ for any given $n ; 1 \leq n '<n ; m$ ' belongs to set of natural numbers including zero.

where $6 n+1$ is the current element, $6 n '+1$ is the previous prime element

Number of possible values of m' may be arrived as:-

Number of such composites $=$ Number of possible values of $m^{\prime}=s=\left[\left\{\left(6 \mathrm{I}_{2}{ }^{\prime}+1\right)-\right.\right.$ $(6 n '+1)\} / 6(6 n '+1)]+1$

Number of values of $\mathrm{s}=\sum_{\mathrm{n}^{\prime}=1}$ to $\mathrm{n}-1$; such that $6 \mathrm{n}^{\prime}+1$ is prime $\left[\left[\left\{\left(6 \mathrm{I}^{\prime}+1\right)-\left(6 \mathrm{n}^{\prime}+1\right)\right\} / 6\left(6 \mathrm{n}^{\prime}+1\right)\right]+1\right]$

This will give the total number of composites formed by previous prime elements of the $\mathrm{S} 7$ series, lying prior to the number $6 \mathrm{n}+1$ under consideration.

However this ' $\mathrm{s}$ ' may comprise of such composites that may have been derived by earlier elements of the S5 series or S7series. These need to be identified and accounted for since, as mentioned earlier, just as it is important to avoid multiple counting, it is equally important to avoid multiple removal.

For this we introduce the following terms:-

Conditions for deriving composites calculated by s that have already been identified and duly subtracted while counting the number of unique composites formed by elements of S5 series:-

- Such a composite should lie on S7 series 
- It should be divisible by the number $6 n+1$ (for which $\mathrm{s}$ has been calculated) and by prime elements of the S5 series.

The first such composite number would be the product of ' $6 \mathrm{n}+1$ ' (for which $\mathrm{s}$ has been calculated) denoted as $\mathrm{p} 2$ and the square of the prime elements of the S5 series (since the square of any element amounts to product of intra-series elements and thus leading to an S7 series element) denoted as $\mathrm{p} 1$. Thereafter every $6 \mathrm{p} 1 \mathrm{p} 2$ th number would satisfy the above conditions. In general terms this can be written as :-

$$
\mathrm{s}^{\prime}=(6 \mathrm{n}+1) \mathrm{p} 1 \mathrm{p} 2(\mathrm{p} 1+6 \mathrm{n})<=(6 \mathrm{n}+1)\left(6 \mathrm{I}^{\prime}+1\right)
$$

or number of possible values of $\mathrm{s}^{\prime} ; \mathrm{n}\left(\mathrm{s}^{\prime}\right)=\sum\left[\left\{\left(6 \mathrm{I}^{\prime}+1\right)-\mathrm{p} 1^{2} \mathrm{p} 2\right\} / 6 \mathrm{p} 1 \mathrm{p} 2\right]+1$;

where $\mathrm{p} 1$ is a prime element of the S5 series and $\mathrm{p} 2$ is a prime element of the S7 series for which ' $s$ ' has been calculated. This term will give the number of composites counted in ' $\mathrm{s}$ ' that have already been counted and subtracted while computing composites of the S5 series.

To identify composites already derived by previous elements of S7 series:-

From the $3^{\text {rd }}$ element (i.e. 19) onwards an additional step needs to be followed. This is because while identifying and subtracting composites already derived by earlier numbers, there may be some composites that are common to more than one element number of S7. Just as it is important to avoid multiple/double counting of composites to avoid over-stating the total number of composites, it is equally important to identify those common composites and add them to avoid multiple/double subtraction and thereby under-stating the total number of composites. This may be done as follows:-

Such composites need to satisfy the following conditions:

- Such a composite should be divisible by two previous prime elements of S7 series

- It should lie on the S7 series so that its product with 19 would be a composite on $\mathrm{S} 7$ series

First such composite that would satisfy the above conditions would be p1p2 where $\mathrm{p} 1$ and $\mathrm{p} 2$ are two prime elements prior to the $6 n+1$ under consideration. Thereafter every $6 \mathrm{p} 1 \mathrm{p} 2$ th number would satisfy the above condition. In general terms this can be identified as:

$$
\mathrm{s} "=(6 \mathrm{n}+1) \mathrm{p} 1 \mathrm{p} 2\left(1+6 \mathrm{~m}^{\prime \prime}\right) \leq(6 \mathrm{n}+1)\left(6 \mathrm{I}^{\prime}+1\right)
$$

or number of possible values of s', $n\left(m^{\prime \prime}\right)=\left[\left\{\left(6 I^{\prime}+1\right)-p 1 p 2\right\} / 6 p 1 p 2\right]+1$;

This will give the number of composites formed by prior elements of the S7 series. Here p1 and $\mathrm{p} 2$ are prime elements of the S7 series prior to $6 n+1$ under consideration.. All previous prime pairs (p1\&p2) that satisfy the condition $6 \mathrm{p} 1 \mathrm{p} 2 \leq$ $6 \mathrm{I}$ ' 1 ; ; are to be considered.

If $6 n+1=19 ; \mathrm{p} 1$ and $\mathrm{p} 2$ would be 7 and 13 . If $6 \mathrm{n}+1=31 ; \mathrm{p} 1 \mathrm{p} 2$ pairs would be $7 \& 13$, $7 \& 19$ and $13 \& 19$ subject to the condition that $\mathrm{p} 1 \mathrm{p} 2$ should be less than $6 \mathrm{I}+1$ 
Composites formed by earlier elements of S7 series that need to be subtracted from I' to arrive at unique composites for a given number $6 n+1$ can be derived as:-

$\mathrm{n}($ unique composites formed by $6 \mathrm{n}+1)=\mathrm{I}$ ' $-\sum\left(\mathrm{r}-\mathrm{r}\right.$ ') $-\sum(\mathrm{s}-\mathrm{s}$ '-s"')

Deriving number of composites on S7 series for a given 2k: An illustration Consider the even number 16658. It is of SADN 8//8 which means the relevant series is the $\mathrm{S} 1$ series. Unique composites on the S7 series that are less than 16658 are shown in the following tables where the number of composites have been derived by following the steps as mentioned above:-

\begin{tabular}{|l|l|l|l|l|l|l|}
\hline $\begin{array}{l}\text { Element } \\
\text { number }\end{array}$ & $\mathbf{I}$ & $\mathbf{6 I - 1}$ & $\mathbf{q}$ & $\mathbf{q} \mathbf{q}^{\prime}$ & q-q' & $\begin{array}{l}\text { Number of } \\
\text { unique } \\
\text { composites } \\
\sum \mathbf{I}-\sum(\mathbf{q}- \\
\mathbf{q})\end{array}$ \\
\hline 5 & 555 & 3329 & $\ldots$. & $\ldots$ & $\ldots$ & 555 \\
\hline 11 & 252 & 1511 & 51 & $\ldots$ & 51 & 201 \\
\hline 17 & 163 & 977 & 48 & 3 & 45 & 118 \\
\hline 23 & 120 & 719 & 42 & 3 & 39 & 81 \\
\hline 29 & 95 & 569 & 38 & 2 & 36 & 59 \\
\hline 41 & 67 & 401 & 30 & 1 & 29 & 38 \\
\hline 47 & 59 & 353 & 29 & 1 & 28 & 31 \\
\hline 53 & 52 & 311 & 28 & 1 & 27 & 25 \\
\hline 59 & 47 & 281 & 25 & 1 & 24 & 23 \\
\hline 71 & 39 & 233 & 23 & 0 & 23 & 16 \\
\hline 83 & 33 & 197 & 20 & 0 & 20 & 13 \\
\hline 89 & 31 & 185 & 21 & 0 & 21 & 10 \\
\hline 101 & 27 & 161 & 21 & 0 & 21 & 6 \\
\hline 107 & 25 & 149 & 20 & 0 & 20 & 5 \\
\hline 113 & 24 & 143 & 21 & 0 & 21 & 3 \\
\hline TOTAL & & & & & & 1184 \\
\hline
\end{tabular}

Table 5B.1: Unique Composites formed on S7 series upto 16658 by elements of S5 series

\begin{tabular}{|c|c|c|c|c|c|c|c|c|c|c|}
\hline $\begin{array}{l}\text { Element } \\
\text { number }\end{array}$ & I & $6 \mathrm{I}+1$ & $\mathbf{r}$ & $\mathbf{r}^{\prime}$ & r-r' & $\mathbf{S}$ & $\mathbf{s}^{\prime}$ & $\mathbf{s}^{\prime \prime}$ & s-s'-s' & 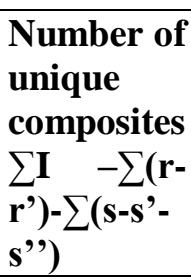 \\
\hline 7 & 396 & 2377 & 162 & 19 & 143 & $\ldots$ & $\ldots$ & $\ldots$ &.. & 253 \\
\hline 13 & 213 & 1279 & 79 & 7 & 72 & 31 & 7 & $\ldots$ & 24 & 117 \\
\hline 19 & 145 & 871 & 51 & 4 & 47 & 33 & 7 & 2 & 24 & 74 \\
\hline 31 & 89 & 535 & 29 & 1 & 28 & 25 & 4 & 4 & 17 & 44 \\
\hline 37 & 74 & 445 & 22 & 1 & 21 & 24 & 3 & 5 & 16 & 37 \\
\hline 43 & 64 & 385 & 19 & 1 & 18 & 21 & 3 & 4 & 14 & 32 \\
\hline 61 & 45 & 271 & 12 & 0 & 12 & 19 & 1 & 5 & 13 & 20 \\
\hline 67 & 41 & 247 & 10 & 0 & 10 & 17 & 1 & 3 & 13 & 18 \\
\hline 73 & 37 & 223 & 9 & 0 & 9 & 16 & 1 & 2 & 13 & 15 \\
\hline 79 & 24 & 205 & 9 & 0 & 9 & 15 & 1 & 1 & 13 & 12 \\
\hline
\end{tabular}




\begin{tabular}{|l|l|l|l|l|l|l|l|l|l|l|}
\hline 97 & 28 & 169 & 6 & 0 & 6 & 15 & 0 & 1 & 14 & 8 \\
\hline 103 & 26 & 157 & 6 & 0 & 6 & 15 & 0 & 1 & 14 & 6 \\
\hline 109 & 25 & 151 & 6 & 0 & 6 & 15 & 0 & 0 & 15 & 4 \\
\hline 127 & 21 & 127 & 5 & 0 & 5 & 16 & 0 & 1 & 15 & 1 \\
\hline Total & & & & & & & & & & 641 \\
\hline
\end{tabular}

Table 5B.2: Unique Composites formed on S7 series upto 16658 by elements of S7 series

Total number of composites on S7 series, less than $16658=1184+641=1825$

This implies that there would be 1825 composite numbers on S7 series whose value is less than 16658

\section{For S5 series:}

For deriving number of unique composites on S5 series:-

Based on similar reasoning as discussed above;

Composites on the S5 series are derived as inter-series products of elements of the S5 and S7 series. In order to calculate the total number of composites formed on S5 series upto a particular even number $2 \mathrm{k}$, following steps may be followed:-

We first find out the total number of composites formed by a particular prime element of the S5 series. This can be done by the following formula:-

Floor function of [1/6 floor function of $[2 \mathrm{k} /(6 \mathrm{n}-1)]]=\mathrm{I}_{\mathrm{n}}{ }^{\prime}$,

Consider the floor function $\mathrm{I}_{\mathrm{n}}{ }^{\prime}$. This integer $\mathrm{I}_{\mathrm{n}}$ " gives the total number of composites on the S5 series of which $6 n-1$ is a factor and values of all of these composites are less than $2 k$. These composites will be of the nature of:-

$$
(6 \mathrm{n}-1) \mathrm{x}(6 \mathrm{n}+1)<2 \mathrm{k}
$$

The biggest $6 \mathrm{n}+1$ number on the $\mathrm{S} 7$ series whose product with $6 \mathrm{n}-1$ will be $<2 \mathrm{k}$ can be derived as:-

$$
6 \mathrm{I}_{\mathrm{n}}{ }^{\prime \prime}+1
$$

For the first element of the $\mathrm{S} 5$ series, i.e. $5, \mathrm{I}_{1}$ " will be the total number of unique composites, on the S5 series upto $2 \mathrm{k}$, of which 5 would be a factor.

When we move to the second $(\mathrm{n}=2)$ number of the $\mathrm{S} 5$ series, i.e. $11, \mathrm{I}_{2}$ ' will indicate the total number of composites on the S5 series upto $2 \mathrm{k}$ of which 11 is a factor, but not necessarily the total number of unique composites since there may be some composites that are common to both elements, 5 and 11 . These composites need to be identified and number of such composites needs to be subtracted from $\mathrm{I}_{2}{ }^{\prime}$, to avoid double counting/addition and thereby over-stating of the number of total composites. The conditions to be followed/satisfied are as follows:

- Such a composite should lie on S7 series, so that its product with 6n-1 number under consideration will lie on S5 series.

- It should be divisible by both ' $6 n-1$ ' under consideration and the 'previous prime element' of the S5 series; denoted as $\mathrm{p} 1$. 
The first such composite number would be the square of the previous prime element since it would lie on the S7 series, whose product with the ' $6 n-1$ ' under consideration would lie on the S5 series.

Thereafter every $6 \mathrm{p} 1$ th number would satisfy the above conditions. In general terms these conditions will be expressed as:

$(6 \mathrm{n}-1)\left(\mathrm{p} 1^{2}+6 \mathrm{np} 1\right) \leq(6 \mathrm{n}-1)\left(6 \mathrm{I}{ }^{\prime \prime}+1\right)$

The number of such composites would be :

$\mathrm{t}=\left[\left(6 \mathrm{I}^{\prime}{ }^{\prime}+1\right)-\mathrm{p} 1^{2}\right] / 6 \mathrm{p} 1+1$

These common composites can be identified as:-

$$
\mathrm{t}_{\mathrm{n}}=\sum_{\mathrm{n}^{\prime}=1 \operatorname{to}\left(6 \mathrm{n}^{\prime}-1\right) .\left(6 \mathrm{n}^{\prime}-1\right)<6 \mathrm{n}^{\prime \prime}+1}\left[\left\{\left(6 \mathrm{I}_{\mathrm{n}}+1\right)-\left(6 \mathrm{n}^{\prime}-1\right)^{2}\right\} / 6\left(6 \mathrm{n}^{\prime}-1\right)\right]+1
$$

Unique composites of the $\mathrm{S} 5$ series for which the $2^{\text {nd }}(n=2)$ element, i.e. 11 , is a factor can be derived as:-

$$
\mathrm{I}_{2}, \mathrm{t}_{\mathrm{n}}
$$

From the $3^{\text {rd }}(n=3)$ element onwards of the S5 series an additional step needs to be followed. This is because while identifying and subtracting composites already derived by earlier numbers, there may be some composites that are common to more than one element number of S5. Just as it is important to avoid multiple/double counting of composites to avoid over-stating the total number of composites, it is equally important to identify those common composites, if any, and add them to avoid multiple/double subtraction and thereby under-stating the total number of composites. Such composites denoted as 'B'; need to satisfy the following conditions:-

- 'B' should be divisible by a pair of previous prime-elements p1 and p2 and also by $6 n-1$ under consideration.

- ' $\mathrm{B}$ ' divided by ' $6 \mathrm{n}-1$ ' should be a composite number on $\mathrm{S} 7$ series. This composite number should be a multiple of both $\mathrm{p} 1$ and $\mathrm{p} 2$.

The first such number would be $7 \mathrm{p} 1 \mathrm{p} 2$ subject to the condition that $7 \mathrm{p} 1 \mathrm{p} 2<\mathrm{p} 2 \mathrm{p} 2$ or in other words; $7 \mathrm{p} 1<\mathrm{p} 2$

Thereafter every $6 \mathrm{p} 1 \mathrm{p} 2$ th number would satisfy the general conditions satisfying the above conditions are as follows:-

$$
\mathrm{t}_{\mathrm{n}}^{\prime}=\sum_{\mathrm{n}=0} \text { to } \mathrm{n}<\{(6 \mathrm{In}+1)-7 \mathrm{p} 1 \mathrm{p} 2\} / 6 \mathrm{p} 1 \mathrm{p} 2 \mathrm{p} 1 \mathrm{p} 2(7+6 \mathrm{~m}) \leq 6 \mathrm{I}_{\mathrm{n}}{ }^{\prime}+1 ;
$$

or number of possible values of $\mathrm{t}^{\prime} ; \mathrm{m}\left(\mathrm{t}^{\prime}\right)=\left[\left\{\left(6 \mathrm{I}_{\mathrm{n}}{ }^{\prime \prime}+1\right)-7 \mathrm{p} 1 \mathrm{p} 2\right\} / 6 \mathrm{p} 1 \mathrm{p} 2\right]+1$;

where $\mathrm{p} 1$ and $\mathrm{p} 2$ are prime element of the S5 series prior to the number $6 \mathrm{n}-1$ under consideration. All possible pairs of $\mathrm{p} 1$ and $\mathrm{p} 2$ that lie on the S5 series prior to $6 \mathrm{n}-1$ under consideration need to be considered here.

Number of unique composites for the $3^{\text {rd }}$ (and onwards) elements of S5 series would be derived as follows:-

$$
\sum \mathrm{I}_{\mathrm{n}}{ }^{\prime}-\sum\left(\mathrm{t}_{\mathrm{n}}-\mathrm{t}_{\mathrm{n}}{ }^{\prime}\right)
$$

An illustration:- 
Consider the even number 19978 which is SADN 7//8. The relevant series would therefore be the S5 series. Unique composites have been derived by following the above mentioned steps and are summarised in the following table:-

\begin{tabular}{|c|c|c|c|c|c|c|}
\hline $\begin{array}{l}\text { Element } \\
\text { number } \\
\mathbf{N}\end{array}$ & $I_{n}{ }^{\prime}$ & $6 I_{n}, 9+1$ & $\mathbf{t}_{\mathbf{n}}$ & $\mathbf{t}_{\mathrm{n}}{ }^{\prime}$ & $t_{n}-t_{n}{ }^{\prime}$ & $\begin{array}{l}\text { Unique } \\
\text { composites } \\
\sum \mathbf{I}_{\mathbf{n}}{ }^{\prime}{ }^{\prime}-\sum\left(\mathbf{t}_{\mathbf{n}}-\right. \\
\left.\mathbf{t}_{\mathbf{n}}{ }^{\prime}\right)\end{array}$ \\
\hline 5 & 665 & 3991 & $\ldots$ & $\ldots$ & $\ldots$ & 665 \\
\hline 11 & 302 & 1813 & 60 & $\ldots$ & 60 & 242 \\
\hline 17 & 195 & 1171 & 55 & 3 & 52 & 143 \\
\hline 23 & 144 & 865 & 47 & 3 & 44 & 100 \\
\hline 29 & 114 & 685 & 38 & 2 & 36 & 78 \\
\hline 41 & 81 & 487 & 24 & 1 & 23 & 58 \\
\hline 47 & 70 & 421 & 21 & 1 & 20 & 50 \\
\hline 53 & 62 & 373 & 17 & 0 & 17 & 45 \\
\hline 59 & 56 & 337 & 16 & 0 & 16 & 40 \\
\hline 71 & 46 & 277 & 12 & 0 & 12 & 34 \\
\hline 83 & 39 & 235 & 10 & 0 & 10 & 29 \\
\hline 89 & 37 & 223 & 9 & 0 & 9 & 28 \\
\hline 101 & 32 & 193 & 8 & 0 & 8 & 24 \\
\hline 107 & 30 & 181 & 7 & 0 & 7 & 23 \\
\hline 113 & 29 & 175 & 7 & 0 & 7 & 22 \\
\hline 131 & 25 & 151 & 6 & 0 & 6 & 19 \\
\hline 137 & 24 & 145 & 6 & 0 & 6 & 18 \\
\hline 149 & 22 & 143 & 5 & 0 & 5 & 17 \\
\hline 167 & 19 & 115 & 4 & 0 & 4 & 15 \\
\hline 173 & 19 & 115 & 4 & 0 & 4 & 15 \\
\hline 179 & 18 & 109 & 3 & 0 & 3 & 15 \\
\hline 191 & 17 & 103 & 3 & 0 & 3 & 14 \\
\hline 197 & 16 & 97 & 3 & 0 & 3 & 13 \\
\hline 227 & 14 & 85 & 3 & 0 & 3 & 11 \\
\hline 233 & 14 & 85 & 3 & 0 & 3 & 11 \\
\hline 239 & 13 & 79 & 2 & 0 & 2 & 11 \\
\hline 251 & 13 & 79 & 2 & 0 & 2 & 11 \\
\hline $\begin{array}{l}257-269 \\
(3)\end{array}$ & 12 & 73 & 2 & 0 & 2 & $10 \times 3=30$ \\
\hline $\begin{array}{l}281-293 \\
(2)\end{array}$ & 11 & 67 & 2 & 0 & 2 & $9 \times 2=18$ \\
\hline $\begin{array}{l}311-317 \\
(2)\end{array}$ & 10 & 61 & 2 & 0 & 2 & $8 \times 2=16$ \\
\hline $\begin{array}{l}347-359 \\
(3)\end{array}$ & 9 & 55 & 2 & 0 & 2 & $7 \times 3=21$ \\
\hline $\begin{array}{l}383-401 \\
(3)\end{array}$ & 8 & 49 & 1 & 0 & 1 & $7 \times 3=21$ \\
\hline $\begin{array}{l}419-461 \\
(5)\end{array}$ & 7 & 43 & 1 & 0 & 1 & $6 \times 5=30$ \\
\hline $\begin{array}{l}467-539 \\
(6)\end{array}$ & 6 & 37 & 1 & 0 & 1 & $5 \times 6=30$ \\
\hline
\end{tabular}

10 |[Section 5: 5B] 


\begin{tabular}{|l|l|l|l|l|l|l|}
\hline $\begin{array}{l}557-641 \\
(8)\end{array}$ & 5 & 31 & 1 & 0 & 1 & $4 \times 8=32$ \\
\hline $\begin{array}{l}647-797 \\
(11)\end{array}$ & 4 & 25 & 1 & 0 & 1 & $11 \times 3=33$ \\
\hline $\begin{array}{l}809- \\
1055 \\
(20)\end{array}$ & 3 & 19 & 0 & 0 & 0 & $20 \times 3=60$ \\
\hline $\begin{array}{l}1061- \\
1535 \\
(34)\end{array}$ & 2 & 13 & 0 & 0 & 0 & $34 \times 2=68$ \\
\hline $\begin{array}{l}1553- \\
2855 \\
(86)\end{array}$ & 1 & 7 & 0 & 0 & 0 & $86 \times 1=86$ \\
\hline Total & & & & & & 2196 \\
\hline
\end{tabular}

Table 5B.3: Derivng unique composites for a given 2k: An illustration

From the above table, it can be implied that there are 2196 composites on the S5 series whose value is less than the considered even number 19978. 


\section{6}

\section{Possible combinations of $\mathbf{p 1 + p 2}$ for even number of particular SADN and a particular last-digit}

\section{Possible combinations of $\mathrm{p} 1+\mathrm{p} 2$ for even number of particular SADN and a particular last-digit:}

Even numbers can be of SADN1 to9 and can end in any of the digits 2,4,6,8 and 0. While an even number of a particular SADN will recur after 18 integers, an even number of a particular SADN ending in a specific digit will recur after 90 integers. For example 12 is an even number of SADN 3 which ends in the digit 2. The next even number with SADN 3 would be $12+18=30$ while the next even number with SADN 3 that ends in the digit 2 will be $12+90=102$. Therefore, if we denote an even number $2 \mathrm{k}$ as $\mathrm{a} / / \mathrm{b}$, where ' $\mathrm{a}$ ' is the SADN of the even number and ' $b$ ' is the digit in which it ends, then $2 k+18$ will in the form of $a / / b-2$ (or $a / / b+8$ if $b-2$ is negative); and $2 k+90$ will be in the form of $a / / b$. Here $a=1$ to 9 while $\mathrm{b}=2,4,6,8,0$.

As mentioned earlier, prime numbers will essentially be odd numbers (with the only exception of the number 2), and can be of SADN 1,2,4,5,7 or 8 (with the only exception of the number 3) and can end in the digits 1,3,7 or 9 (with the only exception of the number 5 which is of SADN 5 and ends in 5). Therefore, prime numbers can be denoted as ap//bp where 'ap' denotes the SADN of the prime number while 'bp' denotes the last digit of the prime. Here ap can be of value $1,2,4,5,7,8$ while bp can be $1,3,7,9$.

If we leave out the exceptions, the combinations of prime numbers in which even numbers of a given SADN can be summed up can be generalized in the following table:-

\begin{tabular}{|l|l|}
\hline $\begin{array}{l}\text { SADN of the even } \\
\text { number } \mathbf{2 k}\end{array}$ & $\begin{array}{l}\text { SADN of combinations of prime numbers that can add up to } \\
\text { the given } \mathbf{2 k}\end{array}$ \\
\hline 1 & $2+8,5+5$ \\
\hline 2 & $1+1,4+7$ \\
\hline 3 & $2+1,4+8,5+7$ \\
\hline 4 & $2+2,5+8$ \\
\hline 5 & $1+4,7+7$ \\
\hline 6 & $1+5,2+4,7+8$ \\
\hline 7 & $2+5,8+8$ \\
\hline 8 & $1+7,4+4$ \\
\hline 9 & $1+8,2+7,4+5$ \\
\hline
\end{tabular}

Table 6.1: SADN of Possible combinations of prime numbers possible for an even number of a given SADN 
It may be noted here that even numbers with SADN 1,2,4,5,7 and 8 can be added up in the form of 3 todd number of a particular SADN. For instance if SADN of $2 k$ is 1 then one possible combination of $\mathrm{p}+\mathrm{p}$ that can add up to $2 \mathrm{k}$ will be $3+$ prime number of SADN 7 . Similarly, if $2 \mathrm{k}=\mathrm{SADN} 2$ then a possible combination can be of $3+$ prime number of SADN 8. However, since odd numbers of SADN 3 are 'generally' composite in nature, in order to consider this combination a limiting condition needs to be placed that it will be applicable only in cases where the corresponding odd number will be a prime number so that when combined with the digit 3 , it will qualify to be a $p+p$ combination i.e. such a combination can be considered for numbers where $2 \mathrm{k}-3$ will be a prime number. Since a general solution is not conceivable with such specific limiting conditions, the current line of analysis will treat these combinations as exceptions and leave them out.

Furthermore, depending on the last digit of $2 \mathrm{k}, 1$ last digit of the odd numbers that can add up in $2 \mathrm{k}$ will also have a role to play. For instance; consider $2 \mathrm{k}=20$, it can be denoted as an even number of the form $2 / / 0$ i.e. SADN 2 ending in 0 . In this case combinations of odd numbers that can add up to $2 \mathrm{k}$ will be of ap//1 + ap'//9 or ap//3+ ap'//7. If $2 \mathrm{k}$ ends in 2 then prime numbers ending in 7 cannot be considered in a general solution since in this case $2 \mathrm{k}$ - 'the odd number' will end in 5 and all odd numbers ending in 5 (with the exception of the number 5) will be composite numbers divisible by 5 . The following table shows the possible combinations of prime numbers ending in specific digits that can be considered in a general solution:-

\begin{tabular}{|l|l|l|}
\hline $\begin{array}{l}\text { Last digit of } \\
\mathbf{2 k}\end{array}$ & $\begin{array}{l}\text { Last digit of combinations of prime numbers } \\
\text { that are possible }\end{array}$ & $\begin{array}{l}\text { Last digit that is not } \\
\text { possible }\end{array}$ \\
\hline 2 & $\mathrm{ap} / / 1+\mathrm{ap} ' / / 1, \mathrm{ap} / / 3+\mathrm{ap} / / 9$ & $\mathrm{ap} / / 7$ \\
\hline 4 & $\mathrm{ap} / / 1+\mathrm{ap} / / 3, \mathrm{ap} / / 7+\mathrm{ap} / / 7$ & $\mathrm{ap} / / 9$ \\
\hline 6 & $\mathrm{ap} / / 3+\mathrm{ap} / / 3, \mathrm{ap} / / 7+\mathrm{ap} / / 9$ & $\mathrm{ap} / / 1$ \\
\hline 8 & $\mathrm{ap} / / 1+\mathrm{ap} ' / / 7, \mathrm{ap} / / 9+\mathrm{ap} / / 9$ & $\mathrm{ap} / / 3$ \\
\hline 0 & $\mathrm{ap} / / 1+\mathrm{ap} / / 9, \mathrm{ap} / / 3+\mathrm{ap} / / 7$ & - \\
\hline
\end{tabular}

Table 6.2: Possible combinations of prime numbers ending in specific digits those which can be considered, and those which are prohibited; in a general solution

A general picture of what combinations of prime numbers can add up to even numbers of a particular SADN and last digit, in terms of SADN and the last digit of the prime combination, can be summarized in the form of 45 matrices as mentioned in Appendix 2. 
7

\section{Why p1+p2 combinations of $\operatorname{SADN}(2,5,8)$ will lie on $\mathrm{S} 7$ series and that of $\operatorname{SADN}(7,4,1)$ will lie on $\mathrm{S} 5$ series?}

Why p1+p2 of SADN $(2,5,8)$ will lie on $\mathrm{S} 7$ series and that of $\operatorname{SADN}(7,4,1)$ will lie on S5 series?

The matrices mentioned in Appendix 1 show that even numbers with $\operatorname{SADN}(2,5,8)$ can be summed up in prime numbers with $\operatorname{SADN}(1,4,7)$. Even numbers with $\operatorname{SADN}(1,4,7)$ can be added up in terms of prime numbers with $\operatorname{SADN}(2,5,8)$. Even numbers with $\operatorname{SADN}(3,6,9)$ can be added up in prime numbers of $\operatorname{SADN}(1,2,4,5,7,8)$. If we consider this in perspective of the 3 series of odd numbers discussed in Section 4A, this can be restated to suggest that prime combinations $(\mathrm{p} 1+\mathrm{p} 2)$ for even numbers with $\operatorname{SADN}(2,5,8)$ will be found on the S7 series of odd numbers while prime combinations for even numbers of $\operatorname{SADN}(1,4,7)$ will be found on the S5 series of odd numbers. Prime combinations for even numbers with $\operatorname{SADN}(3,6,9)$ will be in the form of $\mathrm{p} 1+\mathrm{p} 2$ where $\mathrm{p} 1$ and $\mathrm{p} 2$ will be found on the S5 and S7 series respectively. 


\section{8}

\section{Cyclic-Series-Element (CSE) of even numbers (defined as 2k)}

\section{Cyclical series of even numbers:}

There is a cyclic \& closed series of six numbers viz. 12,2,4,6,4,2,12; where first and last numbers are identical.

Consider a series of consecutive even numbers, e.g. $38,40,42,44,46,48,50,52,54, \ldots \ldots$. It may be written as $2 \times 19,4 \times 10,6 \times 7,4 \times 11,2 \times 23,12 \times 4,2 \times 25,4 \times 13,6 \times 9 \ldots$.

For any length of series of consecutive even numbers, the universal series of factors will be $\{2,4,6,4,2,12\}$ acting as a unit series in cyclic order. We call this series of factors as factorseries and their elements as factor-elements (fe). Hence factor-series is given as $\{2,4,6,4,2,12\}$ in this specific order and 2,4,6,12 are factor-elements (fe). This cyclic order of the factor-series may start from any element of the factor-series. First element of factor-series would depend on the first number of corresponding consecutive-even number-series selected for study.

Corresponding factor-elements are said to be 'fe'

So $f e=\{2,4,6,4,2,12\}$ with order preserved

Consider any even number ' $2 \mathrm{k}$ '

$2 \mathrm{k} / 2=\mathrm{k}$

Number of possible combinations resulting in ' $2 \mathrm{k}$ ' would be ' $\mathrm{k}$ '

Suppose factor-element of ' $2 \mathrm{k}$ ' is ' $\mathrm{fe}$ '

$$
\begin{aligned}
& \quad \begin{array}{l}
12 / \mathrm{fe}=\mathrm{c} \\
2 \mathrm{k}=(\mathrm{k}+\mathrm{nc})+(\mathrm{k}-\mathrm{nc}) ; \mathrm{n}=1,2,3, \ldots \text { such that }(\mathrm{k}+\mathrm{nc})<2 \mathrm{k} \text { OR }(\mathrm{k}-\mathrm{nc})>0 \\
\quad(\mathrm{k}+\mathrm{nc})^{2}-(\mathrm{k}-\mathrm{nc})^{2}=24 \mathrm{n}(2 \mathrm{k} / \mathrm{fe})
\end{array} \\
& \text { LHS }=(\mathrm{k}+\mathrm{nc})^{2}-(\mathrm{k}-\mathrm{nc})^{2} \\
& =[(\mathrm{k}+\mathrm{nc})+(\mathrm{k}-\mathrm{nc})] .[(\mathrm{k}+\mathrm{nc})-(\mathrm{k}-\mathrm{nc})] \\
& =2 \mathrm{k}[2 \mathrm{nc}] \\
& =2 \mathrm{k}[2 \mathrm{n}(12 / \mathrm{fe})] \\
& =24 \mathrm{n}(2 \mathrm{k} / \mathrm{fe}) \\
& =\mathrm{RHS}
\end{aligned}
$$


The cyclic-relation between factor-element (fe) and SADN of even numbers can be understood with the help of following quadrant diagram:-

For fe $=2$;

Even number $=10,22,34,46,58, \ldots .=10+12 \mathrm{n}$ $=2(5,11,17,23,29, \ldots$.

$=2 \cdot[\operatorname{SADN}(5,2,8)]$
For fe $=12$;

Even number $=12,24,36,48,60, \ldots .=12+12 \mathrm{n}$

$$
=12(1,2,3,4,5, \ldots)
$$$$
=12 \cdot[\operatorname{SADN}(1,2,3,4,5,6,7,8,9)]
$$

$=12 .[\operatorname{SADN}(\mathrm{n})]$
For fe $=4$;

Even number $=8,20,32,44,56, \ldots .=8+12 \mathrm{n}$ $=4(2,5,8,11,14, \ldots$.

$=4 \cdot[\operatorname{SADN}(2,5,8)]$
For $\mathrm{fe}=2$;

Even number $=2,14,26,38,50, . .=2+12 \mathrm{n}$

$=2(1,7,13,19,25, \ldots)$

$=2 \cdot[\operatorname{SADN}(1,7,4)]$

For fe $=6$;

Even number $=6,18,30,42,54, \ldots . .=6+12 \mathrm{n}$

$=6(1,3,5,7,9,11,13,15,17, \ldots$.

$=12 \cdot[\operatorname{SADN}(1,3,5,7,9,2,4,6,8)]$

$=12 \cdot[\operatorname{SADN}(\mathrm{n})]$

Diagram 8.1: Quadrant diagram representing cyclic series elements vis-a-vis SADN of even numbers 
9

\section{Identifying nTC (i.e. total number of acceptable combinations) for a given even number (2k) depending on SADN and CSE}

\section{Deriving possible combinations of primes for even numbers}

\section{Case I- Even numbers (2k) of $\operatorname{SADN}(2,5,8)$ that are of CSE 2 type}

For even numbers of $\operatorname{SADN}(2,5,8)$; the relevant series of odd numbers will be the $\mathrm{S} 7$ series as mentioned earlier in Section 7

Here $\{(2 \mathrm{k}-2) / 6\}-1$ will give the total number of elements, worth consideration, of the S7 series up to $2 \mathrm{k}$ that would include both prime and composite element numbers. As evident from Figure 1, (2k-2)/6 gives the total number of elements of S7 series that exist up to $2 \mathrm{k}$, including an element given as $2 \mathrm{k}-1$. As the number ' 1 ' is not considered to be an element in S7 series, its corresponding element (i.e. $2 \mathrm{k}-1$ ) of S7 series is also to be not considered. Hence total number of elements, worth consideration, of the $S 7$ series up to $2 \mathrm{k}$ that would include both prime and composite element numbers would be $\{(2 \mathrm{k}-2) / 6\}-1$. For instance, if $2 \mathrm{k}=32(\mathrm{SADN} 5)$, then $32-2 / 6=5$. Here 5 is the number of elements of the $\mathrm{S} 7$ series whose value is less than 32 and the actual numbers will be 7,13,19,25 and 31 .

If $2 \mathrm{k}$ is a $\operatorname{SADN}(2,5,8)$ number of CSE 2 type, then $\mathrm{k}$ will be an odd number (for proof, see Appendix 3). (k-1)/6 will give the number of combinations of different elements of the S7 series that will add up to $2 \mathrm{k}$ (refer diagram 9.1). It is important to note here that all odd numbers of $\mathrm{SADN}(1,4,7)$ that lie on the $\mathrm{S} 7$ series will find a place in the combinations thus derived irrespective of whether they are prime or composite.

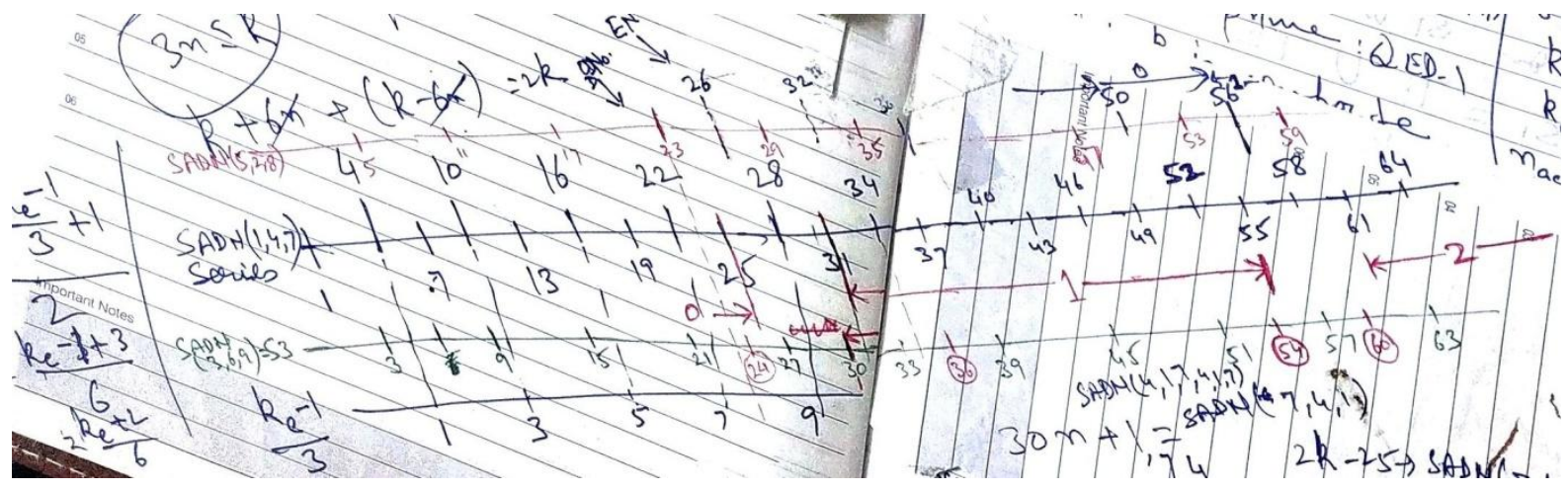

Diagram 9.1: The three series; S1, S3 and S5 alongwith number of unique composites on the relevant series

It is important to note here that since there is no consensus on whether the number 1 is a prime or composite number, this additional combination of $2 k=1+(2 k-1)$ is only of 
academic importance and this combination does not have a role to play, in identifying $p 1+p 2$ combinations for the given $2 k$, in present paper.

\section{Case II - Even numbers (2k) of SADN $(2,5,8)$ that are of CSE 4 type}

In case $2 \mathrm{k}$ is of $\operatorname{SADN}(2,5,8)$ of CSE 4 type, $\mathrm{k}$ will be an even number (for proof, see Appendix 3). Here, (k-4)/6 will give the number of total combinations (nTC) of elements of the $\mathrm{S} 7$ series that will add up to $2 \mathrm{k}$ (refer diagram 9.1).

Therefore, for $2 \mathrm{k}$ of $\operatorname{SADN}(2,5,8)$; the value of nTC will be: -

For $2 \mathrm{k}$ of CSE 2 type- nTC $=(\mathrm{k}-1 / 6)$

For $2 \mathrm{k}$ of CSE 4type- nTC $=(\mathrm{k}-4 / 6)$

\section{Case III- Even numbers (2k) of $\operatorname{SADN}(1,4,7)$ that are of CSE 2 type}

For even numbers of $\operatorname{SADN}(1,4,7)$ the relevant series of odd numbers will be the S5 series as mentioned earlier in Section 7. Here the total number of odd numbers lying on the S5 series up to $2 \mathrm{k}$ which includes both prime and composite element numbers will be given by (2k-4)/6 (for proof, see Appendix 3 and refer diagram 9.1). For instance, consider 2k to be 34 (i.e. SADN 7). This implies that there are (34-4)/6 i.e. 5 elements of the $S 5$ series whose value is less than 34 and the actual numbers will be 5,11,17,23 and 29 .

In case $2 \mathrm{k}$ is a SADN 1,4,7 number of CSE 2 type, then $\mathrm{k}$ will be an odd number and (k-1)/6 will give the value of nTC.

\section{Case IV- Even numbers (2k) of $\operatorname{SADN}(1,4,7)$ that are of CSE 4 type}

In this case, $\mathrm{k}$ will be an even number and (k-2)/6 will give the value of $\mathrm{nTC}$ as is proven in Appendix 3.

\section{Case V- Even numbers (2k) of $\operatorname{SADN}(3,6,9)$}

In case of even numbers of SADN 3, 6 and 9, the numbers would be of either CSE 6 or CSE 12 type and the relevant series will be both the S5 and S7 series since the possible prime combinations will be such that one term will lie on the S5 series while the corresponding term will lie on the $\mathrm{S} 7$ series, as discussed in Section 7 . In this case $2 \mathrm{k} / 3$ will give the number of elements of the S5 and S7 series of odd numbers whose value is less than $2 k$ and $2 k / 6$ will give the value of nTC as is proven in Appendix 3. 
It is important to note here that since nTC for all even numbers irrespective of their SADN includes all elements on the relevant series irrespective of whether they are prime or composite, these combinations are of following three types-

Combination1: $\mathbf{p}+\mathbf{c}$ where one element is prime and the other is composite

Combination2: $\mathbf{c 1 + c 2}$ where both elements being summed up are composites

Combination3: p1+p2 where both elements being summed up are primes

The next step would be to identify the $\mathrm{p} 1+\mathrm{p} 2$ combinations, as discussed in next section. 


\section{Identifying combinations of type $\mathrm{p} 1+\mathrm{p} 2$ for even number $2 \mathrm{k}$}

Once we arrive at the number of unique composites on the relevant series we can now proceed to identify the $\mathrm{p} 1+\mathrm{p} 2$ combinations for any given even number ( $2 \mathrm{k}$ ).

If the number of composites is less than the total number of acceptable combinations derived earlier in Section 9 by at least 1 then it directly follows that even if all composites are primeeaters i.e. are paired with a prime number, there will still be at least one $\mathrm{p} 1+\mathrm{p} 2$ combination. For instance consider the even number 100. This is a SADN 1//0 type number which implies that S5 is the relevant series on which the $\mathrm{p} 1+\mathrm{p} 2$ may be identified. For the number 100 there would be $2 k-4 / 6$ i.e. $100-4 / 6=16$ element numbers on the $S 5$ series, $k-2 / 6$ i.e. $50-2 / 6=8$ acceptable combinations. Since the number of composites on the 5 series $<100=4$, if we consider all these 4 composites to be prime-eaters, they will absorb 4 out of the 8 acceptable combinations. This means that 4 combinations will still be in the nature of $\mathrm{p} 1+\mathrm{p} 2$ combinations. Rather, it would be more appropriate to state that at least 4 of the 8 combinations would be in the nature of $p 1+p 2$ combinations. This is because here we have considered all the composites to be prime-eaters and have not explored the possibility that some of these composites could be in the form of $\mathrm{c} 1+\mathrm{c} 2$ combinations. The number of $\mathrm{P} 1+\mathrm{P} 2$ combinations could increase if there are such $\mathrm{C} 1+\mathrm{C} 2$ combinations. In this example, two of the 4 composites (viz. 35 and 65) come together to form a $\mathrm{C} 1+\mathrm{C} 2$ combination. Therefore, in this example, the total combinations can be classified as: 1 out of 8 combinations are of type $\mathrm{C} 1+\mathrm{C} 2$; 2 out of 8 combinations are of type $\mathrm{P} 1+\mathrm{C} 1$; and 5 out of 8 combinations are of type $\mathrm{P} 1+\mathrm{P} 2$.

While finding out the number of $\mathrm{C} 1+\mathrm{C} 2$ combinations for numbers where $\mathrm{TC}>$ number of composites is an exercise for academic purposes, it becomes mandatory to find them out for numbers where nTC $<$ number of composites.

In general terms; the above discussion can be summarised as follows:

For any even number $(\mathrm{EN}), \mathrm{SADN}$ of $\mathrm{EN}=\{7,4,1\}$ or $\{5,2,8\}$ or $\{6,3,9\}$

Case(1):

$\mathrm{SADN}$ of $\mathrm{EN}=\{7,4,1\}$

$\mathrm{EN}=2 \mathrm{k}$

$\operatorname{Case(1A):~} E N / 2=k$ is a prime number

Case(1B): $E N / 2=k$ is a composite number

If ' $\mathrm{k}$ ' is a composite number: 
Number of acceptable combinations of elements is given as $n_{a c c}$

Case(1BP): If number of composites is less than number of primes (i.e. $n_{c}<n_{p}$ implies that even if all composites are prime-eaters; there exists atleast one $\mathrm{p} 1+\mathrm{p} 2$ pair

Case(1BC): If number of composites is greater than or equal to number of primes (i.e. $\mathrm{n}_{\mathrm{c}} \geq$ $\mathrm{n}_{\mathrm{p}}$ ) implies that we need to find total number of unique $\mathrm{C} 1+\mathrm{C} 2$ pairs

\section{Case(2):}

$\mathrm{SADN}$ of $\mathrm{EN}=\{5,2,8\}$

$\mathrm{EN}=2 \mathrm{k}$

$\operatorname{Case}(\mathbf{2 A}): \mathrm{EN} / 2=\mathrm{k}$ is a prime number

$\operatorname{Case}(2 B): E N / 2=k$ is a composite number

If ' $\mathrm{k}$ ' is a composite number:

Number of acceptable combinations of elements is given as $n_{a c c}$

Case(2BP): If number of composites is less than number of primes (i.e. $n_{c}<n_{p}$ implies that even if all composites are prime-eaters; there exists atleast one $\mathrm{p} 1+\mathrm{p} 2$ pair

Case(2BC): If number of composites is greater than or equal to number of primes (i.e. $\mathrm{n}_{\mathrm{c}} \geq$ $\mathrm{n}_{\mathrm{p}}$ ) implies that we need to find total number of unique $\mathrm{C} 1+\mathrm{C} 2$ pairs

\section{Case(3):}

SADN of $\mathrm{EN}=\{6,3,9\}$

$\mathrm{EN}=2 \mathrm{k}$

$\operatorname{Case}(3 \mathrm{~A}): \mathrm{EN} / 2=\mathrm{k}$ is a prime number, which is never possible as midpoint $(\mathrm{k})$ of even numbers $(2 \mathrm{k})$ of $\operatorname{SADN}(6,3,9)$ would themselves be of $\operatorname{SADN}(3,6,9)$ respectively i.e. a composite number lying on S3 series.

Case(3B): $\mathrm{EN} / 2=\mathrm{k}$ is a composite number

If ' $\mathrm{k}$ ' is a composite number:

Number of acceptable combinations of elements is given as $n_{a c c}$

Case(3BP): If number of composites is less than number of primes (i.e. $n_{c}<n_{p}$ implies that even if all composites are prime-eaters; there exists atleast one $\mathrm{p} 1+\mathrm{p} 2$ pair 
Case(3BC): If number of composites is greater than or equal to number of primes (i.e. $\mathrm{n}_{\mathrm{c}} \geq$ $\mathrm{n}_{\mathrm{p}}$ ) implies that we need to find total number of unique $\mathrm{c} 1+\mathrm{c} 2$ pairs 


\section{1}

\section{Identifying number of unique combinations of type c1+c2 for a given even number}

Identification of unique combinations of type $\mathrm{c} 1+\mathrm{c} 2$ (i.e. such combinations where both components are composites) for any given even number (2k) comprises of following three steps:-

Step1: $c 1+c 2$ of type 1 derived from $k$, i.e. mid-point of the even number $2 k$

Step2: $\mathrm{c1}+\mathrm{c} 2$ of type 2 derived from last digit of $2 \mathrm{k}$

Step3: $\mathrm{c} 1+\mathrm{c} 2$ of type 3 derived from $6 \mathrm{p} 1 \mathrm{p} 2$ where $\mathrm{p} 1$ and $\mathrm{p} 2$ are primes such that $6 \mathrm{p} 1 \mathrm{p} 2$ $\leq \mathbf{2 k}$

\section{$11 \mathrm{~A}$.}

\section{Step1:}

\section{c1+c2 derived from $k$, i.e. mid-point of the even number $2 k$}

Step 1: This step is applicable for even numbers where midpoint $\mathrm{k}$ is a composite number. Suppose ' $a$ ' and ' $b$ ' are factors of the mid-point $k$ i.e. $\mathrm{k}=\mathrm{ab}$

Here the following $\mathrm{C} 1+\mathrm{C} 2$ combinations can be derived:

$$
a(b+6 n)+a(b-6 n) \text {; where } n \text { is an element of the set of Natural numbers }
$$

These combinations will be derived as long as $\mathrm{b}+6 \mathrm{n}$ is less than $2 \mathrm{k}$ OR in other words, as long as $\mathrm{b}-6 \mathrm{n}$ does not lead us to the first element number of the concerned series on which $\mathrm{b}$ is existing.

Number of such combinations is given by number of possible values of $n$ where:

$$
\mathrm{b}+6 \mathrm{n}<2 \mathrm{k} \text { or } \mathrm{n}<\mathrm{ff} \text { of }[(2 \mathrm{k}-\mathrm{b}) / 6] \text { (ff stands for floor function) }
$$

Similarly, another set of $\mathrm{C} 1+\mathrm{C} 2$ combinations will be in the form of $b(a+6 n ')+b(a-6 n ')$. Here again the combinations can be derived till a-6n' does not lead us to the first element of the series OR as long as $\mathrm{a}+6 \mathrm{n}$ ' is less than $2 \mathrm{k}$.

Number of such combinations is given by: $a+6 n '<2 k$ or n' $<$ ff of $[(2 k-a) / 6]$

Hence total number of $c 1+c 2$ combinations of type-I are given as: $n+n$ ' or $f f$ of $[(2 k-b) / 6]+$ ff of $[(2 k-$ a)/6]

Alternately, this implies that:

C1+C2 of Type-1:

1 [Section 11: 11A] 
$\mathrm{k}=\mathrm{a} \cdot \mathrm{b}$ implies that

$a b+a b=2 k$

and

$a(b+6 n)+a(b-6 n)=2 k$; where $n$ is an integer

and

$b\left(a+6 n^{\prime}\right)+b\left(a-6 n^{\prime}\right)=2 k$; where $n^{\prime}$ is an integer

As $\mathrm{b}-6 \mathrm{n}>0$, implies that $\mathrm{n}<$ floor function $[\mathrm{b} / 6]$

As a-6n' $>0$, implies that n'< floor function $[\mathrm{a} / 6]$

Hence number of $\mathrm{C} 1+\mathrm{C} 2$ combinations of type-I $\leq$ floor function $[\mathrm{a} / 6]+$ floor function $[\mathrm{b} / 6]+1$

\section{Example 1:}

For instance consider $2 \mathrm{k}$ to be 598 which is SADN 4//8 type number. Since $2 \mathrm{k}$ is of SADN $(7,4,1)$ type, relevant series is the S5 series on which composites are derived as interseries elements of the S5 and S7 series. Here mid-point is 299 which is a product of $13 \times 23$. In this case the following $\mathrm{C} 1+\mathrm{C} 2$ combinations can be derived

1. $13 \times 5+13 \times 41$

2. $13 \times 11+13 \times 35$

3. $13 \times 17+13 \times 29$

4. $23 \times 7+23 \times 19$

This will give us $4 \mathrm{C} 1+\mathrm{C} 2$ combinations.

For a given $2 \mathrm{k}$ if $\mathrm{k}$ is a composite number, then $\mathrm{c} 1+\mathrm{c} 2$ combinations can be identified in the following manner:-

\section{Case I: For even number (2k) of CSE 2 type where midpoint $k$ is a composite odd number}

For example Consider $2 \mathrm{k}=598$ i.e. SADN 4//8. Here midpoint is a composite odd number $(\mathrm{k}=299)$ that $\mathrm{can}$ be expressed as $299=13 \times 23$ (for $2 \mathrm{k}=598$ ), the $\mathrm{c}+\mathrm{c}$ combinations identified from the mid-point are in the form of $13 x(23+6 n)+13(23-6 n)$ till we reach a value of $n$ that leads (23-6n) to the first element of the $S 5$ series (since 23 is an element of the $\mathrm{S} 5$ series), where $\mathrm{n}$ is a natural number.

The actual combinations are: $13 \times 17+13 \times 29$

$$
\begin{aligned}
& 13 \times 11+13 \times 35 \\
& 13 \times 5+13 \times 41
\end{aligned}
$$

In each of these cases, the addition of the said numbers will add upto 598. Similarly another combination would be in the form of $23 x(13+6 n)+23(13-6 n)$ till we reach a value of $n$ that leads (13-6n) to the first element of the S7 series (since 13 is an element of the S7 series), where $\mathrm{n}$ is a natural number.

The actual combinations are: $23 \times 7+23 \times 19=598$ 
In addition to the $4 \mathrm{c} 1+\mathrm{c} 2$ combinations identified as above, $13 \times 23$ itself would be a c1 $+\mathrm{c} 2$ combination. The total number of $\mathrm{c} 1+\mathrm{c} 2$ combinations thus identified will be 5 .

\section{Example 2:}

Consider $2 \mathrm{k}=902$ which is of $\operatorname{SADN} 2 / / 2$ type. Since $2 \mathrm{k}$ is a $\operatorname{SADN}(5,2,8)$ type number, relevant series would be the S7 series on which composites are derived as intra series elements of either S5 or S7 series. Here mid-point $=451$ which is a composite odd number that can be expressed in terms of its factors as $11 \times 41$. $\mathrm{C} 1+\mathrm{c} 2$ combinations for $2 \mathrm{k}=902 \mathrm{can}$ be derived as:

$11 x(41+6 n)+11(41-6 n)$ till we reach a value of $n$ that leads $(41-6 n)$ to the first element of the S5 series (since 41 is an element of the $\mathrm{S} 5$ series), where $\mathrm{n}$ is a natural number. The actual combinations would be:

$11 \times 35+11 \times 47$

$11 \times 29+11 \times 53$

$11 \times 23+11 \times 59$

$11 \times 17+11 \times 65$

$11 \times 11+11 \times 71$

$11 \times 5+11 \times 77$

In all these combinations the addition of the said numbers gives 902 .

Similarly $\mathrm{c} 1+\mathrm{c} 2$ combinations would also be identified in the nature of $41 \times(11+6 n)+41(11-$ $6 n)$ till we reach a value of $n$ that leads (11-6n) to the first element of the S5 series (since 11 is an element of the S5 series), where $\mathrm{n}$ is a natural number. Such a combination will be $41 \times 5+$ $41 \times 17$ leading to 902 .

In addition to the above $\mathrm{c} 1+\mathrm{c} 2$ combinations identified, $11 \times 41$ itself will also be a combination of $\mathrm{c} 1+\mathrm{c} 2$ type. The total number of $\mathrm{c} 1+\mathrm{c} 2$ type combinations thus identified will be 8 .

\section{Example 3:}

Consider $2 \mathrm{k}=602$ which is of type SADN 8//2. This implies that relevant series would be the S7 series whose composites are derived as intra series products of elements of either S5 or S7 series. Mid-point of 602 is given as 301 which can be expressed in terms of its factors as 301= $7 \mathrm{x} 43$. $\mathrm{C} 1+\mathrm{c} 2$ combinations can be identified as -

$7(43+6 n)+7(43-6 n)$ till we reach a value of $n$ that leads $(43-6 n)$ to the first element of the S7 series (since 43 is an element of the S7 series), where $n$ is a natural number. The actual combinations would be:

$7 \times 37+7 \times 49$

$7 \times 31+7 \times 55$

$7 \times 25+7 \times 61$

$7 \times 19+7 \times 67$

$7 \times 13+7 \times 73$

$7 \times 7+7 \times 79$

In addition to the above, $7 \times 43$ itself will be a $\mathrm{c} 1+\mathrm{c} 2$ combination and the total number of $\mathrm{c} 1+\mathrm{c} 2$ type combinations $=7$

\section{Example 4:}

In case if for a given $2 \mathrm{k}$; $\mathrm{k}$ is a square of a certain number, then $\mathrm{c} 1+\mathrm{c} 2$ combinations would be identified as follows:

Consider $2 \mathrm{k}=1058$ where midpoint $529=23 \times 23 . \mathrm{C} 1+\mathrm{c} 2$ type combinations for this $2 \mathrm{k}$ are: 
$23 \times 23+23 \times 23$

$23 \times 17+23 \times 29$

$23 \times 11+23 \times 35$

$23 \times 5+23 \times 41$

Total number of $\mathrm{c} 1+\mathrm{c} 2$ in this case will be 4 .

\section{Example 5:}

If midpoint of $2 \mathrm{k}$ is a composite odd number having more than 2 factors:

Consider 2k $=2002$ which is SADN 4//2 whose relevant series is the S5 series. Mid-point k is 1001 which can be expressed in terms of its factors as $7 \times 11 \times 13$.

$\mathrm{C} 1+\mathrm{c} 2$ for $2 \mathrm{k}=2002$ would be identified as follows-

Step(i)- Consider (k) $1001=7 \times 143$

$\mathrm{C} 1+\mathrm{c} 2$ would be identified as $7 x(143+6 n)+7 x(143-6 n)$ till we reach a value of $n$ that leads (143-6n) to the first element of the S5 series (since 143 is an element of the S5 series), where $\mathrm{n}$ is a natural number. $\mathrm{C} 1+\mathrm{c} 2$ combinations thus identified would be-

$$
\begin{aligned}
& 7 \times 143+7 \times 143 \\
& 7 \times 137+7 \times 149 \\
& 7 \times 131+7 \times 155 \\
& 7 \times 125+7 \times 161 \\
& 7 \times 119+7 \times 167 \\
& \vdots \\
& 7 \times 5+7 \times 281
\end{aligned}
$$

Total number of $\mathrm{c} 1+\mathrm{c} 2$ thus derived will be 23 .

Now consider $\mathrm{k}=1001$ as $11 \times 91$. $\mathrm{C} 1+\mathrm{c} 2$ will be identified as $11(91+6 n)+11(91-6 n)$ till we reach a value of $n$ that leads (91-6n) to the first element of the S7 series (since 91 is an element of the $\mathrm{S} 7$ series), where $\mathrm{n}$ is a natural number. $\mathrm{C} 1+\mathrm{c} 2$ combinations thus derived would be:

$$
\begin{aligned}
& 11 \times 85+11 \times 97 \\
& 11 \times 79+11 \times 103 \\
& 11 \times 73+11 \times 109 \\
& \vdots \\
& 11 \times 7+11 \times 175
\end{aligned}
$$

However it needs to be noted here that some $\mathrm{c} 1+\mathrm{c} 2$ combinations identified by 11 may have been already identified while calculating $\mathrm{c} 1+\mathrm{c} 2$ for 7 . Those need to be identified and subtracted to avoid double counting of the same $\mathrm{c} 1+\mathrm{c} 2$. For this purpose we need to identify a $c 1+c 2$ that involves a composite number divisible by both 7 and 11 . The first such number would be $7 \mathrm{x} 11$ itself, since it is being derived while identifying $\mathrm{c} 1+\mathrm{c} 2$ corresponding to 11 and have already been identified while calculating $\mathrm{c} 1+\mathrm{c} 2$ corresponding to 7 . Thereafter every $[11 \times 7] \times[1+6 n]$ th number satisfies this condition; as long as $[11 \times 7] .[1+6 n] \leq \mathrm{k}$ where $\mathrm{n}$ is a natural number.

In general terms the conditions for identifying composites already derived can be expressed as:

$\mathrm{p}_{2} \mathrm{p}_{1}[1+/ 6 \mathrm{n}] \leq \mathrm{k}$; where $\mathrm{p} 2$ is the prime element, which is a factor of particular $\mathrm{k}$. Here $\mathrm{p}_{1}$ is the previous prime element which is a factor of $\mathrm{k}$ and whose $\mathrm{c} 1+\mathrm{c} 2$ have already been identified. In this equation $(11 \times 7)+(11 \times 175)$ and $(11 \times 49)+(11 \times 133)$ and $(11 \times 91)+(11 \times 91)$ would be 3 such $\mathrm{c} 1+\mathrm{c} 2$ combinations that are already identified by 7 .

Now consider 1001 as $13 \times 77$ : 
$\mathrm{C} 1+\mathrm{c} 2$ combinations would be identified as $13(77+6 n)+13(77-6 n)$ till we reach a value of $n$ that leads (77-6n) to the first element of the S5 series (since 77 is an element of the S5 series), where $\mathrm{n}$ is a natural number. The actual combinations thus derived would be:-

$13 \times 71+13 \times 83$

$13 \times 65+13 \times 89$

$13 \times 59+13 \times 95$

$\vdots$

$13 \times 5+13 \times 149$

Here again some combinations could be those which have been already identified by 7 and 11. Those need to be identified. Applying the logical conditions given above, we get the following combinations already derived:-

$13 \times 11+13 \times 143$ - already derived while calculating $\mathrm{c} 1+\mathrm{c} 2$ for 11 .

$13 \times 77+13 \times 77$ - already derived while calculating $\mathrm{c} 1+\mathrm{c} 2$ for 11 .

$13 \times 35+13 \times 119$ - already identified while calculating $\mathrm{c} 1+\mathrm{c} 2$ for 7 .

After identifying those common $\mathrm{c} 1+\mathrm{c} 2$ combinations we need to now calculate the number of total $\mathrm{c} 1+\mathrm{c} 2$ identified by the method.

The total number of $\mathrm{c} 1+\mathrm{c} 2$ combinations derived from the midpoint may be summarised in the following table:-

\begin{tabular}{|c|c|c|c|}
\hline Factor of midpoint & $\begin{array}{l}\text { ncc (number of } \\
\text { c1+c2 combinations) } \\
\text { derived, from factor } \\
\text { of midpoint }(k) \text {, } \\
\text { from midpoint }(k)\end{array}$ & $\begin{array}{l}\text { nce already derived } \\
\text { from previous } \\
\text { factors of midpoint }\end{array}$ & $\begin{array}{ll}\text { nucc } \quad(\text { number } & \text { of } \\
\text { unique } & \\
\text { combinations } \\
\text { type c1+c2) }\end{array}$ \\
\hline 7 & 24 & $\ldots$ & 24 \\
\hline 11 & 15 & 3 & 12 \\
\hline 13 & 13 & 3 & 10 \\
\hline \multicolumn{3}{|c|}{$\begin{array}{l}\text { Number of total combinations of type } \mathrm{c} 1+\mathrm{c} 2 \text { derived due to } \\
\text { midpoint }(\mathrm{k}) \text { of the even number }(2 \mathrm{k})=\end{array}$} & $24+12+10=46$ \\
\hline
\end{tabular}

Table 11A.1: Number of unique c1+c2 combinations of type 1 derived from composite mid-point $(k)$ of the even number(2k)

\section{Case-II: For even number (2k) of CSE 4 type where midpoint $k$ is an even number}

\section{Example 6:}

Consider 2k $=196$ i.e. SADN7//6

Midpoint $\mathrm{k}=98$ which is a composite even number whose factors are $7 \times 2 \times 7$.

Here we identify all the factors of $\mathrm{k}$. Of these, we consider the prime factors which lie on the relevant series for derivation of $\mathrm{c} 1+\mathrm{c} 2$ combination due to mid-point $(\mathrm{k})$.

In this equation corresponding factor as $7 \times 2=14$ i.e. we express $\mathrm{k}$ as $7 \times 14$. Here $\mathrm{c} 1+\mathrm{c} 2$ combination will be in nature of:

$7 \mathrm{x}(14-3)+7 \mathrm{x}(14+3)$

i.e. $7 \times 11+7 \times 17$

Here addition (and subtraction) of 3 gives us 17 (and 11) which are elements of S5 series. Thereafter other $\mathrm{c} 1+\mathrm{c} 2$ combinations will be derived as $7 x(11-6 n)+7 x(17+6 n)$ for different values of natural number $n$, till we reach a value of (11-6n) which leads us to the first element of the S5 series. 
Similarly consider the number $2 \mathrm{k}=748$ i.e. SADN1//8. Midpoint $\mathrm{k}=374$ which can be expressed in terms of its factors as $11 \times 2 \times 17$ or $11 \times 34$.

$\mathrm{C} 1+\mathrm{c} 2$ combinations that can be identified here are:-

$11 \times(34-3)+11(34+3)$

i.e. $11 \times 31+11 \times 37$

Thereafter other combinations would be:

$11 x(31-6 n)+11(37+6 n)$ for different values of natural number $n$, till we reach a value of (31$6 n)$ that leads us to the first element of the $S 7$ series.

Similarly since $\mathrm{k}$ can also be expressed as $17 \times 22$, other $\mathrm{c} 1+\mathrm{c} 2$ combinations identified are:$17(22-3)+17(22+3)$

i.e. $17 \times 19+17 \times 25$

Therefore other $\mathrm{c} 1+\mathrm{c} 2$ identified would be:-

$17(19-6 n)+17(25+6 n)$

Till we reach a value of (19-6n) for different values of natural number n, that leads us to the first element of the $\mathrm{S} 7$ series.

\section{Case-III: For even number (2k) of CSE 12 type and CSE 6 type}

\section{Example7:}

Deriving $\mathrm{C} 1+\mathrm{C} 2$ of type 1 for even numbers of $\operatorname{SADN}(3,6,9)$ of CSE 12 type

In case of even numbers of SADN $(3,6,9), c 1+c 2$ combinations derived from the mid-point would be identified in a different manner. Here, if even number (2k) is having $\operatorname{SADN}(3)$, its midpoint (k) would be of SADN(6); if even number (2k) is having $\operatorname{SADN}(6)$, its midpoint (k) would be of SADN(3); and if even number (2k) is having $\operatorname{SADN}(9)$, its midpoint ( $k$ ) would be of $\operatorname{SADN}(9)$. Therefore, $k+/-6$ would also be of SADN $(3,6,9)$. The method that would be employed here would be to find the factors of $2 \mathrm{k}$ and consider them in the following manner. Consider $2 \mathrm{k}=300$. The factors of this number would be $2,3,4,5,6,10,12,15,18,20,25,30,50,60,100,150$. Of these, the factor 5 is such that it lies on the $S-5$ series. The only factor which lies on $\mathrm{S} 1$ or S5 series is 5 . We find the value of $2 k / 5=300 / 5=60$. Thereafter, we identify all possible combinations of two numbers in which 60 can be expressed as a summation of two numbers in the form of $(6 n+1)+[60-(6 n+1)]$ where the value of $n$ ranges from 1 to such a value where $(6 n+1)$ remains $<60$. For instance the combinations would be $7+53 ; 13+47$; $19+41, \ldots ., 55+5$. Now, by multiplying both the terms that are being summed up to 60 by 5 , we can derive $\mathrm{c} 1+\mathrm{c} 2$ combinations of type 1 . For instance, the combinations would be:-

$5 \times 7($ i.e. 35$)+5 \times 53($ i.e. 265$)$

$5 \times 13($ i.e. 65$)+5 \times 47($ i.e. 235$)$

$5 \times 19($ i.e. 95$)+5 \times 41($ i.e. 205$)$

$\vdots$

$5 \times 55($ i.e. 275$)+5 \times 5($ i.e. 25$)$

In this way, the number of $\mathrm{c} 1+\mathrm{c} 2$ combinations of type 1 is equal to the number of possible values of $\mathrm{n}$. So we identify total of $10 \mathrm{c} 1+\mathrm{c} 2$ combinations of type 1 .

\section{Example 8:}

6 [Section 11: 11A] 
Deriving $\mathrm{C} 1+\mathrm{C} 2$ of type 1 for even numbers of SADN $(3,6,9)$ of CSE 6 type

Consider the even number 462. It is of SADN 3 and CSE 6 type. $\mathrm{C} 1+\mathrm{C} 2$ combinations derived from the mid-point can be identified as follows. Firstly identify the factors for the even number. Here, 7 and 11 are factors of $2 \mathrm{k}$. In the next step find the value of $462 / 7$ which would be 66 . Now identify such combinations of numbers that add up to 66 and are in the nature of $(6 n+1)+[66-(6 n+1)]$ where the value of $n$ would range from 1 to such an integer where value of $(6 n+1)$ would be $<66$. Such combinations would be $7+59 ; 13+53 ; 19+47, \ldots ., 61+5$. Now multiplying both the terms in the summation function by 7 will yield $\mathrm{C} 1+\mathrm{C} 2$ combinations. These would be as follows:

7x7(i.e.49)+7x59(i.e.413)

$7 \times 13($ i.e. 91$)+7 \times 53($ i.e. 371$)$

7x19(i.e.133)+7x47(i.e.329)

$\vdots$

7x61(i.e.427)+7x5(i.e.35)

In the above considered case, total number of combinations would be 10 .

Further, find the value of $462 / 11=42$. Now find the combinations of two numbers which would add up to 42 and are in the nature of $(6 n+1)+[42-(6 n+1)]$ where the value of $n$ ranges from 1 to such an integer where value of $6 n+1$ would be $<42$. Such combinations would be $7+35 ; 13+29 ; 19+23, \ldots$, $37+5$. Thereafter multiplying both the terms in the summation function by 11 we can derive $\mathrm{C} 1+\mathrm{C} 2$ combinations. These would be identified as:

$11 \times 7($ i.e. 77$)+11 \times 35($ i.e. 385$)$

11x13(i.e.143)+11x29(i.e.319)

11x19(i.e.209)+11x23(i.e.253)

$\vdots$

$11 \times 37($ i.e. 403$)+11 \times 5($ i.e. 55$)$

From these combinations we need to subtract those which have been derived earlier. For instance, the combination $11 \times 7$ (i.e.77)+11x35(i.e.385) has already been derived earlier and will therefore not be counted here. After accounting for the repetitions, the number of unique combinations would be 6$1=5$. Therefore, the total number of $\mathrm{c} 1+\mathrm{c} 2$ combinations for $2 \mathrm{k}$ as 462 of type 1 would be $10+5=15$. 


\section{$11 B$.}

\section{Step2:}

\section{c1+c2 of type 2 derived from last digit of even number (2k)}

\section{Step2: $\quad c 1+c 2$ derived from last digit of $2 k$}

Step 2: This step depends on the last digit of the even number which will lead us to find out $\mathrm{c} 1+\mathrm{c} 2$ combinations in which one of the terms is a multiple of 5. As mentioned earlier (in section 6), for any even number, depending on the last digit, some combinations of odd numbers cannot be considered in the identification of $\mathrm{p} 1+\mathrm{p} 2$ combinations, since the corresponding number would be a multiple of 5 . For instance; for $2 \mathrm{k}$ ending in 2 , prime numbers ending in 7 cannot be considered since:

$$
(2 \mathrm{k} / / 2)-(\mathrm{ap} / / 7)=(\mathrm{a} / / 5) \text { i.e. } \text { an odd number ending in } 5
$$

Therefore, if we can identify composite numbers on the relevant series that end in 7 , these would constitute $\mathrm{c} 1+\mathrm{c} 2$ alongwith their corresponding number that is a multiple of 5 . Following table shows the last digit of composite odd numbers that need to be identified for $2 \mathrm{k}$ ending in a particular digit:

\begin{tabular}{|c|c|}
\hline Last digit of 2k & Last digit of composite odd number \\
\hline 2 & 7 \\
\hline 4 & 9 \\
\hline 6 & 1 \\
\hline 8 & 3 \\
\hline 0 & 5 \\
\hline
\end{tabular}

Table 11B.1: Last digit of composite odd number which combines with another odd number ending in digit 5 , to form $\mathrm{c} 1+\mathrm{c} 2$ combination corresponding to last digit of given even number

\begin{tabular}{|c|c|c|c|c|c|}
\hline $\begin{array}{l}\text { Last digit of } \\
\text { composite } \\
\text { odd number }\end{array}$ & \multicolumn{5}{|c|}{$\begin{array}{c}\text { Last digits of corresponding factors of } \\
\text { composite odd numbers }\end{array}$} \\
\hline 1 & $1 \times 1$ & $3 \times 7$ & $9 \times 9$ & $\ldots \ldots$ & $\ldots \ldots$ \\
\hline 3 & $1 \times 3$ & $7 \times 9$ & $\ldots \ldots$ & $\ldots \ldots$ & $\ldots \ldots$ \\
\hline 5 & $1 \times 5$ & $3 \times 5$ & $5 \times 5$ & $7 \times 5$ & $9 \times 5$ \\
\hline 7 & $1 \times 7$ & $3 \times 9$ & $\ldots \ldots$ & $\ldots \ldots$ & $\ldots \ldots$ \\
\hline 9 & $1 \times 9$ & $3 \times 3$ & $7 \times 7$ & $\ldots \ldots$ & $\ldots \ldots$ \\
\hline
\end{tabular}

Table 11B.2: Last digits of factors corresponding to last digit of yielding composite odd number 
Table 11B.1 implies that if $2 \mathrm{k}$ ends in 2 , then composite odd numbers on the relevant series that end in 7 will form part of $\mathrm{C} 1+\mathrm{C} 2$ combinations. Composite odd numbers ending in 7 can be derived by multiplying odd numbers that end in 1 with odd numbers that end in 7 (refer table 11B.2). Similarly, composite odd numbers ending in 7 can also be derived as a product of odd numbers ending in $1 \& 7$ or $3 \& 9$. For instance, consider $2 \mathrm{k}$ as 412 (i.e. SADN 7//2 which means the relevant series is the S5 series). As composites on S5 series are derived as products of inter-series elements (refer section 5A), this can be derived as $7 * 11,7 * 41,13 * 29,19 * 23$ and so on. Now consider $2 \mathrm{k}$ to be 422 (i.e. SADN $8 / / 2$ ) which means the relevant series is the S7 series. Composite odd numbers on the S7 series are formed as products of intra-series elements. These can be derived as $7 * 31$, $11 * 187,13 * 17$ and so on. In all these cases the composite odd numbers will form part of $\mathrm{C} 1+\mathrm{C} 2$ combination since the corresponding number in the combination will essentially be a multiple of 5 . The only exception to this pattern will be:

$$
\text { ' } 2 \mathrm{k}-5 \text { ' }
$$

since in such a case:

$2 \mathrm{k}$ - 'composite odd number ending in 7 ' $=5$ and 5 itself is a prime number thus leading us to a $\mathrm{p}+\mathrm{c}$ type of combination.

It is important to note here, as supplement to above discussion, that if $2 k-5$ happens to be prime then it gives us a p1+p2 combination $A N D$ if $2 k-5$ happens to be composite then it gives us a p+c combination.

If $2 \mathrm{k}$ is an even number ending in 4 then composite odd numbers on the relevant series ending in 9 will form part of $\mathrm{c} 1+\mathrm{c} 2$ combinations. These can be derived as products of odd numbers ending in $1 \& 9$ or $3 \& 3$ or $7 \& 7$ (refer table 11B.2).

If $2 \mathrm{k}$ is an even number ending in 6 then composite odd numbers on the relevant series ending in 1 will form part of $\mathrm{C} 1+\mathrm{C} 2$ combinations. These can be derived as products of elements ending in 1 with other element ending in 1 or as products of odd numbers ending in 3 with odd numbers ending in 7 or as products of odd numbers ending in 9 with other odd numbers ending in 9 (refer table11B.2).

If $2 \mathrm{k}$ is an even number ending in 8 then composite odd numbers ending in 3 on the relevant series will form part of $\mathrm{C} 1+\mathrm{C} 2$ combinations which in turn can be derived as products of odd numbers ending in $3 \& 1$ or $7 \& 9$ (refer table 11B.2).

If $2 \mathrm{k}$ is an even number ending in 0 , then composite odd numbers on the relevant series ending in 5 will form part of $\mathrm{C} 1+\mathrm{C} 2$ combinations. Products of all elements ending in 5 with any other odd number will end in 5 (refer table 11B.2).

Number of $\mathrm{C} 1+\mathrm{C} 2$ combinations of this type (i.e. type 2 ) for a given $2 \mathrm{k}$ can be generalized as follows:

Case(1):

2 [Section 11: 11B] 
$\mathrm{SADN}$ of $\mathrm{EN}=\{7,4,1\}$

$\mathrm{EN}=2 \mathrm{k}$

$\operatorname{Case}(\mathbf{1 A}): \mathrm{EN} / 2=\mathrm{k}$ is a prime number

Case(1B): $\mathrm{EN} / 2=\mathrm{k}$ is a composite number

If ' $\mathrm{k}$ ' is a composite number:

Number of acceptable combinations of elements is given as $n_{\text {acc }}$

Case(1BP): If number of composites is less than number of primes (i.e. $n_{c}<n_{p}$ implies that even if all composites are prime-eaters; there exists atleast one $\mathrm{p} 1+\mathrm{p} 2$ pair

Case(1BC): If number of composites is greater than or equal to number of primes (i.e. $n_{c} \geq n_{p}$ implies that we need to find total number of unique $\mathrm{C} 1+\mathrm{C} 2$ pairs

\section{C1+C2 of Type-1:}

It has already been discussed in section 11A.

\section{C1+C2 of Type-2 for even number having SADN $(7,4,1)$ :}

$\mathrm{EN}=\operatorname{SADN}(7,4,1 / / 0)$ OR $\operatorname{SADN}(7,4,1 / / 2)$ OR $\operatorname{SADN}(7,4,1 / / 4)$ OR $\operatorname{SADN}(7,4,1 / / 6) \mathrm{OR}$ $\operatorname{SADN}(7,4,1 / / 8)$

Here $\operatorname{EN}=\operatorname{SADN}(7,4,1 / / 0)$ indicates even numbers having $\operatorname{SADN}(7,4,1)$ and last digit as 0

\section{Case(1BC-iA):}

$\mathrm{EN}=\operatorname{SADN}(7,4,1 / / 0 / / 2)$ indicates even numbers of $\operatorname{SADN}(7,4,1 / / 0)$ and cyclical series element as ' 2 '

$\mathrm{EN}=\operatorname{SADN}(7,4,1 / / 0 / / 2)$

$\mathrm{C} 1$ of $\operatorname{SADN}(5,2,8 / / 5)+\mathrm{C} 2$ of $\operatorname{SADN}(5,2,8 / / 5)=2 \mathrm{k}$

$\left(35+30 \mathrm{n}_{\mathrm{a}}{ }^{\prime \prime}\right)+\left[2 \mathrm{k}-\left(35+30 \mathrm{n}_{\mathrm{a}}{ }^{\prime \prime}\right)\right]=2 \mathrm{k}$

$35+30 \mathrm{n}_{\mathrm{a}}{ }^{\prime}<2 \mathrm{k}$

Number of Composites having last digit as 5 is given as $\mathrm{n}_{\mathrm{a}}{ }^{\prime}<(2 \mathrm{k}-35) / 30$

No. of type- $2 \mathrm{C} 1+\mathrm{C} 2$ combinations $=$ floor function $[(1 / 2) *(2 \mathrm{k}-35) / 30]+1$

\section{Case(1BC-iB):}

$\mathrm{EN}=\operatorname{SADN}(7,4,1 / / 0 / / 4)$ indicates even numbers of $\operatorname{SADN}(7,4,1 / / 0)$ and cyclical series element as ' 4 '

$\mathrm{EN}=\operatorname{SADN}(7,4,1 / / 0 / / 4)$ 
$\mathrm{C} 1$ of $\operatorname{SADN}(5,2,8 / / 5)+\mathrm{C} 2$ of $\operatorname{SADN}(5,2,8 / / 5)=2 \mathrm{k}$

$\left(35+30 \mathrm{n}_{\mathrm{b}}{ }^{\prime \prime}\right)+\left[2 \mathrm{k}-\left(35+30 \mathrm{n}_{\mathrm{b}}{ }^{\prime}\right)\right]=2 \mathrm{k}$

$\left(35+30 \mathrm{n}_{\mathrm{b}}{ }^{\prime}\right)<2 \mathrm{k}$

Number of $\mathrm{C} / / 5$ is given as $\mathrm{n}_{\mathrm{b}}$ " $<(2 \mathrm{k}-35) / 30$

No. of type- $2 \mathrm{C} 1+\mathrm{C} 2$ combinations $=$ floor function $\left[(1 / 2)^{*}(2 \mathrm{k}-35) / 30\right]$

\section{Case(1BC-ii):}

$\mathrm{EN}=\operatorname{SADN}(7,4,1 / / 2)$

Here $\operatorname{EN}=\operatorname{SADN}(7,4,1 / / 2)$ indicates even numbers having $\operatorname{SADN}(7,4,1)$ and last digit as 2

$\mathrm{C} 1[\operatorname{SADN}(5,2,8) / / 5]+\mathrm{C} 2[\operatorname{SADN}(5,2,8) / / 7]=2 \mathrm{k}$

Case(1BC-iiA) For C2[SADN $(5,2,8) / / 7]$ implies that $/ / 1 \mathrm{x} / / 7$

$[\operatorname{SADN}(5,2,8) / / 1] \times[\operatorname{SADN}(7,4,1) / / 7]$

\section{Case(1BC-iiA-i)}

For $\operatorname{SADN}(5,2,8) / / 1$ x $\operatorname{SADN}(7,4,1) / / 7:-$

$\left(11+30 \mathrm{n}^{\prime \prime \prime}\right) \times\left(7+30 \mathrm{n}^{\mathrm{iv}}\right)<=(2 \mathrm{k}-35)$

For $n^{\prime \prime},=0 ; \mathrm{n}^{\mathrm{iv}}{ }_{0}=$ floor function of $[\{(2 \mathrm{k}-35) /(11 * 30)\}-(7 / 30)]$

For $\mathrm{n}^{\prime \prime},=1 ; \mathrm{n}^{\mathrm{iv}}{ }_{1}=$ floor function of $[\{(2 \mathrm{k}-35) /(11+30) * 30\}-(7 / 30)]$

For $n^{\prime \prime},=2 ; \mathrm{n}^{\mathrm{iv}}{ }_{2}=$ floor function of $[\{(2 \mathrm{k}-35) /(11+60) * 30\}-(7 / 30)]$

For n", $=$ n" ${ }_{\max }$ i.e. floor function of $[\{(2 \mathrm{k}-35) /(7 * 30)\}-(11 / 30)] ; \mathrm{n}^{\mathrm{iv}}$ for max value of $\mathrm{n}, "=$ floor function of $\left[(2 \mathrm{k}-35) /\left\{\left(11+30 \mathrm{n}^{\prime}{ }_{\max }\right) * 30\right\}-(7 / 30)\right]$

Hence total number of $n^{\text {iv }}=n^{\text {iv }}{ }_{0}+n^{\text {iv }}{ }_{1}+n^{\text {iv }}{ }_{2}+\ldots \ldots . .+n^{\text {iv }}$ for max value of $n "$,

Or total number of possible values of $\mathrm{n}^{\mathrm{iv}}=\sum_{\mathrm{n}} \mathrm{n}^{\prime \prime}=0$ to floor function of $[\{(2 \mathrm{k}-35) /(7 * 30)\}-(11 / 30)]$ floor function of $[(2 \mathrm{k}-35) /\{(11+30 \mathrm{n},, ') * 30\}-(7 / 30)]$

Number of type- $2 \mathrm{c} 1+\mathrm{c} 2$ combinations $=\sum_{\mathrm{n}}{ }^{\prime \prime}=0$ to floor function of $[\{(2 \mathrm{k}-35) /(7 * 30)\}-(11 / 30)]$ floor function of $\left[(2 \mathrm{k}-35) /\left\{\left(11+30 \mathrm{n},{ }^{\prime \prime}\right) * 30\right\}-(7 / 30)\right]$ 


\section{Case(1BC-iiA-ii)}

For $\operatorname{SADN}(7,4,1) / / 1$ x $\operatorname{SADN}(5,2,8) / / 7:-$

$$
\left(31+30 n^{\mathrm{v}}\right) \times\left(17+30 n^{\mathrm{vi}}\right)<=(2 \mathrm{k}-35)
$$

For $\mathrm{n}^{\mathrm{v}}=0 ; \mathrm{n}^{\mathrm{vi}}=$ floor function of $[(2 \mathrm{k}-35) /(31 * 30)-(17 / 30)]$

For $\mathrm{n}^{\mathrm{v}}=1 ; \mathrm{n}^{\mathrm{vi}}{ }_{1}=$ floor function of $[(2 \mathrm{k}-35) /\{(31+30) * 30\}-(17 / 30)]$

For $\mathrm{n}^{\mathrm{v}}=2 ; \mathrm{n}^{\mathrm{vi}}{ }_{2}=$ floor function of $[(2 \mathrm{k}-35) /\{(31+60) * 30\}-(17 / 30)]$

For $\mathrm{n}^{\mathrm{v}}=\mathrm{n}^{\mathrm{v}}{ }_{\max }$ i.e. floor function of $[\{(2 \mathrm{k}-35) /(17 * 30)\}-(31 / 30)] ; \mathrm{n}^{\mathrm{vi}}=$ floor function of $\left[(2 \mathrm{k}-35) /\left\{\left(31+30 \mathrm{n}_{\text {max }}^{\mathrm{v}}\right) * 30\right\}-(17 / 30)\right]$

Hence total number of $\mathrm{n}^{\mathrm{vi}}=\mathrm{n}^{\mathrm{vi}}{ }_{0}+\mathrm{n}^{\mathrm{vi}}{ }_{1}+\mathrm{n}^{\mathrm{vi}}{ }_{2}+\ldots \ldots . .+\mathrm{n}^{\mathrm{vi}}$ for max value of $\mathrm{n}^{\mathrm{v}}$

Or total number of possible values of $\mathrm{n}^{\mathrm{vi}}=\sum \mathrm{n}^{\mathrm{v}}=0$ to floor function of $[\{(2 \mathrm{k}-35) /(17 * 30)\}-(31 / 30)]$ floor function of $\left[(2 \mathrm{k}-35) /\left\{\left(31+30 \mathrm{n}^{\mathrm{v}}\right)^{*} 30\right\}-(17 / 30)\right]$

Number of type- $2 \mathrm{c} 1+\mathrm{c} 2$ combinations $=\sum \mathrm{n}^{\mathrm{v}}=0$ to floor function of $[\{(2 \mathrm{k}-35) /(17 * 30)\}-(31 / 30)] \quad$ floor function of $\left[(2 \mathrm{k}-35) /\left\{\left(31+30 \mathrm{n}^{\mathrm{v}}\right)^{*} 30\right\}-(17 / 30)\right]$

\section{Case(1BC-iiA-iii)}

For $\operatorname{SADN}(7,4,1) / / 3$ x $\operatorname{SADN}(5,2,8) / / 9:-$

$$
\left(13+30 n^{\text {vii }}\right) \times\left(29+30 n^{\text {viii }}\right) \leq(2 \mathrm{k}-35)
$$

For $\mathrm{n}^{\mathrm{vii}}=0 ; \mathrm{n}^{\mathrm{viii}}{ }_{0}=$ floor function of $[(2 \mathrm{k}-35) /(13 * 30)-(29 / 30)]$

For $\mathrm{n}^{\mathrm{vii}}=1 ; \mathrm{n}^{\mathrm{viii}}{ }_{1}=$ floor function of $[(2 \mathrm{k}-35) /\{(13+30) * 30\}-(29 / 30)]$

For $\mathrm{n}^{\mathrm{vii}}=2 ; \mathrm{n}^{\mathrm{viii}}{ }_{2}=$ floor function of $[(2 \mathrm{k}-35) /\{(13+60) * 30\}-(29 / 30)]$

For $\mathrm{n}^{\mathrm{vii}}=\mathrm{n}^{\mathrm{vii}}$ max i.e. floor function of $[\{(2 \mathrm{k}-35) /(29 * 30)\}-(13 / 30)] ; \mathrm{n}^{\text {viii }}=$ floor function of $\left.\left[(2 \mathrm{k}-35) /\left\{\left(13+30 \mathrm{n}^{\prime}\right)_{\text {max }}\right) * 30\right\}-(29 / 30)\right]$

Hence total number of $\mathrm{n}^{\mathrm{viii}}=\mathrm{n}^{\mathrm{viii}}{ }_{0}+\mathrm{n}^{\mathrm{viii}}{ }_{1}+\mathrm{n}^{\mathrm{viii}}{ }_{2}+\ldots \ldots \ldots+\mathrm{n}^{\mathrm{viii}}$ for max value of $\mathrm{n}^{\mathrm{vii}}$

Or total number of possible values of $\mathrm{n}^{\mathrm{viii}}=\sum \mathrm{n}^{\mathrm{vii}}=0$ to floor function of $[\{(2 \mathrm{k}-35) /(29 * 30)\}-(13 / 30)]$ floor function of $\left[(2 \mathrm{k}-35) /\left\{\left(13+30 \mathrm{n}^{\mathrm{vii}}\right) * 30\right\}-(29 / 30)\right]$

Number of type- $2 \mathrm{c} 1+\mathrm{c} 2$ combinations $=\sum \mathrm{n}^{\mathrm{vii}}=0$ to floor function of $[\{(2 \mathrm{k}-35) /(29 * 30)\}-(13 / 30)]$ floor function of $\left[(2 \mathrm{k}-35) /\left\{\left(13+30 \mathrm{n}^{\mathrm{vii}}\right) * 30\right\}-(29 / 30)\right]$ 


\section{Case(1BC-iiA-iv)}

For $\operatorname{SADN}(5,2,8) / / 3$ x $\operatorname{SADN}(7,4,1) / / 9:-$

$$
\left(23+30 n^{\mathrm{ix}}\right) \times\left(19+30 n^{\mathrm{x}}\right) \leq(2 \mathrm{k}-35)
$$

For $\mathrm{n}^{\mathrm{ix}}=0 ; \mathrm{n}^{\mathrm{x}}{ }_{0}=$ floor function of $[(2 \mathrm{k}-35) /(23 * 30)-(19 / 30)]$

For $\mathrm{n}^{\mathrm{ix}}=1 ; \mathrm{n}^{\mathrm{x}}{ }_{1}=$ floor function of $[(2 \mathrm{k}-35) /\{(23+30) * 30\}-(19 / 30)]$

For $\mathrm{n}^{\mathrm{ix}}=2 ; \mathrm{n}_{2}^{\mathrm{x}}=$ floor function of $[(2 \mathrm{k}-35) /\{(23+60) * 30\}-(19 / 30)]$

For $\mathrm{n}^{\mathrm{ix}}=\mathrm{n}^{\mathrm{ix}}{ }_{\max }$ i.e. floor function of $[\{(2 \mathrm{k}-35) /(19 * 30)\}-(23 / 30)] ; \mathrm{n}^{\text {viii }}=$ floor function of $\left[(2 \mathrm{k}-35) /\left\{\left(23+30 \mathrm{n}^{\prime}{ }_{\max }\right) * 30\right\}-(19 / 30)\right]$

Hence total number of $\mathrm{n}^{\mathrm{x}}=\mathrm{n}^{\mathrm{x}}{ }_{0}+\mathrm{n}^{\mathrm{x}}{ }_{1}+\mathrm{n}^{\mathrm{x}}{ }_{2}+\ldots \ldots . .+\mathrm{n}^{\mathrm{x}}$ for max value of $\mathrm{n}^{\mathrm{ix}}$

Or total number of possible values of $\mathrm{n}^{\mathrm{x}}=\sum \mathrm{n}^{\mathrm{ix}}=0$ to floor function of $[\{(2 \mathrm{k}-35) /(19 * 30)\}-(23 / 30)]$ floor function of $\left[(2 \mathrm{k}-35) /\left\{\left(23+30 \mathrm{n}^{\mathrm{ix}}\right) * 30\right\}-(19 / 30)\right]$

Number of type- $2 \mathrm{c} 1+\mathrm{c} 2$ combinations $=\sum \mathrm{n}^{\mathrm{ix}}=0$ to floor function of $[\{(2 \mathrm{k}-35) /(19 * 30)\}-(23 / 30)]$ floor function of $\left[(2 \mathrm{k}-35) /\left\{\left(23+30 \mathrm{n}^{\mathrm{ix}}\right) * 30\right\}-(19 / 30)\right]$

\section{Case(1BC-iii):}

$\mathrm{EN}=\operatorname{SADN}(7,4,1 / / 4)$

Here $\mathrm{EN}=\operatorname{SADN}(7,4,1 / / 4)$ includes even numbers having $\operatorname{SADN}(7,4,1)$ and last digit as 4 $\mathrm{C} 1[\operatorname{SADN}(5,2,8) / / 5]+\mathrm{C} 2[\operatorname{SADN}(5,2,8) / / 9]=2 \mathrm{k}$

\section{Case(1BC-iiiA)}

For C2[SADN $(5,2,8) / / 9]$

\section{Case(1BC-iiiA-i)}

For $\operatorname{SADN}(7,4,1) / / 1$ x $\operatorname{SADN}(5,2,8) / / 9$

$$
(31+30 \mathrm{n}) \times\left(29+30 n^{\prime}\right) \leq(2 \mathrm{k}-35)
$$

For $\mathrm{n}=0 ; \mathrm{n}{ }_{0}=$ floor function of $[(2 \mathrm{k}-35) /(31 * 30)-(29 / 30)]$

For $\mathrm{n}=1 ; \mathrm{n}^{\prime}{ }_{1}=$ floor function of $[(2 \mathrm{k}-35) /\{(31+30) * 30\}-(29 / 30)]$

For $\mathrm{n}=2 ; \mathrm{n}_{2}=$ floor function of $[(2 \mathrm{k}-35) /\{(31+60) * 30\}-(29 / 30)]$

For $\mathrm{n}=\mathrm{n}^{\prime}{ }_{\max }$ i.e. floor function of $[\{(2 \mathrm{k}-35) /(29 * 30)\}-(31 / 30)] ; \mathrm{n}$ ", $=$ floor function of $\left[(2 \mathrm{k}-35) /\left\{\left(31+30 n^{\prime}{ }_{\text {max }}\right) * 30\right\}-(29 / 30)\right]$ 
Hence total number of $n^{\prime}=n^{\prime}{ }_{0}+n^{\prime}{ }_{1}+n^{\prime}{ }_{2}+\ldots \ldots . .+n^{\prime}$ for max value of $n$

Or total number of possible values of $\mathrm{n}^{\prime}=\sum_{\mathrm{n}=0}$ to floor function of $[\{(2 \mathrm{k}-35) /(29 * 30)\}-(31 / 30)]$ floor function of $[(2 \mathrm{k}-35) /\{(31+30 \mathrm{n}) * 30\}-(29 / 30)]$

Number of type- $2 \mathrm{c} 1+\mathrm{c} 2$ combinations $=\sum \mathrm{n}=0$ to floor function of $[\{(2 \mathrm{k}-35) /(29 * 30)\}-(31 / 30)]$ floor function of $[(2 \mathrm{k}-35) /\{(31+30 \mathrm{n}) * 30\}-(29 / 30)]$

\section{Case(1BC-iiiA-ii)}

For $\operatorname{SADN}(5,2,8) / / 1 \times \operatorname{SADN}(7,4,1) / / 9:-$

$\left(11+30 \mathrm{n}^{\prime \prime}\right) \times\left(19+30 \mathrm{n}^{\prime \prime \prime}\right) \leq(2 \mathrm{k}-35)$

For n" $=0 ; n, "{ }_{0}=$ floor function of $[(2 \mathrm{k}-35) /(11 * 30)-(19 / 30)]$

For n" $=1 ; n,{ }_{1}=$ floor function of $[(2 \mathrm{k}-35) /\{(11+30) * 30\}-(19 / 30)]$

For n" $=2 ; \mathrm{n}^{,{ }^{\mathrm{iv}}}{ }_{2}=$ floor function of $[(2 \mathrm{k}-35) /\{(11+60) * 30\}-(9 / 30)]$

For n" $=$ n' ${ }_{\max }$ i.e. floor function of $[\{(2 \mathrm{k}-35) /(19 * 30)\}-(11 / 30)] ; \mathrm{n},{ }^{\prime},=$ floor function of $\left[(2 \mathrm{k}-35) /\left\{\left(11+30 \mathrm{n}^{\prime}{ }_{\max }\right) * 30\right\}-(19 / 30)\right]$

Hence total number of n", $=\mathrm{n},{ }_{0}+\mathrm{n},{ }_{1}+\mathrm{n},{ }_{2}+\ldots \ldots .+\mathrm{n},{ }^{\prime}$ for max value of $\mathrm{n}$ "

Or total number of possible values of $\mathrm{n}^{\prime \prime},=\sum_{\mathrm{n}}{ }=0$ to floor function of $[\{(2 \mathrm{k}-35) /(19 * 30)\}-(11 / 30)]$

floor function of $[(2 \mathrm{k}-35) /\{(11+30 \mathrm{n} ") * 30\}-(19 / 30)]$

Number of type- $2 \mathrm{c} 1+\mathrm{c} 2$ combinations $=\sum \mathrm{n} "=0$ to floor function of $[\{(2 \mathrm{k}-35) /(19 * 30)\}-(11 / 30)]$ floor function of $\left[(2 \mathrm{k}-35) /\left\{(11+30 \mathrm{n},)^{*} 30\right\}-(19 / 30)\right]$

\section{Case(1BC-iiiA-iii)}

For $\operatorname{SADN}(7,4,1) / / 7$ x $\operatorname{SADN}(5,2,8) / / 7:-$

$$
\left(7+30 n^{\text {iv }}\right) \times\left(17+30 n^{v}\right) \leq(2 k-35)
$$

For $\mathrm{n}^{\mathrm{iv}}=0 ; \mathrm{n}^{\mathrm{v}}=$ floor function of $[(2 \mathrm{k}-35) /(7 * 30)-(17 / 30)]$

For $\mathrm{n}^{\mathrm{iv}}=1 ; \mathrm{n}^{\mathrm{v}}{ }_{1}=$ floor function of $[(2 \mathrm{k}-35) /\{(7+30) * 30\}-(17 / 30)]$

For $\mathrm{n}^{\mathrm{iv}}=2 ; \mathrm{n}_{2}^{\mathrm{v}}=$ floor function of $[(2 \mathrm{k}-35) /\{(7+60) * 30\}-(17 / 30)]$

For $\mathrm{n}^{\mathrm{iv}}=\mathrm{n}^{\mathrm{iv}}{ }_{\max }$ i.e. floor function of $[\{(2 \mathrm{k}-35) /(17 * 30)\}-(7 / 30)] ; \mathrm{n}^{\mathrm{v}}=$ floor function of $[(2 \mathrm{k}-$ $\left.35) /\left\{\left(7+30 \mathrm{n}_{\text {max }}^{\text {iv }}\right) * 30\right\}-(17 / 30)\right]$

Hence total number of $n^{\mathrm{v}}=\mathrm{n}^{\mathrm{v}}{ }_{0}+\mathrm{n}^{\mathrm{v}}{ }_{1}+\mathrm{n}^{\mathrm{v}}{ }_{2}+\ldots \ldots .+\mathrm{n}^{\mathrm{v}}$ for max value of niv 
Or total number of possible values of $\mathrm{n}^{\mathrm{v}}=\sum$ niv $=0$ to floor function of $[\{(2 \mathrm{k}-35) /(17 * 30)\}-(7 / 30)]$ floor function of $\left[(2 \mathrm{k}-35) /\left\{\left(7+30 \mathrm{n}^{\mathrm{iv}}\right) * 30\right\}-(17 / 30)\right]$

Number of type- $2 \mathrm{c} 1+\mathrm{c} 2$ combinations $=\sum$ niv $=0$ to floor function of $[\{(2 \mathrm{k}-35) /(19 * 30)\}-(11 / 30)]$ floor function of $\left[(2 \mathrm{k}-35) /\left\{\left(7+30 \mathrm{n}^{\mathrm{iv}}\right) * 30\right\}-(17 / 30)\right]$

\section{Case(1BC-iiiA-iv)}

For $\operatorname{SADN}(7,4,1) / / 3 \times \operatorname{SADN}(5,2,8) / / 3:-$

$$
\left(13+30 \mathrm{n}^{\mathrm{vi}}\right) \times\left(23+30 \mathrm{n}^{\mathrm{vii}}\right) \leq(2 \mathrm{k}-35)
$$

For $\mathrm{n}^{\mathrm{vi}}=0 ; \mathrm{n}^{\mathrm{vii}}{ }_{0}=$ floor function of $[(2 \mathrm{k}-35) /(13 * 30)-(23 / 30)]$

For $\mathrm{n}^{\mathrm{vi}}=1 ; \mathrm{n}^{\mathrm{vii}}{ }_{1}=$ floor function of $[(2 \mathrm{k}-35) /\{(13+30) * 30\}-(23 / 30)]$

For $\mathrm{n}^{\mathrm{vi}}=2 ; \mathrm{n}^{\mathrm{vii}}{ }_{2}=$ floor function of $[(2 \mathrm{k}-35) /\{(13+60) * 30\}-(23 / 30)]$

For $\mathrm{n}^{\mathrm{vi}}=\mathrm{n}^{\mathrm{vi}}{ }_{\max }$ i.e. floor function of $[\{(2 \mathrm{k}-35) /(23 * 30)\}-(13 / 30)] ; \mathrm{n}^{\mathrm{vii}}=$ floor function of $\left[(2 \mathrm{k}-35) /\left\{\left(13+30 \mathrm{n}^{\mathrm{vii}}{ }_{\text {max }}\right) * 30\right\}-(23 / 30)\right]$

Hence total number of $\mathrm{n}^{\mathrm{vii}}=\mathrm{n}^{\mathrm{vii}}{ }_{0}+\mathrm{n}^{\mathrm{vii}}{ }_{1}+\mathrm{n}^{\mathrm{vii}}{ }_{2}+\ldots \ldots .+\mathrm{n}^{\mathrm{vii}}$ for max value of nvi

Or total number of possible values of $\mathrm{n}^{\mathrm{vii}}=\sum \mathrm{nvi}=0$ to floor function of $[\{(2 \mathrm{k}-35) /(23 * 30)\}-(13 / 30)]$ floor function of $\left[(2 \mathrm{k}-35) /\left\{\left(13+30 \mathrm{n}^{\mathrm{vi}}\right) * 30\right\}-(23 / 30)\right]$

Number of type- $2 \mathrm{c} 1+\mathrm{c} 2$ combinations $=\sum$ nvi=0 to floor function of $[\{(2 \mathrm{k}-35) /(23 * 30)\}-(13 / 30)]$ floor function of $\left[(2 \mathrm{k}-35) /\left\{\left(13+30 \mathrm{n}^{\mathrm{iv}}\right) * 30\right\}-(23 / 30)\right]$

\section{Case(1BC-iv):}

$\mathrm{EN}=\operatorname{SADN}(7,4,1 / / 6)$

Here $\operatorname{EN}=\operatorname{SADN}(7,4,1 / / 6)$ indicates even numbers having $\operatorname{SADN}(7,4,1)$ and last digit as 6

$\mathrm{C} 1[\operatorname{SADN}(5,2,8) / / 5]+\mathrm{C} 2[\operatorname{SADN}(5,2,8) / / 1]=2 \mathrm{k}$

\section{Case(1BC-ivA)}

For C2[SADN $(5,2,8) / / 1]$

Case(1BC-ivA-i)

For $\operatorname{SADN}(7,4,1) / / 3 \times \operatorname{SADN}(5,2,8) / / 7$ :- 
$(13+30 n) \times\left(17+30 n^{\prime}\right) \leq(2 k-35)$

For $\mathrm{n}=0 ; \mathrm{n}_{0}=$ floor function of $[(2 \mathrm{k}-35) /(13 * 30)-(17 / 30)]$

For $\mathrm{n}=1 ; \mathrm{n}_{1}=$ floor function of $[(2 \mathrm{k}-35) /\{(13+30) * 30\}-(17 / 30)]$

For $\mathrm{n}=2 ; \mathrm{n}_{2}=$ floor function of $[(2 \mathrm{k}-35) /\{(13+60) * 30\}-(17 / 30)]$

For $\mathrm{n}=\mathrm{n}^{\prime}{ }_{\text {max }}$ i.e. floor function of $[\{(2 \mathrm{k}-35) /(17 * 30)\}-(13 / 30)] ; \mathrm{n}$ ', $=$ floor function of $\left[(2 \mathrm{k}-35) /\left\{\left(13+30 \mathrm{n}^{\prime}{ }_{\max }\right) * 30\right\}-(17 / 30)\right]$

Hence total number of $n^{\prime}=n^{\prime}{ }_{0}+n^{\prime}{ }_{1}+n^{\prime}{ }_{2}+\ldots \ldots . .+n^{\prime}$ for max value of $n$

Or total number of possible values of n' $=\sum_{n=0}$ to floor function of $[\{(2 \mathrm{k}-35) /(17 * 30)\}-(13 / 30)] \quad$ floor function of $[(2 \mathrm{k}-35) /\{(13+30 \mathrm{n}) * 30\}-(17 / 30)]$

Number of type- $2 \mathrm{c} 1+\mathrm{c} 2$ combinations $=\sum \mathrm{n}=0$ to floor function of $[\{(2 \mathrm{k}-35) /(17 * 30)\}-(13 / 30)]$ floor function of $[(2 \mathrm{k}-35) /\{(13+30 \mathrm{n}) * 30\}-(17 / 30)]$

\section{Case(1BC-ivA-ii)}

For $\operatorname{SADN}(5,2,8) / / 3$ x $\operatorname{SADN}(7,4,1) / / 7:-$

$(23+30 n ') \times,(7+30 n ', ') \leq(2 k-35)$

For n" $=0 ; n,{ }_{0}=$ floor function of $[(2 \mathrm{k}-35) /(23 * 30)-(7 / 30)]$

For n" $=1 ; \mathrm{n} "{ }_{1}=$ floor function of $[(2 \mathrm{k}-35) /\{(23+30) * 30\}-(7 / 30)]$

For n" $=2 ;$ n $^{,,{ }^{i v}}{ }_{2}=$ floor function of $[(2 \mathrm{k}-35) /\{(23+60) * 30\}-(7 / 30)]$

For n" $=$ n" ${ }_{\max }$ i.e. floor function of $[\{(2 \mathrm{k}-35) /(7 * 30)\}-(23 / 30)] ; \mathrm{n},$, , floor function of $\left[(2 \mathrm{k}-35) /\left\{\left(23+30 \mathrm{n}{ }^{\prime}{ }_{\text {max }}\right) * 30\right\}-(7 / 30)\right]$

Hence total number of n", $=\mathrm{n},{ }_{0}+\mathrm{n},{ }_{1}+\mathrm{n},{ }_{2}+\ldots \ldots .+\mathrm{n},{ }^{\prime}$ for max value of $\mathrm{n}$,

Or total number of possible values of $n^{\prime \prime},=\sum_{n}{ }=0$ to floor function of $[\{(2 \mathrm{k}-35) /(7 * 30)\}-(23 / 30)]$ floor function of $[(2 \mathrm{k}-35) /\{(23+30 \mathrm{n} ') * 30\}-(7 / 30)]$

Number of type- $2 \mathrm{c} 1+\mathrm{c} 2$ combinations $=\sum \mathrm{n} "=0$ to floor function of $[\{(2 \mathrm{k}-35) /(7 * 30)\}-(23 / 30)]$ floor function of $\left.\left[(2 \mathrm{k}-35) /\left\{(23+30 \mathrm{n})^{\prime}\right) * 30\right\}-(7 / 30)\right]$

\section{Case(1BC-ivA-iii)}


For $\operatorname{SADN}(7,4,1) / / 1 \times \operatorname{SADN}(5,2,8) / / 1:-$

$$
\left(31+30 n^{\text {iv }}\right) \times\left(11+30 n^{\mathrm{v}}\right) \leq(2 \mathrm{k}-35)
$$

For $\mathrm{n}^{\mathrm{iv}}=0 ; \mathrm{n}^{\mathrm{v}}{ }_{0}=$ floor function of $[(2 \mathrm{k}-35) /(31 * 30)-(11 / 30)]$

For $\mathrm{n}^{\mathrm{iv}}=1 ; \mathrm{n}^{\mathrm{v}}{ }_{1}=$ floor function of $[(2 \mathrm{k}-35) /\{(31+30) * 30\}-(11 / 30)]$

For $\mathrm{n}^{\mathrm{iv}}=2 ; \mathrm{n}_{2}^{\mathrm{v}}=$ floor function of $[(2 \mathrm{k}-35) /\{(31+60) * 30\}-(11 / 30)]$

For $\mathrm{n}^{\mathrm{iv}}=\mathrm{n}^{\mathrm{iv}}{ }_{\max }$ i.e. floor function of $[\{(2 \mathrm{k}-35) /(11 * 30)\}-(31 / 30)] ; \mathrm{n}^{\mathrm{v}}=$ floor function of $\left[(2 \mathrm{k}-35) /\left\{\left(31+30 \mathrm{n}_{\text {max }}^{\mathrm{iv}}\right) * 30\right\}-(11 / 30)\right]$

Hence total number of $n^{\mathrm{v}}=\mathrm{n}^{\mathrm{v}}{ }_{0}+\mathrm{n}^{\mathrm{v}}{ }_{1}+\mathrm{n}^{\mathrm{v}}{ }_{2}+\ldots \ldots .+\mathrm{n}^{\mathrm{v}}$ for max value of niv

Or total number of possible values of $\mathrm{n}^{\mathrm{v}}=\sum$ niv $=0$ to floor function of $[\{(2 \mathrm{k}-35) /(11 * 30)\}-(31 / 30)]$ floor function of $\left[(2 \mathrm{k}-35) /\left\{\left(31+30 \mathrm{n}^{\mathrm{iv}}\right) * 30\right\}-(11 / 30)\right]$

Number of type- $2 \mathrm{c} 1+\mathrm{c} 2$ combinations $=\sum$ niv $=0$ to floor function of $[\{(2 \mathrm{k}-35) /(11 * 30)\}-(31 / 30)]$ floor function of $\left[(2 \mathrm{k}-35) /\left\{\left(31+30 \mathrm{n}^{\mathrm{iv}}\right) * 30\right\}-(11 / 30)\right]$

\section{Case(1BC-ivA-iv)}

For $\operatorname{SADN}(7,4,1) / / 9$ x $\operatorname{SADN}(5,2,8) / / 9:-$

$$
\left(19+30 \mathrm{n}^{\mathrm{vi}}\right) \times\left(29+30 \mathrm{n}^{\mathrm{vii}}\right) \leq(2 \mathrm{k}-35)
$$

For $\mathrm{n}^{\mathrm{vi}}=0 ; \mathrm{n}^{\mathrm{vii}}{ }_{0}=$ floor function of $[(2 \mathrm{k}-35) /(19 * 30)-(29 / 30)]$

For $\mathrm{n}^{\mathrm{vi}}=1 ; \mathrm{n}^{\mathrm{vii}}{ }_{1}=$ floor function of $[(2 \mathrm{k}-35) /\{(19+30) * 30\}-(29 / 30)]$

For $\mathrm{n}^{\mathrm{vi}}=2 ; \mathrm{n}^{\mathrm{vii}}{ }_{2}=$ floor function of $[(2 \mathrm{k}-35) /\{(19+60) * 30\}-(29 / 30)]$

For $\mathrm{n}^{\mathrm{vi}}=\mathrm{n}^{\mathrm{vi}}{ }_{\max }$ i.e. floor function of $[\{(2 \mathrm{k}-35) /(29 * 30)\}-(19 / 30)] ; \mathrm{n}^{\mathrm{vii}}=$ floor function of $\left[(2 \mathrm{k}-35) /\left\{\left(19+30 \mathrm{n}^{\mathrm{vii}}{ }_{\text {max }}\right) * 30\right\}-(29 / 30)\right]$

Hence total number of $\mathrm{n}^{\mathrm{vii}}=\mathrm{n}^{\mathrm{vii}}{ }_{0}+\mathrm{n}^{\mathrm{vii}}{ }_{1}+\mathrm{n}^{\mathrm{vii}}{ }_{2}+\ldots \ldots .+\mathrm{n}^{\mathrm{vii}}$ for max value of nvi

Or total number of possible values of $\mathrm{n}^{\mathrm{vii}}=\sum \mathrm{nvi}=0$ to floor function of $[\{(2 \mathrm{k}-35) /(29 * 30)\}-(19 / 30)]$

floor function of $\left[(2 \mathrm{k}-35) /\left\{\left(19+30 \mathrm{n}^{\mathrm{vi}}\right) * 30\right\}-(29 / 30)\right]$

Number of type- $2 \mathrm{c} 1+\mathrm{c} 2$ combinations $=\sum$ niv $=0$ to floor function of $[\{(2 \mathrm{k}-35) /(29 * 30)\}-(19 / 30)]$ floor function of $\left[(2 \mathrm{k}-35) /\left\{\left(19+30 \mathrm{n}^{\mathrm{iv}}\right) * 30\right\}-(29 / 30)\right]$ 


\section{Case(1BC-v):}

$\mathrm{EN}=\operatorname{SADN}(7,4,1 / / 8)$

Here $\operatorname{EN}=\operatorname{SADN}(7,4,1 / / 6)$ includes even numbers having $\operatorname{SADN}(7,4,1)$ and last digit as 8

$\mathrm{C} 1[\operatorname{SADN}(5,2,8) / / 5]+\mathrm{C} 2[\operatorname{SADN}(5,2,8) / / 3]=2 \mathrm{k}$

\section{$\operatorname{Case}(1 B C-v A)$}

For C2[SADN $(5,2,8) / / 3]$

\section{Case(1BC-vA-i)}

For $\operatorname{SADN}(7,4,1) / / 1$ x $\operatorname{SADN}(5,2,8) / / 3:-$

$$
(31+30 n) \times\left(23+30 n^{\prime}\right)<=(2 k-35)
$$

For $\mathrm{n}=0 ; \mathrm{n}_{0}=$ floor function of $[(2 \mathrm{k}-35) /(31 * 30)-(23 / 30)]$

For $\mathrm{n}=1 ; \mathrm{n}_{1}=$ floor function of $[(2 \mathrm{k}-35) /\{(31+30) * 30\}-(23 / 30)]$

For $\mathrm{n}=2 ; \mathrm{n}_{2}=$ floor function of $[(2 \mathrm{k}-35) /\{(31+60) * 30\}-(23 / 30)]$

For $\mathrm{n}=\mathrm{n}^{\prime}{ }_{\max }$ i.e. floor function of $[\{(2 \mathrm{k}-35) /(23 * 30)\}-(31 / 30)] ; \mathrm{n}$ ', $=$ floor function of $\left[(2 \mathrm{k}-35) /\left\{\left(31+30 n^{\prime}{ }_{\text {max }}\right) * 30\right\}-(23 / 30)\right]$

Hence total number of $n^{\prime}=n^{\prime}{ }_{0}+n^{\prime}{ }_{1}+n^{\prime}{ }_{2}+\ldots \ldots . .+n_{\text {for max value of } n}$

Or total number of possible values of n' $=\sum_{n=0}$ to floor function of $[\{(2 \mathrm{k}-35) /(23 * 30)\}-(31 / 30)] \quad$ floor function of $[(2 \mathrm{k}-35) /\{(31+30 \mathrm{n}) * 30\}-(23 / 30)]$

Number of type- $2 \mathrm{c} 1+\mathrm{c} 2$ combinations $=\sum \mathrm{n}=0$ to floor function of $[\{(2 \mathrm{k}-35) /(23 * 30)\}-(31 / 30)]$ floor function of $[(2 \mathrm{k}-35) /\{(31+30 \mathrm{n}) * 30\}-(23 / 30)]$

\section{Case(1BC-vA-ii)}

For $\operatorname{SADN}(5,2,8) / / 1 \times \operatorname{SADN}(7,4,1) / / 3:-$

$$
(11+30 \mathrm{n} \text { ') } \mathrm{x}(13+30 \mathrm{n}, " ')<=(2 \mathrm{k}-35)
$$

For n" $=0 ; n,{ }_{0}=$ floor function of $[(2 \mathrm{k}-35) /(11 * 30)-(13 / 30)]$

For $\mathrm{n} "=1 ; \mathrm{n},{ }_{1}=$ floor function of $[(2 \mathrm{k}-35) /\{(11+30) * 30\}-(13 / 30)]$

For n" $=2 ; \mathrm{n}^{,{ }^{\mathrm{iv}}}{ }_{2}=$ floor function of $[(2 \mathrm{k}-35) /\{(11+60) * 30\}-(13 / 30)]$ 
For n" $=$ n' ${ }_{\max }$ i.e. floor function of $[\{(2 \mathrm{k}-35) /(13 * 30)\}-(11 / 30)] ; \mathrm{n},{ }^{\prime},=$ floor function of $\left[(2 \mathrm{k}-35) /\left\{\left(11+30 n^{\prime}{ }_{\text {max }}\right) * 30\right\}-(13 / 30)\right]$

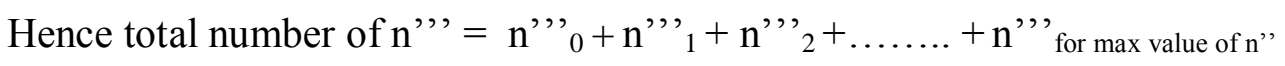

Or total number of possible values of $\mathrm{n}^{\prime \prime},=\sum_{\mathrm{n}}{ }=0$ to floor function of $[\{(2 \mathrm{k}-35) /(13 * 30)\}-(11 / 30)]$ floor function of $\left[(2 \mathrm{k}-35) /\left\{(11+30 \mathrm{n},)^{*} 30\right\}-(13 / 30)\right]$

Number of type- $2 \mathrm{c} 1+\mathrm{c} 2$ combinations $=\sum \mathrm{n} "=0$ to floor function of $[\{(2 \mathrm{k}-35) /(13 * 30)\}-(11 / 30)]$ floor function of $[(2 \mathrm{k}-35) /\{(11+30 \mathrm{n}, ') * 30\}-(13 / 30)]$

\section{Case(1BC-vA-iii)}

For $\operatorname{SADN}(7,4,1) / / 7$ x $\operatorname{SADN}(5,2,8) / / 9:-$

$$
\left(7+30 n^{\text {iv }}\right) \times\left(29+30 n^{v}\right)<=(2 \mathrm{k}-35)
$$

For $\mathrm{n}^{\mathrm{iv}}=0 ; \mathrm{n}^{\mathrm{v}}=$ floor function of $[(2 \mathrm{k}-35) /(7 * 30)-(29 / 30)]$

For $\mathrm{n}^{\mathrm{iv}}=1 ; \mathrm{n}^{\mathrm{v}}{ }_{1}=$ floor function of $[(2 \mathrm{k}-35) /\{(7+30) * 30\}-(29 / 30)]$

For $\mathrm{n}^{\mathrm{iv}}=2 ; \mathrm{n}^{\mathrm{v}}{ }_{2}=$ floor function of $[(2 \mathrm{k}-35) /\{(7+60) * 30\}-(29 / 30)]$

For $\mathrm{n}^{\mathrm{iv}}=\mathrm{n}^{\mathrm{iv}}{ }_{\max }$ i.e. floor function of $[\{(2 \mathrm{k}-35) /(29 * 30)\}-(7 / 30)] ; \mathrm{n}^{\mathrm{v}}=$ floor function of $[(2 \mathrm{k}-$ $35) /\left\{\left(7+30 \mathrm{n}^{\mathrm{iv}}\right.\right.$ max $\left.\left.) * 30\right\}-(29 / 30)\right]$

Hence total number of $\mathrm{n}^{\mathrm{v}}=\mathrm{n}^{\mathrm{v}}{ }_{0}+\mathrm{n}^{\mathrm{v}}{ }_{1}+\mathrm{n}^{\mathrm{v}}{ }_{2}+\ldots \ldots .+\mathrm{n}^{\mathrm{v}}$ for max value of niv

Or total number of possible values of $\mathrm{n}^{\mathrm{v}}=\sum$ niv $=0$ to floor function of $[\{(2 \mathrm{k}-35) /(11 * 30)\}-(31 / 30)]$ floor function of $\left[(2 \mathrm{k}-35) /\left\{\left(7+30 \mathrm{n}^{\mathrm{iv}}\right) * 30\right\}-(29 / 30)\right]$

Number of type- $2 \mathrm{c} 1+\mathrm{c} 2$ combinations $=\sum$ niv $=0$ to floor function of $[\{(2 \mathrm{k}-35) /(29 * 30)\}-(7 / 30)]$ floor function of $\left[(2 \mathrm{k}-35) /\left\{\left(7+30 \mathrm{n}^{\mathrm{iv}}\right) * 30\right\}-(29 / 30)\right]$

\section{Case(1BC-vA-iv)}

For $\operatorname{SADN}(5,2,8) / / 7$ x $\operatorname{SADN}(7,4,1) / / 9:-$

$$
\left(17+30 \mathrm{n}^{\mathrm{vi}}\right) \times\left(19+30 \mathrm{n}^{\mathrm{vii}}\right)<=(2 \mathrm{k}-35)
$$

For $\mathrm{n}^{\mathrm{vi}}=0 ; \mathrm{n}^{\mathrm{vii}}{ }_{0}=$ floor function of $[(2 \mathrm{k}-35) /(17 * 30)-(19 / 30)]$

For $\mathrm{n}^{\mathrm{vi}}=1 ; \mathrm{n}^{\mathrm{vii}}{ }_{1}=$ floor function of $[(2 \mathrm{k}-35) /\{(17+30) * 30\}-(19 / 30)]$ 
For $\mathrm{n}^{\mathrm{vi}}=2 ; \mathrm{n}^{\mathrm{vii}}{ }_{2}=$ floor function of $[(2 \mathrm{k}-35) /\{(17+60) * 30\}-(19 / 30)]$

For $\mathrm{n}^{\mathrm{vi}}=\mathrm{n}^{\mathrm{vi}}{ }_{\max }$ i.e. floor function of $[\{(2 \mathrm{k}-35) /(19 * 30)\}-(17 / 30)] ; \mathrm{n}^{\mathrm{vii}}=$ floor function of $\left[(2 \mathrm{k}-35) /\left\{\left(17+30 \mathrm{n}^{\mathrm{vii}}{ }_{\max }\right) * 30\right\}-(19 / 30)\right]$

Hence total number of $\mathrm{n}^{\mathrm{vii}}=\mathrm{n}^{\mathrm{vii}}{ }_{0}+\mathrm{n}^{\mathrm{vii}}{ }_{1}+\mathrm{n}^{\mathrm{vii}}{ }_{2}+\ldots \ldots .+\mathrm{n}^{\mathrm{vii}}$ for max value of nvi

Or total number of possible values of $\mathrm{n}^{\mathrm{vii}}=\sum \mathrm{nvi}=0$ to floor function of $[\{(2 \mathrm{k}-35) /(29 * 30)\}-(17 / 30)]$ floor function of $\left[(2 \mathrm{k}-35) /\left\{\left(17+30 \mathrm{n}^{\mathrm{vi}}\right) * 30\right\}-(19 / 30)\right]$

Number of type- $2 \mathrm{c} 1+\mathrm{c} 2$ combinations $=\sum$ niv $=0$ to floor function of $[\{(2 \mathrm{k}-35) /(19 * 30)\}-(17 / 30)]$ floor function of $\left[(2 \mathrm{k}-35) /\left\{\left(17+30 \mathrm{n}^{\mathrm{iv}}\right) * 30\right\}-(19 / 30)\right]$

\section{Case(2):}

$\mathrm{SADN}$ of $\mathrm{EN}=\{5,2,8\}$

$\mathrm{EN}=2 \mathrm{k}$

Case(2A): $\mathrm{EN} / 2=\mathrm{k}$ is a prime number

Case(2B): $\mathrm{EN} / 2=\mathrm{k}$ is a composite number

If ' $\mathrm{k}$ ' is a composite number:

Number of acceptable combinations of elements is given as $n_{\text {acc }}$

Case(2BP): If number of composites is less than number of primes (i.e. $n_{c}<n_{p}$ implies that even if all composites are prime-eaters; there exists atleast one $\mathrm{p} 1+\mathrm{p} 2$ pair

Case (2BC): If number of composites is greater than or equal to number of primes (i.e. $\mathrm{n}_{\mathrm{c}}>=$ $\mathrm{n}_{\mathrm{p}}$ implies that we need to find total number of unique $\mathrm{C} 1+\mathrm{C} 2$ pairs

\section{C1+C2 of Type-1:}

It has already been discussed in section 11A.

\section{C1+C2 of Type-2:}

$\mathrm{EN}=\operatorname{SADN}(5,2,8 / / 0)$ OR $\operatorname{SADN}(5,2,8 / / 2)$ OR $\operatorname{SADN}(5,2,8 / / 4)$ OR $\operatorname{SADN}(5,2,8 / / 6)$ OR $\operatorname{SADN}(5,2,8 / / 8)$

Here $\mathrm{EN}=\operatorname{SADN}(5,2,8 / / 0)$ includes even numbers having $\operatorname{SADN}(5,2,8)$ and last digit as 0

\section{Case(2BC-iA):}

$\mathrm{EN}=\operatorname{SADN}(5,2,8 / / 0 / / 2)$ including even numbers of $\operatorname{SADN}(5,2,8 / / 0)$ and cyclical series element as ' 2 ' 
$\mathrm{EN}=\operatorname{SADN}(5,2,8 / / 0 / / 2)$

$\mathrm{C} 1$ of $\operatorname{SADN}(7,4,1 / / 5)+\mathrm{C} 2$ of $\operatorname{SADN}(7,4,1 / / 5)=2 \mathrm{k}$

$\left(25+30 \mathrm{n}_{\mathrm{a}}{ }^{\prime \prime}\right)+\left[2 \mathrm{k}-\left(25+30 \mathrm{n}_{\mathrm{a}}{ }^{\prime \prime}\right)\right]=2 \mathrm{k}$

$25+30 \mathrm{n}_{\mathrm{a}}{ }>2 \mathrm{k}$

Number of Composites of $\operatorname{SADN}(7,4,1 / / 5)$ is given as $\mathrm{n}_{\mathrm{a}}{ }^{\prime}<(2 \mathrm{k}-25) / 30$

or $\mathrm{n}_{\mathrm{a}}{ }^{\prime}=$ floor function of $[(2 \mathrm{k}-25) / 30]$

No. of type- $2 \mathrm{C} 1+\mathrm{C} 2$ combinations $=$ floor function $\left[(1 / 2)^{*}(2 \mathrm{k}-25) / 30\right]+1$

Or No. of type- $2 \mathrm{C} 1+\mathrm{C} 2$ combinations $=$ floor function $[\mathrm{k} / 30]+1$

\section{Case(2BC-iB):}

$\mathrm{EN}=\operatorname{SADN}(5,2,8 / / 0 / / 4)$ including even numbers of $\operatorname{SADN}(5,2,8 / / 0)$ and cyclical series element as ' 4 '

$\mathrm{EN}=\operatorname{SADN}(5,2,8 / / 0 / / 4)$

$\mathrm{C} 1$ of $\operatorname{SADN}(7,4,1 / / 5)+\mathrm{C} 2$ of $\operatorname{SADN}(7,4,1 / / 5)=2 \mathrm{k}$

$\left(25+30 \mathrm{n}_{\mathrm{b}}{ }^{\prime \prime}\right)+\left[2 \mathrm{k}-\left(25+30 \mathrm{n}_{\mathrm{b}}{ }^{\prime \prime}\right)\right]=2 \mathrm{k}$

$\left(25+30 \mathrm{n}_{\mathrm{b}}{ }^{\prime \prime}\right)<2 \mathrm{k}$

Number of C of $\operatorname{SADN}(7,4,1 / / 5)$ is given as $n_{b}{ }^{\prime \prime}<(2 k-25) / 30$

or $\mathrm{n}_{\mathrm{b}}{ }^{\prime}=$ floor function of $[(2 \mathrm{k}-25) / 30]$

No. of type- $2 \mathrm{C} 1+\mathrm{C} 2$ combinations $=$ floor function $[(1 / 2) *(2 \mathrm{k}-25) / 30]+1$

Or No. of type- $2 \mathrm{C} 1+\mathrm{C} 2$ combinations $=$ floor function $[\mathrm{k} / 30]$

\section{Case(2BC-ii):}

$\mathrm{EN}=\operatorname{SADN}(5,2,8 / / 2)$

Here $\mathrm{EN}=\operatorname{SADN}(5,2,8 / / 2)$ includes even numbers having $\operatorname{SADN}(5,2,8)$ and last digit as 2

$\operatorname{C} 1[\operatorname{SADN}(7,4,1) / / 5]+\mathrm{C} 2[\operatorname{SADN}(7,4,1) / / 7]=2 \mathrm{k}$

Case(2BC-iiB)For C2[SADN $(7,4,1) / / 7]$ implies that

CASE(2BC-iiB-i) i.e. //1x//7 [SADN $(7,4,1) / / 1] x[\operatorname{SADN}(7,4,1) / / 7]$ OR 
CASE(2BC-iiB-ii) i.e. //1x//7 [SADN $(5,2,8) / / 1] \times$ [SADN $(5,2,8) / / 7]$

CASE(2BC-iiB-iii) i.e. //3x//9 $[\operatorname{SADN}(7,4,1) / / 3] x[\operatorname{SADN}(7,4,1) / / 9]$ OR

CASE(2BC-iiB-iv) i.e. $/ / 3 x / / 9[\operatorname{SADN}(5,2,8) / / 3] \times[\operatorname{SADN}(5,2,8) / / 9]$

\section{Case(2BC-iiB-i)}

For $\operatorname{SADN}(7,4,1) / / 1 \times \operatorname{SADN}(7,4,1) / / 7$ :-

$\left(31+30 n^{\prime \prime \prime}\right) \times\left(7+30 n^{\text {iv }}\right) \leq(2 \mathrm{k}-25)$

For $\mathrm{n}^{\prime \prime},=0 ; \mathrm{n}^{\mathrm{iv}}{ }_{0}=$ floor function of $[(2 \mathrm{k}-25) /(31 * 30)-(7 / 30)]$

For $\mathrm{n}^{\prime \prime}=1 ; \mathrm{n}^{\mathrm{iv}}{ }_{1}=$ floor function of $[(2 \mathrm{k}-25) /\{(31+30) * 30\}-(7 / 30)]$

For $n ", "=2 ; n^{\text {iv }}{ }_{2}=$ floor function of $[(2 \mathrm{k}-25) /\{(31+60) * 30\}-(7 / 30)]$

For $\mathrm{n} ",{ }^{\prime}=\mathrm{n},{ }_{\max }$ i.e. floor function of $\left[\left\{(2 \mathrm{k}-25) /\left(7^{*} 30\right)\right\}-(31 / 30)\right] ; \mathrm{n}^{\mathrm{iv}}=$ floor function of $\left[(2 \mathrm{k}-25) /\left\{\left(31+30 \mathrm{n}^{\prime}{ }_{\text {max }}\right) * 30\right\}-(7 / 30)\right]$

Hence total number of $n^{\text {iv }}=n^{\text {iv }}{ }_{0}+n^{\text {iv }}{ }_{1}+n^{\text {iv }}{ }_{2}+\ldots \ldots . .+n^{\text {iv }}$ for max value of $n^{\prime \prime}$

Or total number of possible values of $\mathrm{n}^{\mathrm{iv}}=\sum \mathrm{n}{ }^{\prime \prime}=0$ to floor function of $[\{(2 \mathrm{k}-25) /(7 * 30)\}-(31 / 30)]$ floor function of $\left[(2 \mathrm{k}-25) /\left\{\left(31+30 \mathrm{n},{ }^{\prime}\right) * 30\right\}-(7 / 30)\right]$

Number of type- $2 \mathrm{c} 1+\mathrm{c} 2$ combinations $=\sum_{\mathrm{n}}$ "' $=0$ to floor function of $[\{(2 \mathrm{k}-25) /(7 * 30)\}-(31 / 30)]$ floor function of $\left[(2 \mathrm{k}-25) /\left\{(31+30 \mathrm{n}, ',)^{*} 30\right\}-(7 / 30)\right]$

\section{Case(2BC-iiB-ii)}

For $[\operatorname{SADN}(5,2,8) / / 1] \times[\operatorname{SADN}(5,2,8) / / 7]:-$

$\left(11+30 n^{\mathrm{v}}\right) \times\left(17+30 \mathrm{n}^{\mathrm{vi}}\right) \leq(2 \mathrm{k}-25)$

For $\mathrm{n}^{\mathrm{v}}=0 ; \mathrm{n}^{\mathrm{vi}}{ }_{0}=$ floor function of $[(2 \mathrm{k}-25) /(11 * 30)-(17 / 30)]$

For $\mathrm{n}^{\mathrm{v}}=1 ; \mathrm{n}^{\mathrm{vi}}{ }_{1}=$ floor function of $[(2 \mathrm{k}-25) /\{(11+30) * 30\}-(17 / 30)]$

For $\mathrm{n}^{\mathrm{v}}=2 ; \mathrm{n}^{\mathrm{vi}}{ }_{2}=$ floor function of $[(2 \mathrm{k}-25) /\{(11+60) * 30\}-(17 / 30)]$

For $\mathrm{n}^{\mathrm{v}}=\mathrm{n}^{\mathrm{v}}$ max i.e. floor function of $[\{(2 \mathrm{k}-25) /(17 * 30)\}-(11 / 30)] ; \mathrm{n}^{\mathrm{vi}}=$ floor function of $\left[(2 \mathrm{k}-25) /\left\{\left(11+30 \mathrm{n}^{\mathrm{v}}{ }_{\max }\right) * 30\right\}-(17 / 30)\right]$

Hence total number of $\mathrm{n}^{\mathrm{vi}}=\mathrm{n}^{\mathrm{vi}}{ }_{0}+\mathrm{n}^{\mathrm{vi}}{ }_{1}+\mathrm{n}^{\mathrm{vi}}{ }_{2}+\ldots \ldots .+\mathrm{n}^{\mathrm{vi}}$ for max value of $\mathrm{n}^{\mathrm{v}}$

Or total number of possible values of $\mathrm{n}^{\mathrm{vi}}=\sum \mathrm{n}^{\mathrm{v}}=0$ to floor function of $[\{(2 \mathrm{k}-25) /(17 * 30)\}-(11 / 30)]$ floor function of $\left[(2 \mathrm{k}-25) /\left\{\left(11+30 \mathrm{n}^{\mathrm{v}}\right) * 30\right\}-(17 / 30)\right]$ 
Number of type- $2 \mathrm{c} 1+\mathrm{c} 2$ combinations $=\sum \mathrm{n}^{\mathrm{v}}=0$ to floor function of $[\{(2 \mathrm{k}-25) /(17 * 30)\}-(11 / 30)] \quad$ floor function of $\left[(2 \mathrm{k}-25) /\left\{\left(11+30 \mathrm{n}^{\mathrm{v}}\right)^{*} 30\right\}-(17 / 30)\right]$

\section{Case(2BC-iiB-iii)}

For $[\operatorname{SADN}(7,4,1) / / 3] x[\operatorname{SADN}(7,4,1) / / 9]:-$

$\left(13+30 \mathrm{n}^{\mathrm{vii}}\right) \times\left(19+30 \mathrm{n}^{\mathrm{viii}}\right) \leq(2 \mathrm{k}-25)$

For $\mathrm{n}^{\mathrm{vii}}=0 ; \mathrm{n}^{\mathrm{viii}}{ }_{0}=$ floor function of $[(2 \mathrm{k}-25) /(13 * 30)-(19 / 30)]$

For $\mathrm{n}^{\mathrm{vii}}=1 ; \mathrm{n}^{\mathrm{viii}}{ }_{1}=$ floor function of $[(2 \mathrm{k}-25) /\{(13+30) * 30\}-(19 / 30)]$

For $\mathrm{n}^{\mathrm{vii}}=2 ; \mathrm{n}^{\mathrm{viii}}{ }_{2}=$ floor function of $[(2 \mathrm{k}-25) /\{(13+60) * 30\}-(19 / 30)]$

For $\mathrm{n}^{\mathrm{vii}}=\mathrm{n}^{\mathrm{vii}}$ max i.e. floor function of $[\{(2 \mathrm{k}-25) /(19 * 30)\}-(13 / 30)] ; \mathrm{n}^{\mathrm{viii}}=$ floor function of $\left.\left[(2 \mathrm{k}-25) /\left\{\left(13+30 \mathrm{n}^{\prime}\right)_{\text {max }}\right) * 30\right\}-(19 / 30)\right]$

Hence total number of $\mathrm{n}^{\text {viii }}=\mathrm{n}^{\text {viii }}{ }_{0}+\mathrm{n}^{\text {viii }}{ }_{1}+\mathrm{n}^{\text {viii }}{ }_{2}+\ldots \ldots \ldots+\mathrm{n}^{\text {viii }}$ for max value of $\mathrm{n}^{\text {vii }}$

Or total number of possible values of $\mathrm{n}^{\mathrm{viii}}=\sum \mathrm{n}^{\mathrm{vii}}=0$ to floor function of $[\{(2 \mathrm{k}-35) /(19 * 30)\}-(13 / 30)]$ floor function of $\left[(2 \mathrm{k}-25) /\left\{\left(13+30 \mathrm{n}^{\mathrm{vii}}\right) * 30\right\}-(19 / 30)\right]$

Number of combinations of type- $2 \mathrm{c} 1+\mathrm{c} 2$ combinations $=\sum \mathrm{n}^{\mathrm{vii}}=0$ to floor function of $[\{(2 \mathrm{k}-25) /(19 * 30)\}$ (13/30)] floor function of $\left[(2 \mathrm{k}-25) /\left\{\left(13+30 \mathrm{n}^{\mathrm{vii}}\right) * 30\right\}-(19 / 30)\right]$

\section{Case(2BC-iiB-iv)}

For $[\operatorname{SADN}(5,2,8) / / 3] \times[\operatorname{SADN}(5,2,8) / / 9]:-$

$\left(23+30 n^{\mathrm{ix}}\right) \times\left(29+30 \mathrm{n}^{\mathrm{x}}\right) \leq(2 \mathrm{k}-25)$

For $\mathrm{n}^{\mathrm{ix}}=0 ; \mathrm{n}^{\mathrm{x}}{ }_{0}=$ floor function of $[(2 \mathrm{k}-25) /(23 * 30)-(29 / 30)]$

For $\mathrm{n}^{\mathrm{ix}}=1 ; \mathrm{n}^{\mathrm{x}}{ }_{1}=$ floor function of $[(2 \mathrm{k}-25) /\{(23+30) * 30\}-(29 / 30)]$

For $\mathrm{n}^{\mathrm{ix}}=2 ; \mathrm{n}_{2}^{\mathrm{x}}=$ floor function of $[(2 \mathrm{k}-25) /\{(23+60) * 30\}-(29 / 30)]$

For $\mathrm{n}^{\mathrm{ix}}=\mathrm{n}^{\mathrm{ix}}{ }_{\max }$ i.e. floor function of $[\{(2 \mathrm{k}-25) /(29 * 30)\}-(23 / 30)] ; \mathrm{n}^{\text {viii }}=$ floor function of $\left[(2 \mathrm{k}-25) /\left\{\left(23+30 \mathrm{n}^{\prime \prime}{ }_{\max }\right) * 30\right\}-(29 / 30)\right]$

Hence total number of $\mathrm{n}^{\mathrm{x}}=\mathrm{n}^{\mathrm{x}}{ }_{0}+\mathrm{n}^{\mathrm{x}}{ }_{1}+\mathrm{n}^{\mathrm{x}}{ }_{2}+\ldots \ldots . .+\mathrm{n}^{\mathrm{x}}$ for max value of $\mathrm{n}^{\mathrm{ix}}$

Or total number of possible values of $\mathrm{n}^{\mathrm{x}}=\sum \mathrm{n}^{\mathrm{ix}}=0$ to floor function of $[\{(2 \mathrm{k}-25) /(19 * 30)\}-(23 / 30)]$ floor function of $\left[(2 \mathrm{k}-25) /\left\{\left(23+30 \mathrm{n}^{\mathrm{ix}}\right) * 30\right\}-(29 / 30)\right]$ 
Number of combinations of type- $2 \mathrm{c} 1+\mathrm{c} 2$ combinations $=\sum \mathrm{n}^{\mathrm{ix}}=0$ to floor function of $[\{(2 \mathrm{k}-25) /(29 * 30)\}-$ (23/30)] floor function of $\left[(2 \mathrm{k}-25) /\left\{\left(23+30 \mathrm{n}^{\mathrm{ix}}\right) * 30\right\}-(29 / 30)\right]$

\section{Case(2BC-iii):}

$\mathrm{EN}=\operatorname{SADN}(5,2,8 / / 4)$

Here $\mathrm{EN}=\operatorname{SADN}(5,2,8 / / 4)$ includes even numbers having $\operatorname{SADN}(5,2,8)$ and last digit as 4 $\mathrm{C} 1[\operatorname{SADN}(7,4,1) / / 5]+\mathrm{C} 2[\operatorname{SADN}(7,4,1) / / 9]=2 \mathrm{k}$

Case(2BC-iiiB) $\quad$ For C2[SADN $(7,4,1) / / 9]$ implies that

$\mathrm{CASE}(2 \mathrm{BC}$-iiiB-i) i.e. //1x//9 $[\operatorname{SADN}(7,4,1) / / 1] \mathrm{x}[\operatorname{SADN}(7,4,1) / / 9]$

CASE(2BC-iiiB-ii) i.e. //1x//9 [SADN(5,2,8)//1] x [SADN $(5,2,8) / / 9]$

CASE(2BC-iiiB-iii) i.e. //3x//3 [SADN $(7,4,1) / / 3] x[\operatorname{SADN}(7,4,1) / / 3]$

CASE(2BC-iiiB-iv) i.e. //3x//3 [SADN $(5,2,8) / / 3] x[\operatorname{SADN}(5,2,8) / / 3]$

CASE(2BC-iiiB-v) i.e. //7x//7 [SADN $(7,4,1) / / 7]$ x $[\operatorname{SADN}(7,4,1) / / 7]$

CASE(2BC-iiiB-vi) i.e. //7x//7 [SADN $(5,2,8) / / 7]$ x [SADN $(5,2,8) / / 7]$

\section{Case(2BC-iiiB-i)}

For $\operatorname{SADN}(7,4,1) / / 1 \times \operatorname{SADN}(7,4,1) / / 9$

$(31+30 n) \times\left(19+30 n^{\prime}\right) \leq(2 k-25)$

For $\mathrm{n}=0 ; \mathrm{n}_{0}=$ floor function of $[(2 \mathrm{k}-25) /(31 * 30)-(19 / 30)]$

For $\mathrm{n}=1 ; \mathrm{n}_{1}=$ floor function of $[(2 \mathrm{k}-25) /\{(31+30) * 30\}-(19 / 30)]$

For $\mathrm{n}=2 ; \mathrm{n}_{2}=$ floor function of $[(2 \mathrm{k}-25) /\{(31+60) * 30\}-(19 / 30)]$

For $\mathrm{n}=\mathrm{n}_{\max }$ i.e. floor function of $[\{(2 \mathrm{k}-25) /(19 * 30)\}-(31 / 30)] ; \mathrm{n}$ ", $=$ floor function of $\left[(2 \mathrm{k}-25) /\left\{\left(31+30 \mathrm{n}^{\prime}{ }_{\text {max }}\right) * 30\right\}-(19 / 30)\right]$

Hence total number of $n^{\prime}=n^{\prime}{ }_{0}+n^{\prime}{ }_{1}+n^{\prime}{ }_{2}+\ldots \ldots . .+n^{\prime}$ for max value of $n$

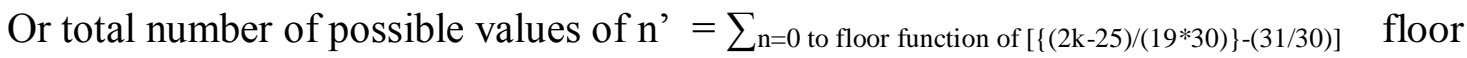
function of $[(2 \mathrm{k}-25) /\{(31+30 \mathrm{n}) * 30\}-(19 / 30)]$ 
Number of combinations of type- $2 \mathrm{c} 1+\mathrm{c} 2$ combinations $=\sum \mathrm{n}=0$ to floor function of $[\{(2 \mathrm{k}-25) /(19 * 30)\}-$ (31/30)] floor function of $[(2 \mathrm{k}-25) /\{(31+30 \mathrm{n}) * 30\}-(19 / 30)]$

\section{Case(2BC-iiiB-ii)}

For $[\operatorname{SADN}(5,2,8) / / 1] \times[\operatorname{SADN}(5,2,8) / / 9]:-$

$(11+30 \mathrm{n} \prime) \times(29+30 \mathrm{n}, ') \leq(2 \mathrm{k}-25)$

For n" $=0 ; n, "{ }_{0}=$ floor function of $[(2 \mathrm{k}-25) /(11 * 30)-(29 / 30)]$

For n" $=1 ; n,{ }_{1}=$ floor function of $[(2 \mathrm{k}-25) /\{(11+30) * 30\}-(29 / 30)]$

For $\mathrm{n} "=2 ; \mathrm{n},{ }_{2}$ iv $=$ floor function of $[(2 \mathrm{k}-25) /\{(11+60) * 30\}-(29 / 30)]$

For $\mathrm{n} "=\mathrm{n}$ " ${ }_{\max }$ i.e. floor function of $[\{(2 \mathrm{k}-25) /(29 * 30)\}-(11 / 30)] ; \mathrm{n}$ " ' $=$ floor function of $\left[(2 \mathrm{k}-25) /\left\{\left(11+30 n^{\prime}{ }_{\text {max }}\right) * 30\right\}-(29 / 30)\right]$

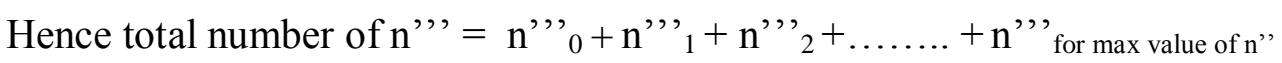

Or total number of possible values of $\mathrm{n}^{\prime \prime},=\sum_{\mathrm{n}}{ }=0$ to floor function of $[\{(2 \mathrm{k}-25) /(29 * 30)\}-(11 / 30)]$ floor function of $[(2 \mathrm{k}-25) /\{(11+30 \mathrm{n} ") * 30\}-(29 / 30)]$

Number of combinations of type- $2 \mathrm{c} 1+\mathrm{c} 2$ combinations $=\sum_{\mathrm{n}}$ " $=0$ to floor function of $[\{(2 \mathrm{k}-25) /(29 * 30)\}-$ $(11 / 30)]$ floor function of $[(2 \mathrm{k}-25) /\{(11+30 \mathrm{n} \prime) * 30\}-(29 / 30)]$

\section{Case(2BC-iiiB-iii)}

For $[\operatorname{SADN}(7,4,1) / / 3] x[\operatorname{SADN}(7,4,1) / / 3]:-$

$\left(13+30 \mathrm{n}^{\mathrm{iv}}\right) \times\left(13+30 \mathrm{n}^{\mathrm{v}}\right) \leq(2 \mathrm{k}-25)$

For $\mathrm{n}^{\mathrm{iv}}=0 ; \mathrm{n}^{\mathrm{v}}{ }_{0}=$ floor function of $[(2 \mathrm{k}-25) /(13 * 30)-(13 / 30)]$

For $\mathrm{n}^{\mathrm{iv}}=1 ; \mathrm{n}^{\mathrm{v}}{ }_{1}=$ floor function of $[(2 \mathrm{k}-25) /\{(13+30) * 30\}-(13 / 30)]$

For $\mathrm{n}^{\mathrm{iv}}=2 ; \mathrm{n}_{2}^{\mathrm{v}}=$ floor function of $[(2 \mathrm{k}-25) /\{(13+60) * 30\}-(13 / 30)]$

For $\mathrm{n}^{\mathrm{iv}}=\mathrm{n}^{\mathrm{iv}}{ }_{\max }$ i.e. floor function of $[\{(2 \mathrm{k}-25) /(13 * 30)\}-(13 / 30)] ; \mathrm{n}^{\mathrm{v}}=$ floor function of $\left[(2 \mathrm{k}-25) /\left\{\left(13+30 \mathrm{n}_{\text {max }}^{\mathrm{iv}}\right) * 30\right\}-(13 / 30)\right]$

Hence total number of $\mathrm{n}^{\mathrm{v}}=\mathrm{n}^{\mathrm{v}}{ }_{0}+\mathrm{n}^{\mathrm{v}}{ }_{1}+\mathrm{n}^{\mathrm{v}}{ }_{2}+\ldots \ldots .+\mathrm{n}^{\mathrm{v}}$ for max value of niv

Or total number of possible values of $\mathrm{n}^{\mathrm{v}}=\sum$ niv $=0$ to floor function of $[\{(2 \mathrm{k}-25) /(13 * 30)\}-(13 / 30)]$ floor function of $\left[(2 \mathrm{k}-25) /\left\{\left(13+30 \mathrm{n}^{\mathrm{iv}}\right) * 30\right\}-(13 / 30)\right]$

Number of combinations of type- $2 \mathrm{c} 1+\mathrm{c} 2$ combinations $=\sum$ niv $=0$ to floor function of $[\{(2 \mathrm{k}-25) /(13 * 30)\}$ $(13 / 30)]$ floor function of $\left[(2 \mathrm{k}-25) /\left\{\left(13+30 \mathrm{n}^{\mathrm{iv}}\right) * 30\right\}-(13 / 30)\right]$ 


\section{Case(2BC-iiiB-iv)}

For $[\operatorname{SADN}(5,2,8) / / 3] x[\operatorname{SADN}(5,2,8) / / 3]:-$

$\left(23+30 n^{\mathrm{vi}}\right) \times\left(23+30 \mathrm{n}^{\mathrm{vii}}\right) \leq(2 \mathrm{k}-25)$

For $\mathrm{n}^{\mathrm{vi}}=0 ; \mathrm{n}^{\mathrm{vii}}{ }_{0}=$ floor function of $[(2 \mathrm{k}-25) /(23 * 30)-(23 / 30)]$

For $\mathrm{n}^{\mathrm{vi}}=1 ; \mathrm{n}^{\mathrm{vii}}{ }_{1}=$ floor function of $[(2 \mathrm{k}-25) /\{(23+30) * 30\}-(23 / 30)]$

For $\mathrm{n}^{\mathrm{vi}}=2 ; \mathrm{n}^{\mathrm{vii}}{ }_{2}=$ floor function of $[(2 \mathrm{k}-25) /\{(23+60) * 30\}-(23 / 30)]$

For $\mathrm{n}^{\mathrm{vi}}=\mathrm{n}^{\mathrm{vi}}{ }_{\max }$ i.e. floor function of $[\{(2 \mathrm{k}-25) /(23 * 30)\}-(23 / 30)] ; \mathrm{n}^{\mathrm{vii}}=$ floor function of $\left[(2 \mathrm{k}-25) /\left\{\left(23+30 \mathrm{n}^{\mathrm{vii}}{ }_{\text {max }}\right) * 30\right\}-(23 / 30)\right]$

Hence total number of $\mathrm{n}^{\mathrm{vii}}=\mathrm{n}^{\mathrm{vii}}{ }_{0}+\mathrm{n}^{\mathrm{vii}}{ }_{1}+\mathrm{n}^{\mathrm{vii}}{ }_{2}+\ldots \ldots . .+\mathrm{n}^{\mathrm{vii}}$ for max value of nvi

Or total number of possible values of $\mathrm{n}^{\mathrm{vii}}=\sum \mathrm{nvi}=0$ to floor function of [\{(2k-25)/(23*30)\}-(13/30)] floor function of $\left[(2 \mathrm{k}-25) /\left\{\left(23+30 \mathrm{n}^{\mathrm{vi}}\right) * 30\right\}-(23 / 30)\right]$

Number of combinations of type- $2 \mathrm{c} 1+\mathrm{c} 2$ combinations $=\sum$ niv $=0$ to floor function of $[\{(2 \mathrm{k}-25) /(23 * 30)\}$ $(13 / 30)]$ floor function of $\left[(2 \mathrm{k}-25) /\left\{\left(23+30 \mathrm{n}^{\mathrm{iv}}\right) * 30\right\}-(23 / 30)\right]$

\section{Case(2BC-iiiB-v)}

For $[\operatorname{SADN}(7,4,1) / / 7] \times[\operatorname{SADN}(7,4,1) / / 7]:-$

$(7+30 n) \times\left(7+30 n^{\prime}\right)<=(2 k-25)$

For $\mathrm{n}=0 ; \mathrm{n}_{0}=$ floor function of $[(2 \mathrm{k}-25) /(7 * 30)-(7 / 30)]$

For $\mathrm{n}=1 ; \mathrm{n}_{1}{ }_{1}=$ floor function of $\left[(2 \mathrm{k}-25) /\left\{(7+30)^{*} 30\right\}-(7 / 30)\right]$

For $\mathrm{n}=2 ; \mathrm{n}_{2}=$ floor function of $[(2 \mathrm{k}-25) /\{(7+60) * 30\}-(7 / 30)]$

For $\mathrm{n}=\mathrm{n}_{\text {max }}$ i.e. floor function of $[\{(2 \mathrm{k}-25) /(7 * 30)\}-(7 / 30)] ; \mathrm{n}$ ', $=$ floor function of $[(2 \mathrm{k}-$ $\left.25) /\left\{\left(7+30 n^{\prime}{ }_{\max }\right) * 30\right\}-(7 / 30)\right]$

Hence total number of $n^{\prime}=n^{\prime}{ }_{0}+n^{\prime}{ }_{1}+n^{\prime}{ }_{2}+\ldots \ldots . .+n_{\text {for max value of } n}$

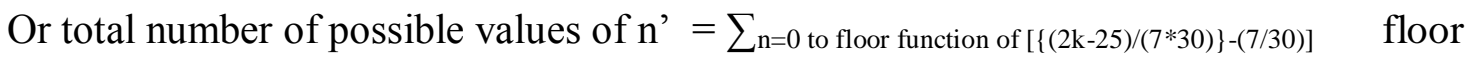
function of $[(2 \mathrm{k}-25) /\{(7+30 \mathrm{n}) * 30\}-(7 / 30)]$ 
Number of combinations of type- $2 \mathrm{c} 1+\mathrm{c} 2$ combinations $=\sum \mathrm{n}=0$ to floor function of $[\{(2 \mathrm{k}-25) /(7 * 30)\}$ (7/30)] floor function of $[(2 \mathrm{k}-25) /\{(7+30 \mathrm{n}) * 30\}-(7 / 30)]$

\section{Case(2BC-iiiB-vi)}

For $[\operatorname{SADN}(5,2,8) / / 7] \times[\operatorname{SADN}(5,2,8) / / 7]:-$

$\left(17+30 \mathrm{n}^{\prime \prime}\right) \times\left(17+30 \mathrm{n}^{\prime \prime \prime}\right) \leq(2 \mathrm{k}-25)$

For n" $=0 ; n, "{ }_{0}=$ floor function of $[(2 \mathrm{k}-25) /(17 * 30)-(17 / 30)]$

For n" $=1 ; n,{ }_{1}=$ floor function of $[(2 \mathrm{k}-25) /\{(17+30) * 30\}-(17 / 30)]$

For $\mathrm{n}^{\prime \prime}=2 ; \mathrm{n}^{,,{ }_{2}}{ }_{2}=$ floor function of $[(2 \mathrm{k}-25) /\{(17+60) * 30\}-(17 / 30)]$

For $\mathrm{n} "=\mathrm{n}$ " ${ }_{\max }$ i.e. floor function of $[\{(2 \mathrm{k}-25) /(17 * 30)\}-(17 / 30)] ; \mathrm{n}$ " ' $=$ floor function of $\left[(2 \mathrm{k}-25) /\left\{\left(17+30 n^{\prime}{ }_{\text {max }}\right) * 30\right\}-(17 / 30)\right]$

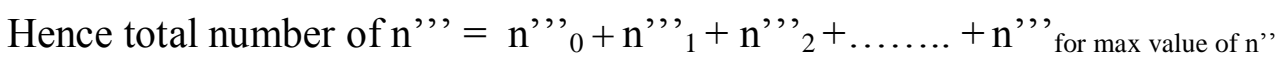

Or total number of possible values of $\mathrm{n}^{\prime \prime},=\sum_{\mathrm{n}}{ }^{\prime}=0$ to floor function of $[\{(2 \mathrm{k}-25) /(17 * 30)\}-(17 / 30)]$ floor function of $[(2 \mathrm{k}-25) /\{(17+30 \mathrm{n} ") * 30\}-(17 / 30)]$

Number of combinations of type- $2 \mathrm{c} 1+\mathrm{c} 2$ combinations $=\sum \mathrm{n} "=0$ to floor function of $[\{(2 \mathrm{k}-25) /(17 * 30)\}-$ $(17 / 30)]$ floor function of $[(2 \mathrm{k}-25) /\{(17+30 \mathrm{n} ’) * 30\}-(17 / 30)]$

\section{Case(2BC-iv):}

$\mathrm{EN}=\operatorname{SADN}(5,2,8 / / 6)$

Here $\mathrm{EN}=\operatorname{SADN}(5,2,8 / / 6)$ includes even numbers having $\operatorname{SADN}(5,2,8)$ and last digit as 6 $\mathrm{C} 1[\operatorname{SADN}(7,4,1) / / 5]+\mathrm{C} 2[\operatorname{SADN}(7,4,1) / / 1]=2 \mathrm{k}$

Case(2BC-ivB) For $\mathrm{C} 2[\operatorname{SADN}(7,4,1) / / 1]$ implies that

CASE(2BC-ivB-i) i.e. //1x//1 $[\operatorname{SADN}(7,4,1) / / 1] x[\operatorname{SADN}(7,4,1) / / 1]$

CASE(2BC-ivB-ii) i.e. //1x//1 [SADN(5,2,8)//1] x [SADN $(5,2,8) / / 1]$

CASE(2BC-ivB-iii) i.e. //3x//7 $[\operatorname{SADN}(7,4,1) / / 3] x[\operatorname{SADN}(7,4,1) / / 7]$

CASE(2BC-ivB-iv) i.e. //3x//7 $[\operatorname{SADN}(5,2,8) / / 3] x[\operatorname{SADN}(5,2,8) / / 7]$

CASE(2BC-ivB-v) i.e. //9x//9 [SADN $(7,4,1) / / 9]$ x $[\operatorname{SADN}(7,4,1) / / 9]$

CASE(2BC-ivB-vi) i.e. //9x//9 [SADN $(5,2,8) / / 9] \times[\operatorname{SADN}(5,2,8) / / 9]$ 


\section{Case(2BC-ivB-i)}

For $[\operatorname{SADN}(7,4,1) / / 1] \times[\operatorname{SADN}(7,4,1) / / 1]$

$(31+30 \mathrm{n}) \times\left(31+30 \mathrm{n}^{\prime}\right) \leq(2 \mathrm{k}-25)$

For $\mathrm{n}=0 ; \mathrm{n}_{0}=$ floor function of $[(2 \mathrm{k}-25) /(31 * 30)-(31 / 30)]$

For $\mathrm{n}=1 ; \mathrm{n}_{1}{ }_{1}=$ floor function of $[(2 \mathrm{k}-25) /\{(31+30) * 30\}-(31 / 30)]$

For $\mathrm{n}=2 ; \mathrm{n}_{2}=$ floor function of $[(2 \mathrm{k}-25) /\{(31+60) * 30\}-(31 / 30)]$

For $\mathrm{n}=\mathrm{n}^{\prime}{ }_{\max }$ i.e. floor function of $[\{(2 \mathrm{k}-25) /(31 * 30)\}-(31 / 30)] ; \mathrm{n}$ ', $=$ floor function of $\left[(2 \mathrm{k}-25) /\left\{\left(31+30 \mathrm{n},{ }_{\max }\right) * 30\right\}-(31 / 30)\right]$

Hence total number of $n^{\prime}=n^{\prime}{ }_{0}+n^{\prime}{ }_{1}+n^{\prime}{ }_{2}+\ldots \ldots . .+n^{\prime}$ for max value of $n$

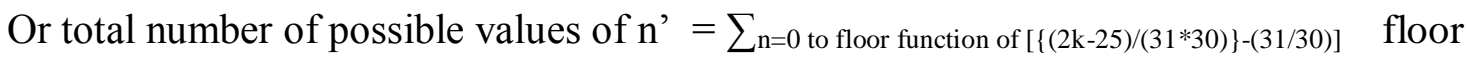
function of $[(2 \mathrm{k}-25) /\{(31+30 \mathrm{n}) * 30\}-(31 / 30)]$

Number of combinations of type- $2 \mathrm{c} 1+\mathrm{c} 2$ combinations $=\sum \mathrm{n}=0$ to floor function of $[\{(2 \mathrm{k}-25) /(31 * 30)\}$ (31/30)] floor function of $[(2 \mathrm{k}-25) /\{(31+30 \mathrm{n}) * 30\}-(31 / 30)]$

\section{Case(2BC-ivB-ii)}

For $\operatorname{SADN}(5,2,8) / / 1$ x $\operatorname{SADN}(5,2,8) / / 1:-$

$(11+30 \mathrm{n}$ ') $\mathrm{x}(11+30 \mathrm{n}, ') \leq(2 \mathrm{k}-25)$

For $n "=0 ; n, "{ }_{0}=$ floor function of $[(2 \mathrm{k}-25) /(11 * 30)-(11 / 30)]$

For n" $=1 ; n, "{ }_{1}=$ floor function of $[(2 \mathrm{k}-25) /\{(11+30) * 30\}-(11 / 30)]$

For n" $=2 ; n^{,},{ }_{2}=$ floor function of $[(2 \mathrm{k}-25) /\{(11+60) * 30\}-(11 / 30)]$

For $\mathrm{n} "=\mathrm{n}$ " ${ }_{\max }$ i.e. floor function of $[\{(2 \mathrm{k}-25) /(11 * 30)\}-(11 / 30)] ; \mathrm{n}$, , $=$ floor function of $\left[(2 \mathrm{k}-25) /\left\{\left(11+30 \mathrm{n}^{\prime}{ }_{\max }\right) * 30\right\}-(11 / 30)\right]$

Hence total number of n", $=n,{ }_{0}+n,{ }_{1}+n,{ }_{2}+\ldots \ldots .+n, "$, for max value of n"

Or total number of possible values of $\mathrm{n}^{\prime \prime},=\sum_{\mathrm{n}}{ }^{\prime}=0$ to floor function of $[\{(2 \mathrm{k}-25) /(11 * 30)\}-(11 / 30)]$ floor function of $[(2 \mathrm{k}-25) /\{(11+30 \mathrm{n} ") * 30\}-(11 / 30)]$ 
Number of combinations of type- $2 \mathrm{c} 1+\mathrm{c} 2$ combinations $=\sum_{\mathrm{n}}$ " $=0$ to floor function of $[\{(2 \mathrm{k}-25) /(11 * 30)\}-$ $(11 / 30)]$ floor function of $[(2 \mathrm{k}-25) /\{(11+30 \mathrm{n} ') * 30\}-(11 / 30)]$

\section{Case(2BC-ivB-iii)}

For $\operatorname{SADN}(7,4,1) / / 3 \times \operatorname{SADN}(7,4,1) / / 7:-$

$\left(13+30 n^{\text {iv }}\right) \times\left(7+30 n^{v}\right) \leq(2 k-25)$

For $\mathrm{n}^{\mathrm{iv}}=0 ; \mathrm{n}^{\mathrm{v}}=$ floor function of $[(2 \mathrm{k}-25) /(13 * 30)-(7 / 30)]$

For $\mathrm{n}^{\mathrm{iv}}=1 ; \mathrm{n}^{\mathrm{v}}{ }_{1}=$ floor function of $[(2 \mathrm{k}-25) /\{(13+30) * 30\}-(7 / 30)]$

For $\mathrm{n}^{\mathrm{iv}}=2 ; \mathrm{n}^{\mathrm{v}}{ }_{2}=$ floor function of $[(2 \mathrm{k}-25) /\{(13+60) * 30\}-(7 / 30)]$

For $\mathrm{n}^{\mathrm{iv}}=\mathrm{n}^{\mathrm{iv}}{ }_{\max }$ i.e. floor function of $[\{(2 \mathrm{k}-25) /(7 * 30)\}-(13 / 30)] ; \mathrm{n}^{\mathrm{v}}=$ floor function of $[(2 \mathrm{k}-$ $\left.25) /\left\{\left(13+30 n_{\text {max }}^{\text {iv }}\right) * 30\right\}-(7 / 30)\right]$

Hence total number of $n^{\mathrm{v}}=\mathrm{n}^{\mathrm{v}}{ }_{0}+\mathrm{n}^{\mathrm{v}}{ }_{1}+\mathrm{n}^{\mathrm{v}}{ }_{2}+\ldots \ldots .+\mathrm{n}^{\mathrm{v}}$ for max value of niv

Or total number of possible values of $\mathrm{n}^{\mathrm{v}}=\sum$ niv $=0$ to floor function of $[\{(2 \mathrm{k}-25) /(7 * 30)\}-(13 / 30)]$ floor function of $\left[(2 \mathrm{k}-25) /\left\{\left(13+30 \mathrm{n}^{\mathrm{iv}}\right) * 30\right\}-(7 / 30)\right]$

Number of combinations of type- $2 \mathrm{c} 1+\mathrm{c} 2$ combinations $=\sum$ niv $=0$ to floor function of $[\{(2 \mathrm{k}-25) /(7 * 30)\}$ (13/30)] floor function of $\left[(2 \mathrm{k}-25) /\left\{\left(13+30 \mathrm{n}^{\mathrm{iv}}\right) * 30\right\}-(7 / 30)\right]$

\section{Case(2BC-ivB-iv)}

For $\operatorname{SADN}(5,2,8) / / 3 \times \operatorname{SADN}(5,2,8) / / 7:-$

$\left(23+30 \mathrm{n}^{\mathrm{vi}}\right) \times\left(17+30 \mathrm{n}^{\mathrm{vii}}\right) \leq(2 \mathrm{k}-25)$

For $\mathrm{n}^{\mathrm{vi}}=0 ; \mathrm{n}^{\mathrm{vii}}{ }_{0}=$ floor function of $[(2 \mathrm{k}-25) /(23 * 30)-(17 / 30)]$

For $\mathrm{n}^{\mathrm{vi}}=1 ; \mathrm{n}^{\mathrm{vii}}{ }_{1}=$ floor function of $[(2 \mathrm{k}-25) /\{(23+30) * 30\}-(17 / 30)]$

For $\mathrm{n}^{\mathrm{vi}}=2 ; \mathrm{n}_{2}^{\mathrm{vii}}=$ floor function of $[(2 \mathrm{k}-25) /\{(23+60) * 30\}-(17 / 30)]$

For $\mathrm{n}^{\mathrm{vi}}=\mathrm{n}^{\mathrm{vi}}{ }_{\max }$ i.e. floor function of $[\{(2 \mathrm{k}-25) /(17 * 30)\}-(23 / 30)] ; \mathrm{n}^{\mathrm{vii}}=$ floor function of $\left[(2 \mathrm{k}-25) /\left\{\left(23+30 \mathrm{n}^{\mathrm{vii}}{ }_{\text {max }}\right) * 30\right\}-(17 / 30)\right]$

Hence total number of $\mathrm{n}^{\mathrm{vii}}=\mathrm{n}^{\mathrm{vii}}{ }_{0}+\mathrm{n}^{\mathrm{vii}}{ }_{1}+\mathrm{n}^{\mathrm{vii}}{ }_{2}+\ldots \ldots .+\mathrm{n}^{\mathrm{vii}}$ for max value of nvi 
Or total number of possible values of $\mathrm{n}^{\mathrm{vii}}=\sum_{\mathrm{nvi}}=0$ to floor function of $[\{(2 \mathrm{k}-25) /(17 * 30)\}-(23 / 30)]$ floor function of $\left[(2 \mathrm{k}-25) /\left\{\left(23+30 \mathrm{n}^{\mathrm{vi}}\right) * 30\right\}-(17 / 30)\right]$

Number of combinations of type- $2 \mathrm{c} 1+\mathrm{c} 2$ combinations $=\sum$ niv $=0$ to floor function of $[\{(2 \mathrm{k}-25) /(17 * 30)\}$ (23/30)] floor function of $\left[(2 \mathrm{k}-25) /\left\{\left(23+30 \mathrm{n}^{\mathrm{iv}}\right) * 30\right\}-(17 / 30)\right]$

\section{Case(2BC-ivB-v)}

For $[\operatorname{SADN}(7,4,1) / / 9] \times[\operatorname{SADN}(7,4,1) / / 9]:-$

$(19+30 n) \times\left(19+30 n^{\prime}\right) \leq(2 k-25)$

For $\mathrm{n}=0 ; \mathrm{n}_{0}=$ floor function of $[(2 \mathrm{k}-25) /(19 * 30)-(19 / 30)]$

For $\mathrm{n}=1 ; \mathrm{n}_{1}=$ floor function of $[(2 \mathrm{k}-25) /\{(19+30) * 30\}-(19 / 30)]$

For $\mathrm{n}=2 ; \mathrm{n}_{2}{ }_{2}=$ floor function of $[(2 \mathrm{k}-25) /\{(19+60) * 30\}-(19 / 30)]$

For $\mathrm{n}=\mathrm{n}^{\prime}{ }_{\max }$ i.e. floor function of $[\{(2 \mathrm{k}-25) /(19 * 30)\}-(19 / 30)] ; \mathrm{n}{ }^{\prime \prime}$ ' $=$ floor function of $\left[(2 \mathrm{k}-25) /\left\{\left(19+30 n^{\prime}{ }_{\text {max }}\right) * 30\right\}-(19 / 30)\right]$

Hence total number of $n^{\prime}=n^{\prime}{ }_{0}+n^{\prime}{ }_{1}+n^{\prime}{ }_{2}+\ldots \ldots . .+n^{\prime}$ for max value of $n$

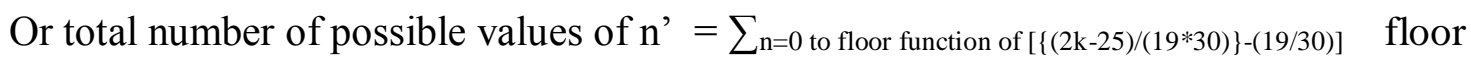
function of $[(2 \mathrm{k}-25) /\{(19+30 \mathrm{n}) * 30\}-(19 / 30)]$

Number of combinations of type- $2 \mathrm{c} 1+\mathrm{c} 2$ combinations $=\sum \mathrm{n}=0$ to floor function of $[\{(2 \mathrm{k}-25) /(19 * 30)\}$ $(19 / 30)$ floor function of $[(2 \mathrm{k}-25) /\{(19+30 \mathrm{n}) * 30\}-(19 / 30)]$

\section{Case(2BC-ivB-vi)}

For $[\operatorname{SADN}(5,2,8) / / 9] \times[\operatorname{SADN}(5,2,8) / / 9]:-$

$\left(29+30 n^{\prime \prime}\right) \times(29+30 n ', ') \leq(2 k-25)$

For n" $=0 ; n,{ }_{0}=$ floor function of $[(2 \mathrm{k}-25) /(29 * 30)-(29 / 30)]$

For $n "=1 ; n,{ }_{1}=$ floor function of $[(2 \mathrm{k}-25) /\{(29+30) * 30\}-(29 / 30)]$

For n" $=2 ; \mathrm{n}^{\prime,{ }^{\mathrm{iv}}}{ }_{2}=$ floor function of $[(2 \mathrm{k}-25) /\{(29+60) * 30\}-(29 / 30)]$ 
For n" $=$ n" ${ }_{\max }$ i.e. floor function of $[\{(2 \mathrm{k}-25) /(29 * 30)\}-(29 / 30)] ; \mathrm{n},{ }^{\prime},=$ floor function of $\left[(2 \mathrm{k}-25) /\left\{\left(29+30 n^{\prime}{ }_{\text {max }}\right) * 30\right\}-(29 / 30)\right]$

Hence total number of n", $=$ n', ${ }_{0}+\mathrm{n},{ }_{1}+\mathrm{n},{ }_{2}+\ldots \ldots .+\mathrm{n},{ }^{\prime}$ for max value of n"

Or total number of possible values of $n^{\prime \prime},=\sum \mathrm{n} "=0$ to floor function of $[\{(2 \mathrm{k}-25) /(29 * 30)\}-(29 / 30)]$ floor function of $\left[(2 \mathrm{k}-25) /\left\{(29+30 \mathrm{n},)^{*} 30\right\}-(29 / 30)\right]$

Number of combinations of type- $2 \mathrm{c} 1+\mathrm{c} 2$ combinations $=\sum \mathrm{n}$ " $=0$ to floor function of $[\{(2 \mathrm{k}-25) /(29 * 30)\}$ $(29 / 30)]$ floor function of $[(2 \mathrm{k}-25) /\{(29+30 \mathrm{n} ’) * 30\}-(29 / 30)]$

\section{Case(2BC-v):}

$\mathrm{EN}=\operatorname{SADN}(5,2,8 / / 8)$

Here $\mathrm{EN}=\operatorname{SADN}(5,2,8 / / 6)$ includes even numbers having $\operatorname{SADN}(5,2,8)$ and last digit as 8 $\mathrm{C} 1[\operatorname{SADN}(7,4,1) / / 5]+\mathrm{C} 2[\operatorname{SADN}(7,4,1) / / 3]=2 \mathrm{k}$

Case(2BC-vB) For $\mathrm{C} 2[\operatorname{SADN}(7,4,1) / / 3]$ implies that

CASE(2BC-vB-i) i.e. //1x//3 $[\operatorname{SADN}(7,4,1) / / 1] x[\operatorname{SADN}(7,4,1) / / 3]$

CASE(2BC-vB-ii) i.e. //1x//3 [SADN $(5,2,8) / / 1] \times[\operatorname{SADN}(5,2,8) / / 3]$

CASE(2BC-vB-iii) i.e. //7x//9 $[\operatorname{SADN}(7,4,1) / / 7] x[\operatorname{SADN}(7,4,1) / / 9]$

CASE(2BC-vB-iv) i.e. //7x//9 [SADN $(5,2,8) / / 7] x[\operatorname{SADN}(5,2,8) / / 9]$

\section{Case(2BC-vB-i)}

For $\operatorname{SADN}(7,4,1) / / 1$ x $\operatorname{SADN}(7,4,1) / / 3:-$

$(31+30 \mathrm{n}) \times\left(13+30 n^{\prime}\right) \leq(2 \mathrm{k}-25)$

For $\mathrm{n}=0 ; \mathrm{n}_{0}=$ floor function of $[(2 \mathrm{k}-25) /(31 * 30)-(13 / 30)]$

For $\mathrm{n}=1 ; \mathrm{n}_{1}{ }_{1}=$ floor function of $[(2 \mathrm{k}-25) /\{(31+30) * 30\}-(13 / 30)]$

For $\mathrm{n}=2 ; \mathrm{n}_{2}=$ floor function of $[(2 \mathrm{k}-25) /\{(31+60) * 30\}-(13 / 30)]$

For $\mathrm{n}=\mathrm{n}^{\prime}{ }_{\max }$ i.e. floor function of $[\{(2 \mathrm{k}-25) /(13 * 30)\}-(31 / 30)] ; \mathrm{n}$ ", $=$ floor function of $\left[(2 \mathrm{k}-25) /\left\{\left(31+30 \mathrm{n}^{\prime}{ }_{\max }\right) * 30\right\}-(13 / 30)\right]$ 
Hence total number of $n^{\prime}=n^{\prime}{ }_{0}+n^{\prime}{ }_{1}+n^{\prime}{ }_{2}+\ldots \ldots . .+n^{\prime}$ for max value of $n$

Or total number of possible values of $\mathrm{n}^{\prime}=\sum_{\mathrm{n}=0}$ to floor function of $[\{(2 \mathrm{k}-25) /(13 * 30)\}-(31 / 30)] \quad$ floor function of $[(2 \mathrm{k}-25) /\{(31+30 \mathrm{n}) * 30\}-(13 / 30)]$

Number of combinations of type- $2 \mathrm{c} 1+\mathrm{c} 2$ combinations $=\sum \mathrm{n}=0$ to floor function of $[\{(2 \mathrm{k}-25) /(13 * 30)\}$ $(31 / 30)]$ floor function of $[(2 \mathrm{k}-25) /\{(31+30 \mathrm{n}) * 30\}-(13 / 30)]$

\section{Case(2BC-vB-ii)}

For $\operatorname{SADN}(5,2,8) / / 1$ x $\operatorname{SADN}(5,2,8) / / 3:-$

$\left(11+30 \mathrm{n}^{\prime \prime}\right) \times\left(23+30 \mathrm{n}^{\prime \prime \prime}\right) \leq(2 \mathrm{k}-25)$

For n" $=0 ; n, "{ }_{0}=$ floor function of $[(2 \mathrm{k}-25) /(11 * 30)-(23 / 30)]$

For $\mathrm{n} "=1 ; \mathrm{n},{ }_{1}=$ floor function of $[(2 \mathrm{k}-25) /\{(11+30) * 30\}-(23 / 30)]$

For n" $=2 ; \mathrm{n}^{\prime,}{ }_{2}$, floor function of $[(2 \mathrm{k}-25) /\{(11+60) * 30\}-(23 / 30)]$

For n" $=$ n' ${ }_{\max }$ i.e. floor function of $[\{(2 \mathrm{k}-25) /(23 * 30)\}-(11 / 30)] ; \mathrm{n}, ",=$ floor function of $\left[(2 \mathrm{k}-25) /\left\{\left(11+30 \mathrm{n}^{\prime}{ }_{\max }\right) * 30\right\}-(23 / 30)\right]$

Hence total number of n", $=\mathrm{n},{ }_{0}+\mathrm{n},{ }_{1}+\mathrm{n},{ }_{2}+\ldots \ldots .+\mathrm{n},{ }^{\prime}$ for max value of $\mathrm{n}$,

Or total number of possible values of $n^{\prime \prime},=\sum \mathrm{n} "=0$ to floor function of $[\{(2 \mathrm{k}-25) /(23 * 30)\}-(11 / 30)]$ floor function of $\left[(2 \mathrm{k}-25) /\left\{(11+30 \mathrm{n} ")^{*} 30\right\}-(23 / 30)\right]$

Number of combinations of type- $2 \mathrm{c} 1+\mathrm{c} 2$ combinations $=\sum_{\mathrm{n}}$ " $=0$ to floor function of $[\{(2 \mathrm{k}-25) /(23 * 30)\}-$ $(11 / 30)]$ floor function of $[(2 \mathrm{k}-25) /\{(11+30 \mathrm{n} ") * 30\}-(23 / 30)]$

\section{Case(2BC-vB-iii)}

For $\operatorname{SADN}(7,4,1) / / 7$ x $\operatorname{SADN}(7,4,1) / / 9:-$

$\left(7+30 n^{\mathrm{iv}}\right) \times\left(19+30 n^{v}\right) \leq(2 \mathrm{k}-25)$

For $\mathrm{n}^{\mathrm{iv}}=0 ; \mathrm{n}^{\mathrm{v}}=$ floor function of $[(2 \mathrm{k}-25) /(7 * 30)-(19 / 30)]$

For $\mathrm{n}^{\mathrm{iv}}=1 ; \mathrm{n}^{\mathrm{v}}{ }_{1}=$ floor function of $[(2 \mathrm{k}-25) /\{(7+30) * 30\}-(19 / 30)]$

For $\mathrm{n}^{\mathrm{iv}}=2 ; \mathrm{n}_{2}^{\mathrm{v}}=$ floor function of $[(2 \mathrm{k}-25) /\{(7+60) * 30\}-(19 / 30)]$ 
For $\mathrm{n}^{\mathrm{iv}}=\mathrm{n}^{\mathrm{iv}}{ }_{\max }$ i.e. floor function of $[\{(2 \mathrm{k}-25) /(19 * 30)\}-(7 / 30)] ; \mathrm{n}^{\mathrm{v}}=$ floor function of $[(2 \mathrm{k}-$ $\left.25) /\left\{\left(7+30 \mathrm{n}_{\text {max }}^{\mathrm{iv}}\right) * 30\right\}-(19 / 30)\right]$

Hence total number of $\mathrm{n}^{\mathrm{v}}=\mathrm{n}^{\mathrm{v}}{ }_{0}+\mathrm{n}^{\mathrm{v}}{ }_{1}+\mathrm{n}^{\mathrm{v}}{ }_{2}+\ldots \ldots . .+\mathrm{n}^{\mathrm{v}}$ for max value of niv

Or total number of possible values of $\mathrm{n}^{\mathrm{v}}=\sum$ niv $=0$ to floor function of $[\{(2 \mathrm{k}-25) /(11 * 30)\}-(31 / 30)]$ floor function of $\left[(2 \mathrm{k}-25) /\left\{\left(7+30 \mathrm{n}^{\mathrm{iv}}\right) * 30\right\}-(19 / 30)\right]$

Number of combinations of type- $2 \mathrm{c} 1+\mathrm{c} 2$ combinations $=\sum$ niv $=0$ to floor function of $[\{(2 \mathrm{k}-25) /(19 * 30)\}$ $(7 / 30)$ floor function of $\left[(2 \mathrm{k}-25) /\left\{\left(7+30 \mathrm{n}^{\mathrm{iv}}\right) * 30\right\}-(19 / 30)\right]$

\section{Case(2BC-vB-iv)}

For $\operatorname{SADN}(5,2,8) / / 7$ x $\operatorname{SADN}(5,2,8) / / 9:-$

$\left(17+30 n^{\mathrm{vi}}\right) \times\left(29+30 \mathrm{n}^{\mathrm{vii}}\right)<=(2 \mathrm{k}-25)$

For $\mathrm{n}^{\mathrm{vi}}=0 ; \mathrm{n}^{\mathrm{vii}}{ }_{0}=$ floor function of $[(2 \mathrm{k}-25) /(17 * 30)-(29 / 30)]$

For $\mathrm{n}^{\mathrm{vi}}=1 ; \mathrm{n}^{\mathrm{vii}}{ }_{1}=$ floor function of $[(2 \mathrm{k}-25) /\{(17+30) * 30\}-(29 / 30)]$

For $\mathrm{n}^{\mathrm{vi}}=2 ; \mathrm{n}^{\mathrm{vii}}{ }_{2}=$ floor function of $[(2 \mathrm{k}-25) /\{(17+60) * 30\}-(29 / 30)]$

For $\mathrm{n}^{\mathrm{vi}}=\mathrm{n}^{\mathrm{vi}}{ }_{\max }$ i.e. floor function of $[\{(2 \mathrm{k}-25) /(29 * 30)\}-(17 / 30)] ; \mathrm{n}^{\mathrm{vii}}=$ floor function of $\left[(2 \mathrm{k}-25) /\left\{\left(17+30 \mathrm{n}_{\text {max }}^{\mathrm{vii}}\right) * 30\right\}-(29 / 30)\right]$

Hence total number of $\mathrm{n}^{\mathrm{vii}}=\mathrm{n}^{\mathrm{vii}}{ }_{0}+\mathrm{n}^{\mathrm{vii}}{ }_{1}+\mathrm{n}^{\mathrm{vii}}{ }_{2}+\ldots \ldots .+\mathrm{n}^{\mathrm{vii}}$ for max value of nvi

Or total number of possible values of $\mathrm{n}^{\mathrm{vii}}=\sum \mathrm{nvi}=0$ to floor function of $[\{(2 \mathrm{k}-25) /(29 * 30)\}-(17 / 30)]$ floor function of $\left[(2 \mathrm{k}-25) /\left\{\left(17+30 \mathrm{n}^{\mathrm{vi}}\right) * 30\right\}-(29 / 30)\right]$

Number of combinations of type- $2 \mathrm{c} 1+\mathrm{c} 2$ combinations $=\sum$ niv $=0$ to floor function of $[\{(2 \mathrm{k}-25) /(29 * 30)\}-$ (17/30)] floor function of $\left[(2 \mathrm{k}-25) /\left\{\left(17+30 \mathrm{n}^{\mathrm{iv}}\right) * 30\right\}-(2 \mathrm{ss} 9 / 30)\right]$

\section{Case(3):}

$\mathrm{SADN}$ of $\mathrm{EN}=\{6,3,9\}$ and $\mathrm{EN}$ not equal to the number ' 6 '

$\mathrm{EN}=2 \mathrm{k}$

$\mathrm{EN} / 2=\mathrm{k}$ can never be a prime and will always be a composite number

' $\mathrm{k}$ ' is a composite number 
Number of acceptable combinations of elements is given as $n_{\text {acc }}$

Case (3A): If number of composites is less than number of primes (i.e. $n_{c}<n_{p}$ implies that even if all composites are prime-eaters; there exists atleast one $\mathrm{p} 1+\mathrm{p} 2$ pair

Case(3B): If number of composites is greater than or equal to number of primes (i.e. $n_{c}>=n_{p}$ implies that we need to find total number of unique $\mathrm{C} 1+\mathrm{C} 2$ pairs

\section{C1+C2 of Type-1:}

It has already been discussed in section 11A.

\section{C1+C2 of Type-2:}

$\mathrm{EN}=\operatorname{SADN}(6,3,9 / / 0)$ OR $\operatorname{SADN}(6,3,9 / / 2)$ OR $\operatorname{SADN}(6,3,9 / / 4)$ OR $\operatorname{SADN}(6,3,9 / / 6)$ OR $\operatorname{SADN}(6,3,9 / / 8)$

Here $\operatorname{EN}=\operatorname{SADN}(6,3,9 / / 0)$ indicates even numbers having $\operatorname{SADN}(6,3,9)$ and last digit as 0

\section{Case(3B-iA):}

$\mathrm{EN}=\operatorname{SADN}(6,3,9 / / 0 / / 6)$ including even numbers of $\operatorname{SADN}(6,3,9 / / 0)$ and cyclical series element as ' 6 '

$\mathrm{EN}=\operatorname{SADN}(6,3,9 / / 0 / / 6)$

$\mathrm{C} 1$ of $\operatorname{SADN}(7,4,1 / / 5)+\mathrm{C} 2$ of $\operatorname{SADN}(7,4,1 / / 5)=2 \mathrm{k}$

$\left(25+30 \mathrm{n}_{\mathrm{a}}{ }^{\prime \prime}\right)+\left[2 \mathrm{k}-\left(25+30 \mathrm{n}_{\mathrm{a}}{ }^{\prime \prime}\right)\right]=2 \mathrm{k}$

$25+30 \mathrm{n}_{\mathrm{a}}{ }^{\prime}<2 \mathrm{k}$

Number of Composites of $\operatorname{SADN}(7,4,1 / / 5)$ is given as $\mathrm{n}_{\mathrm{a}}{ }^{\prime}<(2 \mathrm{k}-25) / 30$

or $\mathrm{n}_{\mathrm{a}}{ }^{\prime}=$ floor function of $[(2 \mathrm{k}-25) / 30]$

No. of type- $2 \mathrm{C} 1+\mathrm{C} 2$ combinations $=$ floor function $[(1 / 2) *(2 \mathrm{k}-25) / 30]+1$

Or No. of type $-2 \mathrm{C} 1+\mathrm{C} 2$ combinations $=$ floor function $[\mathrm{k} / 30]+1$

\section{Case(3B-iB):}

$\mathrm{EN}=\operatorname{SADN}(6,3,9 / / 0 / / 12)$ including even numbers of $\operatorname{SADN}(6,3,9 / / 0)$ and cyclical series element as ' 12 '

$\mathrm{EN}=\operatorname{SADN}(6,3,9 / / 0 / / 12)$

$\mathrm{C} 1$ of $\operatorname{SADN}(7,4,1 / / 5)+\mathrm{C} 2$ of $\operatorname{SADN}(7,4,1 / / 5)=2 \mathrm{k}$

$\left(25+30 \mathrm{n}_{\mathrm{b}}{ }^{\prime \prime}\right)+\left[2 \mathrm{k}-\left(25+30 \mathrm{n}_{\mathrm{b}}{ }^{\prime}\right)\right]=2 \mathrm{k}$ 
$\left(25+30 \mathrm{n}_{\mathrm{b}}{ }^{\prime}\right)<2 \mathrm{k}$

Number of $\mathrm{C}$ of $\operatorname{SADN}(7,4,1 / / 5)$ is given as $\mathrm{n}_{\mathrm{b}}$ "' $<(2 \mathrm{k}-25) / 30$

or $\mathrm{n}_{\mathrm{b}}{ }^{\prime}=$ floor function of $[(2 \mathrm{k}-25) / 30]$

Number of type- $2 \mathrm{C} 1+\mathrm{C} 2$ combinations $=$ floor function $\left[(1 / 2)^{*}(2 \mathrm{k}-25) / 30\right]+1$

Or Number of type- $2 \mathrm{C} 1+\mathrm{C} 2$ combinations $=$ floor function $[\mathrm{k} / 30]$

\section{Case(3B-ii):}

$\mathrm{EN}=\operatorname{SADN}(6,3,9 / / 2)$

Here $\mathrm{EN}=\operatorname{SADN}(6,3,9 / / 2)$ includes even numbers having $\operatorname{SADN}(5,2,8)$ and last digit as 2

$\operatorname{Case}(3 B-i i-A) \quad \operatorname{C} 1[\operatorname{SADN}(7,4,1) / / 5]+\mathrm{C} 2[\operatorname{SADN}(5,2,8) / / 7]=2 \mathrm{k}$

Case(3B-ii-B) $\quad \mathrm{C} 1[\operatorname{SADN}(5,2,8) / / 5]+\mathrm{C} 2[\operatorname{SADN}(7,4,1) / / 7]=2 \mathrm{k}$

\section{Case(3B-ii-A)}

$\mathrm{C} 1[\operatorname{SADN}(7,4,1) / / 5]+\mathrm{C} 2[\operatorname{SADN}(5,2,8) / / 7]=2 \mathrm{k}$

$25+\mathrm{C} 2[\operatorname{SADN}(5,2,8) / / 7]=2 \mathrm{k}$

Or $\quad \mathrm{C} 2[\operatorname{SADN}(5,2,8) / / 7]=2 \mathrm{k}-25$

For C2[SADN(5,2,8)//7] implies that //1x//7 OR //3x//9

With Reference from Cases(1BC-iiA-i) upto (1BC-iiA-iv):-

Case(3B-ii-A-i)

For $\operatorname{SADN}(5,2,8) / / 1$ x $\operatorname{SADN}(7,4,1) / / 7:-$

Number of combinations of type- $2 \mathrm{c} 1+\mathrm{c} 2$ combinations $=\sum_{\mathrm{n}}$ "' $=0$ to floor function of $[\{(2 \mathrm{k}-25) /(7 * 30)\}$ $(11 / 30)]$ floor function of $[(2 \mathrm{k}-25) /\{(11+30 \mathrm{n}, ') * 30\}-(7 / 30)]$

\section{Case(3B-ii-A-ii)}

For $\operatorname{SADN}(7,4,1) / / 1 \times \operatorname{SADN}(5,2,8) / / 7:-$

Number of combinations of type- $2 \mathrm{c} 1+\mathrm{c} 2$ combinations $==\sum \mathrm{n}^{\mathrm{v}}=0$ to floor function of $[\{(2 \mathrm{k}-25) /(17 * 30)\}$ (31/30)] floor function of $\left[(2 \mathrm{k}-25) /\left\{\left(31+30 \mathrm{n}^{\mathrm{v}}\right) * 30\right\}-(17 / 30)\right]$

\section{Case(3B-ii-A-iii)}

For $\operatorname{SADN}(7,4,1) / / 3 \times \operatorname{SADN}(5,2,8) / / 9:-$ 
Number of combinations of type- $2 \mathrm{c} 1+\mathrm{c} 2$ combinations $=\sum \mathrm{n}^{\mathrm{vii}}=0$ to floor function of $[\{(2 \mathrm{k}-25) /(29 * 30)\}$ (13/30)] floor function of $\left[(2 \mathrm{k}-25) /\left\{\left(13+30 \mathrm{n}^{\mathrm{vii}}\right) * 30\right\}-(29 / 30)\right]$

\section{Case(3B-ii-A-iv)}

For $\operatorname{SADN}(5,2,8) / / 3 \times \operatorname{SADN}(7,4,1) / / 9:-$

Number of combinations of type- $2 \mathrm{c} 1+\mathrm{c} 2$ combinations $=\sum \mathrm{n}^{\mathrm{ix}}=0$ to floor function of $[\{(2 \mathrm{k}-25) /(19 * 30)\}$ (23/30)] floor function of $\left[(2 \mathrm{k}-25) /\left\{\left(23+30 \mathrm{n}^{\mathrm{ix}}\right) * 30\right\}-(19 / 30)\right]$

\section{Case(3B-ii-B)}

$\mathrm{C} 1[\operatorname{SADN}(5,2,8) / / 5]+\mathrm{C} 2[\operatorname{SADN}(7,4,1) / / 7]=2 \mathrm{k}$

$35+\mathrm{C} 2[\operatorname{SADN}(7,4,1) / / 7]=2 \mathrm{k}$

Or $\quad \mathrm{C} 2[\operatorname{SADN}(7,4,1) / / 7]=2 \mathrm{k}-35$

For C2[SADN $(7,4,1) / / 7]$ implies that $/ / 1 \mathrm{x} / / 7$ OR //3x//9

With Reference from Cases(2BC-iiB-i) upto (2BC-iiB-iv):-

\section{Case(3B-iiB-i)}

For $\operatorname{SADN}(7,4,1) / / 1 \times \operatorname{SADN}(7,4,1) / / 7$ :-

Number of combinations of type- $2 \mathrm{c} 1+\mathrm{c} 2$ combinations $=\sum_{\mathrm{n}}$ "' $=0$ to floor function of $\left[\left\{(2 \mathrm{k}-35) /\left(7^{*} 30\right)\right\}-\right.$ $(31 / 30)]$ floor function of $[(2 \mathrm{k}-35) /\{(31+30 \mathrm{n},) * 30\}-,(7 / 30)]$

\section{Case(3B-iiB-ii)}

For $[\operatorname{SADN}(5,2,8) / / 1] \times[\operatorname{SADN}(5,2,8) / / 7]:-$

Number of combinations of type- $2 \mathrm{c} 1+\mathrm{c} 2$ combinations $=\sum \mathrm{n}^{\mathrm{v}}=0$ to floor function of $[\{(2 \mathrm{k}-35) /(17 * 30)\}$ $(11 / 30)]$ floor function of $\left[(2 \mathrm{k}-35) /\left\{\left(11+30 \mathrm{n}^{\mathrm{v}}\right) * 30\right\}-(17 / 30)\right]$

\section{Case(3B-iiB-iii)}

For $[\operatorname{SADN}(7,4,1) / / 3] x[\operatorname{SADN}(7,4,1) / / 9]:-$

Number of combinations of type- $2 \mathrm{c} 1+\mathrm{c} 2$ combinations $=\sum \mathrm{n}^{\mathrm{vii}}=0$ to floor function of $[\{(2 \mathrm{k}-35) /(19 * 30)\}$ $(13 / 30)]$ floor function of $\left[(2 \mathrm{k}-35) /\left\{\left(13+30 \mathrm{n}^{\mathrm{vii}}\right) * 30\right\}-(19 / 30)\right]$

\section{Case(3B-iiB-iv)}

For $[\operatorname{SADN}(5,2,8) / / 3] \times[\operatorname{SADN}(5,2,8) / / 9]:-$ 
Number of combinations of type- $2 \mathrm{c} 1+\mathrm{c} 2$ combinations $=\sum \mathrm{n}^{\mathrm{ix}}=0$ to floor function of $[\{(2 \mathrm{k}-35) /(29 * 30)\}$ (23/30)] floor function of $\left[(2 \mathrm{k}-35) /\left\{\left(23+30 \mathrm{n}^{\mathrm{ix}}\right) * 30\right\}-(29 / 30)\right]$

\title{
Case(3B-iii):
}

$\mathrm{EN}=\operatorname{SADN}(6,3,9 / / 4)$

Here $\mathrm{EN}=\operatorname{SADN}(6,3,9 / / 4)$ includes even numbers having $\operatorname{SADN}(6,3,9)$ and last digit as 4
Case(3B-iii-A)
$\mathrm{C} 1[\operatorname{SADN}(7,4,1) / / 5]+\mathrm{C} 2[\operatorname{SADN}(5,2,8) / / 9]=2 \mathrm{k}$
Case(3B-iii-B)
$\mathrm{C} 1[\operatorname{SADN}(5,2,8) / / 5]+\mathrm{C} 2[\operatorname{SADN}(7,4,1) / / 9]=2 \mathrm{k}$

\author{
Case(3B-iii-A) \\ $\mathrm{C} 1[\operatorname{SADN}(7,4,1) / / 5]+\mathrm{C} 2[\operatorname{SADN}(5,2,8) / / 9]=2 \mathrm{k}$ \\ $25+\mathrm{C} 2[\operatorname{SADN}(5,2,8) / / 9]=2 \mathrm{k}$ \\ Or $\quad \mathrm{C} 2[\operatorname{SADN}(5,2,8) / / 9]=2 \mathrm{k}-25$
}

For C2[SADN $(5,2,8) / / 9]$ implies that $/ / 1 x / / 9$ OR //3x//3

With Reference from Cases(1BC-iiiA-i) upto (1BC-iiiA-iv):-

\section{Case(3B-iii-A-i)}

For C2[SADN $(5,2,8) / / 9]$

\section{Case(3B-iiiA-i)}

For $\operatorname{SADN}(7,4,1) / / 1 \times \operatorname{SADN}(5,2,8) / / 9$

Number of combinations of type- $2 \mathrm{c} 1+\mathrm{c} 2$ combinations $=\sum \mathrm{n}=0$ to floor function of $[\{(2 \mathrm{k}-25) /(29 * 30)\}-$ $(31 / 30)]$ floor function of $[(2 \mathrm{k}-25) /\{(31+30 \mathrm{n}) * 30\}-(29 / 30)]$

\section{Case(3B-iiiA-ii)}

For $\operatorname{SADN}(5,2,8) / / 1$ x $\operatorname{SADN}(7,4,1) / / 9:-$

Number of combinations of type- $2 \mathrm{c} 1+\mathrm{c} 2$ combinations $=\sum_{\mathrm{n}}$ " $=0$ to floor function of $[\{(2 \mathrm{k}-25) /(19 * 30)\}-$ $(11 / 30)]$ floor function of $[(2 \mathrm{k}-25) /\{(11+30 \mathrm{n} \prime) * 30\}-(19 / 30)]$

\section{Case(3B-iiiA-iii)}

For $\operatorname{SADN}(7,4,1) / / 7$ x $\operatorname{SADN}(5,2,8) / / 7:-$ 
Number of combinations of type- $2 \mathrm{c} 1+\mathrm{c} 2$ combinations $=\sum$ niv $=0$ to floor function of $[\{(2 \mathrm{k}-25) /(19 * 30)\}$ $(11 / 30)]$ floor function of $\left[(2 \mathrm{k}-25) /\left\{\left(7+30 \mathrm{n}^{\mathrm{iv}}\right) * 30\right\}-(17 / 30)\right]$

\section{Case(3B-iiiA-iv)}

For $\operatorname{SADN}(7,4,1) / / 3 \times \operatorname{SADN}(5,2,8) / / 3:-$

Number of combinations of type- $2 \mathrm{c} 1+\mathrm{c} 2$ combinations $=\sum$ niv $=0$ to floor function of $[\{(2 \mathrm{k}-25) /(23 * 30)\}$ $(13 / 30)]$ floor function of $\left[(2 \mathrm{k}-25) /\left\{\left(13+30 \mathrm{n}^{\mathrm{iv}}\right) * 30\right\}-(23 / 30)\right]$

\section{Case(3B-iii-B)}

$\mathrm{C} 1[\operatorname{SADN}(5,2,8) / / 5]+\mathrm{C} 2[\operatorname{SADN}(7,4,1) / / 9]=2 \mathrm{k}$

$35+\mathrm{C} 2[\operatorname{SADN}(7,4,1) / / 9]=2 \mathrm{k}$

Or $\quad \mathrm{C} 2[\operatorname{SADN}(7,4,1) / / 9]=2 \mathrm{k}-35$

For C2[SADN $(7,4,1) / / 9]$ implies that $/ / 1 \mathrm{x} / / 9$ OR $/ / 3 \mathrm{x} / / 3$ OR $/ / 7 \mathrm{x} / / 7$

With Reference from Cases(2BC-iiiB-i) upto (2BC-iiiB-vi):-

\section{Case(3B-iiiB-i)}

For $\operatorname{SADN}(7,4,1) / / 1 \times \operatorname{SADN}(7,4,1) / / 9$

Number of combinations of type- $2 \mathrm{c} 1+\mathrm{c} 2$ combinations $=\sum_{\mathrm{n}=0}$ to floor function of $[\{(2 \mathrm{k}-35) /(19 * 30)\}-$ (31/30)] floor function of $[(2 \mathrm{k}-35) /\{(31+30 \mathrm{n}) * 30\}-(19 / 30)]$

\section{Case(3B-iiiB-ii)}

For $[\operatorname{SADN}(5,2,8) / / 1] \times[\operatorname{SADN}(5,2,8) / / 9]:-$

Number of combinations of type- $2 \mathrm{c} 1+\mathrm{c} 2$ combinations $=\sum \mathrm{n} "=0$ to floor function of $[\{(2 \mathrm{k}-35) /(29 * 30)\}-$ $(11 / 30)]$ floor function of $[(2 \mathrm{k}-35) /\{(11+30 \mathrm{n} ") * 30\}-(29 / 30)]$

\section{Case(3B-iiiB-iii)}

For $[\operatorname{SADN}(7,4,1) / / 3] x[\operatorname{SADN}(7,4,1) / / 3]$ :-

Number of combinations of type- $2 \mathrm{c} 1+\mathrm{c} 2$ combinations $=\sum$ niv $=0$ to floor function of $[\{(2 \mathrm{k}-35) /(13 * 30)\}$ $(13 / 30)]$ floor function of $\left[(2 \mathrm{k}-35) /\left\{\left(13+30 \mathrm{n}^{\mathrm{iv}}\right) * 30\right\}-(13 / 30)\right]$

\section{Case(3B-iiiB-iv)}

For $[\operatorname{SADN}(5,2,8) / / 3] x[\operatorname{SADN}(5,2,8) / / 3]$ :- 
Number of combinations of type- $2 \mathrm{c} 1+\mathrm{c} 2$ combinations $=\sum$ niv $=0$ to floor function of $[\{(2 \mathrm{k}-35) /(23 * 30)\}$ $(13 / 30)]$ floor function of $\left[(2 \mathrm{k}-35) /\left\{\left(23+30 \mathrm{n}^{\mathrm{iv}}\right) * 30\right\}-(23 / 30)\right]$

\section{Case(3B-iiiB-v)}

For $[\operatorname{SADN}(7,4,1) / / 7] \times[\operatorname{SADN}(7,4,1) / / 7]:-$

Number of combinations of type- $2 \mathrm{c} 1+\mathrm{c} 2$ combinations $=\sum \mathrm{n}=0$ to floor function of $[\{(2 \mathrm{k}-35) /(7 * 30)\}$ (7/30)] floor function of $[(2 \mathrm{k}-35) /\{(7+30 \mathrm{n}) * 30\}-(7 / 30)]$

\section{Case(3B-iiiB-vi)}

For $[\operatorname{SADN}(5,2,8) / / 7] \times[\operatorname{SADN}(5,2,8) / / 7]:-$

Number of combinations of type- $2 \mathrm{c} 1+\mathrm{c} 2$ combinations $=\sum \mathrm{n} "=0$ to floor function of $[\{(2 \mathrm{k}-35) /(17 * 30)\}$ $(17 / 30)]$ floor function of $[(2 \mathrm{k}-35) /\{(17+30 \mathrm{n} ’) * 30\}-(17 / 30)]$

\section{Case(3B-iv):}

$\mathrm{EN}=\operatorname{SADN}(6,3,9 / / 6)$

Here $\operatorname{EN}=\operatorname{SADN}(6,3,9 / / 6)$ includes even numbers having $\operatorname{SADN}(6,3,9)$ and last digit as 6

Case(3B-iv-A) $\mathrm{C} 1[\operatorname{SADN}(7,4,1) / / 5]+\mathrm{C} 2[\operatorname{SADN}(5,2,8) / / 1]=2 \mathrm{k}$

Case(3B-iv-B)

$\mathrm{C} 1[\operatorname{SADN}(5,2,8) / / 5]+\mathrm{C} 2[\operatorname{SADN}(7,4,1) / / 1]=2 \mathrm{k}$

\section{Case(3B-iv-A)}

$\mathrm{C} 1[\operatorname{SADN}(7,4,1) / / 5]+\mathrm{C} 2[\operatorname{SADN}(5,2,8) / / 1]=2 \mathrm{k}$

$25+\mathrm{C} 2[\operatorname{SADN}(5,2,8) / / 1]=2 \mathrm{k}$

Or $\quad \mathrm{C} 2[\operatorname{SADN}(5,2,8) / / 1]=2 \mathrm{k}-25$

For C2[SADN $(5,2,8) / / 1]$ implies that $/ / 3 x / / 7$ OR //1x//1 OR //9x//9

With Reference from Cases(1BC-ivA-i) upto (1BC-ivA-iv):-

For C2[SADN $(5,2,8) / / 1]$

\section{Case(3B-ivA-i)}

For $\operatorname{SADN}(7,4,1) / / 3 \times \operatorname{SADN}(5,2,8) / / 7:-$

$(13+30 \mathrm{n}) \times\left(17+30 \mathrm{n}^{\prime}\right)<=(2 \mathrm{k}-25)$ 
Number of combinations of type- $2 \mathrm{c} 1+\mathrm{c} 2$ combinations $=\sum \mathrm{n}=0$ to floor function of $[\{(2 \mathrm{k}-25) /(17 * 30)\}$ (13/30)] floor function of $[(2 \mathrm{k}-25) /\{(13+30 \mathrm{n}) * 30\}-(17 / 30)]$

\section{Case(3B-ivA-ii)}

For $\operatorname{SADN}(5,2,8) / / 3 \times \operatorname{SADN}(7,4,1) / / 7:-$

$$
\left(23+30 n^{\prime \prime}\right) \times\left(7+30 n^{\prime \prime \prime}\right)<=(2 k-25)
$$

Number of combinations of type- $2 \mathrm{c} 1+\mathrm{c} 2$ combinations $=\sum \mathrm{n}$ " $=0$ to floor function of $[\{(2 \mathrm{k}-25) /(7 * 30)\}$ $(23 / 30)]$ floor function of $[(2 \mathrm{k}-25) /\{(23+30 \mathrm{n} ') * 30\}-(7 / 30)]$

\section{Case(3B-ivA-iii)}

For $\operatorname{SADN}(7,4,1) / / 1 \times \operatorname{SADN}(5,2,8) / / 1:-$

$$
\left(31+30 n^{\mathrm{iv}}\right) \times\left(11+30 \mathrm{n}^{\mathrm{v}}\right)<=(2 \mathrm{k}-25)
$$

Number of combinations of type- $2 \mathrm{c} 1+\mathrm{c} 2$ combinations $=\sum$ niv $=0$ to floor function of $[\{(2 \mathrm{k}-25) /(11 * 30)\}$ $(31 / 30)]$ floor function of $\left[(2 \mathrm{k}-25) /\left\{\left(31+30 \mathrm{n}^{\mathrm{iv}}\right) * 30\right\}-(11 / 30)\right]$

\section{Case(3B-ivA-iv)}

For $\operatorname{SADN}(7,4,1) / / 9$ x $\operatorname{SADN}(5,2,8) / / 9:-$

$$
\left(19+30 \mathrm{n}^{\mathrm{vi}}\right) \times\left(29+30 \mathrm{n}^{\mathrm{vii}}\right)<=(2 \mathrm{k}-25)
$$

Number of combinations of type- $2 \mathrm{c} 1+\mathrm{c} 2$ combinations $=\sum$ niv $=0$ to floor function of $[\{(2 \mathrm{k}-25) /(29 * 30)\}-$ $(19 / 30)]$ floor function of $\left[(2 \mathrm{k}-25) /\left\{\left(19+30 \mathrm{n}^{\mathrm{iv}}\right) * 30\right\}-(29 / 30)\right]$

\section{Case(3B-iv-B)}

$\mathrm{C} 1[\operatorname{SADN}(5,2,8) / / 5]+\mathrm{C} 2[\operatorname{SADN}(7,4,1) / / 1]=2 \mathrm{k}$

$35+\mathrm{C} 2[\operatorname{SADN}(7,4,1) / / 1]=2 \mathrm{k}$

Or $\quad \mathrm{C} 2[\operatorname{SADN}(7,4,1) / / 1]=2 \mathrm{k}-35$

For C2[SADN(7,4,1)//1] implies that $/ / 1 \mathrm{x} / / 1$ OR $/ / 3 x / / 7$ OR $/ / 9 x / / 9$

With Reference from Cases(2BC-ivB-i) upto (2BC-ivB-vi):-

\section{Case(3B-ivB-i)}


For $[\operatorname{SADN}(7,4,1) / / 1] \times[\operatorname{SADN}(7,4,1) / / 1]$

$(31+30 \mathrm{n}) \times\left(31+30 \mathrm{n}^{\prime}\right)<=(2 \mathrm{k}-35)$

Number of combinations of type- $2 \mathrm{c} 1+\mathrm{c} 2$ combinations $=\sum \mathrm{n}=0$ to floor function of $[\{(2 \mathrm{k}-35) /(31 * 30)\}$ (31/30)] floor function of $[(2 \mathrm{k}-35) /\{(31+30 \mathrm{n}) * 30\}-(31 / 30)]$

\section{Case(3B-ivB-ii)}

For $\operatorname{SADN}(5,2,8) / / 1$ x $\operatorname{SADN}(5,2,8) / / 1:-$

$(11+30 \mathrm{n} ') \times\left(11+30 \mathrm{n}^{\prime \prime \prime}\right)<=(2 \mathrm{k}-35)$

Number of combinations of type- $2 \mathrm{c} 1+\mathrm{c} 2$ combinations $=\sum_{\mathrm{n}}{ }^{\prime}=0$ to floor function of $[\{(2 \mathrm{k}-35) /(11 * 30)\}-$ $(11 / 30)]$ floor function of $[(2 \mathrm{k}-35) /\{(11+30 \mathrm{n} ') * 30\}-(11 / 30)]$

\section{Case(3B-ivB-iii)}

For $\operatorname{SADN}(7,4,1) / / 3 \times \operatorname{SADN}(7,4,1) / / 7:-$

$\left(13+30 n^{\mathrm{iv}}\right) \times\left(7+30 \mathrm{n}^{\mathrm{v}}\right)<=(2 \mathrm{k}-35)$

Number of combinations of type- $2 \mathrm{c} 1+\mathrm{c} 2$ combinations $=\sum$ niv $=0$ to floor function of $[\{(2 \mathrm{k}-35) /(7 * 30)\}$ $(13 / 30)]$ floor function of $\left[(2 \mathrm{k}-35) /\left\{\left(13+30 \mathrm{n}^{\mathrm{iv}}\right) * 30\right\}-(7 / 30)\right]$

\section{Case(3B-ivB-iv)}

For $\operatorname{SADN}(5,2,8) / / 3 \times \operatorname{SADN}(5,2,8) / / 7:-$

$\left(23+30 n^{\mathrm{vi}}\right) \times\left(17+30 \mathrm{n}^{\mathrm{vii}}\right)<=(2 \mathrm{k}-35)$

Number of combinations of type- $2 \mathrm{c} 1+\mathrm{c} 2$ combinations $=\sum$ niv $=0$ to floor function of $[\{(2 \mathrm{k}-35) /(17 * 30)\}$ $(23 / 30)]$ floor function of $\left[(2 \mathrm{k}-35) /\left\{\left(23+30 \mathrm{n}^{\mathrm{iv}}\right) * 30\right\}-(17 / 30)\right]$

\section{Case(3B-ivB-v)}

For $[\operatorname{SADN}(7,4,1) / / 9] \times[\operatorname{SADN}(7,4,1) / / 9]:-$

$(19+30 \mathrm{n}) \times\left(19+30 \mathrm{n}^{\prime}\right)<=(2 \mathrm{k}-35)$

Number of combinations of type- $2 \mathrm{c} 1+\mathrm{c} 2$ combinations $=\sum \mathrm{n}=0$ to floor function of $[\{(2 \mathrm{k}-35) /(19 * 30)\}-$ (19/30)] floor function of $[(2 \mathrm{k}-35) /\{(19+30 \mathrm{n}) * 30\}-(19 / 30)]$ 


\title{
Case(3B-ivB-vi)
}

For $[\operatorname{SADN}(5,2,8) / / 9] \times[\operatorname{SADN}(5,2,8) / / 9]:-$

$(29+30 \mathrm{n}, ') \times(29+30 \mathrm{n}, ')<=(2 \mathrm{k}-35)$

Number of combinations of type- $2 \mathrm{c} 1+\mathrm{c} 2$ combinations $=\sum_{\mathrm{n}}$ " $=0$ to floor function of $[\{(2 \mathrm{k}-35) /(29 * 30)\}-$ $(29 / 30)]$ floor function of $[(2 \mathrm{k}-35) /\{(29+30 \mathrm{n}) * 30\}-,(29 / 30)]$

\section{Case(3B-v):}

$\mathrm{EN}=\operatorname{SADN}(6,3,9 / / 8)$

Here $\mathrm{EN}=\operatorname{SADN}(6,3,9 / / 6)$ includes even numbers having $\operatorname{SADN}(6,3,9)$ and last digit as 8

$\operatorname{Case}(3 B-v-A) \quad \operatorname{C} 1[\operatorname{SADN}(7,4,1) / / 5]+\mathrm{C} 2[\operatorname{SADN}(5,2,8) / / 3]=2 \mathrm{k}$

Case(3B-v-B) $\quad \mathrm{C} 1[\operatorname{SADN}(5,2,8) / / 5]+\mathrm{C} 2[\operatorname{SADN}(7,4,1) / / 3]=2 \mathrm{k}$

\author{
Case(3B-v-A) \\ $\mathrm{C} 1[\operatorname{SADN}(7,4,1) / / 5]+\mathrm{C} 2[\operatorname{SADN}(5,2,8) / / 3]=2 \mathrm{k}$ \\ $25+\mathrm{C} 2[\operatorname{SADN}(5,2,8) / / 3]=2 \mathrm{k}$ \\ Or $\quad \mathrm{C} 2[\operatorname{SADN}(5,2,8) / / 3]=2 \mathrm{k}-25$
}

For C2[SADN $(5,2,8) / / 3]$ implies that $/ / 1 \mathrm{x} / / 3$ OR $/ / 7 \mathrm{x} / / 9$

With Reference from Cases(1BC-vA-i) upto (1BC-vA-iv):-

\section{Case(3B-vA-i)}

For $\operatorname{SADN}(7,4,1) / / 1$ x $\operatorname{SADN}(5,2,8) / / 3:-$

$$
(31+30 n) \times\left(23+30 n^{\prime}\right)<=(2 k-25)
$$

Number of combinations of type- $2 \mathrm{c} 1+\mathrm{c} 2$ combinations $=\sum \mathrm{n}=0$ to floor function of $[\{(2 \mathrm{k}-25) /(23 * 30)\}-$ $(31 / 30)]$ floor function of $[(2 \mathrm{k}-25) /\{(31+30 \mathrm{n}) * 30\}-(23 / 30)]$

\section{Case(3B-vA-ii)}

For $\operatorname{SADN}(5,2,8) / / 1$ x $\operatorname{SADN}(7,4,1) / / 3:-$

$$
\left(11+30 \text { n') } \times\left(13+30 n^{\prime \prime \prime}\right)<=(2 k-25)\right.
$$


Number of combinations of type- $2 \mathrm{c} 1+\mathrm{c} 2$ combinations $=\sum \mathrm{n} "=0$ to floor function of $\left[\left\{(2 \mathrm{k}-25) /\left(13^{*} 30\right)\right\}-\right.$ $(11 / 30)]$ floor function of $\left[(2 \mathrm{k}-25) /\left\{(11+30 \mathrm{n},)^{*} 30\right\}-(13 / 30)\right]$

\section{Case(3B-vA-iii)}

For $\operatorname{SADN}(7,4,1) / / 7$ x $\operatorname{SADN}(5,2,8) / / 9:-$

$$
\left(7+30 n^{\text {iv }}\right) \times\left(29+30 n^{\mathrm{v}}\right)<=(2 \mathrm{k}-25)
$$

Number of combinations of type- $2 \mathrm{c} 1+\mathrm{c} 2$ combinations $=\sum$ niv $=0$ to floor function of $[\{(2 \mathrm{k}-25) /(29 * 30)\}$ (7/30)] floor function of $\left[(2 \mathrm{k}-25) /\left\{\left(7+30 \mathrm{n}^{\mathrm{iv}}\right) * 30\right\}-(29 / 30)\right]$

\section{Case(3B-vA-iv)}

For $\operatorname{SADN}(5,2,8) / / 7 \times \operatorname{SADN}(7,4,1) / / 9$ :-

$$
\left(17+30 \mathrm{n}^{\mathrm{vi}}\right) \times\left(19+30 \mathrm{n}^{\mathrm{vii}}\right)<=(2 \mathrm{k}-25)
$$

Number of combinations of type- $2 \mathrm{c} 1+\mathrm{c} 2$ combinations $=\sum$ niv $=0$ to floor function of $[\{(2 \mathrm{k}-25) /(19 * 30)\}-$ (17/30)] floor function of $\left[(2 \mathrm{k}-25) /\left\{\left(17+30 \mathrm{n}^{\mathrm{iv}}\right) * 30\right\}-(19 / 30)\right]$

\section{Case(3B-v-B)}

$\mathrm{C} 1[\operatorname{SADN}(5,2,8) / / 5]+\mathrm{C} 2[\operatorname{SADN}(7,4,1) / / 3]=2 \mathrm{k}$

$35+\mathrm{C} 2[\operatorname{SADN}(7,4,1) / / 3]=2 \mathrm{k}$

Or $\quad \mathrm{C} 2[\operatorname{SADN}(7,4,1) / / 3]=2 \mathrm{k}-35$

For C2[SADN $(7,4,1) / / 3]$ implies that $/ / 1 \mathrm{x} / / 3$ OR $/ / 7 \mathrm{x} / / 9$

With Reference from Cases(2BC-vB-i) upto (2BC-vB-iv):-

\section{Case(3B-vB-i)}

For $\operatorname{SADN}(7,4,1) / / 1$ x $\operatorname{SADN}(7,4,1) / / 3:-$

$(31+30 \mathrm{n}) \times\left(13+30 \mathrm{n}^{\prime}\right)<=(2 \mathrm{k}-35)$

Number of combinations of type- $2 \mathrm{c} 1+\mathrm{c} 2$ combinations $=\sum \mathrm{n}=0$ to floor function of $[\{(2 \mathrm{k}-35) /(13 * 30)\}-$ (31/30)] floor function of $[(2 \mathrm{k}-35) /\{(31+30 \mathrm{n}) * 30\}-(13 / 30)]$

\section{Case(3B-vB-ii)}


For $\operatorname{SADN}(5,2,8) / / 1$ x $\operatorname{SADN}(5,2,8) / / 3:-$

$\left(11+30 n^{\prime \prime}\right) \times\left(23+30 n^{\prime \prime \prime}\right)<=(2 k-35)$

Number of combinations of type- $2 \mathrm{c} 1+\mathrm{c} 2$ combinations $=\sum_{\mathrm{n}}$ " $=0$ to floor function of $[\{(2 \mathrm{k}-35) /(23 * 30)\}$ $(11 / 30)]$ floor function of $\left[(2 \mathrm{k}-35) /\left\{(11+30 \mathrm{n},)^{*} * 30\right\}-(23 / 30)\right]$

\section{Case(3B-vB-iii)}

For $\operatorname{SADN}(7,4,1) / / 7$ x $\operatorname{SADN}(7,4,1) / / 9:-$

$\left(7+30 \mathrm{n}^{\mathrm{iv}}\right) \times\left(19+30 \mathrm{n}^{\mathrm{v}}\right)<=(2 \mathrm{k}-35)$

Number of combinations of type- $2 \mathrm{c} 1+\mathrm{c} 2$ combinations $=\sum$ niv $=0$ to floor function of $[\{(2 \mathrm{k}-35) /(19 * 30)\}-$ (7/30)] floor function of $\left[(2 \mathrm{k}-35) /\left\{\left(7+30 \mathrm{n}^{\mathrm{iv}}\right) * 30\right\}-(19 / 30)\right]$

\section{Case(3B-vB-iv)}

For $\operatorname{SADN}(5,2,8) / / 7$ x $\operatorname{SADN}(5,2,8) / / 9:-$

$\left(17+30 n^{\mathrm{vi}}\right) \times\left(29+30 \mathrm{n}^{\mathrm{vii}}\right)<=(2 \mathrm{k}-35)$

Number of combinations of type- $2 \mathrm{c} 1+\mathrm{c} 2$ combinations $=\sum$ niv $=0$ to floor function of $[\{(2 \mathrm{k}-35) /(29 * 30)\}$ (17/30)] floor function of $\left[(2 \mathrm{k}-35) /\left\{\left(17+30 \mathrm{n}^{\mathrm{iv}}\right) * 30\right\}-(2 \mathrm{ss} 9 / 30)\right]$

\section{To find unique $\mathrm{C} 1+\mathrm{C} 2$ combination for a given even number:}

Consider the even number 16658, i.e. SADN8//8 and its relevant series is S7 series.

In this case, composites would be derived as intraseries products of elements of S5 and S7 series. $c 1+c 2$ of type 2 would be in the nature of 5 -p where 5 and some other prime number (p) would be factors on either side of the combination.

Since $2 \mathrm{k}$ ends in 8 , composite odd numbers on the S7 series that end in ' 3 ' will find such $\mathrm{C}+\mathrm{C}$ combinations:

For S7 series: $7 \mathrm{x}(19+30 \mathrm{n}) \leq 7 \mathrm{x}(6 \mathrm{I}+1)$

ncc7; i.e. number of $\mathrm{c} 1+\mathrm{c} 2$ combinations identified by $7=[\{(6 \mathrm{I}+1)-19\} / 30]+1$

Similarly, ncc11; i.e. number of $c 1+c 2$ combinations identified by $11=[\{(6 \mathrm{I}-1)-23\} / 30]+1$

There would be some $\mathrm{c} 1+\mathrm{c} 2$ combinations derived by 11 that may have been already derived while calculating $\mathrm{c} 1+\mathrm{c} 2$ by 7 . The first such combination would have a composite number of 
which 7 is a factor, ends in 3 and lies on the S5 series. Thus the 4 conditions for such a common $\mathrm{c} 1+\mathrm{c} 2$ combination are that the composite component:-

i. $\quad$ Should be divisible by 7

ii. Should be a composite that ends in 3

iii. Should lie on the S5 series

iv. Should be greater than 11 in value

Such a number can be identified as follows:-

The number 7 ends in the digit 7 and will form a composite ending in 3 when multiplied with an odd number ending in 9. The first odd number on the S5 series that ends in 9 is 29. So $7 \times 29=203$ will be a number on the S5 series that will have to be removed from the $\mathrm{c}+\mathrm{c}$ combinations formed by 11 to avoid double/multiple counting. Thereafter every $7 \mathrm{x}(29+30 \mathrm{n})$ th number will be a number divisible by 7 , ending in 3 lying on the S5 series and greater than 11 and will have to be removed as long as its value is < 6I-1

Therefore numbers that need to be removed are obtained by the expression $=7(29+30 \mathrm{n}) \leq 6 \mathrm{I}-$ 1

i.e. $n^{\prime}(c 1+c 2)=$ floor function of $[\{(6 \mathrm{I}-1)-203\} / 210]+1$

General formula for identifying $\mathrm{c} 1+\mathrm{c} 2$ which have been already derived by previous prime elements:

$\mathrm{N}^{\prime}(\mathrm{c} 1+\mathrm{c} 2)\left(\mathrm{p}_{\mathrm{n}}=741\right)=\left[\left\{(6 \mathrm{I}+1)-\left(\mathrm{p}_{\mathrm{e}} \mathrm{x} \mathrm{p}_{\mathrm{a}}\right)\right\} / 30 \mathrm{p}_{\mathrm{e}}\right]+1$

$\mathrm{N}^{\prime}(\mathrm{c} 1+\mathrm{c} 2)\left(\mathrm{p}_{\mathrm{n}}=528\right)=\left[\left\{(6 \mathrm{I}-1)-\left(\mathrm{p}_{\mathrm{e}} \mathrm{x} \mathrm{p}_{\mathrm{a}}\right)\right\} / 30 \mathrm{p}_{\mathrm{e}}\right]+1$

$\mathrm{p}_{\mathrm{e}}<\mathrm{p}_{\mathrm{n}}<\mathrm{p}_{\mathrm{a}}$

- where n' $(\mathrm{c} 1+\mathrm{c} 2)$ will give the number of $\mathrm{c} 1+\mathrm{c} 2$ combinations derived for a particular prime $\mathrm{p}_{\mathrm{n}}$ which have already been derived by earlier prime elements $\mathrm{p}_{\mathrm{e}}$;

- $\mathrm{p}_{\mathrm{n}}$ is the current prime element for which $\mathrm{c} 1+\mathrm{c} 2$ is being derived;

- $\mathrm{p}_{\mathrm{e}}$ is the previous prime element for which such $\mathrm{c} 1+\mathrm{c} 2$ combination has been identified which are being repeated in case of $\mathrm{p}_{\mathrm{n}}$;

- $\quad \mathrm{p}_{\mathrm{a}}$ is the factor whose product with $\mathrm{p}_{\mathrm{e}}$ will give the first such composite component of $\mathrm{c} 1+\mathrm{c} 2$ which is common to $\mathrm{c} 1+\mathrm{c} 2$ derived by both $\mathrm{p}_{\mathrm{n}}$ and $\mathrm{p}_{\mathrm{e}}$.

While calculating unique $\mathrm{c} 1+\mathrm{c} 2$ formed by the number 13 , we first calculate $6 \mathrm{I}+1$ and remove those $\mathrm{c} 1+\mathrm{c} 2$ that have been already derived by 7 and 11 .

Total c1+c2 formed by 13 :

$$
\begin{aligned}
& (31+30 \mathrm{n}) \leq 6 \mathrm{I}+1 \\
& \mathrm{n} \leq[(6 \mathrm{I}+1)-31 / 30]+1
\end{aligned}
$$


Composites already formed by 7 :

There would be some $\mathrm{c} 1+\mathrm{c} 2$ combinations derived by 13 that may have been already derived while calculating $\mathrm{c} 1+\mathrm{c} 2$ by 7 . The first such combination would have a composite number of which 7 is a factor, ends in digit 1 and lies on the S7 series. Thus the 4 conditions for such a common $\mathrm{c} 1+\mathrm{c} 2$ combination are that the composite component:-

i. $\quad$ Should be divisible by 7

ii. Should be a composite that ends in 1

iii. Should lie on the $\mathrm{S} 7$ series since 13 is on $\mathrm{S} 7$ series

iv. Should be greater than 13 in value

v. Should be smaller than $6 \mathrm{I}+1$

Such a number can be identified as follows:-

The number 7 ends in the digit 7 and will form a composite ending in 1 when multiplied with an odd number ending in 3. The first odd number on the S7 series that ends in 3 is 13. So $7 \times 13=91$ will be a number on the S7 series that will have to be removed from the $\mathrm{c} 1+\mathrm{c} 2$ combinations formed by 13 to avoid double/multiple counting. Thereafter every $7 \mathrm{x}(13+30 \mathrm{n})$ th number will be a number divisible by 7 , ending in 1 lying on the $\mathrm{S} 7$ series and greater than 13 and will have to be removed as long as its value is $<6 \mathrm{I}+1$

Therefore numbers that need to be removed are obtained by the expression $=7(13+30 \mathrm{n}) \leq$ $6 \mathrm{I}+1$

i.e. $n^{\prime}(c 1+c 2)=$ floor function of $[\{(6 \mathrm{I}+1)-91\} / 210]+1$

Composites already formed by 11 :

Applying the similar 5 conditions as mentioned above;

$$
\begin{aligned}
& 11(11+30 \mathrm{n}) \leq 6 \mathrm{I}+1 \\
& \mathrm{n} \leq[\{(6 \mathrm{I}+1)-121\} / 330]+1
\end{aligned}
$$

There would be some combination that may be common to both 7 and 11 and will be removed twice if not identified and adjusted accordingly. Just as it is important to avoid double- counting, it is equally important to avoid double removal.

\section{Conditions for identifying a combination that has been counted twice:-}

- Should be divisible by both 7 and 11 . So this number will by default be a multiple of 77 .

- Should end in a digit whose multiplication with 13 will end in 3. Therefore should end in 1. 
- Should be a number on the S7 series. Since 13 is an S7 element number and its multiplication with other S7 series numbers is being considered. Therefore such a number would be $77 \mathrm{x}$ S5 series number that ends in 3

$7 \times 11 \times 23=1771$

Hence 1771 will be the first such number on the S7 series which will be common to both 7 and 11 and needs to be added for arriving at unique $\mathrm{c} 1+\mathrm{c} 2$ for the number 13 . Thereafter every $(7 \mathrm{x} 11 \mathrm{x} 30)$ th number will satisfy the condition . The general condition therefore is:

$77(23+30 n) \leq 6 \mathrm{I}+1$

Or $\mathrm{n} \leq[\{(6 \mathrm{I}+1)-1771\} / 2310]+1$

This number needs to be added to avoid double subtraction.

Suppose we denote the number of $\mathrm{c} 1+\mathrm{c} 2$ combinations that are common to two previous prime elements and are therefore been removed twice, as n' $(\mathrm{c} 1+\mathrm{c} 2)$. The number of such $\mathrm{c} 1+\mathrm{c} 2$ combinations would be:

$n^{\prime}(c 1+c 2)=\left[\left\{(6 \mathrm{I}-1)-\mathrm{p}_{\mathrm{e} 1} \mathrm{p}_{\mathrm{e} 2} \mathrm{p}_{\mathrm{x}}\right\} / 30 \mathrm{p}_{\mathrm{e} 1} \mathrm{p}_{\mathrm{e} 2}\right]+1$

where $\mathrm{p}_{\mathrm{e} 1}$ and $\mathrm{p}_{\mathrm{e} 2}$ are two previous prime elements for which common $\mathrm{c} 1+\mathrm{c} 2$ combinations are being identified.

$\mathrm{p}_{\mathrm{x}}$ is the factor whose product with $\mathrm{p}_{\mathrm{e} 1} \mathrm{p}_{\mathrm{e} 2}$ will give first such common composite component.

\section{In general terms:}

In order to avoid double counting of the same $\mathrm{c} 1+\mathrm{c} 2$ the following conditions have been identified:-

pn is prime factor of the composite component of $\mathrm{c} 1+\mathrm{c} 2$ combination

pe is earlier prime element of the relevant series for which $\mathrm{c} 1+\mathrm{c} 2$ combination identified for $\mathrm{p}_{\mathrm{n}}$ have already been derived i.e. while deriving $\mathrm{c} 1+\mathrm{c} 2$ for $\mathrm{p}_{\mathrm{n}}$, some $\mathrm{c} 1+\mathrm{c} 2$ will be such that they have already been identified for previous elements $p_{e}$ where value of e may range from 1 to $n-1$. These needs to be identified on the basis of following:-

- $\quad$ SADN and last digit of $2 \mathrm{k}$

- $\quad$ SADN and last digit of $\mathrm{p}_{\mathrm{n}}$ and $\mathrm{p}_{\mathrm{e}}$

- Series (S1 or S5) on which $\mathrm{p}_{\mathrm{n}}$ lies

- Relevant series for $2 \mathrm{k}$

We will first consider the case of $2 \mathrm{k}=\operatorname{SADN}(5,2,8)$ which implies that relevant series on which $\mathrm{c} 1+\mathrm{c} 2$ are to be identified is the $\mathrm{S} 7$ series.

For $\mathrm{p}_{\mathrm{n}}$ on $\mathrm{S} 5$ series:

$N^{\prime}(c 1+c 2)=\left[\left\{(6 \mathrm{I}-1)-\left(\mathrm{p}_{\mathrm{e}} \times \mathrm{p}_{\mathrm{a}}\right)\right\} / 30 \mathrm{p}_{\mathrm{e}}\right]+1$ 
For $\mathrm{p}_{\mathrm{n}}$ on $\mathrm{S} 7$ series:

$\mathrm{N}^{\prime}(\mathrm{c} 1+\mathrm{c} 2)=\left[\left\{(6 \mathrm{I}+1)-\left(\mathrm{p}_{\mathrm{e}} \mathrm{x} \mathrm{p}_{\mathrm{a}}\right)\right\} / 30 \mathrm{p}_{\mathrm{e}}\right]+1$

$\operatorname{SADN}(5,2,8) / / 2:$

$\mathrm{p}_{\mathrm{n}} / / 1$ for which $\mathrm{n}(\mathrm{c} 1+\mathrm{c} 2)$ is being calculated

$\mathrm{p}_{\mathrm{e}}=$ earlier prime elements where $\mathrm{p}_{\mathrm{e}}<\mathrm{p}_{\mathrm{n}} \mathrm{C} 1+\mathrm{c} 2$ identified for $\mathrm{p}_{\mathrm{n}}$ which have already been derived by $\mathrm{p}_{\mathrm{e}}$

$\mathrm{p}_{\mathrm{a}}=$ element whose product with $\mathrm{p}_{\mathrm{e}}$ will give the first composite of $\mathrm{c} 1+\mathrm{c} 2$ that has already been identified for $\mathrm{p}_{\mathrm{e}}$ and is being repeated in $\mathrm{p}_{\mathrm{n}}$.

In order to find unique $1+c 2$ combinations; we introduce the following matrix:

$\begin{array}{llllll}\text { First row i.e. } & \text { R1: } & 1 & 7 & 3 & 9\end{array}$

$\begin{array}{llllll}\text { Second row i.e. } & \text { R2: } & 7 & 9 & 1 & 3\end{array}$

$\begin{array}{llllll}\text { Third row i.e. } & \text { R3: } & 3 & 1 & 9 & 7\end{array}$

$\begin{array}{llllll}\text { Fourth row i.e. } & \text { R4: } & 9 & 3 & 7 & 1\end{array}$

We further introduce a term 'A'; which would follow a sequence of 1,3,7 and 9

There would be a prefix ( 5 or 7 ) before $\mathrm{R}$ and A. This prefix indicates the series of S5 or S7; implies that:

5//R1 means $\quad 5 / / 1 ; \quad 5 / / 7 ; \quad 5 / / 3$ and $5 / / 9$

Similarly 7//A means $\quad 7 / / 1 ; \quad 7 / / 3 ; \quad 7 / / 7$ and $7 / / 9$

The correspondence between $\mathrm{R}$ and A would be as shown in the following table:

\begin{tabular}{|c|c|}
\hline 5//A & 5//R1 \\
\hline $5 / / 1$ & $5 / / 1$ \\
\hline $5 / / 3$ & $5 / / 7$ \\
\hline $5 / / 7$ & $5 / / 3$ \\
\hline $5 / / 9$ & $5 / / 9$ \\
\hline
\end{tabular}

Table 11B.3: Correspondence between $R$ and $A$ considering specific example of R1

In order to identify and remove $\mathrm{c} 1+\mathrm{c} 2$ already derived by previous elements:

$\mathrm{p}_{\mathrm{n}}=$ the prime factor of the composite component of $\mathrm{c} 1+\mathrm{c} 2$ combination

$\mathrm{p}_{\mathrm{e}}=$ earlier prime elements where $\mathrm{p}_{\mathrm{e}}<\mathrm{p}_{\mathrm{n}} . \mathrm{C} 1+\mathrm{c} 2$ identified for $\mathrm{p}_{\mathrm{n}}$ which have already been derived by $p_{e}$ 
$\mathrm{p}_{\mathrm{a}}=$ such a factor whose product with $\mathrm{p}_{\mathrm{e}}$ will give the first such composite component which is a part of $\mathrm{c} 1+\mathrm{c} 2$ combination and the same $\mathrm{c} 1+\mathrm{c} 2$ combination is being identified (or repeated) for deriving $\mathrm{c} 1+\mathrm{c} 2$ wherein $\mathrm{p}_{\mathrm{n}}$ is a factor of component composites $\mathbf{O R}$ element whose product with $\mathrm{p}_{\mathrm{e}}$ will give the first composite of $\mathrm{c} 1+\mathrm{c} 2$ that has already been identified for $\mathrm{p}_{\mathrm{e}}$ and is being repeated in $\mathrm{p}_{\mathrm{n}}$.

We would now express the number of $\mathrm{c} 1+\mathrm{c} 2$ combinations in terms of the above matrix. We begin by derivation of total number of $\mathrm{c} 1+\mathrm{c} 2$ as below.

General conditions for identifying number of $\mathrm{c} 1+\mathrm{c} 2$ combinations of type 2 in which a prime element denoted as $\mathrm{p}_{\mathrm{n}}$ is a factor of composite components may be summarised as :-

$\mathrm{N}(\mathrm{c}+\mathrm{c})$ for $\mathrm{p}_{\mathrm{n}}=[\{(6 \mathrm{I} \pm 1)-\mathrm{d}\} / 30]+1$

Here $d$ is the factor of the first such composite component such that $p_{n} x d$ forms part of first $\mathrm{c} 1+\mathrm{c} 2$ combination for $\mathrm{p}_{\mathrm{n}}$.

In order to find value of ' $d$ ', we draw the following table:

\begin{tabular}{|c|c|c|}
\hline $\begin{array}{l}\text { Series and } \\
\text { last digit of } \\
\text { Pn }\end{array}$ & \multicolumn{2}{|c|}{ Finding value of 'd' for 2k of:- } \\
\hline & SADN(5,2,8)//2 & SADN(7,4,1)//2 \\
\hline 5//A & $5 / / R 2$ & $7 / / \mathrm{R} 2$ \\
\hline $7 / / \mathrm{A}$ & $7 / / \mathrm{R} 2$ & $5 / / \mathrm{R} 2$ \\
\hline
\end{tabular}

\begin{tabular}{|c|c|c|}
\hline $\begin{array}{l}\text { Series and } \\
\text { last digit of } \\
\text { Pn }\end{array}$ & \multicolumn{2}{|c|}{ Finding value of 'd' for 2k of:- } \\
\hline & SADN(5,2,8)//4 & SADN(7,4,1)//4 \\
\hline $5 / / \mathrm{A}$ & $5 / / \mathrm{R} 4$ & $7 / / \mathrm{R} 4$ \\
\hline $7 / / \mathrm{A}$ & $7 / / \mathrm{R} 4$ & $5 / / \mathrm{R} 4$ \\
\hline
\end{tabular}

\begin{tabular}{|c|c|c|}
\hline $\begin{array}{l}\text { Series and } \\
\text { last digit of } \\
\text { Pn }\end{array}$ & \multicolumn{2}{|c|}{ Finding value of 'd' for 2k of:- } \\
\hline & $\operatorname{SADN}(5,2,8) / / 6$ & $\operatorname{SADN}(7,4,1) / / 6$ \\
\hline $5 / / \mathrm{A}$ & $5 / / \mathrm{R} 1$ & $7 / / \mathrm{R} 1$ \\
\hline $7 / / \mathrm{A}$ & $7 / / \mathrm{R} 1$ & $5 / / \mathrm{R} 1$ \\
\hline
\end{tabular}

\begin{tabular}{|l|l|}
\hline Series and & Finding value of 'd' for 2k of:- \\
last digit of & \\
Pn & \\
\hline
\end{tabular}




\begin{tabular}{|c|c|c|}
\hline & SADN(5,2,8)//8 & SADN(7,4,1)//8 \\
\hline 5//A & $5 / / \mathrm{R} 3$ & $7 / / \mathrm{R} 3$ \\
\hline 7//A & $7 / / \mathrm{R} 3$ & $5 / / \mathrm{R} 3$ \\
\hline
\end{tabular}

Note:

I. $\quad \mathrm{d}>\mathrm{p}_{\mathrm{n}}$ in all cases.

II. Whether we need to consider the term $6 \mathrm{I}+1$ or $6 \mathrm{I}-1$ would depend on the SADN of the even number and thereby its relevant series. This is summarized in the following table:

\begin{tabular}{|l|l|l|}
\hline SADN of $2 \mathrm{k}$ & SADN of $\mathrm{p}_{\mathrm{n}}$ & $\begin{array}{l}\text { Whether } 6 \mathrm{I}+1 \text { or } 6 \mathrm{I}- \\
1\end{array}$ \\
\hline $2,5,8$ & $2,5,8$ & $6 \mathrm{I}-1$ \\
\hline $7,4,1$ & $2,5,8$ & $6 \mathrm{I}+1$ \\
\hline $2,5,8$ & $7,4,1$ & $6 \mathrm{I}+1$ \\
\hline $7,4,1$ & $7,4,1$ & $6 \mathrm{I}-1$ \\
\hline
\end{tabular}

In order to identify and remove $\mathrm{c} 1+\mathrm{c} 2$ already derived by previous elements:

\begin{tabular}{|l|l|l|l|l|l|l|l|l|}
\hline $\begin{array}{l}\text { Series } \\
\text { and last } \\
\text { digit of } \\
\mathrm{P}_{\mathrm{e}}\end{array}$ & \multicolumn{7}{|c|}{ Finding value of $\mathrm{p}_{\mathrm{a}}$ for 2k=SADN(5,2,8)//2 } \\
\hline & $\mathrm{Pn}=5 / / 1$ & $\mathrm{Pn}=7 / / 1$ & $\mathrm{Pn}=5 / / 3$ & $\mathrm{Pn}=7 / / 3$ & $\mathrm{Pn}=5 / / 7$ & $\mathrm{Pn}=7 / / 7$ & $\mathrm{Pn}=5 / / 9$ & $\mathrm{Pn}=7 / / 9$ \\
\hline 7//A & $5 / / \mathrm{R} 2$ & $7 / / \mathrm{R} 2$ & $5 / / \mathrm{R} 4$ & $7 / / \mathrm{R} 4$ & $5 / / \mathrm{R} 1$ & $7 / / \mathrm{R} 1$ & $5 / / \mathrm{R} 3$ & $7 / / \mathrm{R} 3$ \\
\hline 5//A & $7 / / \mathrm{R} 2$ & $5 / / \mathrm{R} 2$ & $7 / / \mathrm{R} 4$ & $5 / / \mathrm{R} 4$ & $7 / / \mathrm{R} 1$ & $5 / / \mathrm{R} 1$ & $7 / / \mathrm{R} 3$ & $5 / / \mathrm{R} 3$ \\
\hline
\end{tabular}

\begin{tabular}{|l|l|l|l|l|l|l|l|l|}
\hline $\begin{array}{l}\text { Series } \\
\text { and last } \\
\text { digit of } \\
\text { Pe }\end{array}$ & \multicolumn{7}{|c|}{ Finding value of pa for 2k=SADN(5,2,8)//4 } \\
\hline & $\mathrm{Pn}=5 / / 1$ & $\mathrm{Pn}=7 / / 1$ & $\mathrm{Pn}=5 / / 3$ & $\mathrm{Pn}=7 / / 3$ & $\mathrm{Pn}=5 / / 7$ & $\mathrm{Pn}=7 / / 7$ & $\mathrm{Pn}=5 / / 9$ & $\mathrm{Pn}=7 / / 9$ \\
\hline $7 / / \mathrm{A}$ & $5 / / \mathrm{R} 4$ & $7 / / \mathrm{R} 4$ & $5 / / \mathrm{R} 3$ & $7 / / \mathrm{R} 3$ & $5 / / \mathrm{R} 2$ & $7 / / \mathrm{R} 2$ & $5 / / \mathrm{R} 1$ & $7 / / \mathrm{R} 1$ \\
\hline $5 / / \mathrm{A}$ & $7 / / \mathrm{R} 4$ & $5 / / \mathrm{R} 4$ & $7 / / \mathrm{R} 3$ & $5 / / \mathrm{R} 3$ & $7 / / \mathrm{R} 2$ & $5 / / \mathrm{R} 2$ & $7 / / \mathrm{R} 1$ & $5 / / \mathrm{R} 1$ \\
\hline
\end{tabular}

\begin{tabular}{|l|l|}
\hline $\begin{array}{l}\text { Series } \\
\text { and last }\end{array}$ & Finding value of pa for $2 \mathrm{k}=\operatorname{SADN}(5,2,8) / / 6$ \\
digit of & \\
Pe & \\
\hline
\end{tabular}

43 [Section 11: 11B] 


\begin{tabular}{|l|l|l|l|l|l|l|l|l|}
\hline & $\mathrm{Pn}=5 / / 1$ & $\mathrm{Pn}=7 / / 1$ & $\mathrm{Pn}=5 / / 3$ & $\mathrm{Pn}=7 / / 3$ & $\mathrm{Pn}=5 / / 7$ & $\mathrm{Pn}=7 / / 7$ & $\mathrm{Pn}=5 / / 9$ & $\mathrm{Pn}=7 / / 9$ \\
\hline 7//A & $5 / / \mathrm{R} 1$ & $7 / / \mathrm{R} 1$ & $5 / / \mathrm{R} 2$ & $7 / / \mathrm{R} 2$ & $5 / / \mathrm{R} 3$ & $7 / / \mathrm{R} 3$ & $5 / / \mathrm{R} 4$ & $7 / / \mathrm{R} 4$ \\
\hline 5//A & $7 / / \mathrm{R} 1$ & $5 / / \mathrm{R} 1$ & $7 / / \mathrm{R} 2$ & $5 / / \mathrm{R} 2$ & $7 / / \mathrm{R} 3$ & $5 / / \mathrm{R} 3$ & $7 / / \mathrm{R} 4$ & $5 / / \mathrm{R} 4$ \\
\hline
\end{tabular}

\begin{tabular}{|l|l|l|l|l|l|l|l|l|}
\hline $\begin{array}{l}\text { Series } \\
\text { and last } \\
\text { digit of } \\
\mathrm{Pe}\end{array}$ & \multicolumn{7}{|c|}{ Finding value of pa for 2k=SADN(5,2,8)//8 } \\
\hline & $\mathrm{Pn}=5 / / 1$ & $\mathrm{Pn}=7 / / 1$ & $\mathrm{Pn}=5 / / 3$ & $\mathrm{Pn}=7 / / 3$ & $\mathrm{Pn}=5 / / 7$ & $\mathrm{Pn}=7 / / 7$ & $\mathrm{Pn}=5 / / 9$ & $\mathrm{Pn}=7 / / 9$ \\
\hline $7 / / \mathrm{A}$ & $5 / / \mathrm{R} 3$ & $7 / / \mathrm{R} 3$ & $5 / / \mathrm{R} 1$ & $7 / / \mathrm{R} 1$ & $5 / / \mathrm{R} 4$ & $7 / / \mathrm{R} 4$ & $5 / / \mathrm{R} 2$ & $7 / / \mathrm{R} 2$ \\
\hline $5 / / \mathrm{A}$ & $7 / / \mathrm{R} 3$ & $5 / / \mathrm{R} 3$ & $7 / / \mathrm{R} 1$ & $5 / / \mathrm{R} 1$ & $7 / / \mathrm{R} 4$ & $5 / / \mathrm{R} 4$ & $7 / / \mathrm{R} 2$ & $5 / / \mathrm{R} 2$ \\
\hline
\end{tabular}

\begin{tabular}{|l|l|l|l|l|l|l|l|l|}
\hline $\begin{array}{l}\text { Series } \\
\text { and last } \\
\text { digit of } \\
\text { Pe }\end{array}$ & \multicolumn{7}{|c|}{ Finding value of pa for 2k=SADN(7,4,1)//2 } \\
\hline & $\mathrm{Pn}=5 / / 1$ & $\mathrm{Pn}=7 / / 1$ & $\mathrm{Pn}=5 / / 3$ & $\mathrm{Pn}=7 / / 3$ & $\mathrm{Pn}=5 / / 7$ & $\mathrm{Pn}=7 / / 7$ & $\mathrm{Pn}=5 / / 9$ & $\mathrm{Pn}=7 / / 9$ \\
\hline 7//A & $7 / / \mathrm{R} 2$ & $5 / / \mathrm{R} 2$ & $7 / / \mathrm{R} 4$ & $5 / / \mathrm{R} 4$ & $7 / / \mathrm{R} 1$ & $5 / / \mathrm{R} 1$ & $7 / / \mathrm{R} 3$ & $5 / / \mathrm{R} 3$ \\
\hline 5//A & $5 / / \mathrm{R} 2$ & $7 / / \mathrm{R} 2$ & $5 / / \mathrm{R} 4$ & $7 / / \mathrm{R} 4$ & $5 / / \mathrm{R} 1$ & $7 / / \mathrm{R} 1$ & $5 / / \mathrm{R} 3$ & $7 / / \mathrm{R} 3$ \\
\hline
\end{tabular}

\begin{tabular}{|l|l|l|l|l|l|l|l|l|}
\hline $\begin{array}{l}\text { Series } \\
\text { and last } \\
\text { digit of } \\
\mathrm{Pe}\end{array}$ & \multicolumn{7}{|c|}{ Finding value of pa for 2k=SADN(7,4,1)//4 } \\
\hline & $\mathrm{Pn}=5 / / 1$ & $\mathrm{Pn}=7 / / 1$ & $\mathrm{Pn}=5 / / 3$ & $\mathrm{Pn}=7 / / 3$ & $\mathrm{Pn}=5 / / 7$ & $\mathrm{Pn}=7 / / 7$ & $\mathrm{Pn}=5 / / 9$ & $\mathrm{Pn}=7 / / 9$ \\
\hline $7 / / \mathrm{A}$ & $7 / / \mathrm{R} 4$ & $5 / / \mathrm{R} 4$ & $7 / / \mathrm{R} 3$ & $5 / / \mathrm{R} 3$ & $7 / / \mathrm{R} 2$ & $5 / / \mathrm{R} 2$ & $7 / / \mathrm{R} 1$ & $5 / / \mathrm{R} 1$ \\
\hline $5 / / \mathrm{A}$ & $5 / / \mathrm{R} 4$ & $7 / / \mathrm{R} 4$ & $5 / / \mathrm{R} 3$ & $7 / / \mathrm{R} 3$ & $5 / / \mathrm{R} 2$ & $7 / / \mathrm{R} 2$ & $5 / / \mathrm{R} 1$ & $7 / / \mathrm{R} 1$ \\
\hline
\end{tabular}

\begin{tabular}{|l|l|l|l|l|l|l|l|l|}
\hline $\begin{array}{l}\text { Series } \\
\text { and last } \\
\text { digit of } \\
\mathrm{P}_{\mathrm{e}}\end{array}$ & \multicolumn{7}{|c|}{ Finding value of $\mathrm{p}_{\mathrm{a}}$ for 2k=SADN(7,4,1)//6 } \\
\hline & $\mathrm{Pn}=5 / / 1$ & $\mathrm{Pn}=7 / / 1$ & $\mathrm{Pn}=5 / / 3$ & $\mathrm{Pn}=7 / / 3$ & $\mathrm{Pn}=5 / / 7$ & $\mathrm{Pn}=7 / / 7$ & $\mathrm{Pn}=5 / / 9$ & $\mathrm{Pn}=7 / / 9$ \\
\hline $7 / / \mathrm{A}$ & $7 / / \mathrm{R} 1$ & $5 / / \mathrm{R} 1$ & $7 / / \mathrm{R} 2$ & $5 / / \mathrm{R} 2$ & $7 / / \mathrm{R} 3$ & $5 / / \mathrm{R} 3$ & $7 / / \mathrm{R} 4$ & $5 / / \mathrm{R} 4$ \\
\hline $5 / / \mathrm{A}$ & $5 / / \mathrm{R} 1$ & $7 / / \mathrm{R} 1$ & $5 / / \mathrm{R} 2$ & $7 / / \mathrm{R} 2$ & $5 / / \mathrm{R} 3$ & $7 / / \mathrm{R} 3$ & $5 / / \mathrm{R} 4$ & $7 / / \mathrm{R} 4$ \\
\hline
\end{tabular}

\begin{tabular}{|l|l|}
\hline Series & Finding value of $\mathrm{p}_{\mathrm{a}}$ for $2 \mathrm{k}=\operatorname{SADN}(7,4,1) / / 8$ \\
and last & \\
digit of & \\
$\mathrm{P}_{\mathrm{e}}$ & \\
\hline
\end{tabular}

\footnotetext{
44 [Section 11: 11B]
} 


\begin{tabular}{|l|l|l|l|l|l|l|l|l|}
\hline & $\mathrm{Pn}=5 / / 1$ & $\mathrm{Pn}=7 / / 1$ & $\mathrm{Pn}=5 / / 3$ & $\mathrm{Pn}=7 / / 3$ & $\mathrm{Pn}=5 / / 7$ & $\mathrm{Pn}=7 / / 7$ & $\mathrm{Pn}=5 / / 9$ & $\mathrm{Pn}=7 / / 9$ \\
\hline 7//A & $7 / / \mathrm{R} 3$ & $5 / / \mathrm{R} 3$ & $7 / / \mathrm{R} 1$ & $5 / / \mathrm{R} 1$ & $7 / / \mathrm{R} 4$ & $5 / / \mathrm{R} 4$ & $7 / / \mathrm{R} 2$ & 5//R2 \\
\hline 5//A & $5 / / \mathrm{R} 3$ & $7 / / \mathrm{R} 3$ & $5 / / \mathrm{R} 1$ & $7 / / \mathrm{R} 1$ & $5 / / \mathrm{R} 4$ & $7 / / \mathrm{R} 4$ & $5 / / \mathrm{R} 2$ & $7 / / \mathrm{R} 2$ \\
\hline
\end{tabular}

\begin{tabular}{|l|l|l|l|l|l|l|l|l|}
\hline $\begin{array}{l}\text { Series } \\
\text { and } \\
\text { last } \\
\text { digit } \\
\text { of } \mathrm{P}_{\mathrm{n}}\end{array}$ & \multicolumn{7}{|c|}{ Finding value of $\mathrm{p}_{\mathrm{x}}$ for $\mathrm{p}_{\mathrm{e}}{ }^{\prime}=7$ and $\mathrm{p}_{\mathrm{e}}{ }^{\prime \prime}=7$} \\
\hline & $2 \mathrm{k}=$ & $2 \mathrm{k}=$ & $2 \mathrm{k}=$ & $2 \mathrm{k}=$ & $2 \mathrm{k}=$ & $2 \mathrm{k}=$ & $2 \mathrm{k}=$ & $2 \mathrm{k}=$ \\
& $\mathrm{SADN}$ & $\mathrm{SADN}$ & $\mathrm{SADN}$ & $\mathrm{SADN}$ & $\mathrm{SADN}$ & $\mathrm{SADN}$ & $\mathrm{SADN}$ & $\mathrm{SADN}$ \\
& $(5,2,8) / / 2$ & $(7,4,1) / / 2$ & $(5,2,8) / / 4$ & $(7,4,1)$ & $(5,2,8)$ & $(7,4,1)$ & $(5,2,8)$ & $(7,4,1)$ \\
& & & & $/ / 4$ & $/ / 6$ & $/ / 6$ & $/ / 8$ & $/ / 8$ \\
\hline $5 / / \mathrm{A}$ & $5 / / \mathrm{R} 3$ & $7 / / \mathrm{R} 3$ & $5 / / \mathrm{R} 1$ & $7 / / \mathrm{R} 1$ & $5 / / \mathrm{R} 4$ & $7 / / \mathrm{R} 4$ & $5 / / \mathrm{R} 2$ & $7 / / \mathrm{R} 2$ \\
\hline $7 / / \mathrm{A}$ & $7 / / \mathrm{R} 3$ & $5 / / \mathrm{R} 3$ & $7 / / \mathrm{R} 1$ & $5 / / \mathrm{R} 1$ & $7 / / \mathrm{R} 4$ & $5 / / \mathrm{R} 4$ & $7 / / \mathrm{R} 2$ & $5 / / \mathrm{R} 2$ \\
\hline
\end{tabular}

\begin{tabular}{|l|l|l|l|l|l|l|l|l|}
\hline $\begin{array}{l}\text { Series } \\
\text { and } \\
\text { last } \\
\text { digit } \\
\text { of } \mathrm{P}_{\mathrm{n}}\end{array}$ & \multicolumn{7}{|c|}{ Finding value of $\mathrm{p}_{\mathrm{x}}$ for $\mathrm{p}_{\mathrm{e}}{ }^{\prime}=7$ and $\mathrm{p}_{\mathrm{e}}{ }^{\prime}=11$} \\
\hline & $2 \mathrm{k}=$ & $2 \mathrm{k}=$ & $2 \mathrm{k}=$ & $2 \mathrm{k}=$ & $2 \mathrm{k}=$ & $2 \mathrm{k}=$ & $2 \mathrm{k}=$ & $2 \mathrm{k}=$ \\
& $\mathrm{SADN}$ & $\mathrm{SADN}$ & $\mathrm{SADN}$ & $\mathrm{SADN}$ & $\mathrm{SADN}$ & $\mathrm{SADN}$ & $\mathrm{SADN}$ & $\mathrm{SADN}$ \\
& $(5,2,8) / / 2$ & $(7,4,1) / / 2$ & $(5,2,8) / / 4$ & $(7,4,1)$ & $(5,2,8)$ & $(7,4,1)$ & $(5,2,8)$ & $(7,4,1)$ \\
& & & & $/ / 4$ & $/ / 6$ & $/ / 6$ & $/ / 8$ & $/ / 8$ \\
\hline $5 / / \mathrm{A}$ & $7 / / \mathrm{R} 1$ & $5 / / \mathrm{R} 1$ & $7 / / \mathrm{R} 2$ & $5 / / \mathrm{R} 2$ & $7 / / \mathrm{R} 3$ & $5 / / \mathrm{R} 3$ & $7 / / \mathrm{R} 4$ & $5 / / \mathrm{R} 4$ \\
\hline $7 / / \mathrm{A}$ & $5 / / \mathrm{R} 1$ & $7 / / \mathrm{R} 1$ & $5 / / \mathrm{R} 2$ & $7 / / \mathrm{R} 2$ & $5 / / \mathrm{R} 3$ & $7 / / \mathrm{R} 3$ & $5 / / \mathrm{R} 4$ & $7 / / \mathrm{R} 4$ \\
\hline
\end{tabular}

\begin{tabular}{|l|l|l|l|l|l|l|l|l|}
\hline $\begin{array}{l}\text { Series } \\
\text { and } \\
\text { last } \\
\text { digit } \\
\text { of } \mathrm{P}_{\mathrm{n}}\end{array}$ & \multicolumn{2}{|c|}{ Finding value of $\mathrm{p}_{\mathrm{x}}$ for $\mathrm{p}_{\mathrm{e}}{ }^{\prime}=7$ and $\mathrm{p}_{\mathrm{e}}{ }^{\prime}=13$} \\
\hline & $2 \mathrm{k}=$ & $2 \mathrm{k}=$ & $2 \mathrm{k}=$ & $2 \mathrm{k}=$ & $2 \mathrm{k}=$ & $2 \mathrm{k}=$ & $2 \mathrm{k}=$ & $2 \mathrm{k}=$ \\
& $\mathrm{SADN}$ & $\mathrm{SADN}$ & $\mathrm{SADN}$ & $\mathrm{SADN}$ & $\mathrm{SADN}$ & $\mathrm{SADN}$ & $\mathrm{SADN}$ & $\mathrm{SADN}$ \\
& $(5,2,8) / / 2$ & $(7,4,1) / / 2$ & $(5,2,8) / / 4$ & $(7,4,1)$ & $(5,2,8)$ & $(7,4,1)$ & $(5,2,8)$ & $(7,4,1)$ \\
& & & & $/ / 4$ & $/ / 6$ & $/ / 6$ & $/ / 8$ & $/ / 8$ \\
\hline $5 / / \mathrm{A}$ & $5 / / \mathrm{R} 2$ & $7 / / \mathrm{R} 2$ & $5 / / \mathrm{R} 4$ & $7 / / \mathrm{R} 4$ & $5 / / \mathrm{R} 1$ & $7 / / \mathrm{R} 1$ & $5 / / \mathrm{R} 3$ & $7 / / \mathrm{R} 3$ \\
\hline
\end{tabular}




\begin{tabular}{|l|l|l|l|l|l|l|l|l|}
\hline 7//A & $7 / / \mathrm{R} 2$ & $5 / / \mathrm{R} 2$ & $7 / / \mathrm{R} 4$ & $5 / / \mathrm{R} 4$ & $7 / / \mathrm{R} 1$ & $5 / / \mathrm{R} 1$ & $7 / / \mathrm{R} 3$ & $5 / / \mathrm{R} 3$ \\
\hline
\end{tabular}

\begin{tabular}{|l|l|l|l|l|l|l|l|l|}
\hline $\begin{array}{l}\text { Series } \\
\text { and } \\
\text { last } \\
\text { digit } \\
\text { of } \mathrm{P}_{\mathrm{n}}\end{array}$ & \multicolumn{7}{|c|}{ Finding value of $\mathrm{p}_{\mathrm{x}}$ for $\mathrm{p}_{\mathrm{e}}{ }^{\prime}=7$ and $\mathrm{p}_{\mathrm{e}}{ }^{\prime}=17$} \\
\hline & $2 \mathrm{k}=$ & $2 \mathrm{k}=$ & $2 \mathrm{k}=$ & $2 \mathrm{k}=$ & $2 \mathrm{k}=$ & $2 \mathrm{k}=$ & $2 \mathrm{k}=$ & $2 \mathrm{k}=$ \\
& $\mathrm{SADN}$ & $\mathrm{SADN}$ & $\mathrm{SADN}$ & $\mathrm{SADN}$ & $\mathrm{SADN}$ & $\mathrm{SADN}$ & $\mathrm{SADN}$ & $\mathrm{SADN}$ \\
& $(5,2,8) / / 2$ & $(7,4,1) / / 2$ & $(5,2,8) / / 4$ & $(7,4,1)$ & $(5,2,8)$ & $(7,4,1)$ & $(5,2,8)$ & $(7,4,1)$ \\
& & & & $/ / 4$ & $/ / 6$ & $/ / 6$ & $/ / 8$ & $/ / 8$ \\
\hline $5 / / \mathrm{A}$ & $7 / / \mathrm{R} 3$ & $5 / / \mathrm{R} 3$ & $7 / / \mathrm{R} 1$ & $5 / / \mathrm{R} 1$ & $7 / / \mathrm{R} 4$ & $5 / / \mathrm{R} 4$ & $7 / / \mathrm{R} 2$ & $5 / / \mathrm{R} 2$ \\
\hline $7 / / \mathrm{A}$ & $5 / / \mathrm{R} 3$ & $7 / / \mathrm{R} 3$ & $5 / / \mathrm{R} 1$ & $7 / / \mathrm{R} 1$ & $5 / / \mathrm{R} 4$ & $7 / / \mathrm{R} 4$ & $5 / / \mathrm{R} 2$ & $7 / / \mathrm{R} 2$ \\
\hline
\end{tabular}

\begin{tabular}{|l|l|l|l|l|l|l|l|l|}
\hline $\begin{array}{l}\text { Series } \\
\text { and } \\
\text { last } \\
\text { digit } \\
\text { of } \mathrm{P}_{\mathrm{n}}\end{array}$ & \multicolumn{7}{|c|}{ Finding value of $\mathrm{p}_{\mathrm{x}}$ for $\mathrm{p}_{\mathrm{e}}{ }^{\prime}=7$ and $\mathrm{p}_{\mathrm{e}}{ }^{\prime \prime}=19$} \\
\hline & $2 \mathrm{k}=$ & $2 \mathrm{k}=$ & $2 \mathrm{k}=$ & $2 \mathrm{k}=$ & $2 \mathrm{k}=$ & $2 \mathrm{k}=$ & $2 \mathrm{k}=$ & $2 \mathrm{k}=$ \\
& $\mathrm{SADN}$ & $\mathrm{SADN}$ & $\mathrm{SADN}$ & $\mathrm{SADN}$ & $\mathrm{SADN}$ & $\mathrm{SADN}$ & $\mathrm{SADN}$ & $\mathrm{SADN}$ \\
& $(5,2,8) / / 2$ & $(7,4,1) / / 2$ & $(5,2,8) / / 4$ & $(7,4,1)$ & $(5,2,8)$ & $(7,4,1)$ & $(5,2,8)$ & $(7,4,1)$ \\
& & & & $/ / 4$ & $/ / 6$ & $/ / 6$ & $/ / 8$ & $/ / 8$ \\
\hline $5 / / \mathrm{A}$ & $5 / / \mathrm{R} 4$ & $7 / / \mathrm{R} 4$ & $5 / / \mathrm{R} 3$ & $7 / / \mathrm{R} 3$ & $5 / / \mathrm{R} 2$ & $7 / / \mathrm{R} 2$ & $5 / / \mathrm{R} 1$ & $7 / / \mathrm{R} 1$ \\
\hline $7 / / \mathrm{A}$ & $7 / / \mathrm{R} 4$ & $5 / / \mathrm{R} 4$ & $7 / / \mathrm{R} 3$ & $5 / / \mathrm{R} 3$ & $7 / / \mathrm{R} 2$ & $5 / / \mathrm{R} 2$ & $7 / / \mathrm{R} 1$ & $5 / / \mathrm{R} 1$ \\
\hline
\end{tabular}

\begin{tabular}{|l|l|l|l|l|l|l|l|l|}
\hline $\begin{array}{l}\text { Series } \\
\text { and } \\
\text { last } \\
\text { digit } \\
\text { of } \mathrm{P}_{\mathrm{n}}\end{array}$ & \multicolumn{7}{|c|}{ Finding value of $\mathrm{p}_{\mathrm{x}}$ for $\mathrm{p}_{\mathrm{e}}{ }^{\prime}=7$ and $\mathrm{p}_{\mathrm{e}}{ }^{\prime}=23$} \\
\hline & $2 \mathrm{k}=$ & $2 \mathrm{k}=$ & $2 \mathrm{k}=$ & $2 \mathrm{k}=$ & $2 \mathrm{k}=$ & $2 \mathrm{k}=$ & $2 \mathrm{k}=$ & $2 \mathrm{k}=$ \\
& $\mathrm{SADN}$ & $\mathrm{SADN}$ & $\mathrm{SADN}$ & $\mathrm{SADN}$ & $\mathrm{SADN}$ & $\mathrm{SADN}$ & $\mathrm{SADN}$ & $\mathrm{SADN}$ \\
& $(5,2,8) / / 2$ & $(7,4,1) / / 2$ & $(5,2,8) / / 4$ & $(7,4,1)$ & $(5,2,8)$ & $(7,4,1)$ & $(5,2,8)$ & $(7,4,1)$ \\
& & & & $/ / 4$ & $/ / 6$ & $/ / 6$ & $/ / 8$ & $/ / 8$ \\
\hline $5 / / \mathrm{A}$ & $7 / / \mathrm{R} 2$ & $5 / / \mathrm{R} 2$ & $7 / / \mathrm{R} 4$ & $5 / / \mathrm{R} 4$ & $7 / / \mathrm{R} 1$ & $5 / / \mathrm{R} 1$ & $7 / / \mathrm{R} 3$ & $5 / / \mathrm{R} 3$ \\
\hline
\end{tabular}




\begin{tabular}{|l|l|l|l|l|l|l|l|l|}
\hline 7//A & $5 / / \mathrm{R} 2$ & $7 / / \mathrm{R} 2$ & $5 / / \mathrm{R} 4$ & $7 / / \mathrm{R} 4$ & $5 / / \mathrm{R} 1$ & $7 / / \mathrm{R} 1$ & $5 / / \mathrm{R} 3$ & $7 / / \mathrm{R} 3$ \\
\hline
\end{tabular}

\begin{tabular}{|l|l|l|l|l|l|l|l|l|}
\hline $\begin{array}{l}\text { Series } \\
\text { and } \\
\text { last } \\
\text { digit } \\
\text { of } \mathrm{P}_{\mathrm{n}}\end{array}$ & \multicolumn{7}{|c|}{ Finding value of $\mathrm{p}_{\mathrm{x}}$ for $\mathrm{p}_{\mathrm{e}}{ }^{\prime}=7$ and $\mathrm{p}_{\mathrm{e}}{ }^{\prime}=29$} \\
\hline & $2 \mathrm{k}=$ & $2 \mathrm{k}=$ & $2 \mathrm{k}=$ & $2 \mathrm{k}=$ & $2 \mathrm{k}=$ & $2 \mathrm{k}=$ & $2 \mathrm{k}=$ & $2 \mathrm{k}=$ \\
& $\mathrm{SADN}$ & $\mathrm{SADN}$ & $\mathrm{SADN}$ & $\mathrm{SADN}$ & $\mathrm{SADN}$ & $\mathrm{SADN}$ & $\mathrm{SADN}$ & $\mathrm{SADN}$ \\
& $(5,2,8) / / 2$ & $(7,4,1) / / 2$ & $(5,2,8) / / 4$ & $(7,4,1)$ & $(5,2,8)$ & $(7,4,1)$ & $(5,2,8)$ & $(7,4,1)$ \\
& & & & $/ / 4$ & $/ / 6$ & $/ / 6$ & $/ / 8$ & $/ / 8$ \\
\hline $5 / / \mathrm{A}$ & $7 / / \mathrm{R} 4$ & $5 / / \mathrm{R} 4$ & $7 / / \mathrm{R} 3$ & $5 / / \mathrm{R} 3$ & $7 / / \mathrm{R} 2$ & $5 / / \mathrm{R} 2$ & $7 / / \mathrm{R} 1$ & $5 / / \mathrm{R} 1$ \\
\hline $7 / / \mathrm{A}$ & $5 / / \mathrm{R} 4$ & $7 / / \mathrm{R} 4$ & $5 / / \mathrm{R} 3$ & $7 / / \mathrm{R} 3$ & $5 / / \mathrm{R} 2$ & $7 / / \mathrm{R} 2$ & $5 / / \mathrm{R} 1$ & $7 / / \mathrm{R} 1$ \\
\hline
\end{tabular}

\begin{tabular}{|l|l|l|l|l|l|l|l|l|}
\hline $\begin{array}{l}\text { Series } \\
\text { and } \\
\text { last } \\
\text { digit } \\
\text { of } \mathrm{P}_{\mathrm{n}}\end{array}$ & \multicolumn{7}{|c|}{ Finding value of $\mathrm{p}_{\mathrm{x}}$ for $\mathrm{p}_{\mathrm{e}}{ }^{\prime}=7$ and $\mathrm{p}_{\mathrm{e}}{ }^{\prime}=31$} \\
\hline & $2 \mathrm{k}=$ & $2 \mathrm{k}=$ & $2 \mathrm{k}=$ & $2 \mathrm{k}=$ & $2 \mathrm{k}=$ & $2 \mathrm{k}=$ & $2 \mathrm{k}=$ & $2 \mathrm{k}=$ \\
& $\mathrm{SADN}$ & $\mathrm{SADN}$ & $\mathrm{SADN}$ & $\mathrm{SADN}$ & $\mathrm{SADN}$ & $\mathrm{SADN}$ & $\mathrm{SADN}$ & $\mathrm{SADN}$ \\
& $(5,2,8) / / 2$ & $(7,4,1) / / 2$ & $(5,2,8) / / 4$ & $(7,4,1)$ & $(5,2,8)$ & $(7,4,1)$ & $(5,2,8)$ & $(7,4,1)$ \\
& & & & $/ / 4$ & $/ / 6$ & $/ / 6$ & $/ / 8$ & $/ / 8$ \\
\hline $5 / / \mathrm{A}$ & $5 / / \mathrm{R} 1$ & $7 / / \mathrm{R} 1$ & $5 / / \mathrm{R} 2$ & $7 / / \mathrm{R} 2$ & $5 / / \mathrm{R} 3$ & $7 / / \mathrm{R} 3$ & $5 / / \mathrm{R} 4$ & $7 / / \mathrm{R} 4$ \\
\hline $7 / / \mathrm{A}$ & $7 / / \mathrm{R} 1$ & $5 / / \mathrm{R} 1$ & $7 / / \mathrm{R} 2$ & $5 / / \mathrm{R} 2$ & $7 / / \mathrm{R} 3$ & $5 / / \mathrm{R} 3$ & $7 / / \mathrm{R} 4$ & $5 / / \mathrm{R} 4$ \\
\hline
\end{tabular}

\begin{tabular}{|l|l|l|l|l|l|l|l|l|}
\hline $\begin{array}{l}\text { Series } \\
\text { and } \\
\text { last } \\
\text { digit } \\
\text { of } \mathrm{P}_{\mathrm{n}}\end{array}$ & \multicolumn{7}{|c|}{ Finding value of $\mathrm{p}_{\mathrm{x}}$ for $\mathrm{p}_{\mathrm{e}}{ }^{\prime}=11$ and $\mathrm{p}_{\mathrm{e}}{ }^{\prime \prime}=11$} \\
\hline & $2 \mathrm{k}=$ & $2 \mathrm{k}=$ & $2 \mathrm{k}=$ & $2 \mathrm{k}=$ & $2 \mathrm{k}=$ & $2 \mathrm{k}=$ & $2 \mathrm{k}=$ & $2 \mathrm{k}=$ \\
& $\mathrm{SADN}$ & $\mathrm{SADN}$ & $\mathrm{SADN}$ & $\mathrm{SADN}$ & $\mathrm{SADN}$ & $\mathrm{SADN}$ & $\mathrm{SADN}$ & $\mathrm{SADN}$ \\
& $(5,2,8) / / 2$ & $(7,4,1) / / 2$ & $(5,2,8) / / 4$ & $(7,4,1)$ & $(5,2,8)$ & $(7,4,1)$ & $(5,2,8)$ & $(7,4,1)$ \\
& & & & $/ / 4$ & $/ / 6$ & $/ / 6$ & $/ / 8$ & $/ / 8$ \\
\hline $5 / / \mathrm{A}$ & $5 / / \mathrm{R} 2$ & $7 / / \mathrm{R} 2$ & $5 / / \mathrm{R} 4$ & $7 / / \mathrm{R} 4$ & $5 / / \mathrm{R} 1$ & $7 / / \mathrm{R} 1$ & $5 / / \mathrm{R} 3$ & $7 / / \mathrm{R} 3$ \\
\hline $7 / / \mathrm{A}$ & $7 / / \mathrm{R} 2$ & $5 / / \mathrm{R} 2$ & $7 / / \mathrm{R} 4$ & $5 / / \mathrm{R} 4$ & $7 / / \mathrm{R} 1$ & $5 / / \mathrm{R} 1$ & $7 / / \mathrm{R} 3$ & $5 / / \mathrm{R} 3$ \\
\hline
\end{tabular}




\begin{tabular}{|l|l|l|l|l|l|l|l|l|}
\hline $\begin{array}{l}\text { and } \\
\text { last } \\
\text { digit } \\
\text { of } \mathrm{P}_{\mathrm{n}}\end{array}$ & \multicolumn{2}{|l|}{} \\
\hline & $2 \mathrm{k}=$ & $2 \mathrm{k}=$ & $2 \mathrm{k}=$ & $2 \mathrm{k}=$ & $2 \mathrm{k}=$ & $2 \mathrm{k}=$ & $2 \mathrm{k}=$ & $2 \mathrm{k}=$ \\
& $\mathrm{SADN}$ & $\mathrm{SADN}$ & $\mathrm{SADN}$ & $\mathrm{SADN}$ & $\mathrm{SADN}$ & $\mathrm{SADN}$ & $\mathrm{SADN}$ & $\mathrm{SADN}$ \\
& $(5,2,8) / / 2$ & $(7,4,1) / / 2$ & $(5,2,8) / / 4$ & $(7,4,1)$ & $(5,2,8)$ & $(7,4,1)$ & $(5,2,8)$ & $(7,4,1)$ \\
& & & & $/ / 4$ & $/ / 6$ & $/ / 6$ & $/ / 8$ & $/ / 8$ \\
\hline $5 / / \mathrm{A}$ & $7 / / \mathrm{R} 4$ & $5 / / \mathrm{R} 4$ & $7 / / \mathrm{R} 3$ & $5 / / \mathrm{R} 3$ & $7 / / \mathrm{R} 2$ & $5 / / \mathrm{R} 2$ & $7 / / \mathrm{R} 1$ & $5 / / \mathrm{R} 1$ \\
\hline $7 / / \mathrm{A}$ & $5 / / \mathrm{R} 4$ & $7 / / \mathrm{R} 4$ & $5 / / \mathrm{R} 3$ & $7 / / \mathrm{R} 3$ & $5 / / \mathrm{R} 2$ & $7 / / \mathrm{R} 2$ & $5 / / \mathrm{R} 1$ & $7 / / \mathrm{R} 1$ \\
\hline
\end{tabular}

\begin{tabular}{|l|l|l|l|l|l|l|l|l|}
\hline $\begin{array}{l}\text { Series } \\
\text { and } \\
\text { last } \\
\text { digit } \\
\text { of } \mathrm{P}_{\mathrm{n}}\end{array}$ & \multicolumn{7}{|c|}{ Finding value of $\mathrm{p}_{\mathrm{x}}$ for $\mathrm{p}_{\mathrm{e}}{ }^{\prime}=11$ and $\mathrm{p}_{\mathrm{e}}{ }^{\prime \prime}=17$} \\
\hline & $2 \mathrm{k}=$ & $2 \mathrm{k}=$ & $2 \mathrm{k}=$ & $2 \mathrm{k}=$ & $2 \mathrm{k}=$ & $2 \mathrm{k}=$ & $2 \mathrm{k}=$ & $2 \mathrm{k}=$ \\
& $\mathrm{SADN}$ & $\mathrm{SADN}$ & $\mathrm{SADN}$ & $\mathrm{SADN}$ & $\mathrm{SADN}$ & $\mathrm{SADN}$ & $\mathrm{SADN}$ & $\mathrm{SADN}$ \\
& $(5,2,8) / / 2$ & $(7,4,1) / / 2$ & $(5,2,8) / / 4$ & $(7,4,1)$ & $(5,2,8)$ & $(7,4,1)$ & $(5,2,8)$ & $(7,4,1)$ \\
& & & & $/ / 4$ & $/ / 6$ & $/ / 6$ & $/ / 8$ & $/ / 8$ \\
\hline $5 / / \mathrm{A}$ & $5 / / \mathrm{R} 1$ & $7 / / \mathrm{R} 1$ & $5 / / \mathrm{R} 2$ & $7 / / \mathrm{R} 2$ & $5 / / \mathrm{R} 3$ & $7 / / \mathrm{R} 3$ & $5 / / \mathrm{R} 4$ & $7 / / \mathrm{R} 4$ \\
\hline $7 / / \mathrm{A}$ & $7 / / \mathrm{R} 1$ & $5 / / \mathrm{R} 1$ & $7 / / \mathrm{R} 2$ & $5 / / \mathrm{R} 2$ & $7 / / \mathrm{R} 3$ & $5 / / \mathrm{R} 3$ & $7 / / \mathrm{R} 4$ & $5 / / \mathrm{R} 4$ \\
\hline
\end{tabular}

\begin{tabular}{|l|l|l|l|l|l|l|l|l|}
\hline $\begin{array}{l}\text { Series } \\
\text { and } \\
\text { last } \\
\text { digit } \\
\text { of } \mathrm{P}_{\mathrm{n}}\end{array}$ & \multicolumn{7}{|c|}{ Finding value of $\mathrm{p}_{\mathrm{x}}$ for $\mathrm{p}_{\mathrm{e}}{ }^{\prime}=11$ and $\mathrm{p}_{\mathrm{e}}{ }^{\prime}=19$} \\
\hline & $2 \mathrm{k}=$ & $2 \mathrm{k}=$ & $2 \mathrm{k}=$ & $2 \mathrm{k}=$ & $2 \mathrm{k}=$ & $2 \mathrm{k}=$ & $2 \mathrm{k}=$ & $2 \mathrm{k}=$ \\
& $\mathrm{SADN}$ & $\mathrm{SADN}$ & $\mathrm{SADN}$ & $\mathrm{SADN}$ & $\mathrm{SADN}$ & $\mathrm{SADN}$ & $\mathrm{SADN}$ & $\mathrm{SADN}$ \\
& $(5,2,8) / / 2$ & $(7,4,1) / / 2$ & $(5,2,8) / / 4$ & $(7,4,1)$ & $(5,2,8)$ & $(7,4,1)$ & $(5,2,8)$ & $(7,4,1)$ \\
& & & & $/ / 4$ & $/ / 6$ & $/ / 6$ & $/ / 8$ & $/ / 8$ \\
\hline $5 / / \mathrm{A}$ & $7 / / \mathrm{R} 3$ & $5 / / \mathrm{R} 3$ & $7 / / \mathrm{R} 1$ & $5 / / \mathrm{R} 1$ & $7 / / \mathrm{R} 4$ & $5 / / \mathrm{R} 4$ & $7 / / \mathrm{R} 2$ & $5 / / \mathrm{R} 2$ \\
\hline $7 / / \mathrm{A}$ & $5 / / \mathrm{R} 3$ & $7 / / \mathrm{R} 3$ & $5 / / \mathrm{R} 1$ & $7 / / \mathrm{R} 1$ & $5 / / \mathrm{R} 4$ & $7 / / \mathrm{R} 4$ & $5 / / \mathrm{R} 2$ & $7 / / \mathrm{R} 2$ \\
\hline
\end{tabular}




\begin{tabular}{|l|l|l|l|l|l|l|l|l|}
\hline $\begin{array}{l}\text { and } \\
\text { last } \\
\text { digit } \\
\text { of Pn }\end{array}$ & \multicolumn{2}{|l|}{} \\
\hline & $2 \mathrm{k}=$ & $2 \mathrm{k}=$ & $2 \mathrm{k}=$ & $2 \mathrm{k}=$ & $2 \mathrm{k}=$ & $2 \mathrm{k}=$ & $2 \mathrm{k}=$ & $2 \mathrm{k}=$ \\
& $\mathrm{SADN}$ & $\mathrm{SADN}$ & $\mathrm{SADN}$ & $\mathrm{SADN}$ & $\mathrm{SADN}$ & $\mathrm{SADN}$ & $\mathrm{SADN}$ & $\mathrm{SADN}$ \\
& $(5,2,8) / / 2$ & $(7,4,1) / / 2$ & $(5,2,8) / / 4$ & $(7,4,1)$ & $(5,2,8)$ & $(7,4,1)$ & $(5,2,8)$ & $(7,4,1)$ \\
& & & & $/ / 4$ & $/ / 6$ & $/ / 6$ & $/ / 8$ & $/ / 8$ \\
\hline $5 / / \mathrm{A}$ & $5 / / \mathrm{R} 4$ & $7 / / \mathrm{R} 4$ & $5 / / \mathrm{R} 3$ & $7 / / \mathrm{R} 3$ & $5 / / \mathrm{R} 2$ & $7 / / \mathrm{R} 2$ & $5 / / \mathrm{R} 1$ & $7 / / \mathrm{R} 1$ \\
\hline $7 / / \mathrm{A}$ & $7 / / \mathrm{R} 4$ & $5 / / \mathrm{R} 4$ & $7 / / \mathrm{R} 3$ & $5 / / \mathrm{R} 3$ & $7 / / \mathrm{R} 2$ & $5 / / \mathrm{R} 2$ & $7 / / \mathrm{R} 1$ & $5 / / \mathrm{R} 1$ \\
\hline
\end{tabular}

\begin{tabular}{|l|l|l|l|l|l|l|l|l|}
\hline $\begin{array}{l}\text { Series } \\
\text { and } \\
\text { last } \\
\text { digit } \\
\text { of } \mathrm{Pn}\end{array}$ & \multicolumn{7}{|c|}{ Finding value of px for pe'=11 and pe'=29 } \\
\hline & $2 \mathrm{k}=$ & $2 \mathrm{k}=$ & $2 \mathrm{k}=$ & $2 \mathrm{k}=$ & $2 \mathrm{k}=$ & $2 \mathrm{k}=$ & $2 \mathrm{k}=$ & $2 \mathrm{k}=$ \\
& $\mathrm{SADN}$ & $\mathrm{SADN}$ & $\mathrm{SADN}$ & $\mathrm{SADN}$ & $\mathrm{SADN}$ & $\mathrm{SADN}$ & $\mathrm{SADN}$ & $\mathrm{SADN}$ \\
& $(5,2,8) / / 2$ & $(7,4,1) / / 2$ & $(5,2,8) / / 4$ & $(7,4,1)$ & $(5,2,8)$ & $(7,4,1)$ & $(5,2,8)$ & $(7,4,1)$ \\
& & & & $/ / 4$ & $/ / 6$ & $/ / 6$ & $/ / 8$ & $/ / 8$ \\
\hline 5//A & $5 / / \mathrm{R} 3$ & $7 / / \mathrm{R} 3$ & $5 / / \mathrm{R} 1$ & $7 / / \mathrm{R} 1$ & $5 / / \mathrm{R} 4$ & $7 / / \mathrm{R} 4$ & $5 / / \mathrm{R} 2$ & $7 / / \mathrm{R} 2$ \\
\hline $7 / / \mathrm{A}$ & $7 / / \mathrm{R} 3$ & $5 / / \mathrm{R} 3$ & $7 / / \mathrm{R} 1$ & $5 / / \mathrm{R} 1$ & $7 / / \mathrm{R} 4$ & $5 / / \mathrm{R} 4$ & $7 / / \mathrm{R} 2$ & $5 / / \mathrm{R} 2$ \\
\hline
\end{tabular}

\begin{tabular}{|l|l|l|l|l|l|l|l|l|}
\hline $\begin{array}{l}\text { Series } \\
\text { and } \\
\text { last } \\
\text { digit } \\
\text { of } \mathrm{Pn}\end{array}$ & \multicolumn{7}{|c|}{ Finding value of px for pe'=11 and pe'=31 } \\
\hline & $2 \mathrm{k}=$ & $2 \mathrm{k}=$ & $2 \mathrm{k}=$ & $2 \mathrm{k}=$ & $2 \mathrm{k}=$ & $2 \mathrm{k}=$ & $2 \mathrm{k}=$ & $2 \mathrm{k}=$ \\
& $\mathrm{SADN}$ & $\mathrm{SADN}$ & $\mathrm{SADN}$ & $\mathrm{SADN}$ & $\mathrm{SADN}$ & $\mathrm{SADN}$ & $\mathrm{SADN}$ & $\mathrm{SADN}$ \\
& $(5,2,8) / / 2$ & $(7,4,1) / / 2$ & $(5,2,8) / / 4$ & $(7,4,1)$ & $(5,2,8)$ & $(7,4,1)$ & $(5,2,8)$ & $(7,4,1)$ \\
& & & & $/ / 4$ & $/ / 6$ & $/ / 6$ & $/ / 8$ & $/ / 8$ \\
\hline $5 / / \mathrm{A}$ & $7 / / \mathrm{R} 2$ & $5 / / \mathrm{R} 2$ & $7 / / \mathrm{R} 4$ & $5 / / \mathrm{R} 4$ & $7 / / \mathrm{R} 1$ & $5 / / \mathrm{R} 1$ & $7 / / \mathrm{R} 3$ & $5 / / \mathrm{R} 3$ \\
\hline $7 / / \mathrm{A}$ & $5 / / \mathrm{R} 2$ & $7 / / \mathrm{R} 2$ & $5 / / \mathrm{R} 4$ & $7 / / \mathrm{R} 4$ & $5 / / \mathrm{R} 1$ & $7 / / \mathrm{R} 1$ & $5 / / \mathrm{R} 3$ & $7 / / \mathrm{R} 3$ \\
\hline
\end{tabular}

\begin{tabular}{|l|l|}
\hline $\begin{array}{l}\text { Series } \\
\text { and }\end{array}$ & Finding value of $\mathrm{px}$ for $\mathrm{pe} \mathrm{e}^{\prime}=13$ and $\mathrm{pe} \mathrm{e}^{\prime}=13$ \\
last & \\
digit & \\
\hline
\end{tabular}




\begin{tabular}{|l|l|l|l|l|l|l|l|l|}
\hline of Pn & \multicolumn{9}{|l|}{} \\
\hline & $2 \mathrm{k}=$ & $2 \mathrm{k}=$ & $2 \mathrm{k}=$ & $2 \mathrm{k}=$ & $2 \mathrm{k}=$ & $2 \mathrm{k}=$ & $2 \mathrm{k}=$ & $2 \mathrm{k}=$ \\
& $\mathrm{SADN}$ & $\mathrm{SADN}$ & $\mathrm{SADN}$ & SADN & SADN & SADN & SADN & SADN \\
& $(5,2,8) / / 2$ & $(7,4,1) / / 2$ & $(5,2,8) / / 4$ & $\begin{array}{l}(7,4,1) \\
(5,2,8)\end{array}$ & $\begin{array}{l}(7,4,1) \\
(5,2,8)\end{array}$ & $(7,4,1)$ \\
& & & & $/ / 4$ & $/ / 6$ & $/ / 8$ & $/ / 8$ \\
\hline 5//A & $5 / / \mathrm{R} 3$ & $7 / / \mathrm{R} 3$ & $5 / / \mathrm{R} 1$ & $7 / / \mathrm{R} 1$ & $5 / / \mathrm{R} 4$ & $7 / / \mathrm{R} 4$ & $5 / / \mathrm{R} 2$ & $7 / / \mathrm{R} 2$ \\
\hline 7//A & $7 / / \mathrm{R} 3$ & $5 / / \mathrm{R} 3$ & $7 / / \mathrm{R} 1$ & $5 / / \mathrm{R} 1$ & $7 / / \mathrm{R} 4$ & $5 / / \mathrm{R} 4$ & $7 / / \mathrm{R} 2$ & $5 / / \mathrm{R} 2$ \\
\hline
\end{tabular}

\begin{tabular}{|c|c|c|c|c|c|c|c|c|}
\hline Series & \multicolumn{8}{|c|}{ Finding value of $p x$ for $p e^{\prime}=13$ and pe' $=17$} \\
\hline & $\begin{array}{l}2 \mathrm{k}= \\
\mathrm{SADN} \\
(5,2,8) / / 2\end{array}$ & $\begin{array}{l}2 \mathrm{k}= \\
\mathrm{SADN} \\
(7,4,1) / / 2\end{array}$ & $\begin{array}{l}2 \mathrm{k}= \\
\mathrm{SADN} \\
(5,2,8) / / 4\end{array}$ & \begin{tabular}{|l}
$2 \mathrm{k}=$ \\
SADN \\
$(7,4,1)$ \\
$/ / 4$
\end{tabular} & $\begin{array}{l}2 \mathrm{k}= \\
\text { SADN } \\
(5,2,8) \\
/ / 6\end{array}$ & $\begin{array}{l}2 \mathrm{k}= \\
\text { SADN } \\
(7,4,1) \\
/ / 6\end{array}$ & $\begin{array}{l}2 \mathrm{k}= \\
\text { SADN } \\
(5,2,8) \\
/ / 8\end{array}$ & $\begin{array}{l}2 \mathrm{k}= \\
\text { SADN } \\
(7,4,1) \\
/ / 8\end{array}$ \\
\hline $5 / / \mathrm{A}$ & 7//R2 & $5 / / \mathrm{R} 2$ & 7//R4 & $5 / / \mathrm{R} 4$ & 7//R1 & $5 / / \mathrm{R} 1$ & 7//R3 & 5//R3 \\
\hline 7//A & $5 / / \mathrm{R} 2$ & $7 / / \mathrm{R} 2$ & $5 / / \mathrm{R} 4$ & 7//R4 & 5//R1 & 7//R1 & 5//R3 & 7//R3 \\
\hline \multirow[t]{2}{*}{$\begin{array}{l}\text { Series } \\
\text { and } \\
\text { last } \\
\text { digit } \\
\text { of Pn }\end{array}$} & \multicolumn{8}{|c|}{ Finding value of $p x$ for $\mathrm{pe}^{\prime}=13$ and $\mathrm{pe} \mathrm{e}^{\prime}=19$} \\
\hline & $\begin{array}{l}2 \mathrm{k}= \\
\mathrm{SADN} \\
(5,2,8) / / 2\end{array}$ & $\begin{array}{l}2 \mathrm{k}= \\
\mathrm{SADN} \\
(7,4,1) / / 2\end{array}$ & $\begin{array}{l}2 \mathrm{k}= \\
\mathrm{SADN} \\
(5,2,8) / / 4\end{array}$ & \begin{tabular}{|l}
$2 \mathrm{k}=$ \\
SADN \\
$(7,4,1)$ \\
$/ / 4$
\end{tabular} & $\begin{array}{l}2 \mathrm{k}= \\
\text { SADN } \\
(5,2,8) \\
/ / 6\end{array}$ & $\begin{array}{l}2 \mathrm{k}= \\
\text { SADN } \\
(7,4,1) \\
/ / 6\end{array}$ & $\begin{array}{l}2 \mathrm{k}= \\
\mathrm{SADN} \\
(5,2,8) \\
/ / 8\end{array}$ & $\begin{array}{l}2 \mathrm{k}= \\
\text { SADN } \\
(7,4,1) \\
/ / 8\end{array}$ \\
\hline $5 / / \mathrm{A}$ & $5 / / \mathrm{R} 1$ & 7//R1 & $5 / / \mathrm{R} 2$ & 7//R2 & 5//R3 & 7//R3 & $5 / / \mathrm{R} 4$ & 7//R4 \\
\hline 7//A & 7//R1 & $5 / / \mathrm{R} 1$ & 7//R2 & $5 / / \mathrm{R} 2$ & 7//R3 & 5//R3 & 7//R4 & $5 / / \mathrm{R} 4$ \\
\hline
\end{tabular}

\begin{tabular}{|l|l|l|l|l|l|l|l|l|}
\hline $\begin{array}{l}\text { Series } \\
\text { and } \\
\text { last } \\
\text { digit } \\
\text { of } \mathrm{Pn}\end{array}$ & \multicolumn{2}{|c|}{ Finding value of px for pe'=13 and pe' $=23$} \\
\hline & $2 \mathrm{k}=$ & $2 \mathrm{k}=$ & $2 \mathrm{k}=$ & $2 \mathrm{k}=$ & $2 \mathrm{k}=$ & $2 \mathrm{k}=$ & $2 \mathrm{k}=$ & $2 \mathrm{k}=$ \\
& $\mathrm{SADN}$ & $\mathrm{SADN}$ & $\mathrm{SADN}$ & $\mathrm{SADN}$ & $\mathrm{SADN}$ & $\mathrm{SADN}$ & $\mathrm{SADN}$ & $\mathrm{SADN}$ \\
& $(5,2,8) / / 2$ & $(7,4,1) / / 2$ & $(5,2,8) / / 4$ & $(7,4,1)$ & $(5,2,8)$ & $(7,4,1)$ & $(5,2,8)$ & $(7,4,1)$ \\
& & & $/ / 4$ & $/ / 6$ & $/ / 6$ & $/ / 8$ & $/ / 8$ \\
\hline
\end{tabular}




\begin{tabular}{|l|l|l|l|l|l|l|l|l|}
\hline 5//A & $7 / / \mathrm{R} 3$ & $5 / / \mathrm{R} 3$ & $7 / / \mathrm{R} 1$ & $5 / / \mathrm{R} 1$ & $7 / / \mathrm{R} 4$ & $5 / / \mathrm{R} 4$ & $7 / / \mathrm{R} 2$ & $5 / / \mathrm{R} 2$ \\
\hline 7//A & $5 / / \mathrm{R} 3$ & $7 / / \mathrm{R} 3$ & $5 / / \mathrm{R} 1$ & $7 / / \mathrm{R} 1$ & $5 / / \mathrm{R} 4$ & $7 / / \mathrm{R} 4$ & $5 / / \mathrm{R} 2$ & $7 / / \mathrm{R} 2$ \\
\hline
\end{tabular}

\begin{tabular}{|l|l|l|l|l|l|l|l|l|}
\hline $\begin{array}{l}\text { Series } \\
\text { and } \\
\text { last } \\
\text { digit } \\
\text { of } \mathrm{Pn}\end{array}$ & \multicolumn{7}{|c|}{ Finding value of px for pe'=13 and pe'=29 } \\
\hline & $2 \mathrm{k}=$ & $2 \mathrm{k}=$ & $2 \mathrm{k}=$ & $2 \mathrm{k}=$ & $2 \mathrm{k}=$ & $2 \mathrm{k}=$ & $2 \mathrm{k}=$ & $2 \mathrm{k}=$ \\
& $\mathrm{SADN}$ & $\mathrm{SADN}$ & $\mathrm{SADN}$ & $\mathrm{SADN}$ & $\mathrm{SADN}$ & $\mathrm{SADN}$ & $\mathrm{SADN}$ & $\mathrm{SADN}$ \\
& $(5,2,8) / / 2$ & $(7,4,1) / / 2$ & $(5,2,8) / / 4$ & $(7,4,1)$ & $(5,2,8)$ & $(7,4,1)$ & $(5,2,8)$ & $(7,4,1)$ \\
& & & & $/ / 4$ & $/ / 6$ & $/ / 6$ & $/ / 8$ & $/ / 8$ \\
\hline $5 / / \mathrm{A}$ & $7 / / \mathrm{R} 1$ & $5 / / \mathrm{R} 1$ & $7 / / \mathrm{R} 2$ & $5 / / \mathrm{R} 2$ & $7 / / \mathrm{R} 3$ & $5 / / \mathrm{R} 3$ & $7 / / \mathrm{R} 4$ & $5 / / \mathrm{R} 4$ \\
\hline $7 / / \mathrm{A}$ & $5 / / \mathrm{R} 1$ & $7 / / \mathrm{R} 1$ & $5 / / \mathrm{R} 2$ & $7 / / \mathrm{R} 2$ & $5 / / \mathrm{R} 3$ & $7 / / \mathrm{R} 3$ & $5 / / \mathrm{R} 4$ & $7 / / \mathrm{R} 4$ \\
\hline
\end{tabular}

\begin{tabular}{|l|l|l|l|l|l|l|l|l|}
\hline $\begin{array}{l}\text { Series } \\
\text { and } \\
\text { last } \\
\text { digit } \\
\text { of Pn }\end{array}$ & \multicolumn{7}{|c|}{ Finding value of px for pe'=13 and pe'’=31 } \\
\hline & $2 \mathrm{k}=$ & $2 \mathrm{k}=$ & $2 \mathrm{k}=$ & $2 \mathrm{k}=$ & $2 \mathrm{k}=$ & $2 \mathrm{k}=$ & $2 \mathrm{k}=$ & $2 \mathrm{k}=$ \\
& $\mathrm{SADN}$ & $\mathrm{SADN}$ & $\mathrm{SADN}$ & $\mathrm{SADN}$ & $\mathrm{SADN}$ & $\mathrm{SADN}$ & $\mathrm{SADN}$ & $\mathrm{SADN}$ \\
& $(5,2,8) / / 2$ & $(7,4,1) / / 2$ & $(5,2,8) / / 4$ & $(7,4,1)$ & $(5,2,8)$ & $(7,4,1)$ & $(5,2,8)$ & $(7,4,1)$ \\
& & & & $/ / 4$ & $/ / 6$ & $/ / 6$ & $/ / 8$ & $/ / 8$ \\
\hline $5 / / \mathrm{A}$ & $5 / / \mathrm{R} 4$ & $7 / / \mathrm{R} 4$ & $5 / / \mathrm{R} 3$ & $7 / / \mathrm{R} 3$ & $5 / / \mathrm{R} 2$ & $7 / / \mathrm{R} 2$ & $5 / / \mathrm{R} 1$ & $7 / / \mathrm{R} 1$ \\
\hline $7 / / \mathrm{A}$ & $7 / / \mathrm{R} 4$ & $5 / / \mathrm{R} 4$ & $7 / / \mathrm{R} 3$ & $5 / / \mathrm{R} 3$ & $7 / / \mathrm{R} 2$ & $5 / / \mathrm{R} 2$ & $7 / / \mathrm{R} 1$ & $5 / / \mathrm{R} 1$ \\
\hline
\end{tabular}

\begin{tabular}{|l|l|l|l|l|l|l|l|l|}
\hline $\begin{array}{l}\text { Series } \\
\text { and } \\
\text { last } \\
\text { digit } \\
\text { of } \mathrm{Pn}\end{array}$ & \multicolumn{7}{|c|}{ Finding value of px for pe'=17 and pe'’=17 } \\
\hline & $2 \mathrm{k}=$ & $2 \mathrm{k}=$ & $2 \mathrm{k}=$ & $2 \mathrm{k}=$ & $2 \mathrm{k}=$ & $2 \mathrm{k}=$ & $2 \mathrm{k}=$ & $2 \mathrm{k}=$ \\
& $\mathrm{SADN}$ & $\mathrm{SADN}$ & $\mathrm{SADN}$ & $\mathrm{SADN}$ & $\mathrm{SADN}$ & $\mathrm{SADN}$ & $\mathrm{SADN}$ & $\mathrm{SADN}$ \\
& $(5,2,8) / / 2$ & $(7,4,1) / / 2$ & $(5,2,8) / / 4$ & $(7,4,1)$ & $(5,2,8)$ & $(7,4,1)$ & $(5,2,8)$ & $(7,4,1)$ \\
& & & & $/ / 4$ & $/ / 6$ & $/ / 6$ & $/ / 8$ & $/ / 8$ \\
\hline $5 / / \mathrm{A}$ & $5 / / \mathrm{R} 3$ & $7 / / \mathrm{R} 3$ & $5 / / \mathrm{R} 1$ & $7 / / \mathrm{R} 1$ & $5 / / \mathrm{R} 4$ & $7 / / \mathrm{R} 4$ & $5 / / \mathrm{R} 2$ & $7 / / \mathrm{R} 2$ \\
\hline $7 / / \mathrm{A}$ & $7 / / \mathrm{R} 3$ & $5 / / \mathrm{R} 3$ & $7 / / \mathrm{R} 1$ & $5 / / \mathrm{R} 1$ & $7 / / \mathrm{R} 4$ & $5 / / \mathrm{R} 4$ & $7 / / \mathrm{R} 2$ & $5 / / \mathrm{R} 2$ \\
\hline
\end{tabular}




\begin{tabular}{|l|l|l|l|l|l|l|l|l|}
\hline $\begin{array}{l}\text { and } \\
\text { last } \\
\text { digit } \\
\text { of Pn }\end{array}$ & \multicolumn{2}{|l|}{} \\
\hline & $2 \mathrm{k}=$ & $2 \mathrm{k}=$ & $2 \mathrm{k}=$ & $2 \mathrm{k}=$ & $2 \mathrm{k}=$ & $2 \mathrm{k}=$ & $2 \mathrm{k}=$ & $2 \mathrm{k}=$ \\
& $\mathrm{SADN}$ & $\mathrm{SADN}$ & $\mathrm{SADN}$ & $\mathrm{SADN}$ & $\mathrm{SADN}$ & $\mathrm{SADN}$ & $\mathrm{SADN}$ & $\mathrm{SADN}$ \\
& $(5,2,8) / / 2$ & $(7,4,1) / / 2$ & $(5,2,8) / / 4$ & $(7,4,1)$ & $(5,2,8)$ & $(7,4,1)$ & $(5,2,8)$ & $(7,4,1)$ \\
& & & & $/ / 4$ & $/ / 6$ & $/ / 6$ & $/ / 8$ & $/ / 8$ \\
\hline $5 / / \mathrm{A}$ & $7 / / \mathrm{R} 4$ & $5 / / \mathrm{R} 4$ & $7 / / \mathrm{R} 3$ & $5 / / \mathrm{R} 3$ & $7 / / \mathrm{R} 2$ & $5 / / \mathrm{R} 2$ & $7 / / \mathrm{R} 1$ & $5 / / \mathrm{R} 1$ \\
\hline $7 / / \mathrm{A}$ & $5 / / \mathrm{R} 4$ & $7 / / \mathrm{R} 4$ & $5 / / \mathrm{R} 3$ & $7 / / \mathrm{R} 3$ & $5 / / \mathrm{R} 2$ & $7 / / \mathrm{R} 2$ & $5 / / \mathrm{R} 1$ & $7 / / \mathrm{R} 1$ \\
\hline
\end{tabular}

\begin{tabular}{|l|l|l|l|l|l|l|l|l|}
\hline $\begin{array}{l}\text { Series } \\
\text { and } \\
\text { last } \\
\text { digit } \\
\text { of } \mathrm{Pn}\end{array}$ & \multicolumn{7}{|c|}{ Finding value of px for pe'=17 and pe' $=23$} \\
\hline & $2 \mathrm{k}=$ & $2 \mathrm{k}=$ & $2 \mathrm{k}=$ & $2 \mathrm{k}=$ & $2 \mathrm{k}=$ & $2 \mathrm{k}=$ & $2 \mathrm{k}=$ & $2 \mathrm{k}=$ \\
& $\mathrm{SADN}$ & $\mathrm{SADN}$ & $\mathrm{SADN}$ & $\mathrm{SADN}$ & $\mathrm{SADN}$ & $\mathrm{SADN}$ & $\mathrm{SADN}$ & $\mathrm{SADN}$ \\
& $(5,2,8) / / 2$ & $(7,4,1) / / 2$ & $(5,2,8) / / 4$ & $(7,4,1)$ & $(5,2,8)$ & $(7,4,1)$ & $(5,2,8)$ & $(7,4,1)$ \\
& & & & $/ / 4$ & $/ / 6$ & $/ / 6$ & $/ / 8$ & $/ / 8$ \\
\hline 5//A & $5 / / \mathrm{R} 2$ & $7 / / \mathrm{R} 2$ & $5 / / \mathrm{R} 4$ & $7 / / \mathrm{R} 4$ & $5 / / \mathrm{R} 1$ & $7 / / \mathrm{R} 1$ & $5 / / \mathrm{R} 3$ & $7 / / \mathrm{R} 3$ \\
\hline $7 / / \mathrm{A}$ & $7 / / \mathrm{R} 2$ & $5 / / \mathrm{R} 2$ & $7 / / \mathrm{R} 4$ & $5 / / \mathrm{R} 4$ & $7 / / \mathrm{R} 1$ & $5 / / \mathrm{R} 1$ & $7 / / \mathrm{R} 3$ & $5 / / \mathrm{R} 3$ \\
\hline
\end{tabular}

\begin{tabular}{|l|l|l|l|l|l|l|l|l|}
\hline $\begin{array}{l}\text { Series } \\
\text { and } \\
\text { last } \\
\text { digit } \\
\text { of } \mathrm{Pn}\end{array}$ & \multicolumn{7}{|c|}{ Finding value of px for pe'=17 and pe' $=29$} \\
\hline & $2 \mathrm{k}=$ & $2 \mathrm{k}=$ & $2 \mathrm{k}=$ & $2 \mathrm{k}=$ & $2 \mathrm{k}=$ & $2 \mathrm{k}=$ & $2 \mathrm{k}=$ & $2 \mathrm{k}=$ \\
& $\mathrm{SADN}$ & $\mathrm{SADN}$ & $\mathrm{SADN}$ & $\mathrm{SADN}$ & $\mathrm{SADN}$ & $\mathrm{SADN}$ & $\mathrm{SADN}$ & $\mathrm{SADN}$ \\
& $(5,2,8) / / 2$ & $(7,4,1) / / 2$ & $(5,2,8) / / 4$ & $(7,4,1)$ & $(5,2,8)$ & $(7,4,1)$ & $(5,2,8)$ & $(7,4,1)$ \\
& & & & $/ / 4$ & $/ / 6$ & $/ / 6$ & $/ / 8$ & $/ / 8$ \\
\hline $5 / / \mathrm{A}$ & $5 / / \mathrm{R} 4$ & $7 / / \mathrm{R} 4$ & $5 / / \mathrm{R} 3$ & $7 / / \mathrm{R} 3$ & $5 / / \mathrm{R} 2$ & $7 / / \mathrm{R} 2$ & $5 / / \mathrm{R} 1$ & $7 / / \mathrm{R} 1$ \\
\hline $7 / / \mathrm{A}$ & $7 / / \mathrm{R} 4$ & $5 / / \mathrm{R} 4$ & $7 / / \mathrm{R} 3$ & $5 / / \mathrm{R} 3$ & $7 / / \mathrm{R} 2$ & $5 / / \mathrm{R} 2$ & $7 / / \mathrm{R} 1$ & $5 / / \mathrm{R} 1$ \\
\hline
\end{tabular}

\begin{tabular}{|c|c|c|c|c|c|c|c|c|}
\hline Series & \multicolumn{8}{|c|}{ Finding value of $p x$ for $p e^{\prime}=17$ and $p e^{\prime \prime}=31$} \\
\hline & $2 \mathrm{k}=$ & $2 \mathrm{k}=$ & $2 \mathrm{k}=$ & $2 \mathrm{k}=$ & $2 \mathrm{k}=$ & $2 \mathrm{k}=$ & $2 \mathrm{k}=$ & $2 \mathrm{k}=$ \\
\hline
\end{tabular}




\begin{tabular}{|l|l|l|l|l|l|l|l|l|}
\hline & $\begin{array}{l}\text { SADN } \\
(5,2,8) / / 2\end{array}$ & $\begin{array}{l}\text { SADN } \\
(7,4,1) / / 2\end{array}$ & $\begin{array}{l}\text { SADN } \\
(5,2,8) / / 4\end{array}$ & $\begin{array}{l}\text { SADN } \\
(7,4,1) \\
1 / 4\end{array}$ & $\begin{array}{l}\text { SADN } \\
(5,2,8) \\
/ / 6\end{array}$ & $\begin{array}{l}\text { SADN } \\
(7,4,1)\end{array}$ & $\begin{array}{l}\text { SADN } \\
(5,2,8) \\
1 / 8\end{array}$ & $\begin{array}{l}\text { SADN } \\
(7,4,1) \\
/ / 8\end{array}$ \\
\hline 5//A & $7 / / \mathrm{R} 1$ & $5 / / \mathrm{R} 1$ & $7 / / \mathrm{R} 2$ & $5 / / \mathrm{R} 2$ & $7 / / \mathrm{R} 3$ & $5 / / \mathrm{R} 3$ & $7 / / \mathrm{R} 4$ & $5 / / \mathrm{R} 4$ \\
\hline $7 / / \mathrm{A}$ & $5 / / \mathrm{R} 1$ & $7 / / \mathrm{R} 1$ & $5 / / \mathrm{R} 2$ & $7 / / \mathrm{R} 2$ & $5 / / \mathrm{R} 3$ & $7 / / \mathrm{R} 3$ & $5 / / \mathrm{R} 4$ & $7 / / \mathrm{R} 4$ \\
\hline
\end{tabular}

\begin{tabular}{|l|l|l|l|l|l|l|l|l|}
\hline $\begin{array}{l}\text { Series } \\
\text { and } \\
\text { last } \\
\text { digit } \\
\text { of } \mathrm{Pn}\end{array}$ & \multicolumn{7}{|c|}{ Finding value of px for pe'=19 and pe'=19 } \\
\hline & $2 \mathrm{k}=$ & $2 \mathrm{k}=$ & $2 \mathrm{k}=$ & $2 \mathrm{k}=$ & $2 \mathrm{k}=$ & $2 \mathrm{k}=$ & $2 \mathrm{k}=$ & $2 \mathrm{k}=$ \\
& $\mathrm{SADN}$ & $\mathrm{SADN}$ & $\mathrm{SADN}$ & $\mathrm{SADN}$ & $\mathrm{SADN}$ & $\mathrm{SADN}$ & $\mathrm{SADN}$ & $\mathrm{SADN}$ \\
& $(5,2,8) / / 2$ & $(7,4,1) / / 2$ & $(5,2,8) / / 4$ & $(7,4,1)$ & $(5,2,8)$ & $(7,4,1)$ & $(5,2,8)$ & $(7,4,1)$ \\
& & & & $/ / 4$ & $/ / 6$ & $/ / 6$ & $/ / 8$ & $/ / 8$ \\
\hline $5 / / \mathrm{A}$ & $5 / / \mathrm{R} 2$ & $7 / / \mathrm{R} 2$ & $5 / / \mathrm{R} 4$ & $7 / / \mathrm{R} 4$ & $5 / / \mathrm{R} 1$ & $7 / / \mathrm{R} 1$ & $5 / / \mathrm{R} 3$ & $7 / / \mathrm{R} 3$ \\
\hline $7 / / \mathrm{A}$ & $7 / / \mathrm{R} 2$ & $5 / / \mathrm{R} 2$ & $7 / / \mathrm{R} 4$ & $5 / / \mathrm{R} 4$ & $7 / / \mathrm{R} 1$ & $5 / / \mathrm{R} 1$ & $7 / / \mathrm{R} 3$ & $5 / / \mathrm{R} 3$ \\
\hline
\end{tabular}

\begin{tabular}{|l|l|l|l|l|l|l|l|l|}
\hline $\begin{array}{l}\text { Series } \\
\text { and } \\
\text { last } \\
\text { digit } \\
\text { of } \mathrm{Pn}\end{array}$ & \multicolumn{7}{|c|}{ Finding value of px for pe'=19 and pe'"=23 } \\
\hline & $2 \mathrm{k}=$ & $2 \mathrm{k}=$ & $2 \mathrm{k}=$ & $2 \mathrm{k}=$ & $2 \mathrm{k}=$ & $2 \mathrm{k}=$ & $2 \mathrm{k}=$ & $2 \mathrm{k}=$ \\
& $\mathrm{SADN}$ & $\mathrm{SADN}$ & $\mathrm{SADN}$ & $\mathrm{SADN}$ & $\mathrm{SADN}$ & $\mathrm{SADN}$ & $\mathrm{SADN}$ & $\mathrm{SADN}$ \\
& $(5,2,8) / / 2$ & $(7,4,1) / / 2$ & $(5,2,8) / / 4$ & $(7,4,1)$ & $(5,2,8)$ & $(7,4,1)$ & $(5,2,8)$ & $(7,4,1)$ \\
& & & & $/ / 4$ & $/ / 6$ & $/ / 6$ & $/ / 8$ & $/ / 8$ \\
\hline 5//A & $7 / / \mathrm{R} 1$ & $5 / / \mathrm{R} 1$ & $7 / / \mathrm{R} 2$ & $5 / / \mathrm{R} 2$ & $7 / / \mathrm{R} 3$ & $5 / / \mathrm{R} 3$ & $7 / / \mathrm{R} 4$ & $5 / / \mathrm{R} 4$ \\
\hline $7 / / \mathrm{A}$ & $5 / / \mathrm{R} 1$ & $7 / / \mathrm{R} 1$ & $5 / / \mathrm{R} 2$ & $7 / / \mathrm{R} 2$ & $5 / / \mathrm{R} 3$ & $7 / / \mathrm{R} 3$ & $5 / / \mathrm{R} 4$ & $7 / / \mathrm{R} 4$ \\
\hline
\end{tabular}

\begin{tabular}{|l|l|l|l|l|l|l|l|l|}
\hline $\begin{array}{l}\text { Series } \\
\text { and } \\
\text { last } \\
\text { digit } \\
\text { of } \mathrm{Pn}\end{array}$ & \multicolumn{7}{|c|}{ Finding value of px for pe'=19 and pe'”=29 } \\
\hline & $2 \mathrm{k}=$ & $2 \mathrm{k}=$ & $2 \mathrm{k}=$ & $2 \mathrm{k}=$ & $2 \mathrm{k}=$ & $2 \mathrm{k}=$ & $2 \mathrm{k}=$ & $2 \mathrm{k}=$ \\
& $\mathrm{SADN}$ & $\mathrm{SADN}$ & $\mathrm{SADN}$ & $\mathrm{SADN}$ & $\mathrm{SADN}$ & $\mathrm{SADN}$ & $\mathrm{SADN}$ & $\mathrm{SADN}$ \\
& $(5,2,8) / / 2$ & $(7,4,1) / / 2$ & $(5,2,8) / / 4$ & $(7,4,1)$ & $(5,2,8)$ & $(7,4,1)$ & $(5,2,8)$ & $(7,4,1)$ \\
& & & & $/ / 4$ & $/ / 6$ & $/ / 6$ & $/ / 8$ & $/ / 8$ \\
\hline $5 / / \mathrm{A}$ & $7 / / \mathrm{R} 2$ & $5 / / \mathrm{R} 2$ & $7 / / \mathrm{R} 4$ & $5 / / \mathrm{R} 4$ & $7 / / \mathrm{R} 1$ & $5 / / \mathrm{R} 1$ & $7 / / \mathrm{R} 3$ & $5 / / \mathrm{R} 3$ \\
\hline $7 / / \mathrm{A}$ & $5 / / \mathrm{R} 2$ & $7 / / \mathrm{R} 2$ & $5 / / \mathrm{R} 4$ & $7 / / \mathrm{R} 4$ & $5 / / \mathrm{R} 1$ & $7 / / \mathrm{R} 1$ & $5 / / \mathrm{R} 3$ & $7 / / \mathrm{R} 3$ \\
\hline
\end{tabular}




\begin{tabular}{|l|l|l|l|l|l|l|l|l|}
\hline $\begin{array}{l}\text { Series } \\
\text { and } \\
\text { last } \\
\text { digit } \\
\text { of } \mathrm{Pn}\end{array}$ & \multicolumn{7}{|c|}{ Finding value of px for pe'=19 and pe' $=31$} \\
\hline & $2 \mathrm{k}=$ & $2 \mathrm{k}=$ & $2 \mathrm{k}=$ & $2 \mathrm{k}=$ & $2 \mathrm{k}=$ & $2 \mathrm{k}=$ & $2 \mathrm{k}=$ & $2 \mathrm{k}=$ \\
& $\mathrm{SADN}$ & $\mathrm{SADN}$ & $\mathrm{SADN}$ & $\mathrm{SADN}$ & $\mathrm{SADN}$ & $\mathrm{SADN}$ & $\mathrm{SADN}$ & $\mathrm{SADN}$ \\
& $(5,2,8) / / 2$ & $(7,4,1) / / 2$ & $(5,2,8) / / 4$ & $(7,4,1)$ & $(5,2,8)$ & $(7,4,1)$ & $(5,2,8)$ & $(7,4,1)$ \\
& & & & $/ / 4$ & $/ / 6$ & $/ / 6$ & $/ / 8$ & $/ / 8$ \\
\hline $5 / / \mathrm{A}$ & $5 / / \mathrm{R} 3$ & $7 / / \mathrm{R} 3$ & $5 / / \mathrm{R} 1$ & $7 / / \mathrm{R} 1$ & $5 / / \mathrm{R} 4$ & $7 / / \mathrm{R} 4$ & $5 / / \mathrm{R} 2$ & $7 / / \mathrm{R} 2$ \\
\hline $7 / / \mathrm{A}$ & $7 / / \mathrm{R} 3$ & $5 / / \mathrm{R} 3$ & $7 / / \mathrm{R} 1$ & $5 / / \mathrm{R} 1$ & $7 / / \mathrm{R} 4$ & $5 / / \mathrm{R} 4$ & $7 / / \mathrm{R} 2$ & $5 / / \mathrm{R} 2$ \\
\hline
\end{tabular}

\begin{tabular}{|l|l|l|l|l|l|l|l|l|}
\hline $\begin{array}{l}\text { Series } \\
\text { and } \\
\text { last } \\
\text { digit } \\
\text { of } \mathrm{Pn}\end{array}$ & \multicolumn{7}{|c|}{ Finding value of px for pe'=23 and pe'”=23 } \\
\hline & $2 \mathrm{k}=$ & $2 \mathrm{k}=$ & $2 \mathrm{k}=$ & $2 \mathrm{k}=$ & $2 \mathrm{k}=$ & $2 \mathrm{k}=$ & $2 \mathrm{k}=$ & $2 \mathrm{k}=$ \\
& $\mathrm{SADN}$ & $\mathrm{SADN}$ & $\mathrm{SADN}$ & $\mathrm{SADN}$ & $\mathrm{SADN}$ & $\mathrm{SADN}$ & $\mathrm{SADN}$ & $\mathrm{SADN}$ \\
& $(5,2,8) / / 2$ & $(7,4,1) / / 2$ & $(5,2,8) / / 4$ & $(7,4,1)$ & $(5,2,8)$ & $(7,4,1)$ & $(5,2,8)$ & $(7,4,1)$ \\
& & & & $/ / 4$ & $/ / 6$ & $/ / 6$ & $/ / 8$ & $/ / 8$ \\
\hline $5 / / \mathrm{A}$ & $5 / / \mathrm{R} 3$ & $7 / / \mathrm{R} 3$ & $5 / / \mathrm{R} 1$ & $7 / / \mathrm{R} 1$ & $5 / / \mathrm{R} 4$ & $7 / / \mathrm{R} 4$ & $5 / / \mathrm{R} 2$ & $7 / / \mathrm{R} 2$ \\
\hline $7 / / \mathrm{A}$ & $7 / / \mathrm{R} 3$ & $5 / / \mathrm{R} 3$ & $7 / / \mathrm{R} 1$ & $5 / / \mathrm{R} 1$ & $7 / / \mathrm{R} 4$ & $5 / / \mathrm{R} 4$ & $7 / / \mathrm{R} 2$ & $5 / / \mathrm{R} 2$ \\
\hline
\end{tabular}

\begin{tabular}{|l|l|l|l|l|l|l|l|l|}
\hline $\begin{array}{l}\text { Series } \\
\text { and } \\
\text { last } \\
\text { digit } \\
\text { of Pn }\end{array}$ & \multicolumn{7}{|c|}{ Finding value of px for pe'=23 and pe' '=29 } \\
\hline & $2 \mathrm{k}=$ & $2 \mathrm{k}=$ & $2 \mathrm{k}=$ & $2 \mathrm{k}=$ & $2 \mathrm{k}=$ & $2 \mathrm{k}=$ & $2 \mathrm{k}=$ & $2 \mathrm{k}=$ \\
& $\mathrm{SADN}$ & $\mathrm{SADN}$ & $\mathrm{SADN}$ & $\mathrm{SADN}$ & $\mathrm{SADN}$ & $\mathrm{SADN}$ & $\mathrm{SADN}$ & $\mathrm{SADN}$ \\
& $(5,2,8) / / 2$ & $(7,4,1) / / 2$ & $(5,2,8) / / 4$ & $(7,4,1)$ & $(5,2,8)$ & $(7,4,1)$ & $(5,2,8)$ & $(7,4,1)$ \\
& & & & $/ / 4$ & $/ / 6$ & $/ / 6$ & $/ / 8$ & $/ / 8$ \\
\hline $5 / / \mathrm{A}$ & $5 / / \mathrm{R} 1$ & $7 / / \mathrm{R} 1$ & $5 / / \mathrm{R} 2$ & $7 / / \mathrm{R} 2$ & $5 / / \mathrm{R} 3$ & $7 / / \mathrm{R} 3$ & $5 / / \mathrm{R} 4$ & $7 / / \mathrm{R} 4$ \\
\hline $7 / / \mathrm{A}$ & $7 / / \mathrm{R} 1$ & $5 / / \mathrm{R} 1$ & $7 / / \mathrm{R} 2$ & $5 / / \mathrm{R} 2$ & $7 / / \mathrm{R} 3$ & $5 / / \mathrm{R} 3$ & $7 / / \mathrm{R} 4$ & $5 / / \mathrm{R} 4$ \\
\hline
\end{tabular}

\begin{tabular}{|l|l|}
\hline $\begin{array}{l}\text { Series } \\
\text { and }\end{array}$ & Finding value of $\mathrm{px}$ for $\mathrm{pe} '=23$ and $\mathrm{pe}^{\prime \prime}=31$ \\
last & \\
\hline
\end{tabular}




\begin{tabular}{|l|l|l|l|l|l|l|l|l|}
\hline $\begin{array}{l}\text { digit } \\
\text { of Pn }\end{array}$ & \multicolumn{9}{|l|}{$\mid$} \\
\hline & $2 \mathrm{k}=$ & $2 \mathrm{k}=$ & $2 \mathrm{k}=$ & $2 \mathrm{k}=$ & $2 \mathrm{k}=$ & $2 \mathrm{k}=$ & $2 \mathrm{k}=$ & $2 \mathrm{k}=$ \\
& $\mathrm{SADN}$ & $\mathrm{SADN}$ & $\mathrm{SADN}$ & $\mathrm{SADN}$ & $\mathrm{SADN}$ & SADN & SADN & SADN \\
& $(5,2,8) / / 2$ & $(7,4,1) / / 2$ & $(5,2,8) / / 4$ & $(7,4,1)$ & $(5,2,8)$ & $(7,4,1)$ & $(5,2,8)$ & $(7,4,1)$ \\
& & & & $/ / 4$ & $/ / 6$ & $/ / 6$ & $/ / 8$ & $/ / 8$ \\
\hline $5 / / \mathrm{A}$ & $7 / / \mathrm{R} 4$ & $5 / / \mathrm{R} 4$ & $7 / / \mathrm{R} 3$ & $5 / / \mathrm{R} 3$ & $7 / / \mathrm{R} 2$ & $5 / / \mathrm{R} 2$ & $7 / / \mathrm{R} 1$ & $5 / / \mathrm{R} 1$ \\
\hline $7 / / \mathrm{A}$ & $5 / / \mathrm{R} 4$ & $7 / / \mathrm{R} 4$ & $5 / / \mathrm{R} 3$ & $7 / / \mathrm{R} 3$ & $5 / / \mathrm{R} 2$ & $7 / / \mathrm{R} 2$ & $5 / / \mathrm{R} 1$ & $7 / / \mathrm{R} 1$ \\
\hline
\end{tabular}

\begin{tabular}{|l|l|l|l|l|l|l|l|l|}
\hline $\begin{array}{l}\text { Series } \\
\text { and } \\
\text { last } \\
\text { digit } \\
\text { of } \mathrm{Pn}\end{array}$ & \multicolumn{7}{|c|}{ Finding value of px for pe'=29 and pe'=29 } \\
\hline & $2 \mathrm{k}=$ & $2 \mathrm{k}=$ & $2 \mathrm{k}=$ & $2 \mathrm{k}=$ & $2 \mathrm{k}=$ & $2 \mathrm{k}=$ & $2 \mathrm{k}=$ & $2 \mathrm{k}=$ \\
& $\mathrm{SADN}$ & $\mathrm{SADN}$ & $\mathrm{SADN}$ & $\mathrm{SADN}$ & $\mathrm{SADN}$ & $\mathrm{SADN}$ & $\mathrm{SADN}$ & $\mathrm{SADN}$ \\
& $(5,2,8) / / 2$ & $(7,4,1) / / 2$ & $(5,2,8) / / 4$ & $(7,4,1)$ & $(5,2,8)$ & $(7,4,1)$ & $(5,2,8)$ & $(7,4,1)$ \\
& & & & $/ / 4$ & $/ / 6$ & $/ / 6$ & $/ / 8$ & $/ / 8$ \\
\hline $5 / / \mathrm{A}$ & $5 / / \mathrm{R} 2$ & $7 / / \mathrm{R} 2$ & $5 / / \mathrm{R} 4$ & $7 / / \mathrm{R} 4$ & $5 / / \mathrm{R} 1$ & $7 / / \mathrm{R} 1$ & $5 / / \mathrm{R} 3$ & $7 / / \mathrm{R} 3$ \\
\hline $7 / / \mathrm{A}$ & $7 / / \mathrm{R} 2$ & $5 / / \mathrm{R} 2$ & $7 / / \mathrm{R} 4$ & $5 / / \mathrm{R} 4$ & $7 / / \mathrm{R} 1$ & $5 / / \mathrm{R} 1$ & $7 / / \mathrm{R} 3$ & $5 / / \mathrm{R} 3$ \\
\hline
\end{tabular}

\begin{tabular}{|l|l|l|l|l|l|l|l|l|}
\hline $\begin{array}{l}\text { Series } \\
\text { and } \\
\text { last } \\
\text { digit } \\
\text { of } \mathrm{Pn}\end{array}$ & \multicolumn{7}{|c|}{ Finding value of px for pe'=29 and pe'’=31 } \\
\hline & $2 \mathrm{k}=$ & $2 \mathrm{k}=$ & $2 \mathrm{k}=$ & $2 \mathrm{k}=$ & $2 \mathrm{k}=$ & $2 \mathrm{k}=$ & $2 \mathrm{k}=$ & $2 \mathrm{k}=$ \\
& $\mathrm{SADN}$ & $\mathrm{SADN}$ & $\mathrm{SADN}$ & $\mathrm{SADN}$ & $\mathrm{SADN}$ & $\mathrm{SADN}$ & $\mathrm{SADN}$ & $\mathrm{SADN}$ \\
& $(5,2,8) / / 2$ & $(7,4,1) / / 2$ & $(5,2,8) / / 4$ & $(7,4,1)$ & $(5,2,8)$ & $(7,4,1)$ & $(5,2,8)$ & $(7,4,1)$ \\
& & & & $/ / 4$ & $/ / 6$ & $/ / 6$ & $/ / 8$ & $/ / 8$ \\
\hline $5 / / \mathrm{A}$ & $7 / / \mathrm{R} 3$ & $5 / / \mathrm{R} 3$ & $7 / / \mathrm{R} 1$ & $5 / / \mathrm{R} 1$ & $7 / / \mathrm{R} 4$ & $5 / / \mathrm{R} 4$ & $7 / / \mathrm{R} 2$ & $5 / / \mathrm{R} 2$ \\
\hline $7 / / \mathrm{A}$ & $5 / / \mathrm{R} 3$ & $7 / / \mathrm{R} 3$ & $5 / / \mathrm{R} 1$ & $7 / / \mathrm{R} 1$ & $5 / / \mathrm{R} 4$ & $7 / / \mathrm{R} 4$ & $5 / / \mathrm{R} 2$ & $7 / / \mathrm{R} 2$ \\
\hline
\end{tabular}

\begin{tabular}{|l|l|l|l|l|l|l|l|l|}
\hline $\begin{array}{l}\text { Series } \\
\text { and } \\
\text { last } \\
\text { digit } \\
\text { of Pn }\end{array}$ & \multicolumn{7}{|c|}{ Finding value of $p x$ for $p e^{\prime}=31$ and pe''=31 } \\
\hline & $2 \mathrm{k}=$ & $2 \mathrm{k}=$ & $2 \mathrm{k}=$ & $2 \mathrm{k}=$ & $2 \mathrm{k}=$ & $2 \mathrm{k}=$ & $2 \mathrm{k}=$ & $2 \mathrm{k}=$ \\
& $\mathrm{SADN}$ & $\mathrm{SADN}$ & $\mathrm{SADN}$ & $\mathrm{SADN}$ & $\mathrm{SADN}$ & $\mathrm{SADN}$ & $\mathrm{SADN}$ & $\mathrm{SADN}$ \\
& $(5,2,8) / / 2$ & $(7,4,1) / / 2$ & $(5,2,8) / / 4$ & $(7,4,1)$ & $(5,2,8)$ & $(7,4,1)$ & $(5,2,8)$ & $(7,4,1)$ \\
\hline
\end{tabular}




\begin{tabular}{|l|l|l|l|l|l|l|l|l|}
\hline & & & & $/ / 4$ & $/ / 6$ & $/ / 6$ & $/ / 8$ & $/ / 8$ \\
\hline 5//A & $5 / / \mathrm{R} 2$ & $7 / / \mathrm{R} 2$ & $5 / / \mathrm{R} 4$ & $7 / / \mathrm{R} 4$ & $5 / / \mathrm{R} 1$ & $7 / / \mathrm{R} 1$ & $5 / / \mathrm{R} 3$ & $7 / / \mathrm{R} 3$ \\
\hline 7//A & $7 / / \mathrm{R} 2$ & $5 / / \mathrm{R} 2$ & $7 / / \mathrm{R} 4$ & $5 / / \mathrm{R} 4$ & $7 / / \mathrm{R} 1$ & $5 / / \mathrm{R} 1$ & $7 / / \mathrm{R} 3$ & $5 / / \mathrm{R} 3$ \\
\hline
\end{tabular}

Only those values of ' $n$ ' are to be considered, whose value is greater than $p_{n} \cdot d$ and less than $6 \mathrm{I}+1$

Only those values of $p_{e}{ }^{\prime}, p_{e}{ }^{\prime}$ and $p_{x}$ are to be considered, whose value is greater than $p_{e} \cdot d$ and less than $6 \mathrm{I} \pm 1$

Number of unique c1+c2 combinations of type2 $=n(c+c)-\left[n^{\prime}(c+c)-n^{\prime \prime}(c+c)\right]$ 


\section{C.}

\section{Step3:}

\section{$c 1+c 2$ of type 2 derived from $6 p_{1} p_{2}$ where $p_{1}$ and $p_{2}$ are primes}

\section{Step3: $\quad c 1+c 2$ derived from $6 p_{1} p_{2}$ :}

Suppose an even number is denoted as $2 \mathrm{k}$

Suppose $\mathrm{p}_{1}$ and $\mathrm{p}_{2}$ are two primes which are factors of the two composites $\mathrm{c} 1$ and $\mathrm{c} 2$ respectively, which form the combination as $\mathrm{c} 1+\mathrm{c} 2=2 \mathrm{k}$

Now consider the following:-

Floor function of $\left(1 / 6\right.$ (floor function of $\left.\left(\left(2 \mathrm{k} / \mathrm{p}_{1}\right)\right)\right)=\mathrm{I}_{1}$

$2 \mathrm{k}-\mathrm{p}_{1}\left(6 \mathrm{I}_{1}+1\right)=\mathrm{a}$

$\left[a+6 n p_{1}\right] / p_{2}=$ an Integer; for particular value of $n$ viz. $n_{1}\left(n_{1}=4\right.$ in case of $\mathrm{p}_{1}=13 \& \mathrm{p}_{2}=$ 7)

$\left(6 \mathrm{I}_{1}+1\right)-6 \mathrm{n}_{1}=$ integer $_{1}$

And

Floor function of $\left(2 \mathrm{k} / 6 \mathrm{p}_{2}\right)=\mathrm{I}_{2}$

$2 \mathrm{k}-\mathrm{p}_{2}\left(6 \mathrm{I}_{2}+1\right)=\mathrm{b}$

$\left[b+6 p_{2} n^{\prime}\right] / p_{1}=$ Integer for particular value of $n$ viz. $n_{2}\left(n_{2}=11\right.$ in case of $p_{1}=13 \& p_{2}=$ 7)

$\left(6 \mathrm{I}_{2}+1\right)-6 \mathrm{n}_{2}=$ integer $_{2}$

Now first combination of type $\mathrm{c} 1+\mathrm{c} 2$ would be :-

$\left(7\right.$ integer $\left._{2}\right)+\left(13\right.$ integer $\left._{X}\right)=2 \mathrm{k}$

And last combination would be:-

$\left(7\right.$ integer $\left._{X},\right)+13$ integer $_{1}=2 \mathrm{k}$

\section{Example 1:}

Suppose there's an even number as 16658

Say a prime number $\mathrm{p}_{1}$ is 7 and another prime $\mathrm{p}_{2}$ is 11

Now floor function (ff) of $\left[(1 / 6)\left[\mathrm{ff}\right.\right.$ of $\left.\left.\left[2 \mathrm{k} / \mathrm{p}_{1}\right]\right]\right]=\mathrm{ff}$ of $[(1 / 6)$ [ff of $\left.(16658 / 7)]\right]=396=\mathrm{I}$ 


$$
\begin{aligned}
& 2 \mathrm{k}-\left[\mathrm{p}_{1}(6 \mathrm{I}+1)\right]=16658-[7 \times 2377]=19=\mathrm{d}_{1} \\
& \left(2 \mathrm{k}-\mathrm{d}_{1}\right) / \mathrm{p}_{1}=(16658-19) / 7=\text { Integer }=6 \mathrm{I}+1 \\
& {\left[\text { As } 2 \mathrm{k}-\mathrm{d}_{1}=2 \mathrm{k}-\left[2 \mathrm{k}-\mathrm{p}_{1}(6 \mathrm{I}+1)\right]=\mathrm{p}_{1}(6 \mathrm{I}+1) \text { or }\left(2 \mathrm{k}-\mathrm{d}_{1}\right) / \mathrm{p}_{1}=6 \mathrm{I}+1\right]} \\
& (16658-19) / 7=\text { Integer }=6 \mathrm{I}+1
\end{aligned}
$$

Now:-

$\left[\mathrm{d}_{1}+6 \mathrm{p}_{1} \mathrm{n}\right] / \mathrm{p}_{2}=$ an integer for a value of $\mathrm{n}$ such that $0 \leq \mathrm{n}<\mathrm{p}_{2}$

$[19+42 n] / 11=$ an integer for a value of $n$ such that $0 \leq n<11$

Here for $n=0 ; 19 / 11$ is not an integer

$\mathrm{n}=1 ;(19+42) / 11=61 / 11$ not an integer

$\mathrm{n}=2 ;(19+84) / 11=103 / 11$ not an integer

$\mathrm{n}=3 ;(19+126) / 11=145 / 11$ not an integer

$\mathrm{n}=4 ;(19+168) / 11=187 / 11=17=$ an integer

It implies that:-

$16658-187=7 x$ integer'

$16658-(11 \mathrm{x} 17)=7 \mathrm{x}$ integer'

$16658=(7 \mathrm{x}$ integer' $)+(11 \times 17)$

which is an example of $2 \mathrm{k}=\mathrm{c} 1+\mathrm{c} 2=\left(\mathrm{p}_{1} \times\right.$ integer' $)+\left(\mathrm{p}_{2} \times 17\right)$

This leads us to a third type of $c 1+c 2$ combinations where any two primes $\mathrm{p}_{1}$ and $\mathrm{p}_{2}$ would be factors of two composites which form $\mathrm{c} 1+\mathrm{c} 2$ combinations to give $\mathrm{us} 2 \mathrm{k}$.

Any such combination will be formed for primes $\mathrm{p}_{1}$ and $\mathrm{p}_{2}$ if the condition of $2 \mathrm{k} / 6 \mathrm{p}_{1} \mathrm{p}_{2} \geq 1$ is fulfilled.

In the above example when $7 \times 11 x 6 n$ (i.e. 462 times $n$ ) is added to 187 , it will give us further $\mathrm{C} 1+\mathrm{C} 2$ combinations in which 7 and 11 are factors of $\mathrm{C} 1$ and $\mathrm{C} 2$ respectively.

Number of such combinations would be given by $n+1$, where ' $n$ ' would be floor function of [(2k-187)/462]

\section{Generalised as:}

Number of type- $3 \mathrm{c} 1+\mathrm{c} 2$ combinations formed by any two prime numbers $\mathrm{p}$ and $\mathrm{p}$ ' would be floor function of [2k/6pp']

Suppose an even number $(\mathrm{EN})=2 \mathrm{k}$ 
$2 \mathrm{k} / 6 \mathrm{pp} \mathrm{p}^{\prime}=\mathrm{q} \cdot \mathrm{r}$ where $\mathrm{q}$ is an integer and $\mathrm{r}$ is fractional part i.e. $0 \leq \mathrm{r}<1$

Then there exists ' $q$ ' number of combinations such that $p a+p ' b=2 k$

Let these combinations be given as:

$$
\begin{aligned}
& \mathrm{pa}_{1}+\mathrm{p}^{\prime} \mathrm{b}_{1}=2 \mathrm{k} \\
& \mathrm{pa}_{2}+\mathrm{p}^{\prime} \mathrm{b}_{2}=2 \mathrm{k} \\
& \mathrm{pa}_{3}+\mathrm{p}^{\prime} \mathrm{b}_{3}=2 \mathrm{k} \\
& \vdots \\
& \mathrm{pa}_{\mathrm{q}}+\mathrm{p}^{\prime} \mathrm{b}_{\mathrm{q}}=2 \mathrm{k}
\end{aligned}
$$

Since least-common-multiple (lcm) of pp' and $6=6 \mathrm{pp}$ '

Hence here:

$$
\begin{array}{lll}
\mathrm{pa}_{2}=\mathrm{pa}_{1}+6 \mathrm{pp} & \text { OR } & \mathrm{a}_{2}=\mathrm{a}_{1}+6 \mathrm{p} \\
\mathrm{pa}_{3}=\mathrm{pa}_{2}+6 \mathrm{pp}, & & \mathrm{a}_{3}=\mathrm{a}_{2}+6 \mathrm{p}, \\
\mathrm{pa}_{4}=\mathrm{pa}_{3}+6 \mathrm{pp}, & \mathrm{a}_{4}=\mathrm{a}_{3}+6 \mathrm{p} \\
\vdots & \vdots \\
\mathrm{pa}_{\mathrm{q}}=\mathrm{pa}_{\mathrm{q}-1}+6 \mathrm{pp}, & & \mathrm{a}_{\mathrm{q}}=\mathrm{a}_{\mathrm{q}-1}+6 \mathrm{p} \\
& \text { OR } & \mathbf{a}_{\mathrm{q}}=\mathbf{a}_{1}+\mathbf{6}(\mathbf{q}-\mathbf{1}) \mathbf{p}
\end{array}
$$

On similar logic:-

$$
\begin{aligned}
& \mathrm{p}^{\prime} \mathrm{b}_{2}=\mathrm{p}^{\prime} \mathrm{b}_{1}-6 \mathrm{pp}, \quad \text { OR } \quad \mathrm{b}_{2}=\mathrm{b}_{1}-6 \mathrm{p} \\
& \mathrm{p}^{\prime} \mathrm{b}_{3}=\mathrm{p}^{\prime} \mathrm{b}_{2}-6 \mathrm{pp}, \quad \mathrm{b}_{3}=\mathrm{b}_{2}-6 \mathrm{p} \\
& \mathrm{p}^{\prime} \mathrm{b}_{4}=\mathrm{p}^{\prime} \mathrm{b}_{3}-6 \mathrm{pp}, \quad \mathrm{b}_{4}=\mathrm{b}_{3}-6 \mathrm{p} \\
& \text { ! } \\
& \mathrm{p}^{\prime} \mathrm{b}_{\mathrm{q}}=\mathrm{p}^{\prime} \mathrm{b}_{\mathrm{q}-1}-6 \mathrm{pp} \mathrm{p}^{\prime} \quad \mathrm{b}_{\mathrm{q}}=\mathrm{b}_{\mathrm{q}-1}-6 \mathrm{p} \\
& \text { OR } \quad b_{q}=b_{1}-6(q-1) p \\
& \text { In addition to above : } \quad \mathrm{b}_{\mathrm{q}+1}=\mathrm{b}_{1}-6 \mathrm{qp} \\
& \text { and } \quad b_{q+n}=b_{1}-6(q+n-1) p
\end{aligned}
$$

If $\mathrm{r}=\mathrm{pa}_{1}+\mathrm{p}^{\prime} \mathrm{b}_{\mathrm{q}}-6 \mathrm{pp}$; then total number of combinations of $\mathrm{c} 1+\mathrm{c} 2$ type- 3 becomes $\mathrm{q}$ 
If $\mathrm{r}=\mathrm{pa}_{1}+\mathrm{p}^{\prime} \mathrm{b}_{\mathrm{q}+1}$; then total number of combinations of $\mathrm{c} 1+\mathrm{c} 2$ type- 3 becomes $\mathrm{q}+1$

If

$$
b_{q+n(\max )}=b_{1}-6\left(q+n_{\max }-1\right) p>0
$$

then number of $c 1+c 2$ combinations of type- $3=q+n_{\max }$

where $\mathrm{n}_{\max }$ is given by:

$$
\begin{aligned}
& \mathrm{b}_{1}-6\left(\mathrm{q}+\mathrm{n}_{\max }-1\right) \mathrm{p}>0 \\
& \text { OR } \quad \mathrm{n}_{\max } \leq \text { floor function of }\left[\left(\mathrm{b}_{1} / 6 \mathrm{p}\right)-\mathrm{q}+1\right]
\end{aligned}
$$

\section{To find unique c1+c2 combinations of type-3:}

As mentioned earlier $\mathrm{c} 1+\mathrm{c} 2$ combinations of type 3 are formed by any 2 prime elements irrespective of their SADN or SADN of $2 \mathrm{k}$ or its last digit. In these combinations $\mathrm{p}_{1}$ and $\mathrm{p}_{2}$ are factors of the components on either side of the summation sign used in the combination. The general method for calculating $\mathrm{n}(\mathrm{c} 1+\mathrm{c} 2)$ of third type has been discussed above and can be generally derived as $2 \mathrm{k} / 6 \mathrm{p}_{1} \mathrm{p}_{2}=\mathrm{q} . \mathrm{r}$ where $\mathrm{q}$ is the number of $\mathrm{c} 1+\mathrm{c} 2$ combinations that would be formed by the pair of primes $\mathrm{p}_{1} \mathrm{p}_{2}$ for a given $2 \mathrm{k}$ and $\mathrm{r}$ is the fractional part. Also if the fractional part of the quotient i.e. $\mathrm{r}$ can be split into two numbers that are both composite in nature and are such that $\mathrm{p} 1$ and $\mathrm{p} 2$ are factors of either composite, then $n(c 1+c 2)=q+1$

Once we arrive at $n(c 1+c 2)$ for a given pair of $\mathrm{p}_{1} \mathrm{p}_{2}$, we need to identify the unique $\mathrm{c} 1+\mathrm{c} 2$ combinations. Two types of repetitions are possible while deriving such $\mathrm{c} 1+\mathrm{c} 2 \mathrm{combinations}$. First, those that have been already derived while calculating $\mathrm{n}(\mathrm{c} 1+\mathrm{c} 2)$ for combinations of type- 2 and second, those that have been derived by earlier pairs of $\mathrm{p}_{1} \mathrm{p}_{2}$ while calculating $\mathrm{c} 1+\mathrm{c} 2$ combinations of type- 3 . These combinations need to be identified and removed to avoid double counting.

Since $\mathrm{c} 1+\mathrm{c} 2$ of type- 2 depends on the last digit of composite odd numbers and their series vis-à-vis the last digit of $2 \mathrm{k}$ and its relevant series, those 2 factors would play an important role in identifying $\mathrm{c} 1+\mathrm{c} 2$ already derived.

If $2 \mathrm{k}=\mathrm{S} 5 / / 2$ (i.e. even number lies on S5 series and has its last digit as 2), then all such $\mathrm{c} 1+\mathrm{c} 2$ combinations which include a composite odd number ending in 7 , would form a $\mathrm{c} 1+\mathrm{c} 2$ combination of type2.

Consider $2 \mathrm{k}=16658$

Number of $\mathrm{c} 1+\mathrm{c} 2$ for $\mathrm{p} 1=7, \mathrm{p} 2=11$ :

$2 \mathrm{k} / 6 \mathrm{p}_{1} \mathrm{p}_{2}=36.05$

Total number of $\mathrm{c} 1+\mathrm{c} 2$ formed by $7 \& 11$ upto $2 \mathrm{k}$ is given as 36 . Since $2 \mathrm{k}=\mathrm{S} 5 / / 8$, then composite odd numbers ending in 3 will form $\mathrm{c} 1+\mathrm{c} 2$ combinations of type-2.

To find such $\mathrm{c} 1+\mathrm{c} 2$ combinations the following steps may be followed:

Step A: Identify the first $\mathrm{c} 1+\mathrm{c} 2$ using the method discussed above.

The first such combination $=187($ i.e. $11 \times 17)+16471($ i.e. $7 \times 2353)$ 
When we add 462(i.e. $7 \times 11 \times 6)$ to 187 and subtract 462 from 16471 ; we get the next $\mathrm{c} 1+\mathrm{c} 2$ combination:-

$649($ i.e. $11 \times 59)+16009($ i.e. $7 \times 2287)$

By adding 462n to 187 , and subtracting 462n from 16471; we get c1+c2 combinations of which 7 and 11 are factors.

Since the first number of the combinations is 187 i.e. ends in 7, adding 462, a number ending in 2 will give an odd number in the nature of $7+2=9$ and the corresponding number would be 16471(number ending 1) - 462(number ending 2) yielding an odd number ending in 9.

To this odd number ending in 9 when we add 462, we get an odd number ending in 1 and when we subtract 462 from the corresponding number ending 9, we get an odd number ending 7 . Since none of those numbers identified so far ends in 3 , they can not be derived as $\mathrm{c} 1+\mathrm{c} 2$ combination of type- 2 .

When we add 462 to the former term of the third $\mathrm{c} 1+\mathrm{c} 2$ ending in 1 , we get an odd number ending in 3. By subtracting 462 from the corresponding number ending in 7 we get an odd number ending in 5 .

This is a $\mathrm{c} 1+\mathrm{c} 2$ combination already identified.

Further when we add 462 to the former term of the $c 1+c 2$ ending in 3 (i.e. having last digit as ' 3 '), we get an odd number ending in 5 and by subtracting 462 from the corresponding number ending in 5 will end in 3. This again would be a c1+c2 combination already derived. The combinations thus derived would be as follows:-

Adding 462n

$$
\begin{aligned}
\text { i. } & 187+462=649 \\
\text { ii. } & 649+462=1111 \\
\text { iii. } & 1111+462=1573 \\
\text { iv. } & 1573+462=2035 \\
\text { v. } & 2035+462=2497
\end{aligned}
$$

Subtracting $462 \mathrm{n}$

$$
\begin{array}{rlrl}
\text { i. } & & 16471-462 & =16009 \\
\text { ii. } & & 16009-462=15547 \\
\text { iii. } & 15547-462=15085 \\
\text { iv. } & 15085-462=14623 \\
\text { v. } & 14623-462=14161
\end{array}
$$

There is a similarity between the $1^{\text {st }}$ and $6^{\text {th }}$ combination in that the composite numbers in the combination end in the same digit. This is because odd numbers end in any one of the following 5 digits- 1,3,5,7,9 and this sequence will occur in a cyclic manner. If we start adding the same even digit to any odd number, a cyclical series of odd numbers ending in different digits will be formed.

Consider the following sequences for odd number ending in digit ' 1 ':

(1) If even number ends in digit 2 then last digits will appear as: 
$1+2=3$

$3+2=5$

$5+2=7$

$7+2=9$

$9+2=1$

$1+2=3$

$\vdots$

(2) If even number ends in digit 4 then last digits will appear as:

$1+4=5$

$5+4=9$

$9+4=3$

$3+4=7$

$7+4=1$

$1+4=5$

$\vdots$

(3) If even number ends in digit 6 then last digits will appear as:

$1+6=7$

$7+6=3$

$3+6=9$

$9+6=5$

$5+6=1$

$\vdots$

(4)If even number ends in digit 8 then last digits will appear as:

$1+8=9$

$9+8=7$

$7+8=5$

$5+8=3$

$3+8=1$ 
$\vdots$

Therefore when we add the even number ending in the same digit to any odd number we get odd numbers ending in odd digits in a specific sequence which repeats itself after every 5 numbers (this is because every even number would be a multiple of 2, and adding the even number 5 times is equivalent to adding an even number having last digit as ' 0 ', which implies that the last digit remains unchanged as the last digit of added number is a '0' which is an additive identity). That is, if we add any even number ending in 2,4,6,8 to any odd number ending in a particular digit, last digit of the $1^{\text {st }}$, $1+5=6^{\text {th }}, 6+5=11^{\text {th }}, 11+5=16^{\text {th }}, 16+5=21^{\text {st }}$ number will end in the same digit. Similarly when we add the same even number to an odd number the $2^{\text {nd }}, 2+5=7^{\text {th }}, 7+5=12^{\text {th }}, 12+5=17^{\text {th }}, 17+5=22^{\text {nd }}$ number will end in the same digit. This cyclical series will be infinite in nature and the sequence will remain the same no matter which number we begin from.

Further when we add the same even number to an odd number and study the pattern of resultant number, it follows that one number out of every 5 numbers will end in the digit 5 and thus the resulting odd numbers will end in 1,3,5,7,9 in same order depending on the value of the even number that is being added.

Therefore it can be concluded that 1 out of every 5 resulting numbers will end in 1,3,5,7 and 9. We now return to the rationale behind $\mathrm{c} 1+\mathrm{c} 2$ combinations of type- 2 involving composites ending in 5 and same odd composite number ending in a particular digit depending on the SADN//last digit of $2 \mathrm{k}$ i.e. if $2 \mathrm{k}=\mathrm{S} 5$ or $\mathrm{S} 7 / / 2$, then $\mathrm{c} 1+\mathrm{c} 2$ combinations of type- 2 include composites ending in 7 and corresponding composites ending in 5 .

Putting the above patterns together it is possible to conclude that 1 out of every 5 consecutive odd numbers derived by adding the same even number to an odd number, will end in 5 and also 1 out of the same set of 5 odd numbers will end in a composite odd number.

This brings us to the pattern that since $c 1+c 2$ combinations of type- 3 are derived by adding $6 p_{1} p_{2}$ to the former term of the first $\mathrm{c} 1+\mathrm{c} 2$ combination, 2 out of every 5 resulting combinations would be such that those have been already derived as $\mathrm{c} 1+\mathrm{c} 2$ combination of type- 2 .

Therefore if $n(c 1+c 2)$ of type-3 is ' $a$ ', i.e. number of $c 1+c 2$ combinations of type- 3 is ' $a$ '; then $a / 5=b . r$ where ' $r$ ' is the fractional part. It will give the number of blocks of 5 consecutive odd numbers that would end in 5 different odd digits.

Since 2 out of 5 such consecutive odd numbers have already been derived as $c 1+c 2$ combination of type-2, it follows that $2 \mathrm{~b}$ will be the number of $\mathrm{c} 1+\mathrm{c} 2$ combinations already derived by the method for calculating $\mathrm{c} 1+\mathrm{c} 2$ of type- 2 .

In the above example,

$16658 /(7 \times 11 \times 6)=36$

$36 / 5=7.2$

There are 7 blocks of 5 consecutive odd numbers ending in 5 different odd digits. Therefore $2 b=2 x 7$ $=14$

14 out of $36 \mathrm{c} 1+\mathrm{c} 2$ combinations formed by $7 \& 11$ are those that have already been derived while calculating $\mathrm{c} 1+\mathrm{c} 2$ combinations of type- 2 . 
It is important to note that the exact number of $\mathrm{c} 1+\mathrm{c} 2$ already derived while calculating $\mathrm{c} 1+\mathrm{c} 2$ combinations of type- 2 would depend on the last digit of the first $\mathrm{c} 1+\mathrm{c} 2$ derived while finding $\mathrm{c} 1+\mathrm{c} 2$ combinations of type-3. However it can be generalized that the number of $\mathrm{c} 1+\mathrm{c} 2$ already derived as $c 1+c 2$ of type- 2 would be $2 b$ or $2 b+1$ or $2 b+2$ maximum.

The second type of possible repetitions is those $\mathrm{c} 1+\mathrm{c} 2$ combinations that have been already derived by earlier $\mathrm{p}_{1} \mathrm{p}_{2}$ combinations.

\section{Identifying $\mathbf{c 1 + c 2}$ combinations already derived by earlier $\mathbf{p}_{1} \& \mathbf{p}_{2}$ :}

In the above example, $7 \& 11$ is the first $\mathrm{p}_{1} \mathrm{p}_{2}$ pair whose $\mathrm{c} 1+\mathrm{c} 2$ of type- 3 is being identified. Therefore $\mathrm{c} 1+\mathrm{c} 2$ combination already derived earlier would be those identified while calculating $\mathrm{c} 1+\mathrm{c} 2$ combinations of type- 2 .

Therefore unique $\mathrm{c} 1+\mathrm{c} 2$ pair derived by prime pair of $7 \& 11$ would be:

Total $\mathrm{c} 1+\mathrm{c} 2=2 \mathrm{k} / 462=36$

$\mathrm{N}(\mathrm{c} 1+\mathrm{c} 2)$ of type- $2=14$

$36-14=22$

The next pair of primes would be $7 \& 13$. While deriving $\mathrm{c} 1+\mathrm{c} 2$ of type- 3 for this pair, 2 varieties of repetitions are possible. First, those already derived as $\mathrm{c} 1+\mathrm{c} 2$ of type-2. Second, those already derived as $\mathrm{c} 1+\mathrm{c} 2$ of type- 3 for the previous pair of primes $7 \& 11$. This may be done as follows:-

Step A: Calculate total c1+c2 of type-3 for the pair of primes $7 \& 13$

$16658 /(7 \times 13 \times 6)=16658 / 546=30$

$\mathrm{N}(\mathrm{c} 1+\mathrm{c} 2)$ of type- $3=30$

Number of blocks of 5 odd numbers that would occur in a cyclical manner-

$30 / 5=6$

As mentioned above, in every block of 5 odd numbers there would be 2 such c1+c2 combinations which have already been derived while calculating $\mathrm{c} 1+\mathrm{c} 2$ combinations of type- 2 . Hence in present case, their number would be $2 \times 6=12$

This implies that 12 out of $30 \mathrm{c} 1+\mathrm{c} 2$ combinations of type- 3 formed by $7 \& 13$ have already been identified while calculating $\mathrm{c} 1+\mathrm{c} 2$ of type- 2 .

For identifying $\mathrm{c} 1+\mathrm{c} 2$ already derived while calculating $\mathrm{c} 1+\mathrm{c} 2$ of type- 3 for $7 \& 11$ the following reasoning is applied:

Here one of the numbers in the prime numbers $7 \& 11$ and $7 \& 13$ is the number 7 . This means 7 would be a factor on one side of the $c 1+c 2$ combination. Those composites on the other side of the combination of which $11 \& 13$ are factors need to be identified since such composites alongwith corresponding composites of which 7 is a factor would have been already identified by the previous prime pair of $7 \& 11$. This can be done as follows- 
We first identify the first $\mathrm{c} 1+\mathrm{c} 2$ of which $7 \& 13$ are factors-

$16658-7(6 \mathrm{I}+1)=(7 \times 2377)$

$16658-16639=19$

$(19+42 n) / 13=I$

Here we need to find the value of 'n' where 'I' becomes an integer.

$(19+42 n) / 13$ becomes a integer for $n=11$

$\{19+(42 \times 11)\} / 13=37$

So $13 \times 37(=481)+7 \times 2311(=16177)=16658$ i.e. $2 \mathrm{k}$

Thereafter $13 x(37+42 n)$ would be the former term of further $c 1+c 2$ combinations and the corresponding terms would be $7 \times(2311-78 n)$

Adding $42 \mathrm{n}$ to 37 will give further composites of which 13 would be a factor. If we can identify such a composite of which 11 is also a factor derived by $7 \& 11$ prime pair.

i.e. $(37+42 n) / 11$ should be an integer

This condition is fulfilled for the value of $\mathrm{n}=2$ since $37+(42 \times 2)=121$ which is divisible by 11 .

Therefore $13 \times 121$ is the first such $\mathrm{c} 1+\mathrm{c} 2$ combination which is divisible by both $13 \& 11$ and will be a $\mathrm{c} 1+\mathrm{c} 2$ that has already been derived by the prime pair $7 \& 11$.

Thereafter every $(11 \times 42)$ nd number will be such a c1+c2

i.e. $121+(11 \times 42)=462^{\text {nd }}$ number

$121+462 \mathrm{n} \leq 6 \mathrm{I}+1($ i.e. 13$)$

This would give us the following numbers $=121,583,1045$

$13 x$ these numbers would give $\mathrm{c} 1+\mathrm{c} 2$ combinations already derived by the prime pair $7 \& 11$

However it needs to be noted that it is possible that such $\mathrm{c} 1+\mathrm{c} 2$ identified may have been identified and adjusted while calculating $\mathrm{c} 1+\mathrm{c} 2$ of type- 2 already derived. These need to be identified and adjusted to avoid double subtraction of the same $\mathrm{c} 1+\mathrm{c} 2$.

This may be identified through the following rationale-

16658 is a $\operatorname{SADN}(8 / / 8)$ number which means $(\mathrm{c} 1+\mathrm{c} 2)$ combinations of type-2 would involve composite odd numbers ending in 3. Since 13 (the number for which $n(c+c)$ or $n(c 1+c 2)$ is being calculated) ends in 3 its product with numbers ending in 1 and 5 would yield $\mathrm{c} 1+\mathrm{c} 2$ combinations of type-2. Similarly the product of 13 with numbers ending in 5 would yield such composites where corresponding number in the $\mathrm{c} 1+\mathrm{c} 2$ combination would end in 3 and would qualify therefore to be a $\mathrm{c} 1+\mathrm{c} 2$ combination of type- 2 . 
Therefore of the composite numbers identified as common to both 13 and 11, those ending in the digits 1 and 5 need to be identified as these are $c 1+c 2$ combinations already removed on account of being identified as relevant $\mathrm{c} 1+\mathrm{c} 2$ combinations of type- 2 .

In the above example the 3 such composites were identified-

$13 \times 121,13 \times 583,13 \times 1045$

Of these 13x121 would yield a composite ending in 3 and $13 \times 1045$ would yield a composite ending in 5. So these composites may be understood to have formed $\mathrm{c} 1+\mathrm{c} 2$ combinations of type- 2 which have already been identified and removing those again would result in double-removal and therefore underreporting of unique $\mathrm{c} 1+\mathrm{c} 2$ for the prime pair of $7 \& 13$. Therefore here we consider only one composite- $15 \times 583$ to form a $\mathrm{c} 1+\mathrm{c} 2$ with 7 on the other side that has already been identified while deriving $\mathrm{c} 1+\mathrm{c} 2$ combinations of type- 3 for the prime pair of $7 \& 11$.

Therefore unique $\mathrm{c} 1+\mathrm{c} 2$ for the prime pair $7 \& 13$ are given as:-

30-12[i.e. $n(c 1+c 2)$ of type-2]-1[i.e. n'(c1+c2) of type-3 for $7 \& 11)=30-13=17$

This implies that the prime pair of $7 \& 13$ will form 17 unique $c 1+c 2$ combinations of type- 3 for the even number $2 \mathrm{k}$ as 16658.

\section{Deriving unique c1+c2 for the prime pair 7\&17:}

$16658 /(7 \times 17 \times 6)=23$

As ff of $(23 / 5)=4$, there would be 4 blocks of 5 different odd numbers.

So number of $\mathrm{c} 1+\mathrm{c} 2$ combinations which have already been derived as type- $2=4 \times 2=8$ [as per mentioned above]

To determine the value of $6 \mathrm{I}-1$ for even number 16658 :

$\mathrm{I}=\mathrm{ff}$ of $[(1 / 6) \mathrm{ff}$ of $(16658 / 17)]=163$

Hence $6 \mathrm{I}-1=977$

$\mathrm{c} 1+\mathrm{c} 2$ already derived by previous prime pairs $7 \& 11,7 \& 13$ :

$(19+42 n) / 17=$ Integer for $n$ equals to 4

First $\mathrm{c} 1+\mathrm{c} 2=187($ i.e. $11 \mathrm{x} 17)+16471($ i.e. $7 x 2353)$

To identify $\mathrm{c} 1+\mathrm{c} 2$ already derived by previous prime pairs $7 \& 11$ and $7 \& 13$, we need to identify composites common to $11 \& 17$ and $13 \& 17$ as one part of $\mathrm{c} 1+\mathrm{c} 2$ for the prime pair $7 \& 17$.

For this we calculate:

$17 x[(11+42 n) / 11]=$ an integer for a particular value of ' $n$ '. 
Here it would be an integer for value of $\mathrm{n}=0$. So 187 , the first term of the $\mathrm{c} 1+\mathrm{c} 2 \mathrm{combination}$ formed by $7 \& 17$ is divisible by 11 . Thereafter every $17(11 \times 7 \times 6)^{\text {th }}$ number would be a composite already derived while calculating $\mathrm{c} 1+\mathrm{c} 2$ for $7 \& 11$.

This would be $7 x(11+42 n) \leq 6 I-1$

$11,473,935$

Of these $17 \mathrm{x} 935$ has already [how do we know that?] been derived while identifying $\mathrm{c} 1+\mathrm{c} 2$ type combinations. So we need to remove combinations formed by $11 \times 17$ and $17 \times 473$

Similarly to identify $\mathrm{c} 1+\mathrm{c} 2$ combination already derived by the prime pair $7 \& 13$ we need to identify a $\mathrm{c} 1+\mathrm{c} 2$ formed by $7 \& 17$ in which 17 and 13 form a common composite. This can be derived as:

$17 x[(11 \times 42 n) / 13]$

Here $(11 \times 42 n) / 13$ becomes an integer for the value of $n$ as 5 i.e. $[11+(42 \times 5)] / 13=221$

Here on every $13 \times 42^{\text {nd }}$ number will also be a composite divisible by 13 and a part of $c 1+c 2$ already derived by $7 \& 13$ :

$17 x[221+42 x 13 n]$ i.e. $17(221+546 n) \leq 6 \mathrm{I}-1$

221, 767, will be two such numbers whose product with 17 will form $\mathrm{c} 1+\mathrm{c} 2$ combination for the prime pair $7 \& 17$ and which have already been derived while calculating $\mathrm{c} 1+\mathrm{c} 2$ for the prime pair $7 \& 13$.

Total unique $\mathrm{c} 1+\mathrm{c} 2$ formed by the prime pair $7 \& 17=$

23 - 9[i.e. number of $\mathrm{c} 1+\mathrm{c} 2$ combinations already derived while calculating $\mathrm{c} 1+\mathrm{c} 2$ combinations of type-2 for 17] - 2[i.e. number of $\mathrm{c} 1+\mathrm{c} 2$ combinations already derived while calculating $\mathrm{c} 1+\mathrm{c} 2$ of type 3 for $7 \& 11$ ] - 2[i.e. number of $\mathrm{c} 1+\mathrm{c} 2$ combinations already derived while calculating $\mathrm{c} 1+\mathrm{c} 2$ of type 3 for the prime pair $7 \& 13]$

i.e. $23-(9+2+2)=23-13=10$

This implies that 17 forms 10 unique c1+c2 combinations with 7 upto the even number 16658 .

Similarly for calculating number of $\mathrm{c} 1+\mathrm{c} 2$ combinations of type- 3 for the prime pair $7 \& 19$, we first calculate the total number of $\mathrm{c} 1+\mathrm{c} 2$ combinations of type- 3 using the method:

$2 \mathrm{k} /(6 \times 7 \times 19)$ which gives us $n(c 1+c 2)=12$

Here again we first identify and remove the number of $c 1+c 2$ combinations already derived while calculating number of combinations of $\mathrm{c} 1+\mathrm{c} 2$ of type- 2 by applying the method of dividing $\mathrm{n}(\mathrm{c} 1+\mathrm{c} 2)$ into as many blocks of 5 odd numbers as possible. Here $n(c 1+c 2)=12$, so $f f$ of $(12 / 5)=2$. There are 2 complete blocks of 5 odd numbers of which 2 out of 5 would be already derived while calculating $\mathrm{c} 1+\mathrm{c} 2$ combinations of type- 2 . Therefore $2 \times 2=4 \mathrm{c} 1+\mathrm{c} 2$ combinations would be removed. 
We next identify and remove $\mathrm{c} 1+\mathrm{c} 2$ already derived while calculating $\mathrm{c} 1+\mathrm{c} 2$ for the previous prime pairs $7 \& 11,7 \& 13$ and $7 \& 17$. This will first require identification of the first $\mathrm{c} 1+\mathrm{c} 2$ combination of type- 3 formed by the prime pair $7 \& 19$. For this we follow the step-

$(19+42 n) / 19=\mathrm{I}$

To identify the value of $\mathrm{n}$ where I becomes an integer: Here I becomes an integer for $\mathrm{n}=19$. So first c1+c2 combination formed by $7 \& 19$ would be 817 (i.e. $19 x 43)+15841$ (i.e. $7 x 2263$ )

To identify first $\mathrm{c} 1+\mathrm{c} 2$ combination already derived by $7 \& 11$, we need to identify the $\mathrm{c} 1+\mathrm{c} 2$ combinations where one composite term is divisible by 7 and the other is divisible by both 19 and 11 . This requires the following step:

$19[(43+42 n) / 11]=$ an integer for a specific value of $n$.

Here this condition is satisfied for value of $n=5$. So $19 \times 253$ will be the first such composite of which $19 \& 11$ are both factors and whose corresponding number in the combination i.e. $2 \mathrm{k}-(19 \times 253)$ would be divisible by 7 . Thereafter all terms those satisfy the condition:

$19(253+(11 \times 42) n) \leq 6 \mathrm{I}+1$

$19(253+462 n) \leq 6 \mathrm{I}+1$

will form further $\mathrm{c} 1+\mathrm{c} 2$ combination already derived by the previous prime pairs $7 \& 11$ which are now being identified again while deriving $\mathrm{c} 1+\mathrm{c} 2$ of type-3 for the prime pairs $7 \& 19$.

Similarly $19[(43+42 n) / 13]=I$

So if we find value of $\mathrm{n}$ for which I becomes an integer for the above equation, we will get the first $\mathrm{c} 1+\mathrm{c} 2$ common to the prime pairs $7 \& 13$ and $7 \& 19$. Here I becomes an integer for value of $\mathrm{n}$ equals to 3. This implies $19 \times 169$ is the composite form of the first $\mathrm{c} 1+\mathrm{c} 2$ combination common to the prime pairs $7 \& 13$ and $7 \& 19$.

Thereafter all composites that satisfy the condition $19(169+546 n) \leq 6 \mathrm{I}+1$ will be $\mathrm{c} 1+\mathrm{c} 2$ combination common to the prime pairs $7 \& 13$ and $7 \& 19$.

After identifying these $\mathrm{c} 1+\mathrm{c} 2$ already obtained for previous prime pairs, the next step would be to identify if any of these have been already derived by the $c 1+c 2$ earlier or are common to any previous prime pair. These need to be identified and adjusted to avoid double removal of the same $\mathrm{c} 1+\mathrm{c} 2$ combination.

Combinations common to any 2 previous prime pairs would be derived for value of $n$ where I would become an integer in the following formula:-

Suppose unique number of $\mathrm{c} 1+\mathrm{c} 2$ combinations for $7 \& 19$ is calculated and we want to identify $\mathrm{c} 1+\mathrm{c} 2$ combinations already derived by $7 \& 11$ and $7 \& 13$ that are common to both these previous prime pairs then $19[(43+42 \mathrm{n}) /(11 \times 13)]=\mathrm{I}$

The value of integer ' $n$ ' is such that the resultant value is $<2 \mathrm{k}$. Thereafter all terms that satisfy the condition $19(143+(6 \times 143) n) \leq 6 \mathrm{I}+1$ will form further $\mathrm{c} 1+\mathrm{c} 2$ common to the prime pairs $7 \& 11$ and $7 \& 13$. 
Once all unique $\mathrm{c} 1+\mathrm{c} 2$ combinations formed by 7 with other prime elements have been derived, we need to identify $\mathrm{c} 1+\mathrm{c} 2$, combinations for other prime pairs like $11 \& 13,11 \& 17,11 \& 19$ where one of the terms would be common to all prime pairs and would be a prime number $>7$. While calculating unique $\mathrm{c} 1+\mathrm{c} 2$ for such a prime pair, we follow the same steps as above.

Only an additional step would be to identify these $\mathrm{c} 1+\mathrm{c} 2$ already derived by previous prime pairs in the nature of $7 \mathrm{p} 1$ i.e. those prime pairs where 7 is a common component of the prime pair. For this we follow the following method:-

Identify total number of $\mathrm{c} 1+\mathrm{c} 2$ combinations of type-3 for the prime pair $11 \& 13$, i.e. ff of $[16658 /(6 \times 11 \times 13)]=19$

Hence $11 \& 13$ prime pair will form $19 \mathrm{c} 1+\mathrm{c} 2$ combinations of type-3 upto $2 \mathrm{k}$.

The next step will be to divide this $\mathrm{n}(\mathrm{c} 1+\mathrm{c} 2)$ into blocks of 5 odd numbers and calculate number of $\mathrm{c} 1+\mathrm{c} 2$ combinations already derived while calculating $\mathrm{c} 1+\mathrm{c} 2$ combinations of type- 2 .

Thereafter we find $\mathrm{c} 1+\mathrm{c} 2$ combinations already derived while calculating $\mathrm{c} 1+\mathrm{c} 2$ for prime pairs in the nature of $7 \mathrm{p} 1$. For this we follow the following steps:-

First c1+c2 of 11\&13:-

187(i.e. $11 x 17)+16471($ i.e. $13 \times 1267)$

Now we find the term

$11[(17+78 n) / 7]=$ an integer, for a particular value of $n$

Here this expression becomes an integer for value of $n=4$. So $11 \times 329$ is the first number that is a component in a $\mathrm{c} 1+\mathrm{c} 2$ combination common to $11 \& 13$ and to a particular prime pair $7 \mathrm{p} 1$. Thereafter all natural numbers that satisfy the condition $11(329+(7 \times 78) n) \leq 6 \mathrm{I}-1$ will be further $\mathrm{c} 1+\mathrm{c} 2$ combinations common to the prime pairs $11 \& 13$ and $7 \mathrm{p} 1$.

Similarly, we need to identify such components common to $7 \& 13$ also since they too will constitute $\mathrm{c} 1+\mathrm{c} 2$ common to both $11 \& 13$ and $7 \mathrm{p} 1$.

For this we apply the formula to get:-

$13[(1267-66 n) / 7]=\mathrm{I}$

and find values of $\mathrm{n}$ where $\mathrm{I}$ becomes an integer. Here I becomes an integer for value of $\mathrm{n}=0$. So $13 \times 1267$ itself is a component common to $13 \& 7$ and will therefore constitute a c1+c 2 common to the prime pairs $11 \& 13$ and $7 \mathrm{p} 1$.

Therefore all numbers that satisfy the condition:-

13(1267-(7x66)n $)>0$ will give other numbers that form part of $\mathrm{c} 1+\mathrm{c} 2$ combination common to $11 \& 13$ and $7 \mathrm{p} 1$. Once these common $\mathrm{c} 1+\mathrm{c} 2$ combinations have been identified we need to find out if there is any commonality between these $c 1+c 2$ and those $c 1+c 2$ identified while calculating $c 1+c 2$ combinations of type- 2 . Adjusting for these terms we arrive at unique number of $c 1+c 2$ combinations of type-3 for the prime pair $11 \& 13$.

General method to derive number of unique $\mathrm{c} 1+\mathrm{c} 2$ combinations of type-3:- 
Step-1:

Step1: calculate total number of $\mathrm{c}+\mathrm{c} 3$ type combinations for first prime pair $\mathrm{p} 1 \mathrm{p} 2$ as follows:-

$2 \mathrm{k} / 6 \mathrm{p} 1 \mathrm{p} 2=\mathrm{q} \cdot \mathrm{r}$

If fractional part $\mathrm{r}=\mathrm{p} 1 \mathrm{a} 1+\mathrm{p} 2 \mathrm{~b}_{\mathrm{q}-1}$

The $n c+c 3=q+1$

If fractional part $\mathrm{r}+6 \mathrm{p} 1 \mathrm{p} 2=\mathrm{p} 1 \mathrm{a} 1+\mathrm{p} 2 \mathrm{bq}$ then

$\mathrm{Nc}+\mathrm{c} 3=\mathrm{q}$

Step-2:

Step2: identify those $\mathrm{c}+\mathrm{c}$ out of $\mathrm{nc}+\mathrm{c} 3$ that have already been derived while calculating $\mathrm{c}+\mathrm{c} 2$ type combinations. For this divide nc+c $3 / 5$ which gives the number of blocks of 5 odd numbers ending in 5 different possible odd digits. 2 out of every 5 blocks of 5 will be part of a c+c already derived while calculating $\mathrm{c}+\mathrm{c} 2$ type combinations (as details discussed above)

If $\mathrm{nc}+\mathrm{c} 3 / 5=\mathrm{a}$

Then number of $c+c$ already derived while calculating $c+c 2=2 a$

Note: this number may increase by 1 or maximum 2 depending on 2 factors

(a) Last digits of the components of first $\mathrm{c}+\mathrm{c}$ formed by the prime pair $\mathrm{p} 1 \mathrm{p} 2$

(b) Remainder of the value of $n(c+c 3) / 5=a . r$, where ff of $[N(c+c 3) / 5]=a$

This value needs to be calculated from $\mathrm{n}(\mathrm{c}+\mathrm{c} 3)$.

Step3:

For the first prime pair $\mathrm{p} 1 \mathrm{p} 2 ; \mathrm{n}(\mathrm{c}+\mathrm{c} 3)-2 \mathrm{a}$ will give the number of unique $\mathrm{c} 1+\mathrm{c} 2$ combinations of type3 formed by this prime pair for the given $2 \mathrm{k}$.

Step4:

For the next prime pair $\mathrm{p}_{1} \mathrm{p}_{3}$ after calculating $\mathrm{n}(\mathrm{c}+\mathrm{c} 3)$ and $2 \mathrm{a}$, an additional step required would be to identify $c 1+c 2$ already derived by the previous prime pair $\mathrm{p}_{1} \mathrm{p}_{2}$. Since $\mathrm{p}_{1}$ is common to both the prime pairs $\mathrm{p}_{1} \mathrm{p}_{2}$ and $\mathrm{p}_{1} \mathrm{p}_{3}$, any $\mathrm{c} 1+\mathrm{c} 2$ formed by $\mathrm{p}_{1} \mathrm{p}_{3}$ wherein one of the two components of the combinations is divisible by $\mathrm{p}_{1}$ and the other is divisible by both $\mathrm{p}_{2}$ and $\mathrm{p}_{3}$ would necessarily be a $\mathrm{c} 1+\mathrm{c} 2$ common to both these prime pairs $\mathrm{p}_{1} \mathrm{p}_{2}$ and $\mathrm{p}_{1} \mathrm{p}_{3}$. This common $\mathrm{c} 1+\mathrm{c} 2$ may be identified as follows:-

(a) Find out the first $\mathrm{c} 1+\mathrm{c} 2$ of which $\mathrm{p}_{1} \mathrm{p}_{3}$ are factors on either side of the combination.

$2 \mathrm{k}-\mathrm{p}_{1}(6 \mathrm{I} \pm 1)=\mathrm{W}$

$(\mathrm{W}+6 \mathrm{np} 1) / \mathrm{p} 3=$ an integer, for a particular value of $\mathrm{n}$.

Find the value of $\mathrm{n}$ where this expression becomes an integer. Let us denote this integer as $\mathrm{y}$. This implies $\mathrm{p}_{3} \mathrm{y}$ is the composite component divisible by $\mathrm{p}_{3}$ which alongwith $2 \mathrm{k}-\mathrm{p}_{3} \mathrm{y}$ will form the first $\mathrm{c} 1+\mathrm{c} 2$ combination for the prime pair $\mathrm{p}_{1} \mathrm{p}_{3}$. 
(b) Now we need to find the $c 1+c 2$ combination for $\mathrm{p}_{1} \mathrm{p}_{3}$ in which one component would be composite whose factors are $\mathrm{p}_{2}$ and $\mathrm{p}_{3}$. For this we calculate the following:-

$\mathrm{P} 3[$ ( $y+n .6 . p 1) / p 2]=$ an integer, for a particular value of $n$.

Find value of $n$ which makes this expression as an integer. Let us denote this integer as $z$. It implies that $\mathrm{p}_{3} \mathrm{z}$ is a composite component of which $\mathrm{p}_{2}$ and $\mathrm{p}_{3}$ are factors and which is a part of the first such $\mathrm{c} 1+\mathrm{c} 2$ combination that is common to both the prime pairs $\mathrm{p}_{1} \mathrm{p}_{2}$ and $\mathrm{p}_{1} \mathrm{p}_{3}$. Thereafter every such combination that satisfies the condition $\mathrm{p}_{2} \mathrm{z}+6 \mathrm{p}_{1} \mathrm{p}_{2} \leq 6 \mathrm{I}+1$ will form further such $c 1+c 2$ combinations that are common to the $c 1+c 2$ combinations obtained from prime pairs $\mathrm{p}_{1} \mathrm{p}_{2}$ and $\mathrm{p}_{1} \mathrm{p}_{3}$. Let us call this number of combinations as $\mathrm{n}^{\prime}(\mathrm{c}+\mathrm{c} 3)$.

Therefore $n^{\prime}(\mathrm{c}+\mathrm{c} 3)=\left[\left\{(6 \mathrm{I}+1)-\left(\mathrm{p}_{2} \mathrm{z}\right)\right\} / 6 \mathrm{p}_{1} \mathrm{p}_{2}\right]+1$

This n' $(c+c 3)$ will give total number of $c 1+c 2$ combinations common to both prime pairs $\mathrm{p}_{1} \mathrm{p}_{2}$ and $\mathrm{p}_{1} \mathrm{p}_{3}$.

(c) The next step would be to identify if any of these n' $(\mathrm{c}+\mathrm{c} 3)$ combinations include a component whose last digit is 5 . If there is/are; then this would indicate $\mathrm{c} 1+\mathrm{c} 2$ combinations already removed while counting for repetitions due to $c 1+c 2$ combinations of type-2. Those need to be identified and adjusted to avoid double removal of the same $\mathrm{c} 1+\mathrm{c} 2$ combination. ff of $\left(n^{\prime}(c+c 3) / 5\right)$ will give the number of such $c 1+c 2$ already derived while identifying $c 1+c 2$ combinations of type- 2 that are being identified again while identifying common $c 1+c 2$ combinations for the prime pairs $\mathrm{p}_{1} \mathrm{p}_{2}$ and $\mathrm{p}_{1} \mathrm{p}_{3}$. Lets denote the number of such common $\mathrm{c}_{1}+\mathrm{c}_{2}$ combinations as n' (c+c3).

Hence Unique $\mathrm{c} 1+\mathrm{c} 2$ combinations for the prime pair $\mathrm{p}_{1} \mathrm{p}_{3}=\mathrm{n}(\mathrm{c}+\mathrm{c} 3)-2 \mathrm{a}-\mathrm{n}{ }^{\prime}(\mathrm{c}+\mathrm{c} 3)-\mathrm{n}$ ' $(\mathrm{c}+\mathrm{c} 3)$

Step 5:

For the next prime pair $\mathrm{p}_{1} \mathrm{p}_{4}$, we first calculate $\mathrm{n}(\mathrm{c}+\mathrm{c} 3)$ and $2 \mathrm{a}$ :

$2 \mathrm{k} / 6 \mathrm{p}_{1} \mathrm{p}_{4}=\mathrm{q} . \mathrm{r}$, where ' $\mathrm{r}$ ' is the fractional part

ff of $(q / 5)=a$

we then calculate $n^{\prime}(c+c 3)$ for identifying $c 1+c 2$ common to the prime pairs $p_{1} p_{2}$ and $p_{1} p_{4}$.

First $\mathrm{c} 1+\mathrm{c} 2$ for $\mathrm{p}_{1} \mathrm{p}_{4}$ is obtained as:-

$\left(\mathrm{W}+6 \mathrm{np}_{1}\right) / \mathrm{p} 4=$ an integer, for a particular value of $\mathrm{n}$

Find value of $\mathrm{n}$ for which this expression becomes an integer, denoted as $\mathrm{y}$.

$\mathrm{p}_{4} \mathrm{y}$ would be part of the first $\mathrm{c} 1+\mathrm{c} 2$ formed by $\mathrm{p}_{1} \mathrm{p}_{4}$

$\mathrm{p}_{4}\left[\left(\mathrm{y}+6 \mathrm{p}_{1} \mathrm{n}\right) / \mathrm{p}_{2}\right]=\mathrm{I}$

Find values of $\mathrm{n}$ for which $\mathrm{I}$ becomes an integer, denoted as $\mathrm{z}$.

$\mathrm{p}_{4} \cdot \mathrm{p}_{2} \mathrm{z}$ is the first such component which is divisible by both $\mathrm{p}_{2}$ and $\mathrm{p}_{4}$ and is a part of $\mathrm{c} 1+\mathrm{c} 2$ combinations formed by $\mathrm{p}_{1} \mathrm{p}_{4}$. Thereafter all combinations that satisfy the condition $\mathrm{p}_{2} z+6 \mathrm{p}_{1} \mathrm{p}_{2}$ $\leq 6 \mathrm{I}+1$ will be part of such $\mathrm{c} 1+\mathrm{c} 2$ that are common to both prime pairs $\mathrm{p}_{1} \mathrm{p}_{2}$ and $\mathrm{p}_{1} \mathrm{p}_{4}$ and would involve a component whose factors are $\mathrm{p}_{2}$ and $\mathrm{p} 4$. Such number of $\mathrm{c} 1+\mathrm{c} 2$ combinations may be denoted as n'(c+c3).

Therefore $n^{\prime}(\mathrm{c}+\mathrm{c} 3)=\left[\left\{(6 \mathrm{I} \pm 1)-\mathrm{p}_{2} \mathrm{z}\right\} / 6 \mathrm{p} 1 \mathrm{p} 2\right]+1$ 
Similarly we derive $\mathrm{c} 1+\mathrm{c} 2$ common to the prime pairs $\mathrm{p}_{1} \mathrm{p}_{3}$ and $\mathrm{p}_{1} \mathrm{pp}_{4}$. To identify the first such $\mathrm{c} 1+\mathrm{c} 2$ the following steps are to be followed:

$\mathrm{p}_{4}\left[\left(\mathrm{y}+6 \mathrm{p}_{1}\right) / \mathrm{p}_{3}\right]=\mathrm{I}$

find value of $\mathrm{n}$ for which I becomes an integer denoted as $\mathrm{z}$.

$\mathrm{p}_{4} \mathrm{z}^{\prime}$ would be a composite divisible by both $\mathrm{p}_{3}$ and $\mathrm{p}_{4}$ and would be a component of $\mathrm{c} 1+\mathrm{c} 2$ common to both prime pairs $\mathrm{p}_{1} \mathrm{p}_{3}$ and $\mathrm{p}_{1} \mathrm{p}_{4}$. Further such $\mathrm{c} 1+\mathrm{c} 2$ combinations common to the prime pairs $p_{1} p_{3}$ and $p_{1} p_{4}$ would be derived as those fulfilling the $p_{3} z^{\prime}+6 p_{1} p_{2} \leq 6 I \pm 1$

$\mathrm{n}^{\prime}(\mathrm{c}+\mathrm{c} 3)=\left[\left\{(6 \mathrm{I} \pm 1)-\mathrm{p}_{3} \mathrm{Z}^{\prime}\right\} / 6 \mathrm{p}_{1} \mathrm{p}_{2}\right]+1$

in order to avoid double removal of the same $\mathrm{c} 1+\mathrm{c} 2$, we need to derive n"' $(\mathrm{c}+\mathrm{c} 3)$ for both the prime pairs $\mathrm{p} 1 \mathrm{p} 2$ and $\mathrm{p} 1 \mathrm{p} 3$. Here an additional step would be to identify those components that are common to both $\mathrm{p}_{1} \mathrm{p}_{2}$ and $\mathrm{p}_{1} \mathrm{p}_{3}$ and removing them while calculating $\mathrm{c} 1+\mathrm{c} 2$ for $\mathrm{p}_{1} \mathrm{p}_{4}$ would result in double removal. These may be identified as those $c 1+c 2$ combinations where 1 component is divisible by $\mathrm{p}_{2}, \mathrm{p}_{3}$ and $\mathrm{p}_{4}$ and forms part of $\mathrm{c} 1+\mathrm{c} 2$ combination for $\mathrm{p}_{1} \mathrm{p}_{4}$. The first such $\mathrm{c} 1+\mathrm{c} 2$ combination would include a component which satisfies the following condition:-

$\mathrm{p}_{4}\left[\left\{\left(\mathrm{y}+6 \mathrm{p}_{1} \mathrm{n}\right) / \mathrm{p}_{2} \mathrm{p}_{3}\right\}\right]=\mathrm{I}$

Find value of $n$ where I (denoted as $\left.z^{\prime \prime}\right)$ becomes an integer. Thereafter further $\mathrm{c} 1+\mathrm{c} 2$ that satisfy the condition:

$\mathrm{p}_{2} \mathrm{p}_{3} \mathrm{z} "+6 \mathrm{p}_{1} \mathrm{p}_{2} \mathrm{p}_{3} \leq 6 \mathrm{I} \pm 1$

This number would be derived as n'”, $(c+c 3)=\left[\left\{(6 \mathrm{I} \pm 1)-\mathrm{p}_{2} \mathrm{p}_{3} \mathrm{Z}^{\prime \prime}\right\} / 6 \mathrm{p}_{1} \mathrm{p}_{2} \mathrm{p}_{3}\right]+1$

Number of Unique composites for the prime pair $\mathrm{p}_{1} \mathrm{p}_{4}$ would be derived as $\mathrm{n}(\mathrm{c}+\mathrm{c} 3)-2 \mathrm{a}-$ $\left\{n^{\prime}(\mathrm{c}+\mathrm{c} 3)-\mathrm{n}^{\prime \prime}(\mathrm{c}+\mathrm{c} 3)-\mathrm{n}^{\prime \prime},(\mathrm{c}+\mathrm{c} 3)\right\}$

Step6:

Identifying unique $\mathrm{c} 1+\mathrm{c} 2$ for the prime pair $\mathrm{p}_{2} \mathrm{p}_{3}$ while deriving $\mathrm{c} 1+\mathrm{c} 2$ for $\mathrm{p}_{2} \mathrm{p}_{3}$, two types of repetitions, i.e. $\mathrm{c} 1+\mathrm{c} 2$ derived by previous steps, need to be identified. First those that have been already calculated while deriving $\mathrm{c} 1+\mathrm{c} 2$ combinations of type- 2 . Second, those that have been derived by previous prime pairs $\mathrm{p}_{1} \mathrm{p}_{2}, \mathrm{p}_{1} \mathrm{p}_{3}, \mathrm{p}_{1} \mathrm{p}_{4}, \ldots ., \mathrm{p}_{1} \mathrm{p}_{\mathrm{n}}$.

We begin by deriving $n(c+c 3)$ for $\mathrm{p}_{2} \mathrm{p}_{3}$ prime pair by applying the formula ff of $\left(2 \mathrm{k} / 6 \mathrm{p}_{2} \mathrm{p}_{3}\right)=\mathrm{q}$ Thereafter we derive $\mathrm{c} 1+\mathrm{c} 2$ combinations already identified while calculating $\mathrm{c} 1+\mathrm{c} 2$ of type2.

ff of $(n(c+c 3) / 5)=a$ and number of $c 1+c 2$ identified while calculating $c 1+c 2$ of type- 2 is as $2 a$

Find value of $n$ where $I$ becomes an integer denoted as $y$.

$\mathrm{p}_{3} \mathrm{y}+\left(2 \mathrm{k}-\mathrm{p}_{3} \mathrm{y}\right)$ will be the first $\mathrm{c} 1+\mathrm{c} 2$ combination for the prime pair $\mathrm{p}_{2} \mathrm{p}_{3}$. Let us say the two components of this combination are $\mathrm{p}_{2} \mathrm{y}^{\prime}$ and $\mathrm{p}_{3} \mathrm{y}$.

Further combinations would be $\mathrm{p}_{3}\left(\mathrm{y}+6 \mathrm{np}_{2}\right) \leq 6 \mathrm{I}+1$ while the corresponding components would be:

$$
\mathrm{p}_{2}\left(\mathrm{y}^{\prime}-6 \mathrm{np}_{3}\right) \leq 6 \mathrm{I} \pm 1
$$

To identify $\mathrm{c} 1+\mathrm{c} 2$ already derived by previous prime pairs including p' we follow the following steps:- $\left(\mathrm{y}+6 \mathrm{p}_{2} \mathrm{n}\right) / \mathrm{p}_{1}=\mathrm{I}$ 
Find value of $\mathrm{n}$ for which I becomes an integer, denoted as $\mathrm{z}$.

Therefore all $\mathrm{c} 1+\mathrm{c} 2$ that satisfy the following conditions would be such $\mathrm{c} 1+\mathrm{c} 2$ that have been derived by previous prime pairs:- $\mathrm{z}+6 \mathrm{np}_{1} \mathrm{p}_{2} \leq 6 \mathrm{I} \pm 1$

For all these combinations, $\mathrm{p}_{1}$ would be a factor and it would be a component of $\mathrm{c} 1+\mathrm{c} 2$ already derived by previous prime pairs.

Similarly:-

$\left(\mathrm{y}^{\prime}-6 \mathrm{np}_{3}\right) / \mathrm{p} 1=\mathrm{I}$

Find value of $\mathrm{n}$ for which I becomes an integer, denoted as $\mathrm{z}$ '.

This would also give a component of which $\mathrm{p}_{2}$ and $\mathrm{p}_{1}$ are factors and would constitute $\mathrm{c} 1+\mathrm{c} 2$ already derived by previous prime pairs. Thereafter all components that satisfy the following condition will constitute $\mathrm{c} 1+\mathrm{c} 2$ already derived by previous prime pairs:-

$\mathrm{z}^{\prime}-6 \mathrm{np}_{1} \mathrm{p}_{3} \leq 6 \mathrm{I} \pm 1$

Once these combinations have been identified, the last step would be to identify if there are any common $\mathrm{c} 1+\mathrm{c} 2$ combinations that are being removed twice i.e. while calculating $\mathrm{c} 1+\mathrm{c} 2$ combinations of type- 2 and those derived by previous prime pairs.

This is possible by identifying $\mathrm{c} 1+\mathrm{c} 2$ in which any one component ends in the digit 5 . This $\mathrm{c} 1+\mathrm{c} 2$ may be denoted as n' $(\mathrm{c}+\mathrm{c} 3)$

Unique $\mathrm{c} 1+\mathrm{c} 2$ for the prime pair $\mathrm{p}_{2} \mathrm{p}_{3}=\mathrm{n}(\mathrm{c}+\mathrm{c} 3)-2 \mathrm{a}-\left(\mathrm{n}^{\prime}(\mathrm{c}+\mathrm{c})-\mathrm{n}^{\prime \prime}(\mathrm{c}+\mathrm{c})\right)$

After deriving the total number of $\mathrm{c} 1+\mathrm{c} 2$ combinations of the three steps discussed above, the number of unique $\mathrm{c} 1+\mathrm{c} 2$ is to be derived. These would be represented through the following Venn diagram:-

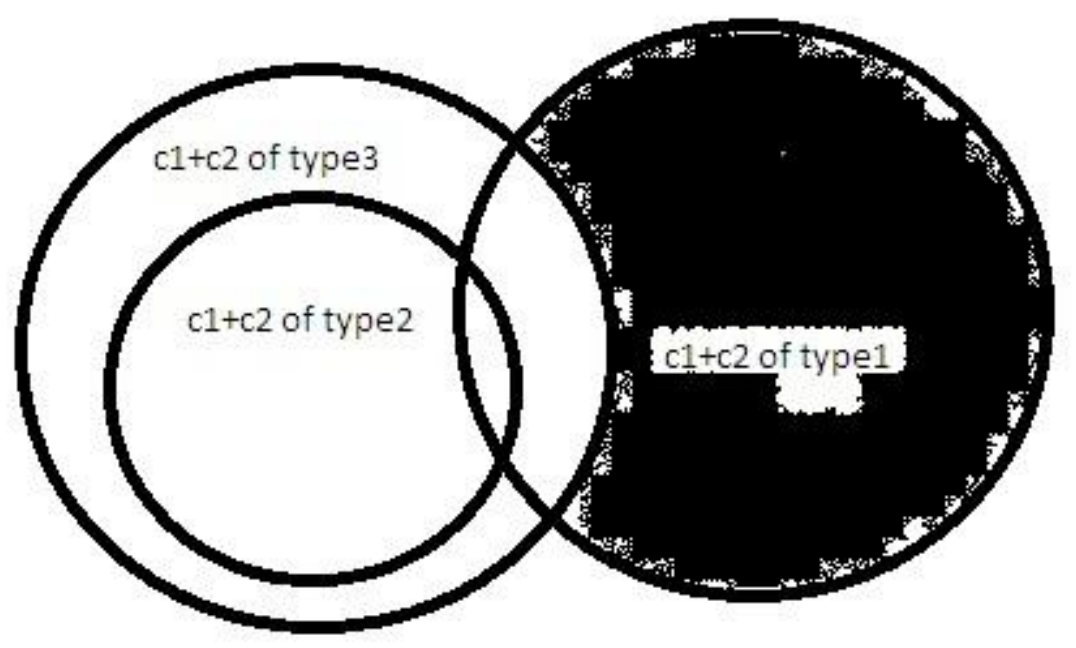

Diagram 11C.1: Venn diagram representing the relation of subset and superset among the $\mathrm{c} 1+\mathrm{c} 2$ combinations of types 1,2 and 3

Difference between $\mathrm{c} 1+\mathrm{c} 2$ of type 2 and $\mathrm{c} 1+\mathrm{c} 2$ of type 3 are:- 
$\mathrm{C} 1+\mathrm{c} 2$ of type 2 is a special case of $\mathrm{c} 1+\mathrm{c} 2$ of type 3 . The points of difference between these 2 types of $\mathrm{c} 1+\mathrm{c} 2$ combinations may be summarised as follows:-

I. For deriving $\mathrm{c} 1+\mathrm{c} 2$ of type 2 , the last digit of $2 \mathrm{k}$ plays a determining factor, which has no role to play in deriving $\mathrm{c} 1+\mathrm{c} 2$ of type 3 .

II. A particular $\mathrm{c} 1+\mathrm{c} 2$ of type 2 once derived for an even number having a particular SADN and ending in a particular last digit will be a $\mathrm{c} 1+\mathrm{c} 2$ of type 2 for all even numbers of the same SADN ending with the same digit. For example the first $\mathrm{c} 1+\mathrm{c} 2$ of type 2 for $2 \mathrm{k}$ of SADN741//2 would be $77+35=112$; since 35 is the first composite ending in 5 on the S5 series and 77 is the first composite ending in 7 on the S5 series. Therefore it would be considered as $\mathrm{c} 1+\mathrm{c} 2$ for $2 \mathrm{k}=112$. Thereafter 77 will form a $\mathrm{c} 1+\mathrm{c} 2$ combination for all even numbers of SADN741//2 infinitely, since for any such number $2 \mathrm{k}-77$ will be a composite number ending in 5 . In case of $\mathrm{c} 1+\mathrm{c} 2$ of type 3 , this will not hold true as same composite component may form part of $\mathrm{c} 1+\mathrm{c} 2$ for a particular $2 \mathrm{k}$ but may form a $\mathrm{p}+\mathrm{c}$ combination for some other $2 \mathrm{k}$.

For example for $2 \mathrm{k}=196, \mathrm{SADN} 7 / / 6,77$ will form part of $\mathrm{c} 1+\mathrm{c} 2$ combination for this $2 \mathrm{k}$ since the corresponding number would be 119 which is also a composite number but for $2 \mathrm{k}=$ 226, again SADN741//6, 2k-77 = 149 which is a prime number. Therefore, here 77 will form part of $\mathrm{p}+\mathrm{c}$ combinations.

III. For a given $2 \mathrm{k}$, identifying the first $\mathrm{c} 1+\mathrm{c} 2$ of type 2 is predictable. For example for $2 \mathrm{k}=$ SADN 741//2, a component of $\mathrm{c} 1+\mathrm{c} 2$ of type 2 will be identified as $(7+30 \mathrm{n}) \mathrm{x}(11+30 \mathrm{n})$ and this will be universal across the number line. In case of $\mathrm{c} 1+\mathrm{c} 2$ of type 3 , there is no such predictability. This is because $c 1+c 2$ of type 3 for any prime pair $p_{1} p_{2}$ is derived as follows:

$\left[\left\{2 \mathrm{k}-\left(\mathrm{p}_{1}(6 \mathrm{I} \pm 1)\right)\right\} / \mathrm{p}_{2}\right]+6 \mathrm{np}_{1}=$ an integer, for a particular value of ' $\mathrm{n}$ '.

and the first $\mathrm{c} 1+\mathrm{c} 2$ for this prime pair $\mathrm{p}_{1} \mathrm{p}_{2}$ will be identified for a value of $\mathrm{n}$ where $\mathrm{I}$ becomes an integer. Since $2 k-\left(p_{1} x(6 I \pm 1)\right)$ will be different for different even numbers, the first $c 1+c 2$ formed by $\mathrm{p}_{1} \mathrm{p}_{2}$ will be different for different even numbers, the first $\mathrm{c} 1+\mathrm{c} 2$ formed by $\mathrm{p} 1 \mathrm{p} 2$ will also be different for different even numbers. 


\section{$11 D$.}

\section{Deriving total number of $\mathrm{c} 1+\mathrm{c} 2$ combinations for a given $2 \mathrm{k}$ : Some illustrations}

\section{Illustration 1:}

Deriving $\mathrm{c} 1+\mathrm{c} 2$ combinations for $2 \mathrm{k}$ of $\operatorname{SADN}(5,2,8)$ :-

Consider the even number 1682 . The relevant details required for deriving $\mathrm{c} 1+\mathrm{c} 2$ combinations for this number are summarized in the following table:

\begin{tabular}{|l|l|}
\hline SADN & 8 \\
\hline Relevant series & S7 series \\
\hline Last digit & 2 \\
\hline $\mathrm{k}$ & 841 \\
\hline Nature of $\mathrm{k}$ & Composite $(29 \mathrm{x} 29)$ \\
\hline Total no of combinations & $(841-1) / 6=140$ \\
\hline Total no of elements & $2 \mathrm{nTC}=280$ \\
\hline No of primes & 127 \\
\hline No of composites & 153 \\
\hline
\end{tabular}

Table 11D.1: Details required for deriving c1+c2 combinations for illustration of $\operatorname{SADN}(8) / / 2$

As mentioned in table11D.1, $\mathrm{k}=841$ which is a composite odd number derived as $29 \times 29$.

We begin by identifying $\mathrm{c} 1+\mathrm{c} 2$ combinations by following the steps as mentioned above.

\section{Deriving c1+c2 combinations of type 1:}

As mentioned above these $c 1+c 2$ combinations are derived as $(k+6 n)+(k-6 n)$ till we reach a value of $\mathrm{n}$ that leads us to the first element of the concerned series. Accordingly the following $\mathrm{c} 1+\mathrm{c} 2$ combinations can be identified for $2 \mathrm{k}=1682$ :
i. $29 \times 29+29 \times 29$
ii. $29 \times 35+29 \times 23$
iii. $29 \times 41+29 \times 17$
iv. $29 \times 47+29 \times 11$
v. $29 \times 53+29 \times 5$

Total number of $\mathrm{c} 1+\mathrm{c} 2$ combinations of type 1 thus derived are 5 .

\section{Deriving c1+c2 combinations of type 2:}

As mentioned above these $\mathrm{c} 1+\mathrm{c} 2$ combinations are derived from the last digit of the even number. Since the even number under consideration ends in 2 , composite odd numbers on 
the S7 series which end in 7 will form part of $c 1+c 2$ combinations since the corresponding number in the combination would end in 5 and would thereby be a multiple of 5 . We begin by identifying $\mathrm{c} 1+\mathrm{c} 2$ combinations of type 2 involving the prime number 7.

$\mathrm{N}(\mathrm{c}+\mathrm{c})$ for $7=\mathrm{ff}$ of $[[(235-31) / 30]+1]=\mathrm{ff}$ of $(7.8)$

ff of $7.8=7$

The combinations thus derived would be :-
i. $\quad 7 \times 31(=217)+1465$
ii. $\quad 7 \times 61(=427)+1255$
iii. $\quad 7 \times 91(=637)+1045$
iv. $7 \times 121(=847)+835$
v. $7 \times 151(=1057)+625$
vi. $\quad 7 \times 181(=1267)+415$
vii. $7 \times 211(=1477)+205$

$\mathrm{N}(\mathrm{c}+\mathrm{c})$ for the prime number 11 will be derived as ff of $[[(149-17) / 30]+1]=\mathrm{ff}$ of $(5.4)$

ff of $5.4=5$

$\mathrm{C}+\mathrm{C}$ combinations thus derived are:
i. $11 \times 17($ i.e. 187$)+1495$
ii. $\quad 11 \times 47($ i.e. 517$)+1165$
iii. $11 \times 77($ i.e. 847$)+835$
iv. $11 \times 107($ i.e. 1177$)+505$
v. $11 \times 137($ i.e. 1507$)+175$

Of these combinations $11 \times 77($ i.e. 847$)+835$ has already been derived while identifying $\mathrm{c} 1+\mathrm{c} 2$ combinations for the previous prime number 7 , so it will have to be removed from total number of $\mathrm{c} 1+\mathrm{c} 2$ combinations for 11 to avoid double counting. Unique $\mathrm{c}+\mathrm{c}$ combinations involving 11 would therefore be 4 .

$\mathrm{nC}+\mathrm{C}$ for the prime number 13 will be derived as ff of $[[(127-19) / 30]+1]=$ ff of $(4.6)$

ff of $4.6=4$

$\mathrm{C}+\mathrm{C}$ combinations thus derived would be:-
i. $\quad 13 \times 19($ i.e. 247$)+1435$
ii. $13 \times 49($ i.e. 637$)+1045$ 


\section{iii. $\quad 13 \times 79($ i.e. 1027$)+655$ \\ iv. $13 \times 109($ i.e. 1417$)+265$}

Of these, the combination $637+1045$ has already been derived while identifying $\mathrm{C}+\mathrm{C}$ combinations for the previous prime number 7 so it needs to be subtracted from the total $\mathrm{C}+\mathrm{C}$ combinations involving the number 13 to avoid double counting. Unique $\mathrm{C}+\mathrm{C}$ combinations of type 2 for the prime number 13 would therefore be 3 .

$\mathrm{n}(\mathrm{c}+\mathrm{c})$ for the prime number 17 would be derived as ff of $[[(95-41) / 30]+1]=\mathrm{ff}$ of $(2.8)$

ff of $2.8=2$

$\mathrm{c} 1+\mathrm{c} 2$ combinations thus derived would be:-

i. $\quad 17 x 41($ i.e. 697$)+985$

ii. $\quad 17 \times 71($ i.e. 1207$)+475$

$\mathrm{n}(\mathrm{c}+\mathrm{c})$ of type 2 for the prime number 19 would be derived as $\mathrm{ff}$ of $[[(85-43) / 30]+1]=\mathrm{ff}$ of (2.4)

ff of $2.4=2$

$\mathrm{c} 1+\mathrm{c} 2$ combinations thus identified are-

i. $\quad 19 \times 43($ i.e. 817$)+865$

ii. $19 \times 73($ i.e. 1387$)+295$

$\mathrm{n}(\mathrm{c}+\mathrm{c})$ combinations for the prime number 23 would be derived as ff of [[(71$29) / 30]+1]=$ ff of (2.4) and the combinations thus derived are-

$23 \times 29($ i.e. 667$)+1015$

$23 \times 59($ i.e. 1357$)+325$

Of these combinations $667+1015$ has already been counted while identifying $\mathrm{c} 1+\mathrm{c} 2$ combinations of type 1 and will not be considered here to avoid double counting. Therefore, effectively the total number of $\mathrm{C}+\mathrm{C}$ combinations involving the prime number 23 would be 1 . 
$\mathrm{n}(\mathrm{c}+\mathrm{c})$ for the prime number 29 would be derived as ff of $[(53-53) / 30]+1=1$ and the combination thus derived would be $29 \times 53($ i.e. 1537$)+145$

It may be noted here that this combination has already been derived while identifying $\mathrm{c} 1+\mathrm{c} 2$ of type- 1 and will therefore not be counted here again.

$\mathrm{n}(\mathrm{c}+\mathrm{c})$ for the next prime number 31 would be derived as ff of[ [(49-37)/30]+1]= ff of (1.4) and the combination thus derived would be $31 \times 37$ (i.e.1147) +535

Total number of $\mathrm{c} 1+\mathrm{c} 2$ combinations of type 2 identified $=20$

\section{Deriving $\mathrm{C}+\mathrm{C}$ combinations of type 3 for $2 k$ as 1682 :}

As mentioned above $\mathrm{C}+\mathrm{C}$ combinations of type 3 are identified for prime pairs which satisfy the general condition of $2 \mathrm{k} / 6 \mathrm{p} 1 \mathrm{p} 2 \geq 1$. By following the steps discussed above, the following $\mathrm{C}+\mathrm{C}$ combinations of type 3 may be identified for the $2 \mathrm{k}$ under consideration:

Deriving $\mathrm{C}+\mathrm{C}$ combinations of type 3 for the prime pair $7 \& 11$ :-

Since ff of $[1682 /(7 \times 11 \times 6)]=$ ff of $(1682 / 462)=$ ff of $(3.64)$, it may be expected that $\mathrm{C}+\mathrm{C}$ combinations of type 3 would be identified for this prime pair such that $7 \& 11$ would be factors on either side of the combination. In order to identify the first such combination we need to first find the value of $2 \mathrm{k}-(7 \mathrm{x}(6 \mathrm{I}+1))$. Here this value would be 1682 $(7 \times 235)=1682-1645=37$. Thereafter we need to solve for the equation $(37+42 n) / 11=$ Int (an Integer), to find the value of $\mathrm{n}$ where Int becomes an integer. Here $(37+(42 \times 2)) / 11=11$ which implies that the first $\mathrm{c}+\mathrm{c}$ combination involving the prime pair $7 \& 11$ would be $(11 \times 11)+(7 \times 223)$ i.e. $121+1561$. Thereafter we can derive further combinations by adding (and subtracting) $7 \times 11 \times 6$ (i.e.462) to the first (and second) term of the combination. The combinations thus derived would be as follows-
i. $\quad 121+1561$
ii. $\quad 583+1099$
iii. $\quad 1045+637$
iv. $1507+175$

Of these, the third and fourth combinations have already been derived while identifying $\mathrm{c} 1+\mathrm{c} 2$ combinations of type 2 so these need to be removed from the total count of 4 to avoid double counting of the same combination. Unique combinations of type 3 for the prime pair $7 \& 11$ would therefore be 2 .

Deriving $\mathrm{C}+\mathrm{C}$ combinations for the prime pair $7 \& 13$ : 
Here again to identify the first $\mathrm{C}+\mathrm{C}$ combination involving the prime pair $7 \& 13$ we solve for the equation $(37+42 n) / 13=$ Int (an Integer), to find the value of $n$ where Int becomes an integer. Since $(37+42 \times 5) / 13=19$, the first $\mathrm{C}+\mathrm{C}$ combination for the prime pair $7 \& 13$ would be $(13 \times 19)+(7 \times 205)=247+1435$. Further combinations can be derived by adding 546 (i.e. $7 \times 6 \times 13$ ) to the first term and subtracting the same from the second term. The $\mathrm{C}+\mathrm{C}$ combinations thus derived would be :-
i. $\quad 247+1435$
ii. $\quad 793+889$
iii. $1339+343$

Of these, the first combination has already been identified while deriving $\mathrm{C}+\mathrm{C}$ combinations of type 2 so it will be subtracted from the total count to avoid double counting and thus the total unique $\mathrm{C}+\mathrm{C}$ combinations for the prime pair $7 \& 13$ would be 2 .

Deriving $\mathrm{c} 1+\mathrm{c} 2$ combinations for the prime pair $7 \& 17$

To identify the first $\mathrm{C}+\mathrm{C}$ combination involving the prime pair $7 \& 17$ we solve for the equation $(37+42 n) / 17=$ Int (an Integer), to find the value of $n$ where Int becomes an integer. Here $(37+42 \times 6) / 17=17$ and the $\mathrm{C}+\mathrm{C}$ combinations thus derived would be as follows-
i. $289+1393$
ii. $1003+679$

Since neither of these combinations has appeared earlier while identifying $\mathrm{C}+\mathrm{C}$ of type 1 or type 2 , both of them would be considered as unique $\mathrm{C}+\mathrm{C}$ combinations of type 3 for the prime pair of 7-17.

Deriving $\mathrm{C}+\mathrm{C}$ combinations for the prime pair $7 \& 19$ 
In order to identify the $\mathrm{C}+\mathrm{C}$ combinations for the prime pair $7 \& 19$ we solve for the equation $(37+42 n) / 19=$ Int (an Integer), to find the value of $n$ where Int becomes an integer. Since $(37+42 \times 5) / 19=13$, the $C+C$ combinations thus derived are $247+1435$ and $1045+637$. Since both these combinations have already been identified while deriving $\mathrm{C}+\mathrm{C}$ combinations of type 2 ; the unique $\mathrm{C}+\mathrm{C}$ combinations of type 3 for the prime pair would be 0 .

In the same manner $\mathrm{C}+\mathrm{C}$ combinations for the prime pair $7 \& 23$ would be identified as $667+1015$ and $1633+49$ of which the former combination has already been identified while deriving $\mathrm{C}+\mathrm{C}$ combinations of type 1 and therefore the number of unique combinations for this prime pair would be 1 . Furthermore, the combination $667+1015$ would be derived as $23 \times 29+7 \times 145$ and this is the only combination involving the prime pair 7-29 so effectively the unique $\mathrm{C}+\mathrm{C}$ combinations of type 3 for this prime pair would be 0 . Derived on similar lines, the $\mathrm{C}+\mathrm{C}$ combination for the prime pair 7-31 would be 961(i.e $31 \times 31)+721$ (i.e. $7 \times 103$ ) and the number of unique $C+C$ combinations of type 3 for this prime pair would be 1 . Likewise, the combination 1591(i.e.37x43)+91(i.e.7x13) would be derived for the prime pair $7 \& 37$ and the total number of unique $\mathrm{C}+\mathrm{C}$ combinations of type 3 for this prime pair would be 1 .

Deriving unique $\mathrm{C}+\mathrm{C}$ combinations of type 3 involving the prime number 11:-

The prime pairs involving the prime number 11 which satisfy the general condition $2 \mathrm{k} / 6 \mathrm{p} 1 \mathrm{p} 2 \geq 1$ would be $11 \& 13,11 \& 17,11 \& 19$ and $11 \& 23$. In order to identify the combinations we need to first find the value of $2 \mathrm{k}-11 \mathrm{x}(6 \mathrm{I}-1)$. This would be 1682 $(11 \times 149)=1682-1639=43$. Accordingly $\mathrm{C}+\mathrm{C}$ combinations for the relevant prime pairs would be derived as follows -

For the prime $11 \& 13$ :

In order to find the first $\mathrm{C}+\mathrm{C}$ combination for this prime pair we solve for the equation $(43+66 n) / 13=$ Int (an Integer), to find the value of $n$ where Int becomes an integer. Since $(43+66 \times 9) / 13=49$, the combinations thus derived would be $637+1045$ and $1495+187$. Since both these combinations have already been derived while identifying $\mathrm{C}+\mathrm{C}$ combinations of type 2 ; unique $\mathrm{C}+\mathrm{C}$ of type 3 for the prime pair $11 \& 13$ would be 0 . Derived on similar lines, the $\mathrm{C}+\mathrm{C}$ combinations of type 3 for the prime pair 11-17 would be 901(17x53)+781(11x71) since this combination has not been derived earlier, it would be considered as a unique $\mathrm{C}+\mathrm{C}$ combination of type 3 for the prime pair $11 \& 17$. Likewise, the unique $\mathrm{C}+\mathrm{C}$ combination of type 3 for the prime pair 11-19 would be 703(i.e.19x37)+979(i.e.11x89). C+C combination of 1495(i.e.23x65)+187 (i.e.11x17) for 
the prime pair $11 \& 23$ has already been derived while identifying $\mathrm{C}+\mathrm{C}$ of type 2 and therefore, the unique combinations of type 3 for this prime pair would be 0 .

Deriving $\mathrm{C}+\mathrm{C}$ combinations of type 3 for the prime pairs involving 13:

The general condition of $2 \mathrm{k} / 6 \mathrm{p} 1 \mathrm{p} 2 \geq 1$ for identifying $\mathrm{C}+\mathrm{C}$ combinations of type 3 involving the prime number 13 would be satisfied for the prime pairs $13 \& 17$ and $13 \& 19$. In order to identify these combinations, we first find the value of $2 \mathrm{k}-13 \times 6 \mathrm{I}+1=1682$ $13 \times 127=1682-1651=31$. Further, to identify the $\mathrm{C}+\mathrm{C}$ combination/s for the prime pair $13 \& 17$ we solve for the equation $(31+78 n) / 17=I$ to find the value of $n$ where $I$ becomes an integer. Here, $31+78 \times 2 / 17=11$ so the combinations thus derived would be 187(i.e.17x11)+1495(i.e.13x115) and 1513(i.e.17x89)+169(i.e.13x13). Of these, the first combination $187+1495$ has already been derived while identifying $\mathrm{C}+\mathrm{C}$ combinations of type 2 and therefore the unique $\mathrm{C}+\mathrm{C}$ combination of type 3 for the prime pair $13 \& 17$ would be 1 . Derived similarly, the $\mathrm{C}+\mathrm{C}$ combination for the prime pair $13 \& 19$ would be 637(i.e.13x49)+1045(i.e.19x55). Since this combination has already been derived earlier while identifying $\mathrm{C}+\mathrm{C}$ combinations of type 2 , the unique $\mathrm{C}+\mathrm{C}$ combinations of type 3 for the prime pair $13 \& 19$ would be 0 .

Total number of $\mathrm{C}+\mathrm{C}$ combinations for the even number 1682 would be given as summation of number of combinations of type1, number of combinations of type 2 and number of combinations of type 3 . These would be $5+20+12=37$. This implies that as many as $37 \mathrm{C}+\mathrm{C}$ combinations would be identified for $2 \mathrm{k}=1682$.

\section{Illustration 2:}

Deriving $\mathrm{C}+\mathrm{C}$ combinations for $2 \mathrm{k}$ of $\operatorname{SADN}(7,4,1)$ :

Consider the even number 1498 . The relevant details required to identify $\mathrm{C}+\mathrm{C}$ combinations for this number are summarized in the following table:-

\begin{tabular}{|l|l|}
\hline SADN & 4 \\
\hline Relevant series & S5 series \\
\hline Last digit & 8 \\
\hline K & 749 \\
\hline Nature of $\mathrm{k}$ & Composite $(7 \times 107)$ \\
\hline Total no of combinations & $(749+1) / 6=125$ \\
\hline Total no of elements & 249 \\
\hline No of primes & 121 \\
\hline No of composites & 128 \\
\hline
\end{tabular}




\section{Table 11D.2: Details required for deriving c1+c2 combinations for illustration of $\operatorname{SADN}(4) / / 8$}

\section{Deriving c1+c2 combinations of type 1 for $2 k$ as 1498:-}

As mentioned in the table 11D.2, mid-point of the $2 \mathrm{k}$ under consideration $1498 / 2=749$ is a composite odd number derived as $7 \times 107$. Therefore, $\mathrm{C}+\mathrm{C}$ combinations of type 1 would be derived as $7 x(107+6 n)+7 x(107-6 n)$ where value of $n$ ranges from 0 to such an integer that leads us to the first element of the S-5 series. The combinations thus derived would be as follows-

$$
\begin{aligned}
& 7 \times 107+7 \times 107 \\
& 7 \times 113+7 \times 101 \\
& 7 \times 119+7 \times 95 \\
& \vdots \\
& 7 \times 5+7 \times 209
\end{aligned}
$$

The total number of combinations thus derived would be 18 .

\section{Deriving $C+C$ combinations of type 2 for $2 k$ as 1498 :}

The even number under consideration 1498 ends in the digit 8 so all composite odd numbers ending in 3 lying on the $\mathrm{S}-5$ series would form part of $\mathrm{C}+\mathrm{C}$ combinations of type 2 since the corresponding number in the combination would necessarily end in 5 and would therefore be a multiple of 5 .

We begin by noting here that all $\mathrm{c} 1+\mathrm{c} 2$ combinations of type 2 involving the prime number 7 have already been derived above while identifying $\mathrm{c} 1+\mathrm{c} 2$ combinations of type 1 so deriving them again here would amount to double counting. Therefore, we will begin the calculation of $\mathrm{c} 1+\mathrm{c} 2$ of type 2 from the next prime number which is 11 .

Hence $n(c+c)$ of type 2 for the prime number 11 would be derived as ff of [ $\{(133-$ $13) / 30\}+1]=5$ and the combinations thus derived would be:

$$
\begin{aligned}
\text { i. } & 11 \times 13(\text { i.e. } 143)+1355 \\
\text { ii. } & 11 \times 43(\text { i.e. } 473)+1025 \\
\text { iii. } & 11 \times 73(\text { i.e. } 803)+695 \\
\text { iv. } & 11 \times 103(\text { i.e. } 1133)+365 \\
\text { v. } & 11 \times 133(\text { i.e. } 1463)+35
\end{aligned}
$$


Of these, the fifth combination $1463+35$ has already been derived while identifying $\mathrm{c} 1+\mathrm{c} 2$ combinations of type 1 and therefore will be removed to avoid double counting. The total number of $\mathrm{c} 1+\mathrm{c} 2$ combinations of type 2 for the prime number 11 would therefore be 4 .

$\mathrm{C} 1+\mathrm{c} 2$ combinations of type 2 for the prime number 13 would be derived as ff of [ $\{(113-$ $41) / 30\}+1]=$ ff of $(3.4)=3$ and the combinations thus derived would be as follows-
i. $\quad 13 \times 41($ i.e. 533$)+965$
ii. $\quad 13 \times 71($ I.e. 923$)+575$
iii. $13 \times 101($ i.e. 1313$)+185$

Since none of these combinations have been identified earlier, all these 3 would be considered as unique combinations for the prime number 13.

Now $n(c+c)$ for the prime number 17 would be derived as ff of $[\{(85-19) / 30\}+1]=\mathrm{ff}$ of $(3.2)=3$ and the combinations thus derived would be:
i. $\quad 17 \times 19($ i.e. 323$)+1175$
ii. $17 \times 49$ (i.e. 833$)+665$
iii. $\quad 17 \times 79($ i.e. 1343$)+155$

Of these, the second combination $833+665$ has already been derived earlier while identifying $\mathrm{c} 1+\mathrm{c} 2$ combinations of type 1 and will therefore be removed to avoid double counting. The unique $\mathrm{c} 1+\mathrm{c} 2$ combinations of type 2 for the prime number 17 would thus be 2 .

Derived similarly, unique $\mathrm{c} 1+\mathrm{c} 2$ combinations of type 2 for the prime number 19 would be $893+605$ since the other combination 19x77(i.e.1463)+35 involving the prime number 19 has already been derived while identifying $c 1+c 2$ combinations of type 1 and will therefore not be counted again. Unique $\mathrm{c} 1+\mathrm{c} 2$ of type 2 for the prime number 19 would therefore be 1 .

Likewise, $c 1+c 2$ combinations of type 2 for the prime number 23 would be $713+785$ and $1403+95$. Both these combinations would be considered as unique to the prime number 
23 since they have not been identified earlier. c1+c2 of type 2 for the prime number 29 would be $1073+425$ and it would be considered unique since it has not been identified earlier.

Hence total number of $\mathrm{c} 1+\mathrm{c} 2$ combinations of type 2 for $2 \mathrm{k}$ as 1498 would be 13 .

\section{Deriving c1+c2 combinations of type 3 for $2 k$ as 1498 :}

Here again we begin by noting that prime pairs that satisfy the general condition for identification of $\mathrm{c} 1+\mathrm{c} 2$ combinations of type 3 involving the prime number 7 would already have been derived earlier while identifying $\mathrm{c} 1+\mathrm{c} 2$ combinations of type 1 and therefore these will not be derived again. We will begin by identifying $\mathrm{c} 1+\mathrm{c} 2$ combinations of type 3 for the prime pairs involving the next prime number 11. In order to identify these combinations we begin by finding the value of $2 \mathrm{k}-11 \mathrm{x}(6 \mathrm{I}+1)$ which would be $1498-(11 \times 133)=1498-35$. To identify the $c 1+c 2$ combinations involving the prime pair $11 \& 13$, we solve for the equation $(35+66 n) / 13=$ Int (an Integer), to find the value of $n$ where Int becomes an integer. Since $(35+66 \times 4) / 13=23$, the $c 1+c 2$ thus derived would be:-
i. $299+1199$
ii. $1157+341$

Since neither of these combinations has been identified earlier, these would be considered as unique to the prime pair 11-13. Derived on similar lines, the $\mathrm{C}+\mathrm{C}$ combination/s for the prime pair 11-17 would be $17 \times 37(=629)+11 \times 79(=869)$ and this combination would be considered as unique to this prime pair since it has not been identified earlier. $\mathrm{C}+\mathrm{C}$ combination for the prime pair 11-19 which is $893(19 \times 77)+605(11 \times 55)$ has already been identified while deriving $\mathrm{C}+\mathrm{C}$ combinations of type 1 and will therefore not be considered unique to the prime pair 11-19.

$\mathrm{c} 1+\mathrm{c} 2$ of type 3 for prime pairs involving 13:-

The prime pairs $13 \& 17$ and $13 \& 19$ satisfy the general condition of $2 \mathrm{k} / 6 \mathrm{p} 1 \mathrm{p} 2 \geq 1$. In order to identify the combinations we begin by finding the value of $2 \mathrm{k}-13 \mathrm{x}(6 \mathrm{I}-1)=1498$ $13 \times 113=1498-1469=29$ 
To identify the $\mathrm{c} 1+\mathrm{c} 2$ combination of type 3 for the prime pair $13 \& 17$ we solve for the equation $(29+78 n) / 17=$ Int (an Integer), to find the value of $n$ where Int becomes an integer. Here $(29+78 \times 9) / 17=43$

Therefore the $c 1+c 2$ combination thus derived would be $731(17 \times 43)+767(13 \times 59)$. Since this combination has not been derived earlier, it would be considered unique to the prime pair $13 \& 17$. Derived on similar lines a unique combination for the prime pair $13 \& 19$ would be identified as $1121(19 \times 59)+377(13 \times 29)$. Since this combination has not been identified earlier it would be considered unique to the prime pair $13 \& 19$.

Total number of $\mathrm{c} 1+\mathrm{c} 2$ combinations of type 3 for $2 \mathrm{k}$ as 1498 would be 5 .

From the above discussion it may be derived that total number of $\mathrm{c} 1+\mathrm{c} 2$ combinations for the even number 1498 would be summation of number of $c 1+c 2$ combinations of type 1 ; and number of combinations of $\mathrm{c} 1+\mathrm{c} 2$ combinations of type 2 ; and number of $\mathrm{c} 1+\mathrm{c} 2$ combinations of type 3 which would be $18+13+5=36$. This implies that the total number of $\mathrm{C}+\mathrm{C}$ combinations for the even number 1498 would be 36 .

\section{Illustration 3:}

Deriving $\mathrm{C}+\mathrm{C}$ combinations for $2 \mathrm{k}$ of $\operatorname{SADN}(3,6,9)$

Consider the even number 1596 . The relevant details required for deriving $\mathrm{c} 1+\mathrm{c} 2$ combinations for this number are summarized in the following table:-

\begin{tabular}{|l|l|}
\hline SADN & 3 \\
\hline Relevant series & S5 and S7 series \\
\hline Last digit & 6 \\
\hline $\mathrm{k}$ & 798 \\
\hline Nature of $\mathrm{k}$ & Composite $(7 \times 19 \times 6)$ \\
\hline Total no of combinations & $(1596) / 6=266$ \\
\hline Total no of elements & $2 \mathrm{TC}=532$ \\
\hline No of primes & 249 \\
\hline No of composites & 283 \\
\hline
\end{tabular}

Table 11D.3: Details required for deriving $\mathrm{c} 1+\mathrm{c} 2$ combinations for illustration of $\operatorname{SADN}(3) / / 6$ 
It is important to note here that $\mathrm{c} 1+\mathrm{c} 2$ combinations for even numbers of $\operatorname{SADN}(3,6,9)$ are different from even numbers of $\operatorname{SADN}(2,5,8)$ and $\operatorname{SADN}(7,4,1)$ on two accounts. Firstly, since mid-point of even numbers of $\operatorname{SADN}(3), \operatorname{SADN}(6)$ or $\operatorname{SADN}(9)$ would be of SADN 6, SADN 3 or SADN 9 respectively, the mid-point would essentially lie on the $\mathrm{S} 3$ series whereas the relevant series for $2 \mathrm{k}$ of $\operatorname{SADN}(3,6,9)$ are both the $\mathrm{S} 5$ and $\mathrm{S} 7$ series. Therefore, in this case, $\mathrm{c} 1+\mathrm{c} 2$ combinations of type 1 which are derived from the midpoint will be identified in a different manner. Secondly, since the combinations for these numbers are such that one component lies on the S5 series and the other lies on the S7 series while identifying $\mathrm{c} 1+\mathrm{c} 2$ combinations; composites on both the series need to be considered. This will be evident from the following discussion.

Deriving $\mathrm{C}+\mathrm{C}$ combinations of type 1 for $2 \mathrm{k}$ as 1596

Mid-point for the even number 1596 is 798 which is of SADN 6 and its factors are 7, 19 and $6 . c 1+c 2$ combinations of type 1 will be derived as follows:

As $1596 / 7=228$, combinations of elements of the S5 and S7 series which can be summed up to 228 , needs to be identified here to derive $\mathrm{c} 1+\mathrm{c} 2$ combinations of type 1 . For this, the method that can be applied is summing up $(6 n+1)+[228-(6 n+1)]$ where value of $n$ ranges from 1 to such an integer such that $6 n+1$ would be $<228$. These combinations would be derived as 7+221 (i.e.228-7); 13+215 (i.e.228-13); 19+209 (i.e. 228-19), ... , 223 (i.e. value of $\mathrm{n}$ is 37)+5(i.e.228-223). By multiplying both terms of the addition function by 7 we can derive $c 1+c 2$ combinations of type 1 . The combinations thus derived would be as follows-

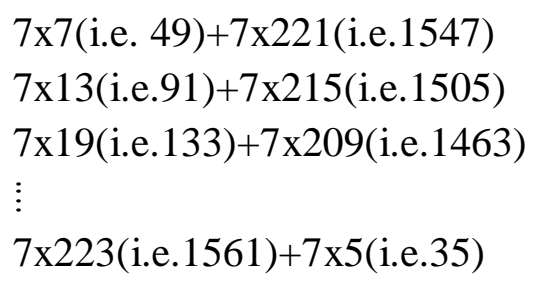

In all, 37 such combinations can be identified.

Similarly, since another factor of the even number under consideration is $19, \mathrm{c} 1+\mathrm{c} 2$ combinations of type 1 will be identified for this factor as well. These may be derived as follows: 
As $1596 / 19=84$, applying the same rationale as above, $c 1+c 2$ combinations of type 1 can be identified as :

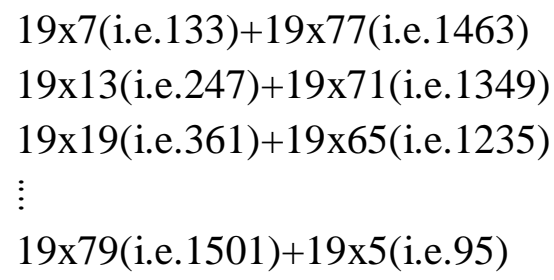

In this manner 13 combinations have been identified. However, 2 of these combinations 19x7(i.e.133)+19x77(i.e.1463) and 19x49(i.e.931)+19x35(i.e.665) have been identified while deriving $\mathrm{c} 1+\mathrm{c} 2$ combinations of type 1 for the earlier factor 7 . Therefore, these combinations will not be considered here to avoid double counting. The unique $\mathrm{c} 1+\mathrm{c} 2$ combinations derived for the prime factor 19 would therefore be $13-2=11$.

Thus total number of $\mathrm{c} 1+\mathrm{c} 2$ combinations of type 1 for the even number 1596 would be $37+11=48$.

Deriving $\mathrm{c} 1+\mathrm{c} 2$ combinations of type 2 for $2 \mathrm{k}$ as 1596

Since the even number under consideration ends in the digit 6 , odd composite numbers ending in 1 on the relevant series (both the S5 and S7 series) would form part of $\mathrm{c} 1+\mathrm{c} 2$ combinations of type 2 since the corresponding number in the combination would essentially end in 5 and would therefore be a multiple of 5. It may be noted here that the first relevant prime number, 7 , need not be considered while identifying $\mathrm{c} 1+\mathrm{c} 2$ combinations of type 2 since these would have already been derived while identifying $\mathrm{c} 1+\mathrm{c} 2$ combinations of type 1 . Therefore, we begin by identifying $\mathrm{c} 1+\mathrm{c} 2$ combinations of type 2 formed by the prime number 11 on the S5 series. These combinations can be derived as ff of $[\{(145-31) / 30\}+1]=$ ff of $(4.8)=4$; and the combinations thus derived would be:

$$
\begin{aligned}
\text { i. } & 11 \times 31(\text { i.e. } 341)+1255 \\
\text { ii. } & 11 \times 61(\text { i.e. } 671)+925 \\
\text { iii. } & 11 \times 91(\text { i.e. } 1001)+595 \\
\text { iv. } & 111 \times 121(\text { i.e. } 1331)+265
\end{aligned}
$$

Of these, the third combination $1001+595$ has already been derived as $7 x 143($ i.e. 1001) +595 while identifying $\mathrm{c} 1+\mathrm{c} 2$ combinations involving the previous prime number 7 so this combination will not be considered here. Therefore, the total number of unique $\mathrm{c} 1+\mathrm{c} 2$ combinations in which 11 is a factor of the component on the S5 series would be 3 . 
$\mathrm{c} 1+\mathrm{c} 2$ combinations in which 11 is a factor of the component on the S7 series can be derived as $\mathrm{ff}$ of $[(143-11) / 30+1]=\mathrm{ff}$ of $(5.4)=5$ and the combinations thus derived are:
i. $\quad 11 \times 11($ i.e. 121$)+1475$
ii. $\quad 11 \times 41($ i.e. 451$)+1145$
iii. $\quad 11 \times 71($ i.e. 781$)+815$
iv. $11 \times 101($ i.e. 1111$)+485$
v. $11 \times 131($ i.e. 1441$)+155$

All these combinations are unique to the prime number 11 and therefore the total number of $\mathrm{c} 1+\mathrm{c} 2$ combinations involving the number 11 can be derived as 3(in which 11 is a factor of the component on the S5 series) and 5 (in which 11 is a factor of the component on the $S 7$ series). Thus total number of combinations would be $3+5=8$.

$\mathrm{n}(\mathrm{c}+\mathrm{c})$ of type 2 for prime number 13 :

$\mathrm{c} 1+\mathrm{c} 2$ combinations where 13 is a factor of the component on the $\mathrm{S} 5$ series can be derived as ff of $[\{(119-17) / 30\}+1]=$ ff of $(4.4)=4$ and the combinations thus derived are-
i. $\quad 13 \times 17($ i.e. 221$)+1375$
ii. $13 \times 47($ i.e. 611$)+985$
iii. $13 \times 77($ i.e. 1001$)+595$
iv. $13 \times 107($ i.e. 1391$)+205$

Of these, the third combination 1001+595 has already been derived earlier and will not be considered here. Total number of $c 1+c 2$ in which 13 is a factor of the component on the S5 series would therefore be 3 .

$\mathrm{c} 1+\mathrm{c} 2$ combinations where 13 is a factor of the component on the S7 series would be derived as ff of $[\{(121-37) / 30\}+1]=$ ff of $(3.8)=3$ and the combinations thus derived would be
i. $13 \times 37($ i.e. 481$)+1115$
ii. $13 \times 67($ i.e. 871$)+725$
iii. $13 \times 97($ i.e. 1261$)+335$ 
All these combinations are unique to the number 13 so the total number of unique combinations would be 3(in which 13 is a factor of the component on the S5 series) and 3 (in which 13 is a factor of the component on the S7 series). The total number of combinations would therefore be $3+3=6$.

Deriving $\mathrm{c} 1+\mathrm{c} 2$ combinations of type 2 for the prime number 17 :

$\mathrm{c} 1+\mathrm{c} 2$ combinations where 17 is a factor of the component on the S5 series would be derived as ff of $[\{(91-43) / 30\}+1]=$ ff of $(2.6)=2$ and the combinations thus derived would be

i. $\quad 17 x 43($ i.e. 731$)+865$

ii. $\quad 17 \times 73($ i.e. 1241$)+355$

$\mathrm{c} 1+\mathrm{c} 2$ combinations where 17 is a factor of the component on the $\mathrm{S} 7$ series can be derived as ff of $[\{(89-23) / 30\}+1]=$ ff of $(3.2)=3$ and the combinations thus derived would be:
i. $\quad 17 \times 23($ i.e. 391$)+1205$
ii. $17 \times 53($ i.e. 901$)+695$
iii. $\quad 17 \times 83($ i.e. 1411$)+185$

Total number of combinations would be $2+3=5$.

Deriving $\mathrm{c} 1+\mathrm{c} 2$ combinations for the prime number 19:

Here again it may be noted that $\mathrm{c} 1+\mathrm{c} 2$ combinations in which 19 is a factor of the composite component would have already been derived while identifying $\mathrm{c} 1+\mathrm{c} 2$ combinations of type 1 therefore, deriving them again would result in double counting.

Deriving $\mathrm{c} 1+\mathrm{c} 2$ combinations of type 2 for the prime number 23 : 
$\mathrm{c} 1+\mathrm{c} 2$ combinations where 23 is a factor of the component on the S5 series can be derived as ff of $[\{(67-37) / 30\}+1]=$ ff of $(2)=2$ and the combinations thus derived are:

\section{i. $23 \times 37($ i.e. 851$)+745$ \\ ii. $23 \times 67($ i.e. 1541$)+55$}

$\mathrm{c} 1+\mathrm{c} 2$ combinations where 23 is a factor of the component on the $\mathrm{S} 7$ series can be derived as ff of $[\{(65-47) / 30\}+1]=$ ff of $(1.6)=1$ and the combination thus derived would be $1081+515$. Total number of $c 1+c 2$ combinations in which 23 is a factor would therefore be $2+1=3$.

Deriving $\mathrm{c} 1+\mathrm{c} 2$ combinations of type 2 for prime number 29

Where 29 is a factor of the component on the S-5 series can be derived as 55$49 / 30+1=1.2$ and the combination thus derived would be $1421+175$. Since this combination has already been derived earlier it will not be considered here.

Where 29 is a factor of the components on the S-7 series can be derived as [(53$29) / 30]+1=1.8$ and the combination thus derived would be $29 \times 29(=841)+755$. Total number of combinations for the number 29 would therefore be 1 .

Deriving $\mathrm{c} 1+\mathrm{c} 2$ combinations of type 2 for the number 31 :

$\mathrm{c} 1+\mathrm{c} 2$ combinations where 31 is a factor of the component on the S5 series can be derived as ff of $[\{(47-41) / 30\}+1]=$ ff of $(1.2)=1$ and the combination thus derived would be $31 \times 41($ i.e. 1271$)+325$

$\mathrm{c} 1+\mathrm{c} 2$ combinations where 31 is a factor of the component on the $\mathrm{S} 7$ series can be derived as ff of $[\{(49-31) / 30\}+1]=$ ff of $(1.6)=1$ and the combination thus derived would be $31 \times 31($ i.e. 961$)+635$. Total number of combinations would be 2 .

The total number of $\mathrm{c} 1+\mathrm{c} 2$ combinations of type 2 for $2 \mathrm{k}$ as 1596 would be 44 . 
Deriving $\mathrm{c} 1+\mathrm{c} 2$ combinations of type 3 for $2 \mathrm{k}$ as 1596 :

While deriving $\mathrm{c} 1+\mathrm{c} 2$ combinations of type 3 for even numbers of $\operatorname{SADN}(3,6,9)$, it is important to note that two types of combinations would be identified. Firstly, those in which $\mathrm{p} 1$ is a factor of the component on the S5 series and $\mathrm{p} 2$ is a factor of the component on the S7 series and secondly in the form where $\mathrm{p} 1$ is a factor of the component on the S7 series while $\mathrm{p} 2$ is a factor of the component on the S5 series. Further, it may be noted that since 7 is a factor of the even number under consideration, all $\mathrm{c} 1+\mathrm{c} 2$ combinations involving 7 would be derived as $c 1+c 2$ combinations of type 1 . Therefore, while identifying $\mathrm{c} 1+\mathrm{c} 2$ combinations of type 3 , we begin with the prime pair $11 \& 13$.

Deriving $\mathrm{c} 1+\mathrm{c} 2$ combinations of type 3 for the prime pair $11 \& 13$ :

$\mathrm{c} 1+\mathrm{c} 2$ combination where 11 is a factor of the composite component on the S7 series and 13 is a factor of the composite component on the $\mathrm{S} 5$ series:

We begin by first finding the value of $2 \mathrm{k}-11 \times(6 \mathrm{I}-1)=1596-(11 \times 143)=1596-1573=23$. Thereafter we solve for the equation $(23+66 n) / 13=$ Int (an Integer), to find the value of $n$ where Int becomes an integer. Here $(23+66 \times 3) / 13=17$ which leads us to the first $\mathrm{c} 1+\mathrm{c} 2$ combination $13 \times 17$ (i.e.221)+11x125(i.e.1375). Further combinations would be derived by adding $11 \times 13 \times 6$ (i.e.858) to the first term and subtracting the same from the second term. The combination/s thus derived would be $1079(13 \times 83)+517(11 \times 47)$. Of these, the first combination $221+1375$ has already been derived while identifying $\mathrm{c} 1+\mathrm{c} 2$ combinations of type 2 so it will not be considered here. Number of unique $\mathrm{c} 1+\mathrm{c} 2$ combinations of type 3 for the prime pair $11 \& 13$ would therefore be 1 .

Deriving $\mathrm{c} 1+\mathrm{c} 2$ combinations for $\mathrm{p}_{1} \mathrm{p}_{2}$ as $11 \& 13$ wherein 11 is a factor of the composite component on the S5 series and 13 is a factor of the composite component on the S7 series. Here we begin by identifying the value of $2 \mathrm{k}-11(6 \mathrm{I}+1)=1596-(11 \times 145)=1596$ $1595=1$. Thereafter we solve for the equation $(1+66 \mathrm{n}) / 13=$ Int (an Integer), to find the value of $n$ where Int becomes an integer. Here $(1+66 \times 12) / 13=61$ and the combination

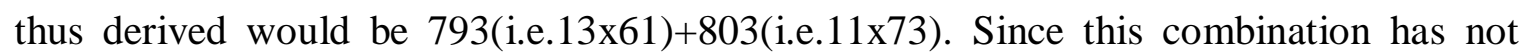
been derived earlier, it would be considered as a unique $\mathrm{c} 1+\mathrm{c} 2$ combination for the prime pair 11-13. Total number of $c 1+c 2$ combinations for this prime pair would be $1+1=2$. 
Deriving $\mathrm{C}+\mathrm{C}$ combinations of type 3 for the prime pair $11 \& 17$ :

The combinations would be derived as $(23+66 n) / 17=$ Integer and $(1+66 n) / 17=$ Int (an Integer), to find the value of $n$ where Int becomes an integer; $(23+66 \times 3) / 17=13$. The $\mathrm{c} 1+\mathrm{c} 2$ combination thus derived would be $221+1375$. Further combination/s would be derived by adding $11 \times 17 \times 6$ (i.e.1122) to the first term and subtracting the same from the second term. This leads us to the combination 1343(i.e.17x79)+253(i.e.11x23). Of these, the first combination $221+1375$ has already been identified while deriving $\mathrm{C}+\mathrm{C}$ combinations of type 2 and will not be considered here and accordingly only $1 \mathrm{c} 1+\mathrm{c} 2$ combination can be identified.

Likewise $(1+66 \times 9) / 17=35$ which leads us to the combination 1001(i.e.11x91)+595(i.e.17x85). This is the only $\mathrm{c} 1+\mathrm{c} 2$ combination derived for the prime pair $11 \& 17$ in which the former is a factor of the composite component on the S5 series and the latter is a factor of the component on the S7 series. Since this combination has already been derived earlier while identifying $\mathrm{c} 1+\mathrm{c} 2$ combinations of type 1 ; it will not be considered here. In sum, the total number of unique $\mathrm{c} 1+\mathrm{c} 2$ combinations for the prime pair $11 \& 17$ would be 1 .

$\mathrm{c} 1+\mathrm{c} 2$ combinations for the prime pair $11 \& 19$ would have already been derived while identifying $\mathrm{c} 1+\mathrm{c} 2$ combinations of type 1 so these need not be derived again.

Deriving $\mathrm{c} 1+\mathrm{c} 2$ combinations of type 3 for the prime pair $11 \& 23$ :

$\mathrm{c} 1+\mathrm{c} 2$ combination where 11 is a factor of the component on the S5 series while 23 is a factor of the component on the S7 series. In order to find such a combination we will first solve the equation $1+66 \mathrm{n} / 23=\mathrm{I}$ to find the value of $\mathrm{n}$ where I becomes an integer. Here, $1+66 \times 8$ and the combination thus derived would be 529(i.e.23x23)+1067(i.e.11x97). Likewise in order to identify the combination in which 11 is a factor of the component on the $\mathrm{S} 7$ series while 23 is a factor of the component on the S5 series we solve for the equation $(23+66 n) / 23=I$ to find the value of $n$ where I becomes an integer. Here, $(23+66 \times 23) / 23=67$ and the combination thus derived would be 1541(i.e.23x67)+55(i.e.11x5). Since this combination has already been derived while identifying $\mathrm{c} 1+\mathrm{c} 2$ combinations of type 2 , it will not be considered here. In effect the total number of unique $\mathrm{c} 1+\mathrm{c} 2$ combinations of type 3 for the prime pair $11 \& 23$ will be 1 .

Deriving $\mathrm{c} 1+\mathrm{c} 2$ combinations of type 3 for the prime pair $13 \& 17$ : 
$\mathrm{c} 1+\mathrm{c} 2$ combination where 13 is a factor of the component on the S5 series while 17 is a factor of the component on the S7 series

We begin by first finding the value of $2 \mathrm{k}-13 \times(6 \mathrm{I}+1)$ which is $1596-(13 \times 121)=1596-$ $1573=23$. Thereafter we solve the equation $(23+78 n) / 17=$ Int (an Integer), to find the value of $\mathrm{n}$ where Int becomes an integer. Here $[23+(78 \times 13)] / 17=61$ and the $\mathrm{C}+\mathrm{C}$ combination thus derived would be $1037(17 \times 61)+559(13 \times 43)$.

Likewise in order to find the combination where 13 is a factor of the component on the S5 series while 17 is a factor of the component on the S-7 series we first find the value of $2 \mathrm{k}-13 \times(6 \mathrm{I}-1)$. This would be $1596-13 \times 119=1596-1547=49$. Thereafter we solve the equation $(49+78 n) / 17=$ Int (an Integer), to find the value of $n$ where Int becomes an integer. Here $(49+78 \times 7) / 17=35$ and the combination thus derived would be 595(i.e.17x35)+1001(i.e.13x77). Since this combination has already been derived earlier it will not be considered again. The total number of unique $\mathrm{c} 1+\mathrm{c} 2$ combinations for the prime pair $13 \& 17$ would be 1 .

Thus total number of $\mathrm{c} 1+\mathrm{c} 2$ combinations of type 3 for the even number 1596 would be 5 .

Therefore total number of $\mathrm{c} 1+\mathrm{c} 2$ combinations for $2 \mathrm{k}$ as 1596 would be summation of number of $\mathrm{c} 1+\mathrm{c} 2$ combinations of type 1 ; and number of $\mathrm{c} 1+\mathrm{c} 2$ combinations of type 2 ; and number of $\mathrm{c} 1+\mathrm{c} 2$ combinations of type 3 . These would be $48+44+5=97$

Therefore, total number of $\mathrm{c} 1+\mathrm{c} 2$ combinations for 1596 would be 97 . 


\section{E.}

\section{PYTHON Codes used to compute for verification in case of any given even number $(2 k)$ of $\operatorname{SADN}(5,2,8)$, $\operatorname{SADN}(7,4,1)$ or $\operatorname{SADN}(6,3,9)$}

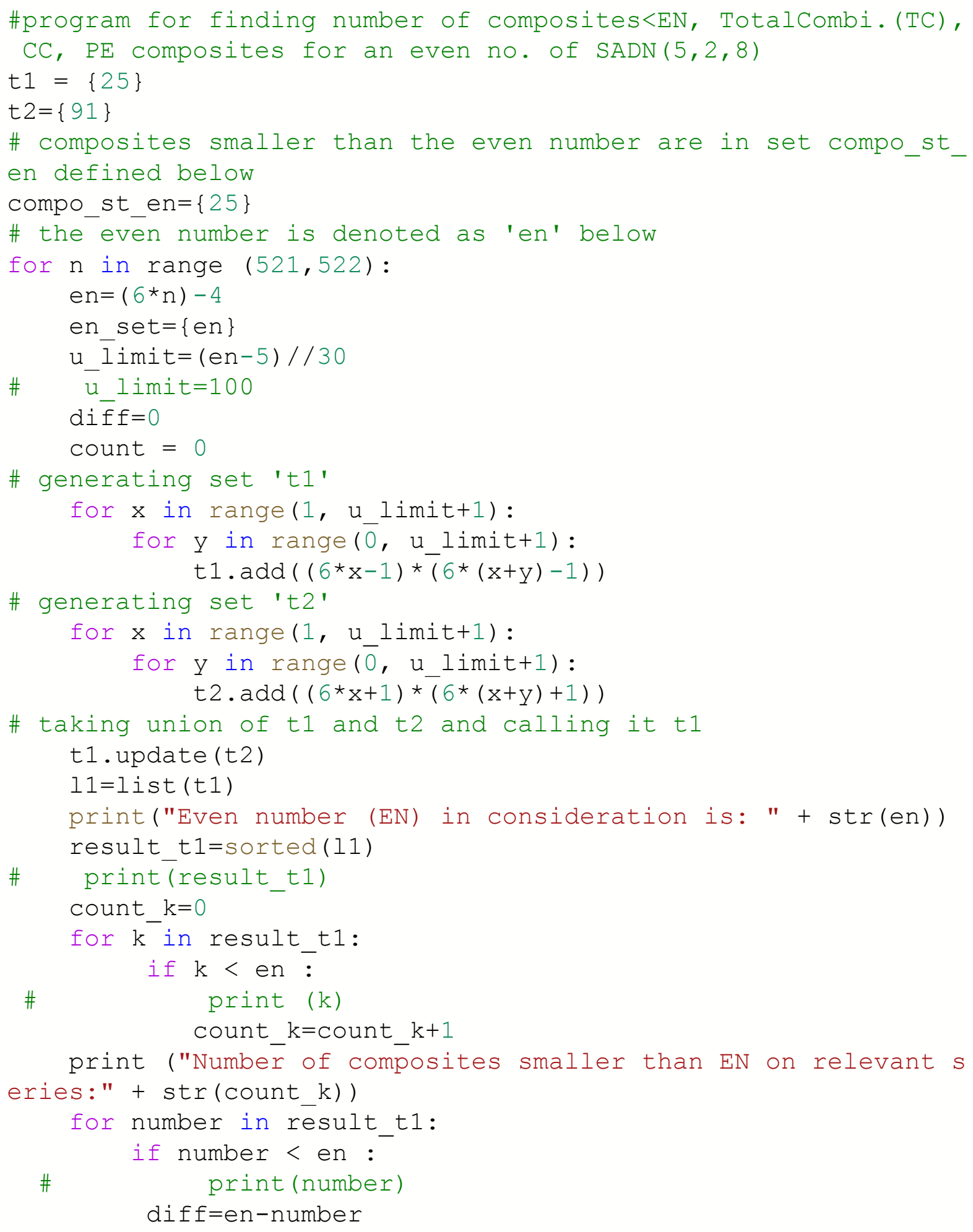


\# $\quad$ print (diff)

if diff in result_t1:

count $=$ count +1

cc_combi=count $/ / 2$

tot combi=( (en//2)-1)//6

print ("Number of TOTAL combinations:" + str(tot_combi))

if en/2 in result t1:

$\mathrm{CC}$ combi=CC combit1

print("Number of CC combinations:" + str(CC_combi))

pe_composites=count_k-(2*Cc_combi)

if en/2 in result t $\overline{1}$ :

pe composites=pe composites+1

print ("Number of PRIME-

EATER composites:" + str(pe_composites))

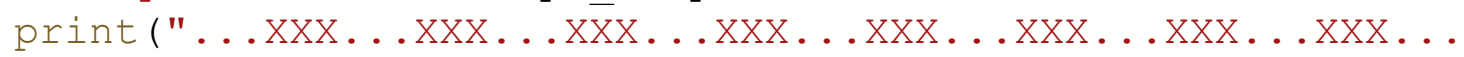

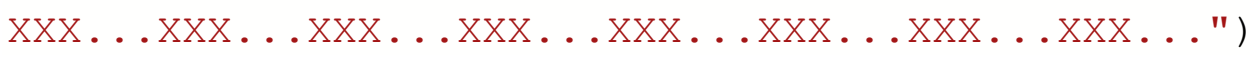

Python code 1: Code for finding number of composites less than given Even Number(2k), Number of Total Combinations(TC), Number of Composite(CC) combinations, Number of Prime Eater (PE) composites for an even no. of $\operatorname{SADN}(5,2,8)$

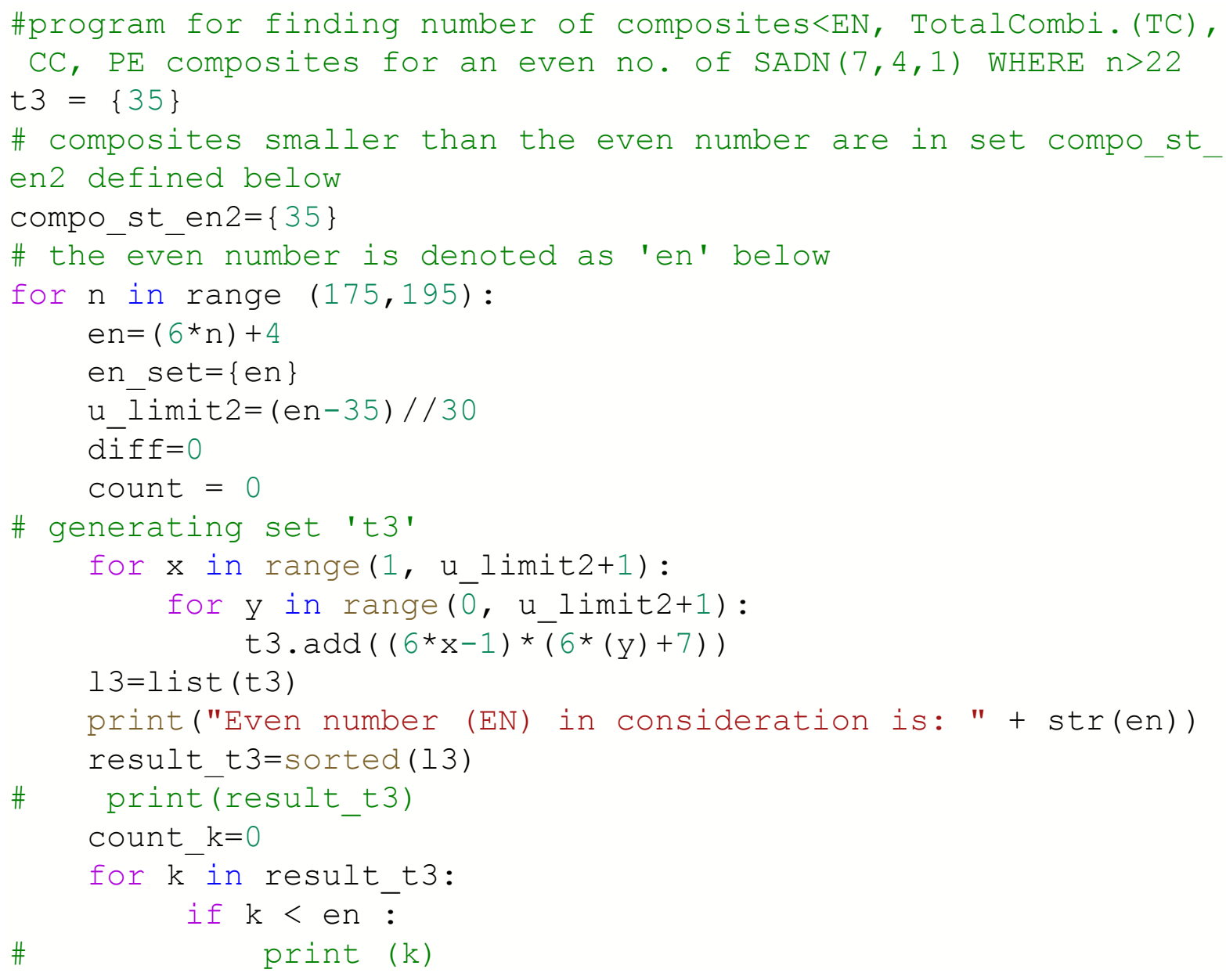




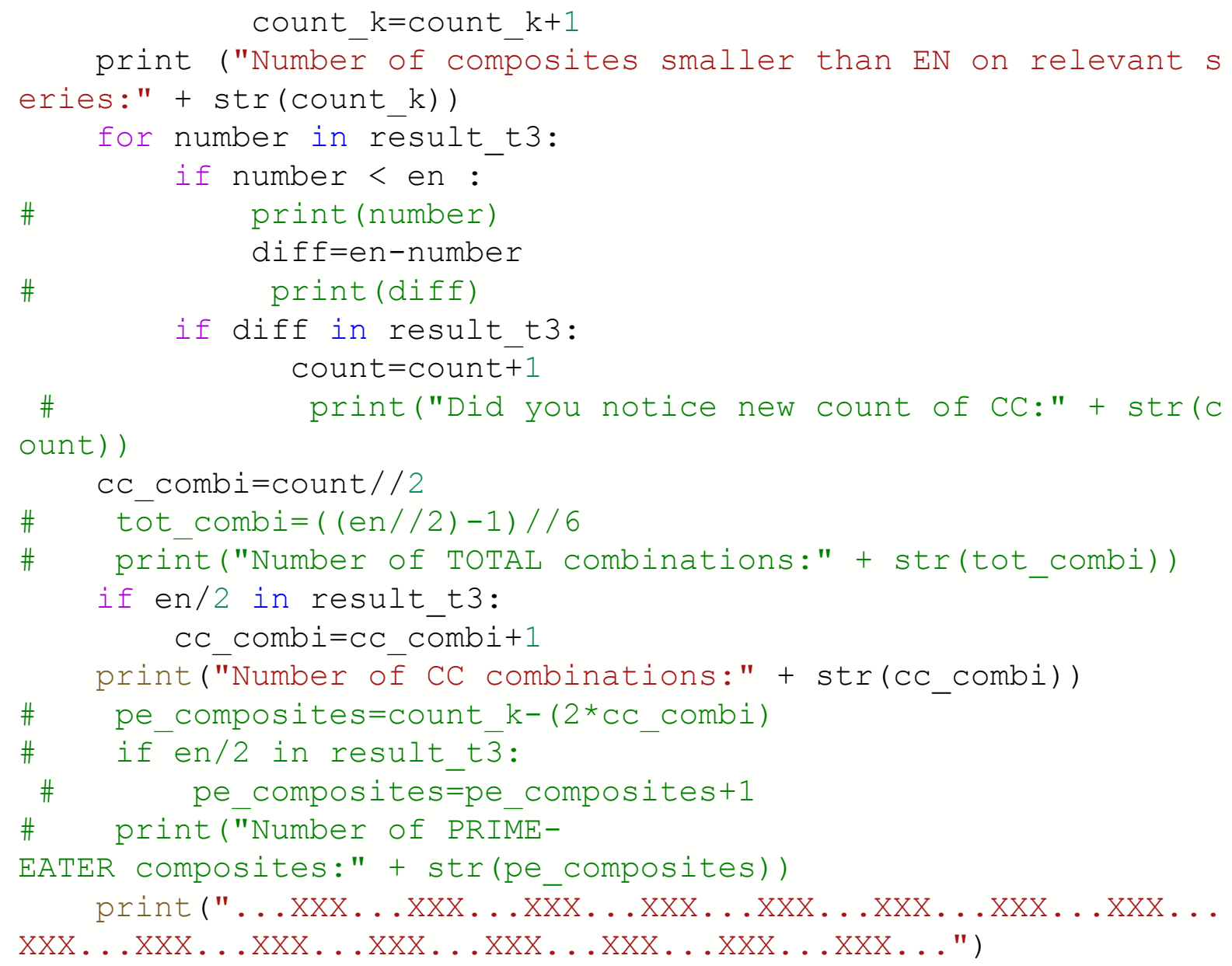

Python code 2: Code for finding number of composites less than given Even Number(2k), Number of Total Combinations(TC), Number of Composite(CC) combinations, Number of Prime Eater (PE) composites for an even no. of $\operatorname{SADN}(7,4,1)$

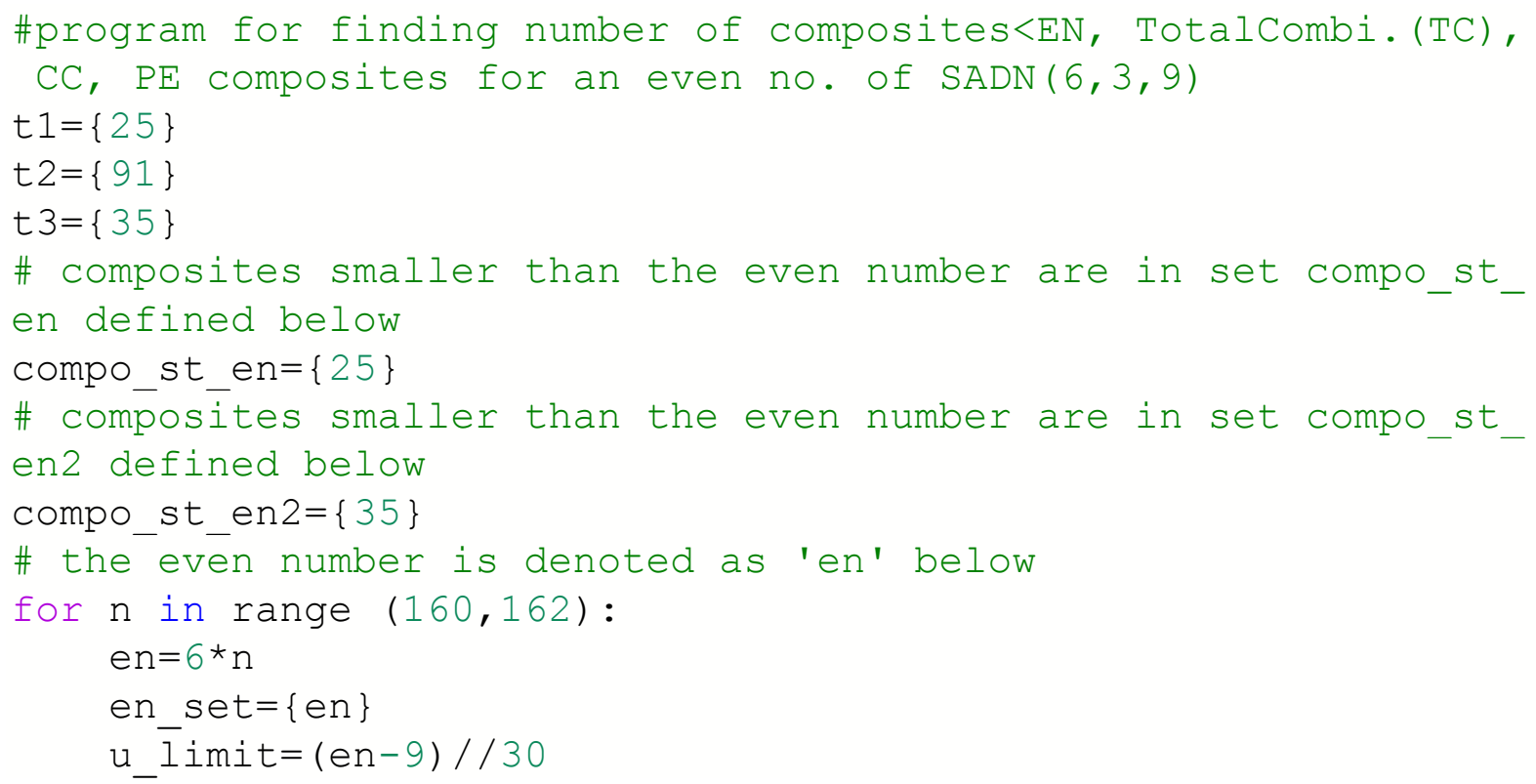




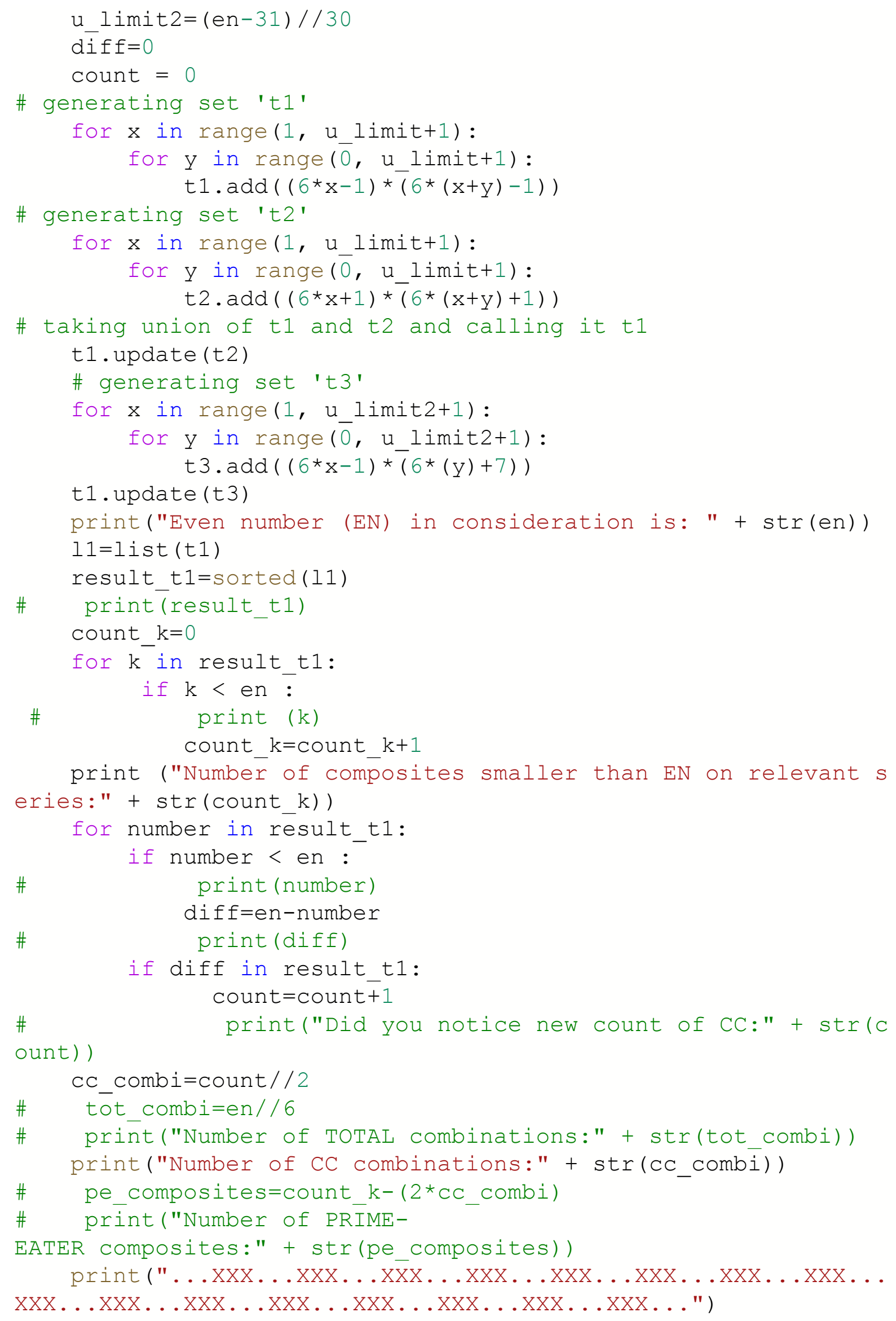


Python code 3: Code for finding number of composites less than given Even Number(2k), Number of Total Combinations(TC), Number of Composite(CC) combinations, Number of Prime Eater (PE) composites for an even no. of $\operatorname{SADN}(6,9,3)$ 
12

\section{Number of c1+c2 combinations: minimum vis-à-vis actual number of c1+c2 combinations}

\section{Concepts of minimum number of $\mathrm{c} 1+\mathrm{c} 2$ combinations and actual number of c1+c2 combinations for even numbers if $\mathrm{nTC}<\mathrm{nc}$ :}

For a given even number (given as $2 \mathrm{k}$ ) if total number of acceptable combinations is greater than total number of unique composites by even 1 , it directly follows that even if all the composites are prime-eaters, there would still remain a $\mathrm{p} 1+\mathrm{p} 2$ combination. Suppose total number of acceptable combinations is denoted as nTC and total number of unique composites is denoted as nc, then if nTC $>$ nc by atleast 1 then even if all composites are prime-eaters; $\mathrm{p} 1+\mathrm{p} 2$ combinations would still be identified and their number would be nTC -nc. In this case, nTC - nc would be the minimum number of $\mathrm{p} 1+\mathrm{p} 2$ for the given $2 \mathrm{k}$. Since we have not explored the possibility of $\mathrm{c} 1+\mathrm{c} 2$ combinations so far, it may be noted that with identification of $\mathrm{c} 1+\mathrm{c} 2$ combinations, difference between nTC and number of combinations absorbed by composites in the nature of $\mathrm{c} 1+\mathrm{c} 2$ and $\mathrm{p}+\mathrm{c}$ combinations will go on increasing and thereby the number of $\mathrm{p} 1+\mathrm{p} 2$ combinations will also increase.

For a given $2 \mathrm{k}$ if $\mathrm{nTC}<\mathrm{nc}$ then it is not possible to directly arrive at the possibility of the existence of $\mathrm{p} 1+\mathrm{p} 2$ combinations. Consider the following situations:-

Number of total acceptable combinations $=50$ and no. of unique composites $=62$ which implies that $(50 \times 2)-62$ i.e. $100-62$ i.e. 38 would be the number of prime numbers (on the relevant series in case of given $2 \mathrm{k}$ ), which would be smaller than $2 \mathrm{k}$. If all composites are considered to be prime-eaters then number of $\mathrm{p}+\mathrm{c}$ combinations would be 38 since number of primes is 38 and maximum number of $\mathrm{p}+\mathrm{c}$ combinations can be equal to the number of primes. Since $\mathrm{nTC}=50$, it follows that the remaining combinations (i.e. nTC- number of combinations of type $(p+c)$ ) i.e. nTC $-\mathrm{nPC}=50-$ $38=12$ will be number of $\mathrm{c} 1+\mathrm{c} 2$ combinations. This is because TC comprises of 3 components:- $\mathrm{p}+\mathrm{c}, \mathrm{c} 1+\mathrm{c} 2$ and $\mathrm{p} 1+\mathrm{p} 2$. Here all primes have been absorbed by composites so there would be no $\mathrm{p} 1+\mathrm{p} 2$ combinations. Therefore the remaining combinations will be in the nature of $\mathrm{c} 1+\mathrm{c} 2$ combinations. In the above example 38 would be the maximum number of $\mathrm{p}+\mathrm{c}$ combinations and 12 would be the minimum number of $\mathrm{c} 1+\mathrm{c} 2$ combinations.

From this we can define the concept of minimum number of $c 1+c 2$ as the number of $\mathrm{c} 1+\mathrm{c} 2$ combinations that would be identified if nTC $>\mathrm{np}$ and all primes are absorbed by $\mathrm{p}+\mathrm{c}$ type of combinations.

In general terms minctc (i.e. number of $\mathrm{c} 1+\mathrm{c} 2$ combinations if all primes are theoretically absorbed by $\mathrm{p}+\mathrm{c}$ combinations) can be derived as follows:-

Minc $+c=n T C-n p$ which is equal to nc-nTC which is equal to (nc-np)/2

1 [Section 12] 


\section{Maximum and minimum values of minc+c:}

An important question is what could be the minimum and maximum value of minimum number of $\mathrm{c} 1+\mathrm{c} 2$ type of combinations (i.e. $\operatorname{minc}+\mathrm{c}$ ). Since minimum $\mathrm{c} 1+\mathrm{c} 2$ may be defined as the number of $\mathrm{c} 1+\mathrm{c} 2$ that would be identified if all primes are absorbed by $\mathrm{p}+\mathrm{c}$ combinations, its value will depend on number of primes vis-a-vis number of composites. For a given $2 \mathrm{k}$ if $\mathrm{nTC}=\mathrm{np}$ (i.e. number of primes) it follows that $\mathrm{np}=\mathrm{nc}$ (i.e. number of composites). This is because $2 \mathrm{nTC}=\mathrm{nc}+\mathrm{np}$, so if $\mathrm{nTC}=\mathrm{np}$ then $\mathrm{nTC}=\mathrm{nc}$ as well i.e. $\mathrm{nTC}=\mathrm{np}=\mathrm{nc}$. Here minimum $\mathrm{c} 1+\mathrm{c} 2$ will be 0 (zero) i.e. if all prime elements are absorbed by $\mathrm{p}+\mathrm{c}$ combinations (and $\mathrm{nTC}=\mathrm{np}$ ) then only one type of combinations will be identified i.e. $\mathrm{p}+\mathrm{c}$ type of combinations. For example consider the even number 800 (i.e.SADN8//0); for this number $\mathrm{nTC}=66$ and the number of primes as well as the number of composites $=66$. In this case minimum $\mathrm{c} 1+\mathrm{c} 2=0$.

Similarly if $2 \mathrm{k}=806$ (i.e.SADN5//6); for this number $\mathrm{nTC}=67$ and $\mathrm{nc}$ as well as $\mathrm{np}=67$, here again minimum $\mathrm{c} 1+\mathrm{c} 2=0$. If instead for a given $2 \mathrm{k}$ all primes form part of $\mathrm{p}+\mathrm{c}$ combinations, then minimum $\mathrm{c} 1+\mathrm{c} 2$ will become equal to actual $\mathrm{c} 1+\mathrm{c} 2$. So it follows that the maximum value of minimum $\mathrm{c} 1+\mathrm{c} 2$ will be the number of actual $\mathrm{c} 1+\mathrm{c} 2$ derived by following the steps mentioned in an earlier section, i.e. section 11.

\section{Derivation of number of combinations of p+c type:}

Correspondingly we can derive the number of prime\&composite combinations as follows:-

If the number of total combinations is greater than the number of prime for a given $2 \mathrm{k}$, the maximum possible number of prime-eater composites would be the number of primes less than $2 \mathrm{k}$. This situation would occur if all prime numbers combine with composite numbers to form $\mathrm{p}+\mathrm{c}$ type of combinations. The actual number of $\mathrm{p}+\mathrm{c}$ type of combinations would be equal to the number of composite elements that remain after absorption of composite numbers by $\mathrm{c} 1+\mathrm{c} 2$ combinations. Every $\mathrm{c} 1+\mathrm{c} 2$ combination will absorb two composite numbers.

Therefore total number of composites absorbed by $\mathrm{c} 1+\mathrm{c} 2$ combination would be twice of $\mathrm{nc}+\mathrm{c}$. After we calculate this number of composites absorbed by $\mathrm{c} 1+\mathrm{c} 2$ combinations, the remaining composites would combine with prime numbers to form $\mathrm{p}+\mathrm{c}$ combinations.

Number of combinations of type $\mathrm{p}+\mathrm{c}=\mathrm{nc}-2 \mathrm{nc}+\mathrm{c}$

Where $\mathrm{nc}=$ number of composites,

$\mathrm{nc}+\mathrm{c}=$ number of actual composite combinations or $\mathrm{c} 1+\mathrm{c} 2$ combinations.

\section{Concept of minimum number of required combinations of c1+c2 type:}

We would now return to the above example where minimum $\mathrm{c} 1+\mathrm{c} 2$ was derived to be 12 . 
By applying the steps to calculate $\mathrm{c} 1+\mathrm{c} 2$ discussed in section 11 , if we can identify even 1 more than the minimum $\mathrm{c} 1+\mathrm{c} 2$, then the composition of TC would change as follows:-

$$
\begin{array}{lll}
\text { nTC }=50 ; & \mathrm{nc} 1+\mathrm{c} 2=13 ; & \mathrm{np}+\mathrm{c}=36 ; \quad \mathrm{np} 1+\mathrm{p} 2=1 \\
\mathrm{nc}=62 ; & \mathrm{nc} 1+\mathrm{c} 2=13 \times 2=26 ; & \mathrm{np}+\mathrm{c}=62-26=36
\end{array}
$$

It therefore follows that if number of $\mathrm{c} 1+\mathrm{c} 2$ is greater than minimum $\mathrm{c}+\mathrm{c}$ (considering all composites to be prime-eaters) by even 1 then a $\mathrm{p} 1+\mathrm{p} 2$ combination would be identified. In general terms the minimum number of $\mathrm{c} 1+\mathrm{c} 2$ required to identify at least $1 \mathrm{p} 1+\mathrm{p} 2$ for a given $2 \mathrm{k}$ if $\mathrm{nTC}<\mathrm{nc}$ is $\mathrm{nTC}-\mathrm{np}+1$

i.e. minimum number of $\mathrm{c} 1+\mathrm{c} 2$ required to identify atleast one $\mathrm{p} 1+\mathrm{p} 2$ combination is denoted as minreq $\mathrm{c}+\mathrm{c}$

minreq $\mathrm{c}+\mathrm{c}=\mathrm{nTC}-\mathrm{np}+1$

\section{Relation between actual and minimum $\mathrm{c} 1+\mathrm{c} 2$ and identification of $\mathrm{p} 1+\mathrm{p} 2$ combinations:}

As mentioned earlier if $\mathrm{TC}>\mathrm{np}$, then minimum $\mathrm{c}+\mathrm{c}$ will be a positive number and if $\mathrm{TC}=\mathrm{np}$ then minimum $c+c=0$. Further the concept of minimum required $c+c$ has also been defined which says that if actual number of combinations of type $\mathrm{c} 1+\mathrm{c} 2$ (i.e. actual $\mathrm{c}+\mathrm{c}$ ) is greater than minimum $\mathrm{c}+\mathrm{c}$ by even 1 (one), then $\mathrm{p} 1+\mathrm{p} 2$ combinations would be identified.

Consider the following situation:-

$\mathrm{Tc}=100 ; \quad \mathrm{np}=80 ; \quad \mathrm{nc}=120$.

Also minimum $\mathrm{c} 1+\mathrm{c} 2=100-80=20$

Therefore minimum required $\mathrm{c} 1+\mathrm{c} 2=21$

If actual $\mathrm{c} 1+\mathrm{c} 2$ is now calculated, its value can range from value of minimum $\mathrm{c} 1+\mathrm{c} 2=\mathrm{tc}-\mathrm{np}$ $=100-80=20$ to maximum value of $\mathrm{c} 1+\mathrm{c} 2$ which is equal to number of composites $<\mathrm{k}$ which is equal to 59. So value of actual number of combinations of type $c 1+c 2$ can range from 20 to 59 .

Now upon calculating number of combinations of type $\mathrm{c} 1+\mathrm{c} 2$, if its value $=21$, then out of the $100 \mathrm{tc}, 21$ would be $\mathrm{c} 1+\mathrm{c} 2$ in nature. As defined earlier actual $\mathrm{p}+\mathrm{c}$ would be $=\mathrm{nc}-2 \mathrm{ncc}$ i.e. $120-2 \times 21=120-42=78$

Therefore, composition of nTC will be as follows:-

nTC $(100) ; \quad n c+c=21 ; \quad n p+c=78 ; \quad n p+p=1$

If value of actual number of combinations of $c 1+c 2$ type is derived as 22 then accordingly the composition of nTC will emerge as follows:-

$\mathrm{nTC}(100) ; \quad \mathrm{nc}+\mathrm{c}=22 ; \quad \mathrm{np}+\mathrm{c}=76 ; \quad \mathrm{np}+\mathrm{p}=2$ 
Likewise if actual $\mathrm{c} 1+\mathrm{c} 2=30$ then

Composition of nTC will be nTC $(100) ; \quad n c+c=30 ; \quad n p+c=60 ; \quad n p+p=10$

If actual $c+c$ attains its maximum value of 59 , then composition of nTC will be as follows:-

$\mathrm{nTC}(100) ; \quad \mathrm{nc}+\mathrm{c}=59 ; \quad \mathrm{np}+\mathrm{c}=2 ; \quad \mathrm{np}+\mathrm{p}=39$

It therefore follows that the number of $\mathrm{p} 1+\mathrm{p} 2$ will be derived as the difference between minimum $\mathrm{c}+\mathrm{c}$ and actual $\mathrm{c}+\mathrm{c}$.

\section{Behaviour of number of $\mathrm{c} 1+\mathrm{c} 2$ combinations over a range of even numbers:}

In order to understand the behaviour of $\mathrm{c} 1+\mathrm{c} 2$ combinations over a range of numbers, we now consider the number of such combinations for $2 \mathrm{k}$ of different SADN at fixed intervals. Specifically we will consider $2 \mathrm{k}$ of SADN 8//2 beginning from the number 242 (why 242?) at an interval of 720 (why 720?) natural numbers which will be representative (why representative?) of even numbers of $\operatorname{SADN}(2,5,8)$. Similarly we will consider $2 \mathrm{k}$ of SADN $4 / / 8$ beginning from the number 238 again at an interval of 720 natural numbers which would be representative of even numbers of $\operatorname{SADN}(1,4,7)$. Likewise we will consider $2 \mathrm{k}$ of SADN 6//0 beginning from the number 240 again at an interval of 720 numbers which would be representative of even numbers of $\operatorname{SADN}(3,6,9)$. The numbers considered here are consecutive even numbers to ensure that the beginning point remains more or less the same and the intervals have been kept the same to ensure that the behaviour remains comparable over the range of numbers under consideration. The following table shows the number of $\mathrm{c} 1+\mathrm{c} 2$ combinations as a proportion of number of composites on the relevant series as also the correspondence between number of $\mathrm{c} 1+\mathrm{c} 2$ combinations and number of total combinations which increase at a fixed number of 60 (why 60?) combinations.

For SADN8//2:

\begin{tabular}{|c|c|c|c|c|c|}
\hline $2 \mathbf{k}$ & nTC & $\mathrm{Nc}$ & $\mathrm{nC}+\mathrm{C}$ & $\begin{array}{c}\mathrm{nC}+\mathrm{C} \text { as \% } \\
\text { of } \mathrm{nTC}\end{array}$ & $\begin{array}{c}\mathrm{nC}+\mathrm{C} \text { as \% } \\
\text { of nc }\end{array}$ \\
\hline 242 & 20 & 15 & 3 & 15 & 20 \\
\hline 962 & 80 & 83 & 19 & 23.75 & 22.89157 \\
\hline 1682 & 140 & 153 & 37 & 26.42857 & 24.18301 \\
\hline 2402 & 200 & 225 & 60 & 30 & 26.66667 \\
\hline 3122 & 260 & 304 & 88 & 33.84615 & 28.94737 \\
\hline 3842 & 320 & 378 & 107 & 33.4375 & 28.30688 \\
\hline 4562 & 380 & 457 & 129 & 33.94737 & 28.22757 \\
\hline 5282 & 440 & 535 & 155 & 35.22727 & 28.97196 \\
\hline 6002 & 500 & 616 & 177 & 35.4 & 28.73377 \\
\hline 6722 & 560 & 691 & 200 & 35.71429 & 28.94356 \\
\hline 7442 & 620 & 775 & 229 & 36.93548 & 29.54839 \\
\hline
\end{tabular}

4 [Section 12] 


\begin{tabular}{|r|r|r|r|r|r|}
\hline 8162 & 680 & 858 & 283 & 41.61765 & 32.98368 \\
\hline 8882 & 740 & 934 & 282 & 38.10811 & 30.19272 \\
\hline 9602 & 800 & 1015 & 292 & 36.5 & 28.76847 \\
\hline 10322 & 860 & 1095 & 334 & 38.83721 & 30.50228 \\
\hline
\end{tabular}

Table 12.1: Behaviour of number of c1+c2 combinations over a range of even numbers (2k) of SADN8//2

For SADN4//8:

\begin{tabular}{|c|c|c|c|c|c|}
\hline $2 k$ & nTC & Nc & $\mathrm{nC}+\mathrm{C}$ & $\begin{array}{c}\mathrm{nC}+\mathrm{C} \text { as \% } \\
\text { of } \mathrm{nTC}\end{array}$ & $\begin{array}{c}\mathrm{nC}+\mathrm{C} \text { as \% } \\
\text { of nc }\end{array}$ \\
\hline 238 & 20 & 14 & 4 & 20 & 28.57143 \\
\hline 958 & 80 & 76 & 18 & 22.5 & 23.68421 \\
\hline 1678 & 140 & 145 & 36 & 25.71429 & 24.82759 \\
\hline 2398 & 200 & 220 & 58 & 29 & 26.36364 \\
\hline 3118 & 260 & 293 & 74 & 28.46154 & 25.25597 \\
\hline 3838 & 320 & 371 & 109 & 34.0625 & 29.38005 \\
\hline 4558 & 380 & 446 & 125 & 32.89474 & 28.02691 \\
\hline 5278 & 440 & 526 & 171 & 38.86364 & 32.50951 \\
\hline 5998 & 500 & 602 & 174 & 34.8 & 28.90365 \\
\hline 6718 & 560 & 684 & 203 & 36.25 & 29.67836 \\
\hline 7438 & 620 & 764 & 226 & 36.45161 & 29.58115 \\
\hline 8158 & 680 & 839 & 246 & 36.17647 & 29.32062 \\
\hline 8878 & 740 & 921 & 275 & 37.16216 & 29.85885 \\
\hline 9598 & 800 & 1001 & 298 & 37.25 & 29.77023 \\
\hline 10318 & 860 & 1080 & 359 & 41.74419 & 33.24074 \\
\hline
\end{tabular}

Table 12.2: Behaviour of number of $\mathrm{c} 1+\mathrm{c} 2$ combinations over a range of even numbers (2k) of SADN4//8

For SADN6//0:

\begin{tabular}{|r|r|r|r|r|r|}
\hline \multicolumn{1}{|c|}{$\mathbf{2 k}$} & \multicolumn{1}{|c|}{ nTC } & \multicolumn{1}{c|}{ nC+C } & \multicolumn{1}{c|}{$\begin{array}{c}\text { nC+C as \% } \\
\text { of nTC }\end{array}$} & \multicolumn{1}{c|}{$\begin{array}{c}\text { nC+C as \% } \\
\text { of nc }\end{array}$} \\
\hline 240 & 40 & 29 & 8 & 20 & 27.58621 \\
\hline 960 & 160 & 159 & 44 & 27.5 & 27.67296 \\
\hline 1680 & 280 & 298 & 101 & 36.07143 & 33.89262 \\
\hline 2400 & 400 & 444 & 135 & 33.75 & 30.40541 \\
\hline 3120 & 520 & 597 & 195 & 37.5 & 32.66332 \\
\hline 3840 & 640 & 749 & 237 & 37.03125 & 31.64219 \\
\hline 4560 & 760 & 904 & 291 & 38.28947 & 32.19027 \\
\hline 5280 & 880 & 1061 & 357 & 40.56818 & 33.6475 \\
\hline
\end{tabular}

5 [Section 12] 


\begin{tabular}{|r|r|r|r|r|r|}
\hline 6000 & 1000 & 1218 & 396 & 39.6 & 32.51232 \\
\hline 6720 & 1120 & 1374 & 494 & 44.10714 & 35.95342 \\
\hline 7440 & 1240 & 1539 & 509 & 41.04839 & 33.07342 \\
\hline 8160 & 1360 & 1698 & 576 & 42.35294 & 33.92226 \\
\hline 8880 & 1480 & 1855 & 631 & 42.63514 & 34.01617 \\
\hline 9600 & 1600 & 2017 & 678 & 42.375 & 33.61428 \\
\hline 10320 & 1720 & 2176 & 733 & 42.61628 & 33.68566 \\
\hline
\end{tabular}

Table 12.3: Behaviour of number of $\mathrm{c} 1+\mathrm{c} 2$ combinations over a range of even numbers (2k) of SADN6//0

From abovementioned tables 12.1-12.3, it is evident that the ratio of number of $c 1+c 2$ combinations to total number of combinations as well as ratio of number of $c 1+c 2$ combinations to total number of composites goes on increasing as the even number increases. It would be important to identify the reasons for this behavioural pattern of number of $\mathrm{c} 1+\mathrm{c} 2$ combinations over the range of even numbers. This is as discussed below.

Consider the even number 494. Since the number ends in 4, composite odd numbers ending in 9 would form part of $\mathrm{c} 1+\mathrm{c} 2$ combinations of type 2 . These can be derived as follows:-

(i) $2 \mathrm{k}=494$, i.e. of $\mathrm{SADN} 8$, so the relevant series would be the $\mathrm{S} 7$ series

(ii) Composite numbers on the $\mathrm{S} 7$ series would be derived as products of intraseries elements of the S5 and S7 series. We begin by deriving composite odd numbers on the S7 series ending in 9 of which 7 is a factor. This can be calculated as follows:-

$$
7(7+30 \mathrm{n}) \leq 2 \mathrm{k}
$$

The numbers thus derived would be 49, 259, 469 and correspondingly the $\mathrm{c} 1+\mathrm{c} 2$ combinations would be:-

$49+445$

$259+235$

$469+25$

Similarly c1+c2 formed by 11 can be derived as follows:-

$11(29+30 \mathrm{n}) \leq 2 \mathrm{k}$

The only composite; of which 11 is a factor, ends in 9 , and is $<494$; is given as $11 \times 29=319$. The $\mathrm{c} 1+\mathrm{c} 2$ combination formed by this number would be:-

$319+175$

6 [Section 12] 
Similarly c $1+\mathrm{c} 2$ formed by 13 would be:

As $13 \times 13=169$; hence $\mathrm{c} 1+\mathrm{c} 2$ combination is given as $169+325$

Similarly c1 $+\mathrm{c} 2$ formed by $17=289+205$

These are the $c 1+c 2$ of type 2 ; for the even number 494 ; which are 6 in number.

Apart from these $\mathrm{c} 1+\mathrm{c} 2$ of type 2 ; some $\mathrm{c} 1+\mathrm{c} 2$ of type 1 can also be identified in the following manner:

As $494 / 2=247$

And $247=13 \times 19$ so the following $\mathrm{c} 1+\mathrm{c} 2$ can be derived

$$
19 \times 7+19 \times 19 \text { i.e. } 133+361
$$

$13 \times 7+13 \times 31$ i.e. $91+403$

$$
13 \times 19+13 \times 19 \text { i.e. } 247+247
$$

Further, the condition for deriving $\mathrm{c} 1+\mathrm{c} 2$ of type 3 is $2 \mathrm{k} / 6 \mathrm{p} 1 \mathrm{p} 2 \geq 1$

This condition is fulfilled by prime pair $7 \& 11$ since $6 \mathrm{p} 1 \mathrm{p} 2$ i.e. $6 \times 7 \times 11=462$ which is $<494$. So it may be expected that there would be $1 \mathrm{c} 1+\mathrm{c} 2$ of which $7 \& 11$ are factors on either side of the combination.

Now if we double the value of $2 \mathrm{k}$ and consider the closest approximate even number of $\operatorname{SADN}(2,5,8)$ that ends in 4 , say 974 , consider the $\mathrm{c} 1+\mathrm{c} 2$ combination for this number .

$\mathrm{c} 1+\mathrm{c} 2$ of type 2 formed by $7:-$

$49,259,469,679,889$

c1+c2 formed by 11:-

$319,649,979$

c1+c2 formed by 13:-

$169,559,949$

c1+c2 formed by 17:-

289,799

It is important to note here that $c 1+c 2$ of type 2 were formed by those numbers for 494 as well. The total number of $\mathrm{c} 1+\mathrm{c} 2$ combinations formed by these numbers (viz. 7, 11, 13 and 17) for $974=13$ which was 6 for the number 494. 
However $\mathrm{c} 1+\mathrm{c} 2$ combinations of type 2 will be formed by some other numbers as well. These can be derived as:-

$19 \mathrm{x}(31+30 \mathrm{n}) \leq 2 \mathrm{k}$

589

$23 x(23+30 n) \leq 2 k$

529

Therefore the actual number of $\mathrm{c} 1+\mathrm{c} 2$ of type 2 for $974=15$

It is important to note here that the increase in number of c1+c 2 of type 2 occurs on two accounts. Firstly numbers which formed $\mathrm{c} 1+\mathrm{c} 2$ for 494 would form twice as many $\mathrm{c} 1+\mathrm{c} 2$ of type 2 for 974.

In this example number of $\mathrm{c} 1+\mathrm{c} 2$ combinations formed by 7, 11, 13 and 17 for $494=6$ and this number more than doubled to 13 with approximate doubling of $2 \mathrm{k}$ to 974 . This may be referred to as an intensive increase in the number of $c 1+c 2$ combinations of type 2 wherein prime numbers forming $\mathrm{c} 1+\mathrm{c} 2$ of type 2 for a given $2 \mathrm{k}$ can be observed to form a larger number of $c 1+c 2$ combinations for even numbers of greater value.

Secondly, some numbers wherein very first composite odd number of which these numbers are a factor is greater than the earlier $2 \mathrm{k}$ and therefore were not relevant will now come into the picture. For example the first composite formed by 19 on the S7 series is 589 (19x31 i.e. 589) which itself is $>494$. So this composite is not relevant for the even number 494. But when we consider $2 \mathrm{k}=974$; 589 will play a role in forming $\mathrm{c} 1+\mathrm{c} 2$ of type 2 . Similarly, the first composite number on the S7 series ending in 9 of which 23 is a factor would be 529 (i.e. $23 \times 23)$. Since 529 is greater than 494, it will not form a c1+c2 combination for 494 but since 529 is less than 974, it would participate in formation of $\mathrm{c} 1+\mathrm{c} 2$ combination of type 2 for 974 . This takes the total number of $c 1+c 2$ of type 2 to 15 . This may be referred to as an extensive increase in number of $\mathrm{c} 1+\mathrm{c} 2$ combinations wherein odd composite numbers formed by prime numbers which were earlier irrelevant will now have a role to play for even numbers of greater value.

Due to this intensive and extensive increase in number of $\mathrm{c} 1+\mathrm{c} 2$ combinations of type 2 , the overall number of $\mathrm{c} 1+\mathrm{c} 2$ combinations of type 2 will increase more than proportionately with a given increase in value of $2 \mathrm{k}$ i.e.: with a doubling of $2 \mathrm{k}, \mathrm{c} 1+\mathrm{c} 2$ of type 2 will increase by more than double.

This trend in number of $\mathrm{c} 1+\mathrm{c} 2$ combinations wherein with a given increase in values of even number, the number of $\mathrm{c} 1+\mathrm{c} 2$ combinations increases more than proportionately can be observed in $\mathrm{c} 1+\mathrm{c} 2$ combination of type 3 as well. Continuing with the same example given above, it was mentioned that the earlier prime pairs that satisfy the condition $2 \mathrm{k} / 6 \mathrm{p} 1 \mathrm{p} 2 \geq 1$ for the number 494 was the prime pair $7 \& 11$. Since $6 \times 7 \times 11=462$ is $\leq 494$. 
However when we consider the number 974 , number of $\mathrm{c} 1+\mathrm{c} 2$ combinations will increase on two accounts. Firstly, since 494/462 = 1 and 974/462 = 2, it may be expected that at least 2 $\mathrm{c} 1+\mathrm{c} 2$ combinations of the prime pair $7 \& 11$ will be derived. Secondly, a few more prime pairs will now satisfy the condition $2 \mathrm{k} / 6 \mathrm{p} 1 \mathrm{p} 2 \geq 1$. These are $7 \& 13=546,7 \& 17=714$, $7 \& 19=798,7 \& 23=966,11 \& 13=858$.

This implies that while $\mathrm{c} 1+\mathrm{c} 2$ combination of type 3 in which $7 \& 11$ are factors on either side of the combinations were formed for $2 \mathrm{k}=494$, for the even number 974 , this number of $\mathrm{c} 1+\mathrm{c} 2$ combinations for prime pair $7 \& 11$ will double. Additionally, 5 more prime pairs will now satisfy the condition of type 3 . The increase in number of $\mathrm{c} 1+\mathrm{c} 2$ formed by the prime pair $7 \& 11$ may be referred to as an intensive increase in number of $\mathrm{c} 1+\mathrm{c} 2$ combinations of type 3 . The increase in number of $\mathrm{c} 1+\mathrm{c} 2$ combinations of type 3 because of additional prime pairs satisfying the condition for identification of $\mathrm{c} 1+\mathrm{c} 2$ combination of type 3 may be considered as an extensive increase.

The above discussion shows that with a given increase in the value of $2 \mathrm{k}$ due to the intensive and extensive nature of increase in number of $\mathrm{c} 1+\mathrm{c} 2$ combinations, the overall number of $\mathrm{c} 1+\mathrm{c} 2$ will increase more than proportionately. This is evident from the abovementioned tables 12.1-12.3. It is important to note here that this behaviour may be attributed to the intensive and extensive rise in the number of $\mathrm{c} 1+\mathrm{c} 2$ combinations over a range of even numbers and this behavioural pattern can be observed for any range of even numbers lying anywhere on the number-line.

\section{Behaviour of minimum number of $\mathrm{c} 1+\mathrm{c} 2$ combinations over a range of even numbers:-}

As discussed above, minimum number of $\mathrm{c} 1+\mathrm{c} 2$ combinations can be derived as nTC-np or $n c-n T C$ or $(n c-n p) / 2$. Therefore in order to understand the behavioural pattern of minimum number of $\mathrm{c} 1+\mathrm{c} 2$ combinations, we need to first examine the behaviour of the underlined factors of $\mathrm{np}$ and nc over a range of even numbers. The following tables present the minimum number of $\mathrm{c} 1+\mathrm{c} 2$ over the same range of even numbers for which the actual number of $\mathrm{c} 1+\mathrm{c} 2$ combinations was discussed above.

\section{For even numbers of SADN8//2:}

\begin{tabular}{|r|r|r|r|r|}
\hline \multicolumn{1}{|r|}{$\mathbf{n}$} & nTC & nc & np & \multicolumn{2}{|c|}{ min C+C } \\
\hline 242 & 20 & 15 & 25 & $\ldots \ldots$. \\
\hline 962 & 80 & 83 & 77 & 3 \\
\hline 1682 & 140 & 153 & 127 & 13 \\
\hline 2402 & 200 & 225 & 175 & 44 \\
\hline 3122 & 260 & 304 & 216 & 58 \\
\hline 3842 & 320 & 378 & 262 & 77 \\
\hline 4562 & 380 & 457 & 303 & 95 \\
\hline 5282 & 440 & 535 & 345 & 116 \\
\hline 6002 & 500 & 616 & 384 & \\
\hline
\end{tabular}

9 [Section 12] 


\begin{tabular}{|r|r|r|r|r|}
\hline 6722 & 560 & 691 & 429 & 131 \\
\hline 7442 & 620 & 775 & 465 & 155 \\
\hline 8162 & 680 & 858 & 502 & 178 \\
\hline 8882 & 740 & 934 & 546 & 194 \\
\hline 9602 & 800 & 1015 & 585 & 215 \\
\hline 10322 & 860 & 1095 & 625 & 235 \\
\hline
\end{tabular}

Table 12.4: Behaviour of Minimum c+c over a range of Even numbers for SADN 8//2

For even numbers of SADN4//8:

\begin{tabular}{|r|r|r|r|r|}
\hline 2k & nTC & nc & np & \multicolumn{2}{|c|}{ min C+C } \\
\hline 238 & 20 & 14 & 26 & $\ldots$ \\
\hline 958 & 80 & 76 & 84 & $\ldots$ \\
\hline 1678 & 140 & 145 & 135 & 5 \\
\hline 2398 & 200 & 220 & 180 & 33 \\
\hline 3118 & 260 & 293 & 227 & 51 \\
\hline 3838 & 320 & 371 & 269 & 66 \\
\hline 4558 & 380 & 446 & 314 & 102 \\
\hline 5278 & 440 & 526 & 354 & 124 \\
\hline 5998 & 500 & 602 & 398 & 144 \\
\hline 6718 & 560 & 684 & 436 & 159 \\
\hline 7438 & 620 & 764 & 476 & 181 \\
\hline 8158 & 680 & 839 & 521 & 201 \\
\hline 8878 & 740 & 921 & 559 & 220 \\
\hline 9598 & 800 & 1001 & 599 & 640 \\
\hline 10318 & 860 & 1080 & & \\
\hline
\end{tabular}

Table 12.5: Behaviour of Minimum c+c over a range of Even numbers for SADN 4//8

For even numbers of SADN6//0:

\begin{tabular}{|r|r|r|r|r|}
\hline \multicolumn{1}{|c|}{ 2kTC } & nc & \multicolumn{1}{|c|}{ np } & \multicolumn{2}{|c|}{ min C+C } \\
\hline 240 & 40 & 29 & 51 & $\ldots$ \\
\hline 960 & 160 & 159 & 161 & $\ldots$ \\
\hline 1680 & 280 & 298 & 262 & 18 \\
\hline 2400 & 400 & 444 & 356 & 44 \\
\hline 3120 & 520 & 597 & 443 & 109 \\
\hline 3840 & 640 & 749 & 531 & 144 \\
\hline 4560 & 760 & 904 & 616 & 181 \\
\hline 5280 & 880 & 1061 & 699 & 218 \\
\hline 6000 & 1000 & 1218 & 782 & \\
\hline
\end{tabular}




\begin{tabular}{|r|r|r|r|r|}
\hline 6720 & 1120 & 1374 & 866 & 254 \\
\hline 7440 & 1240 & 1539 & 941 & 299 \\
\hline 8160 & 1360 & 1698 & 1022 & 338 \\
\hline 8880 & 1480 & 1855 & 1105 & 375 \\
\hline 9600 & 1600 & 2017 & 1183 & 417 \\
\hline 10320 & 1720 & 2176 & 1264 & 456 \\
\hline
\end{tabular}

Table 12.6: Behaviour of Minimum c+c over a range of Even numbers for SADN 6//0

It can be observed from the above tables 12.4-12.6 that there would be a steady increase in the minimum number of $c 1+c 2$ combinations but the rate of increase would be less than the rate of increase in actual number of $\mathrm{c} 1+\mathrm{c} 2$ combinations. In order to understand the reason for this pattern, we need to understand the nature of increase in number of composites.

The method for calculating total number of unique composites for a given $2 \mathrm{k}$ has been discussed in detail in section 5B. In a nutshell composite numbers on the S7 series are derived as follows:-

\section{Composites formed by elements of the $\mathrm{S} 5$ series}

(6n-1)x 5 onwards every (6n-1)x6nth number; for example composites formed by 5 would be derived as $5 \times 5$ onwards $5 \times 6$ nth numbers i.e. $25,55,85, \ldots$. Similarly, composites formed by 11 would be derived as $11 \times 5$ onwards as $11 \times 6$ nth number i.e. $55,121,187,253, \ldots$.

However since $5 \times 11$ has clearly been derived while calculating composites formed by 5 , the first effective composite formed by 11 is 121 . Similarly composites formed by 17 can be observed as $17 \times 5$ onwards $17 x 6$ nth number i.e. $85,187,289,391, \ldots$

Here again 17x5 has already been derived while calculating composites for 5 and 17 i.e. calculating composites for 11 . So the first effective composite formed by $17=289$. This shows that the first effective composite on the S7 series by a given prime number would be its square since all earlier composites of which the number would be a factor would have been derived by earlier prime numbers on the series. The same rationale can be applied to imply that the first effective composite formed be elements of the S7 series on the S7 series would be the square of the number and thereafter the number multiplied by $6 \mathrm{n}$ would give further composites. The question now is how the number of composites on the series behaves over a range of even numbers. Let us consider the same numbers discussed above for understanding the behaviour of $\mathrm{c} 1+\mathrm{c} 2$ combinations.

There are 38 composites on the S7 series < 494 and this number increases to 83 composites, $<974$. This increase in number of composites may be attributed to two factors:-

Prime numbers for which unique composites were identified for 494, the number of composites formed by these numbers between 494 and 974 would be greater. This may be extended as follows: 
This shows that number that were relevant for 494 while deriving number of composites now form a higher number of composites for 974 . This may be referred to as an intensive increase in number of composites.

However a few more composites can be observed while moving from $2 k=494$ to $2 k=974$ because squares of some more numbers will now become relevant. For example $23^{2}=529$, which is greater than 494. So number of unique composites formed by 23 is relevant for 494 but for $974,23^{2}$ will be counted as a unique composite as also other composites formed by 23 whose value would be < 974 . In case of 23 , as many as 3 composites formed by 23 will be counted while calculating number of unique composites for 974.

Besides $23,29^{2}=841$ and $31^{2}=962$ will also be counted while calculating unique composites for 974 .

This increase in number of unique composites with an increase in value of $2 \mathrm{k}$ may be referred to as extensive increase in number of composites. Due to this extensive and intensive increase in number of composites the total number of composites increases with an increase in value of $2 \mathrm{k}$.

Stated differently, tables 12.1-12.6 show that the density of composites increases as we move along the number line in positive direction. However it is important to note that the rate of increase in number of composites would be slow due to the following reasons. Firstly, while calculating number of unique composites we found that composites formed by prime numbers with other prime numbers greater than its own value and composites of which its previous prime elements are not factors would be identified. For instance while calculating number of composites formed by 11, we found that unique composites of which 11 is a factor are the prime numbers on the S5 series that are $>11$ and the composite numbers on the S5 series of which 5 is not a factor.

Similarly while calculating unique composites of 17, we found that only composites would be considered which 17 forms with prime numbers greater than 17 on the S5 series as also with the composites on the S5 series of which 5 and 11 are not factors.

Since elements on the S5 and S7 series comprise of both the prime and composite numbers, a rise in composite numbers would result in a corresponding decrease in the number of primes. This in turn will cause a decrease in the rate at which composite numbers would be formed.

Secondly, the first relevant composite number on the S7 series would be the square of a prime element after which the number under consideration multiplied by $6 \mathrm{n}$ would give further composites. Since the gap between consecutive squares goes on increasing as we progress along the number line, the numbers which come into the picture increase at a decreasing rate.

Secondly, as discussed above; the first unique composite formed by a number would be its square. This implies that if the square of a certain prime number $\mathrm{p} 1$ i.e. $\mathrm{p} 1^{2}$ is such that it greater than $2 \mathrm{k}$ and less than $2 \mathrm{k}$, then $\mathrm{p} 1$ would have a role to play in identifying composites 
for $2 \mathrm{k}$ ' which was not the case for $2 \mathrm{k}$. As mentioned above, it causes an extensive rise in the number of composites over a range of numbers.

Due to this the extrinsic increase in number of composites occurs at a decreasing rate.

Over the range of numbers where an extensive increase does not occur, only the intensive increase in number of composites plays a role.

Another important factor here is that as composites are derived as $5 x(6 n-1)$ onwards each $6(6 n-1)$ th number on the S5 series, for every successive numbers on the S5 series, value of starting point and the subsequent numbers would go on increasing. For instance, $17 \times 5=85$ and $17 \times 6=102$ while $23 \times 5=115$ and $23 \times 6=138$. So the $(6 n-1) \times 6 n$th number goes on increasing with successive numbers.

So even in case of an intensive increase, the rate at which successive elements of the series contributes to formation of composites goes on decreasing.

Due to the operation of these factors, the overall number of composites increases at a decreasing rate.

Since elements on the series comprise of either prime elements or composite elements, an increase in number of composites at a decreasing rate will cause an increase in number of primes also at a decreasing rate.

As mentioned above, minimum number of $\mathrm{c}+\mathrm{c}$ combinations depends on the number of composites and primes. While both TC and np increase; TC increases at a fixed rate whereas $n p$ increases at a decreasing rate. Therefore the resultant variable would increase at a rather slow pace. This is evident from the above tables and this pattern can be observed over any range of even numbers.

\section{Zeno's Achilles and tortoise paradox..}

Zeno's Achilles and tortoise paradox associated with the Greek philosopher Zeno presents a very interesting prospective on what would transpire in the race between Achilles and tortoise under certain conditions. The paradox says that even though the tortoise runs at a speed evidently slower than that of Achilles, the latter would never be able to win the race with tortoise under two conditions- firstly that the tortoise has a headstart, in the race, of a finite distance and secondly, both the Achilles and tortoise run at a constant speed.

The reasoning goes as follows:-

Achilles runs at a speed of $\mathrm{x} \mathrm{km} / \mathrm{h}$ while tortoise runs at a speed of $\mathrm{y} \mathrm{km} / \mathrm{h}$ such that $\mathrm{y}=\mathrm{x} / 2$ i.e. Achilles runs twice the speed of the tortoise. Further suppose Achilles gives tortoise a headstart of $\mathrm{z}$ meters where $\mathrm{z}$ is a finite positive number. 
Once the race commences, in order to beat the tortoise in the race, Achilles needs to first catch up with the tortoise. Achilles would cover the distance $z$ at its speed of $x \mathrm{~km} / \mathrm{h}$ and reach where the tortoise started from. But by that time the tortoise has moved ahead at its speed of $\mathrm{y} \mathrm{km} / \mathrm{h}$ and tortoise needs to cover this distance in order to catch up. But by the time Achilles covers this distance, tortoise has travelled further. Even though the distance between Achilles and tortoise goes on decreasing and tends to become zero, it remains a non-zero quantity. If we consider any distance that is even infinitesimally greater than zero, it is a nonzero distance nevertheless. The tortoise remains ahead of the Achilles infinitely. This makes the Zeno's Achilles and tortoise paradox conceptually sound.

Now consider what would happen to this if we introduce two changes to the situation. First, both Achilles' and tortoise's speeds increase over the race, but the rate of increase in Achilles' speed is greater than the rate of increase in tortoise's speed. Second, it is Achilles and not the tortoise that gets a headstart in the race. Effectively what would happen is tortoise running the race at a speed less than that of Achilles throughout and beginning the race at a distance behind the Achilles. The question is: Will the tortoise ever be able to catch up with the Achilles. Conceptually, if the fast runner is not able to catch up with the slow runner if the latter gets a headstart then the slow runner starting the race at a disadvantageous position would never be able to catch up with the fast runner. Consider the following situation. Achilles runs at a speed of $x \mathrm{~km} / \mathrm{h}$ and begins the race at point $\mathrm{z}$. Tortoise runs at a speed of $y$ $\mathrm{km} / \mathrm{h}$ and begins the race at point $\mathrm{z}^{\prime}$. Note that value of $\mathrm{x}$ and $\mathrm{y}$ may change but $\mathrm{x}>\mathrm{y}$ at all times and $z$ is ahead of $z^{\prime}$ by a finite distance.

In this situation if tortoise has to catch up with Achilles, it needs to first cover the distance between z' and z. But by the time tortoise reaches point z, Achilles has covered a distance of $\mathrm{z}-\mathrm{z}$ ' ' and as Achilles' speed is greater than tortoise's speed, z' $-\mathrm{z}$ would be definitely greater than $z^{\prime}-z$. This means at this stage the gap between Achilles and tortoise is now greater than what it was at the beginning of the race. By the time tortoise reaches point $z$ ', Achilles would have covered a greater distance which further widens the gap between Achilles and tortoise. This would logically widen the gap between Achilles and tortoise continuously and infinitely.

\section{Who is Achilles and who is the tortoise?}

The behaviour of actual $\mathrm{c} 1+\mathrm{c} 2$ and minimum $\mathrm{c} 1+\mathrm{c} 2$ has been discussed above alongwith the reasoning for their corresponding behaviour. It would be useful to now compare their behaviour. The following table shows the difference between the minimum and actual number of $\mathrm{c} 1+\mathrm{c} 2$ combinations:

\section{For SADN 8//2:-}

\begin{tabular}{|c|c|c|c|}
\hline $\mathbf{2 k}$ & act cc & min cc & act- min cc \\
\hline 242 & 3 & $\ldots$ & $\ldots$ \\
\hline 962 & 19 & 3 & 16 \\
\hline 1682 & 37 & 13 & 24 \\
\hline
\end{tabular}

14 [Section 12] 


\begin{tabular}{|c|c|c|c|}
\hline 2402 & 60 & 25 & 35 \\
\hline 3122 & 88 & 44 & 44 \\
\hline 3842 & 107 & 58 & 49 \\
\hline 4562 & 129 & 77 & 52 \\
\hline 5282 & 155 & 95 & 60 \\
\hline 6002 & 177 & 116 & 61 \\
\hline 6722 & 200 & 131 & 69 \\
\hline 7442 & 229 & 155 & 74 \\
\hline 8162 & 283 & 178 & 105 \\
\hline 8882 & 282 & 194 & 88 \\
\hline 9602 & 292 & 215 & 77 \\
\hline 10322 & 334 & 235 & 99 \\
\hline
\end{tabular}

Table 12.7: Difference between actual and minimum number of $\mathrm{c1}+\mathrm{c} 2$ combinations for even numbers of type SADN 8//2

For SADN 4//8:-

\begin{tabular}{|c|c|c|c|}
\hline $\mathbf{2 k}$ & act cc & min cc & act- min cc \\
\hline 238 & 4 & $\ldots$ & $\ldots$ \\
\hline 958 & 18 & $\ldots$ & $\ldots$ \\
\hline 1678 & 36 & 5 & 31 \\
\hline 2398 & 58 & 20 & 38 \\
\hline 3118 & 74 & 33 & 41 \\
\hline 3838 & 109 & 51 & 58 \\
\hline 4558 & 125 & 66 & 59 \\
\hline 5278 & 171 & 86 & 85 \\
\hline 5998 & 174 & 102 & 72 \\
\hline 6718 & 203 & 124 & 82 \\
\hline 7438 & 226 & 144 & 87 \\
\hline 8158 & 246 & 159 & 94 \\
\hline 8878 & 275 & 181 & 97 \\
\hline 9598 & 298 & 201 & 139 \\
\hline 10318 & 359 & 220 & 79 \\
\hline
\end{tabular}

Table 12.8: Difference between actual and minimum number of $\mathrm{c1}+\mathrm{c} 2$ combinations for even numbers of type SADN 4//8

For SADN 6//0:-

\begin{tabular}{|c|c|c|c|}
\hline $\mathbf{2 k}$ & act $\mathbf{c c}$ & $\min \mathbf{c c}$ & act- $\mathbf{m i n} \mathbf{c c}$ \\
\hline 240 & 8 & $\ldots$ & $\ldots$ \\
\hline
\end{tabular}




\begin{tabular}{|c|c|c|c|}
\hline 960 & 44 & $\ldots$ & $\ldots$ \\
\hline 1680 & 101 & 18 & 83 \\
\hline 2400 & 135 & 44 & 91 \\
\hline 3120 & 195 & 77 & 118 \\
\hline 3840 & 237 & 109 & 128 \\
\hline 4560 & 291 & 144 & 147 \\
\hline 5280 & 357 & 181 & 176 \\
\hline 6000 & 396 & 218 & 240 \\
\hline 6720 & 494 & 254 & 210 \\
\hline 7440 & 509 & 299 & 238 \\
\hline 8160 & 576 & 338 & 256 \\
\hline 8880 & 631 & 375 & 261 \\
\hline 9600 & 678 & 417 & 277 \\
\hline 10320 & 733 & 456 & \\
\hline
\end{tabular}

Table 12.9: Difference between actual and minimum number of c1+c2 combinations for even numbers of type SADN 6//0

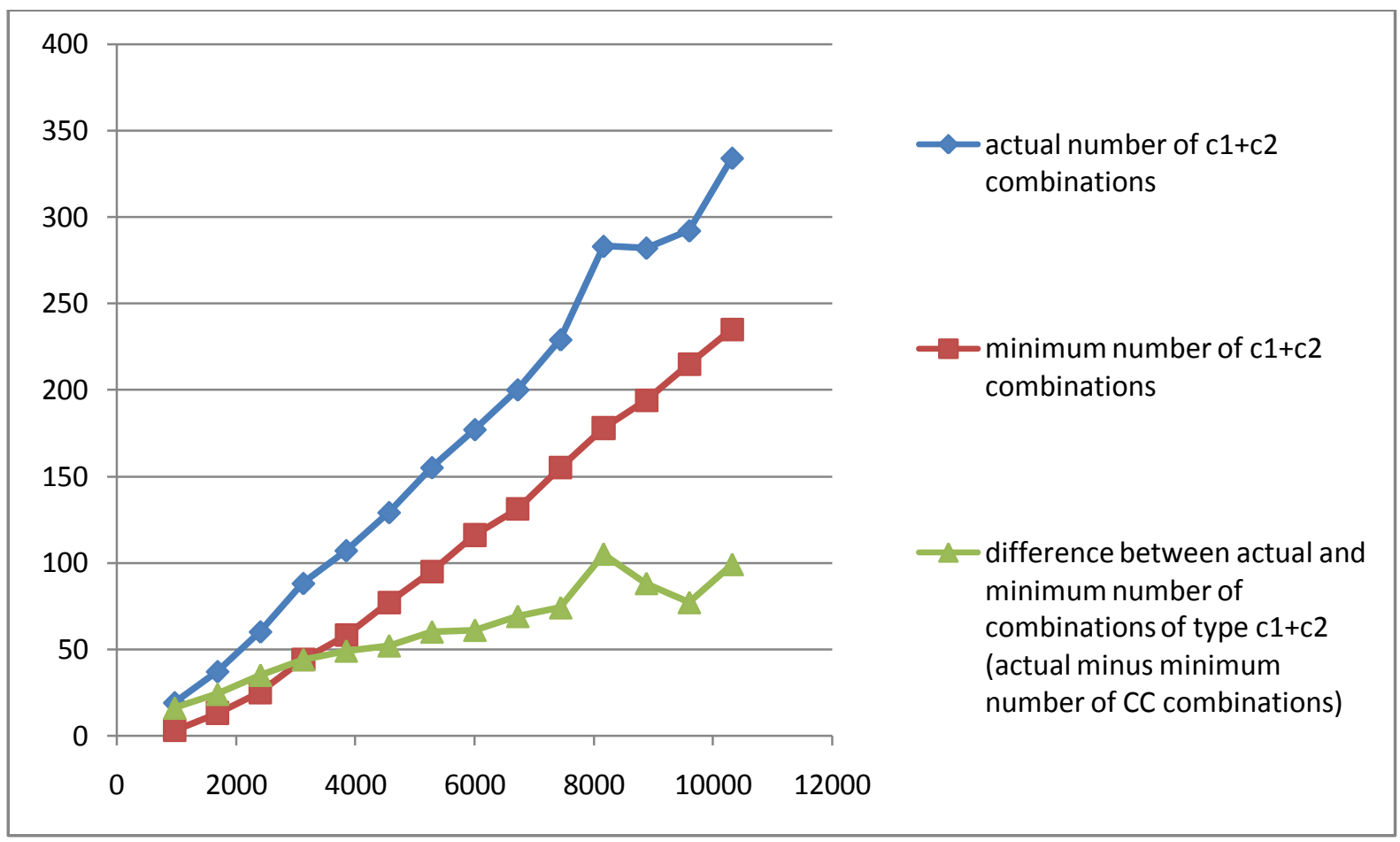

Graph 12.1: Depiction of actual number of $c 1+c 2$ combinations, minimum number of $c 1+c 2$ combinations and difference between actual vis-à-vis minimum number of $c 1+c 2$ combinations for even numbers of SADN8//2 


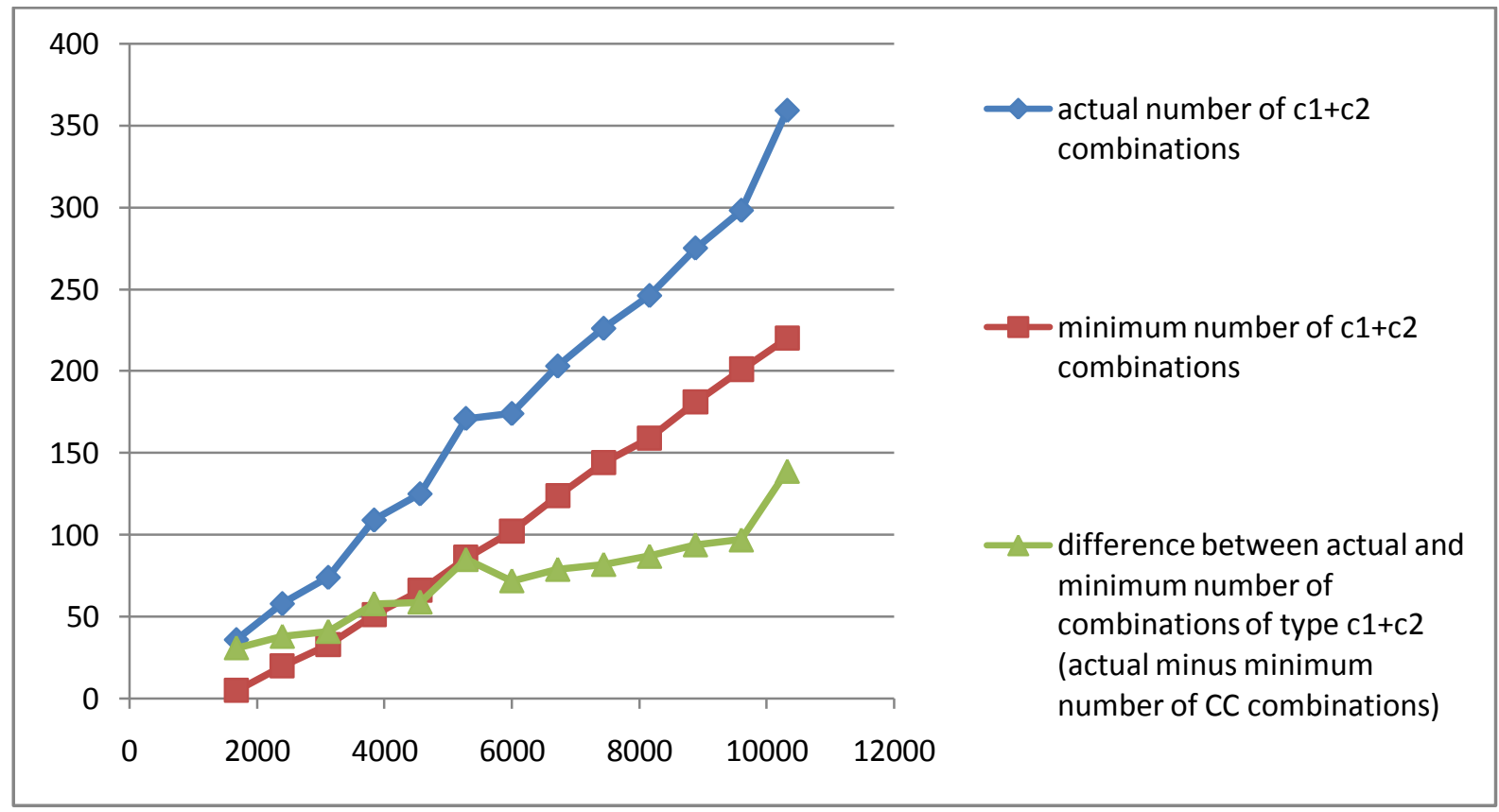

Graph 12.2: Depiction of actual number of $c 1+c 2$ combinations, minimum number of c1+c2 combinations and difference between actual vis-à-vis minimum number of $\mathbf{c 1}+\mathbf{c} 2$ combinations for even numbers of SADN4//8

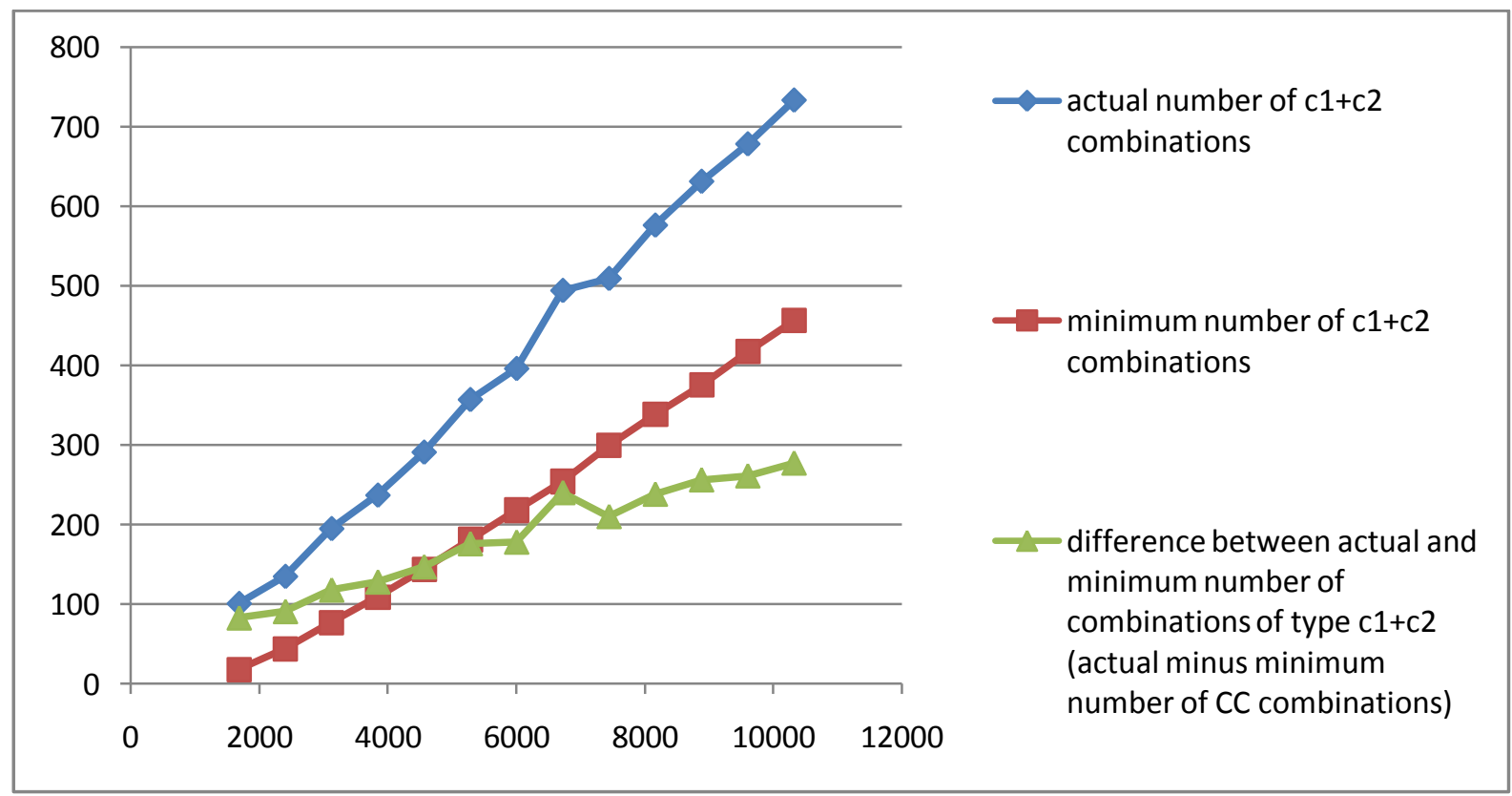

Graph 12.3: Depiction of actual number of $\mathrm{c} 1+\mathrm{c} 2$ combinations, minimum number of c1+c2 combinations and difference between actual vis-à-vis minimum number of c1+c2 combinations for even numbers of SADN6//0 
It is evident from the tables 12.7-12.9 as well as the graphs 12.1-12.3 that the difference between the actual and minimum number of $\mathrm{c} 1+\mathrm{c} 2$ combinations goes on increasing thereby causing a continuous divergence between the actual and minimum $\mathrm{c} 1+\mathrm{c} 2$ functions.

From this discussion it is concluded that actual $\mathrm{c} 1+\mathrm{c} 2$ is in the role of the Achilles and min $\mathrm{c} 1+\mathrm{c} 2$ is in the role of the tortoise.

Both actual $\mathrm{c} 1+\mathrm{c} 2$ and minimum $\mathrm{c} 1+\mathrm{c} 2$ increase over a range of numbers but the former increases at a rate higher than that of the latter which causes a divergence between the distance covered by the tortoise and the Achilles.

An important question here is that where do these functions begin from. An examination of all even numbers of $\operatorname{SADN}(2,5,8)$ shows that for all numbers less than 800 , TC $>$ number of composites. 800 is the first even number where $\mathrm{TC}=$ number of composites $=$ number of primes $=67$.

Here minimum $\mathrm{c} 1+\mathrm{c} 2=\mathrm{TC}-\mathrm{np}=67-67=0$

So minimum required $\mathrm{c} 1+\mathrm{c} 2=0+1=1$

In case of any even number of $\operatorname{SADN}(5,2,8)$; if we calculate the actual number of $\mathrm{c} 1+\mathrm{c} 2$ for 800 we find that there are $20 \mathrm{c} 1+\mathrm{c} 2$ combinations for the number 800 whereas the minimum required $\mathrm{c} 1+\mathrm{c} 2=1$. This implies that at the point on the number line where the actual and minimum $\mathrm{c} 1+\mathrm{c} 2$ functions become relevant, actual $\mathrm{c} 1+\mathrm{c} 2$ is observed to be substantially greater than minimum required $\mathrm{c} 1+\mathrm{c} 2$. This may be interpreted as the Achilles having a headstart of 19 in the race with the tortoise.

An examination of all even numbers of $\operatorname{SADN}(7,4,1)$ shows that for all numbers less than 1144 , nTC > number of composites. 1144 is the first even number where $\mathrm{nTC}=$ number of composites $=$ number of primes $=95$.

Here minimum $\mathrm{c} 1+\mathrm{c} 2=\mathrm{tc}-\mathrm{np}=95-95=0$

So minimum required $\mathrm{c} 1+\mathrm{c} 2=0+1=1$

In case of any even number of $\operatorname{SADN}(7,4,1)$; if we calculate the actual number of $\mathrm{c} 1+\mathrm{c} 2$ for 1144 we find that there are $24 \mathrm{c} 1+\mathrm{c} 2$ for the number 1144 whereas the minimum required $\mathrm{c} 1+\mathrm{c} 2=1$. This implies that at the point on the number line where the actual and minimum $\mathrm{c} 1+\mathrm{c} 2$ functions become relevant, actual $\mathrm{c} 1+\mathrm{c} 2$ is observed to be substantially greater than minimum required $\mathrm{c} 1+\mathrm{c} 2$. This may be interpreted as the Achilles having a headstart of 23 in the race with the tortoise.

An examination of all even numbers of $\operatorname{SADN}(6,3,9)$ shows that for all numbers less than 966, TC > number of composites. 966 is the first even number where $t c=$ number of composites $=$ number of primes $=161$. 
Here minimum $\mathrm{c} 1+\mathrm{c} 2=\mathrm{tc}-\mathrm{np}=161-161=0$

So minimum required $\mathrm{c} 1+\mathrm{c} 2=0+1=1$

If we calculate the actual number of $\mathrm{c} 1+\mathrm{c} 2$ for 966 we find that there are $45 \mathrm{c} 1+\mathrm{c} 2$ for the number 966 whereas the minimum required number of combinations of type $\mathrm{c} 1+\mathrm{c} 2=1$. This implies that at the point on the number line where the actual and minimum $\mathrm{c} 1+\mathrm{c} 2$ functions become relevant, actual $\mathrm{c} 1+\mathrm{c} 2$ is observed to be substantially greater than minimum required $\mathrm{c} 1+\mathrm{c} 2$. This may be interpreted as the Achilles having a headstart of 44 in the race with the tortoise.

In a nutshell therefore, the relation between the actual and minimum $\mathrm{c} 1+\mathrm{c} 2$ functions is analogous to the race between the Achilles and the tortoise where the former has a headstart over the latter and also the speed of the former increases at a rate faster than the increase in the speed of the latter. This will evidently cause a divergence between the two functions continuously and infinitely.

Two exceptions to the pattern of divergence will be found. Firstly, the actual $\mathrm{c} 1+\mathrm{c} 2$ function will appear to dip for an even number where mid-point $\mathrm{k}$ is a prime and such an even number follows one whose mid-point is composite.

Consider an even number $2 \mathrm{k}$ of SADN2 whose mid-point $\mathrm{k}$ is a prime. The previous even number on this series would be $2 \mathrm{k}-6$. If the mid-point of $2 \mathrm{k}-6$ is a composite number, it will appear that $n c+c$ for $2 k$ is less than $n c+c$ for $2 k-6$. Since $2 k-6$ appears before $2 k$ on the number line, it will appear that the actual $\mathrm{c} 1+\mathrm{c} 2$ function is dipping. This may be attributed to the correlation between the number of $\mathrm{c} 1+\mathrm{c} 2$ combinations for a given $2 \mathrm{k}$ and the nature of $\mathrm{k}$; i.e. whether $\mathrm{k}$ is prime or composite.

As mentioned earlier, $\mathrm{c} 1+\mathrm{c} 2$ combinations can be derived across three steps for a given even number. However since $\mathrm{c} 1+\mathrm{c} 2$ of type 1 are derived from the factors of mid-point $\mathrm{k}$, such combinations would exist for even numbers if mid-point is composite in nature. However for even numbers whose mid-point is a prime, $c 1+c 2$ of type 1 will not exist and only $c 1+c 2$ combinations of type 2 and type 3 will exist. The Venn diagram described in section 11C, and reproduced below, may be referred in this context. 


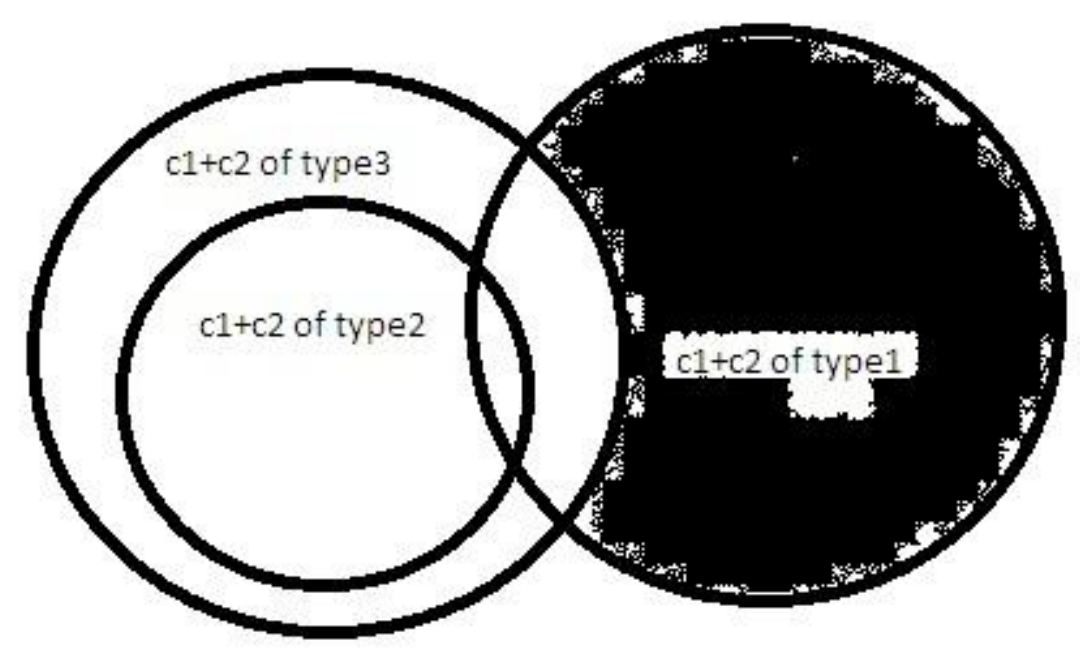

\section{Reproduced here Diagram 11C.1: Venn diagram representing the relation of subset and superset among the $1+c 2$ combinations of types 1,2 and 3}

It is evident from the abovementioned Venn diagram that some $\mathrm{c} 1+\mathrm{c} 2$ of type 1 will overlap with $\mathrm{c} 1+\mathrm{c} 2$ of types 2 and 3 whereas some $\mathrm{c} 1+\mathrm{c} 2$ are derived uniquely only by $\mathrm{c} 1+\mathrm{c} 2$ of type1.

These $\mathrm{c} 1+\mathrm{c} 2$ represented by the shaded portion will be derived only for $2 \mathrm{k}$ where $\mathrm{k}$ is composite. Therefore if $\mathrm{k}$ is prime then $\mathrm{c} 1+\mathrm{c} 2$ of type 1 will not exist thereby bringing the number of $\mathrm{c} 1+\mathrm{c} 2$ down. Therefore for even numbers $(2 \mathrm{k})$ where $\mathrm{k}$ is prime, $\mathrm{nc}+\mathrm{c}$ will be less than $\mathrm{nc}+\mathrm{c}$ for even numbers where $\mathrm{k}$ is composite. This also explains the dependence of number of $\mathrm{p} 1+\mathrm{p} 2$ combinations on the nature of mid-point $\mathrm{k}$; whether $\mathrm{k}$ is prime or composite. This pattern has been reported as an observation by Watanabe [12].

Another exception where actual $\mathrm{c} 1+\mathrm{c} 2$ function will appear to converge towards the minimum $\mathrm{c} 1+\mathrm{c} 2$ function is for numbers that immediately follow even numbers ending in zero(0) i.e. consider an even number $2 \mathrm{k}$ of SADN 2 ending in 0 and having ' $\mathrm{B}$ ' number of nc+c. For the next even number which would be of $\operatorname{SADN} 8$, the last digit would be 6 and generally $n c+c$ for this number would be less than 'B'. Here also it appears that the actual and minimum $\mathrm{c} 1+\mathrm{c} 2$ functions converge towards one another. This dip in $\mathrm{nc}+\mathrm{c}$ can be attributed to the following reasoning:-

For even numbers ending in zero(0), all composite odd numbers ending in 5 whose value is less than $2 \mathrm{k}$ will form part of $\mathrm{c} 1+\mathrm{c} 2$ combinations of type 2 . Since composites of which 5 is a factor occur at the highest frequency i.e. at a gap of 30 natural numbers, the number of composites of which 5 is a factor would be the highest. Since all these composites would form part of $\mathrm{c} 1+\mathrm{c} 2$ combinations of type 2 , the overall number of $\mathrm{c} 1+\mathrm{c} 2$ combinations for these numbers ending in zero(0) would be higher as compared to even numbers ending in other digits. Due to this $n c+c$ for $2 \mathrm{k} / / 0$ would be in the nature of local maxima and $n c+c$ for 
$2 \mathrm{k}$ immediately following these numbers would be less in number as compared with the number of $\mathrm{c} 1+\mathrm{c} 2$ combinations for the previous even number ending in 0 . This causes the actual $\mathrm{c} 1+\mathrm{c} 2$ function to appear to converge towards the minimum $\mathrm{c} 1+\mathrm{c} 2$ function.

However it is logically reasoned to note that these convergences are temporary (relative to the location on the number line) in nature and the general nature of relation between the actual and minimum $\mathrm{c} 1+\mathrm{c} 2$ function is one of continuous/resultant divergence.

\section{Will the tortoise ever be able to catch up with the Achilles?}

The tortoise would be able to catch up with the Achilles only if its speed abruptly rises and rises to an extent that it covers the earlier divergence between the two that has been created during the race. In terms of the actual and minimum $\mathrm{c} 1+\mathrm{c} 2$ it implies that the minimum $\mathrm{c} 1+\mathrm{c} 2$ will rise and intersect the actual $c 1+c 2$ function if the prime gap at that point is so large that it causes the minimum $\mathrm{c} 1+\mathrm{c} 2$ function to rise sharply.

It may be noted that since the speed at which the tortoise runs the race increases during the course of the race, it will attain that much speed in due course of the race but by then the required speed to catch up with the Achilles would have become significantly greater (Since in the mean time the distance between Achilles and the tortoise would have increased further).

\section{Consider the following hypothetical situation:-}

Achilles begins the race at a speed of $11 \mathrm{~km} /$ hour while tortoise begins at $5 \mathrm{~km} /$ hour. Further let us assume this speed increases after every $1 \mathrm{~km}$ distance and Achilles begins the race one $\mathrm{km}$ ahead of the tortoise. Also assume that the speed of the Achilles increases at rate of $1 \mathrm{~km} / \mathrm{h}$ after every $1 \mathrm{~km}$ distance while speed of the tortoise increases by $0.5 \mathrm{~km} / \mathrm{hour}$ after every $1 \mathrm{~km}$ distance.

For the tortoise to catch up Achilles in the race, it has to cover the distance for which Achilles has a headstart and also the distance which Achilles will travel in the meantime.

Tortoise will cover the initial distance of $1 \mathrm{~km}$ at its speed of $5 \mathrm{~km} /$ hour in 12 minutes. By this time Achilles will cover an additional distance of a bit more than $2 \mathrm{kms}$ at its initial speed of $11 \mathrm{~km} /$ hour causing the distance between Achilles and tortoise to widen.

At the beginning of the race, in order to beat Achilles, the tortoise needs to run at a constant speed of $12 \mathrm{~km} /$ hour to catch Achilles; also running at a constant speed, after 1 hour.

It is important to note that the speed of the tortoise would, at a point be $12 \mathrm{~km} /$ hour since its speed rises at the rate of $0.5 \mathrm{~km} /$ hour after every $1 \mathrm{~km}$ distance. But by the time the tortoise's speed rises to this much rate, by that time the speed of Achilles has increased upto 25 $\mathrm{km} /$ hour, which is greater than the tortoise's speed of $12 \mathrm{~km} / \mathrm{hour}$ at this moment of time.

An analogy may be derived here to the role of prime gaps. The prime gap required to cause minimum $\mathrm{c} 1+\mathrm{c} 2$ to rise and catch up with the actual $\mathrm{c} 1+\mathrm{c} 2$ function will be identified at some location on the number line, but at the location on the number line where such a required 
prime gap would be identified the divergence between the minimum and actual $\mathrm{c} 1+\mathrm{c} 2$ functions would have increased causing the required prime gap for minimum $\mathrm{c} 1+\mathrm{c} 2$ to rise further to the level of actual $\mathrm{c} 1+\mathrm{c} 2$.

By the time this gap would be reached, the divergence between minimum and actual $\mathrm{c} 1+\mathrm{c} 2$ will rise further causing the required prime gap to rise further. This brings us to the argument that not only is the magnitude of the prime gap important but also the location at number line where this prime gap occurs. For example, a prime gap of 50 numbers at a value of $2 \mathrm{k}=600$ would be significant in its implications as compared to a prime gap of 50 numbers at the value of $2 \mathrm{k}=100000$.

It may be inferred from the above discussion that due to two factors, firstly the rate at which the actual $\mathrm{c} 1+\mathrm{c} 2$ function rises is greater than the rate at which the minimum $\mathrm{c} 1+\mathrm{c} 2$ function rises. Second, the actual $\mathrm{c} 1+\mathrm{c} 2$ function has a headstart over the minimum $\mathrm{c} 1+\mathrm{c} 2$ function at the value of $2 \mathrm{k}$ where these functions become relevant. Due to these two factors, there would be a continuous divergence between the actual and minimum $\mathrm{c} 1+\mathrm{c} 2$ functions and thus minimum $\mathrm{c} 1+\mathrm{c} 2$ function would never be able to intersect the actual $\mathrm{c} 1+\mathrm{c} 2$ function.

As discussed earlier the actual $\mathrm{c} 1+\mathrm{c} 2$ function has a headstart over the minimum $\mathrm{c} 1+\mathrm{c} 2$ function and increases at a rate faster than the rate of increase in minimum $\mathrm{c} 1+\mathrm{c} 2$ function causing a continuous divergence between the two functions. Since the difference between minimum $\mathrm{c} 1+\mathrm{c} 2$ and actual $\mathrm{c} 1+\mathrm{c} 2$ is equal to the number of $\mathrm{p} 1+\mathrm{p} 2$ combinations, or divergence between minimum $\mathrm{c} 1+\mathrm{c} 2$ and actual $\mathrm{c} 1+\mathrm{c} 2$ function indicates that the number of $\mathrm{p} 1+\mathrm{p} 2$ combinations continuously increases over a range of numbers.

\section{What does this imply?}

As discussed above, the difference between actual and minimum numbers of $\mathrm{c} 1+\mathrm{c} 2$ combinations indicates the existence of $\mathrm{p} 1+\mathrm{p} 2$ combinations. Once again we return to the above table 12.7-12.9 which presented the difference between these two variables. Accordingly we can now disintegrate TC into its three components by applying the following reasoning:-

$n T C=(n c+c)+(n p+c)+(n p+p)$

$\mathrm{nc}+\mathrm{c}$ has been derived by following the steps mentioned in section 11 .

$\mathrm{np}+\mathrm{c}$ is equal to $\mathrm{nc}-2 \mathrm{x}(\mathrm{nc}+\mathrm{c})$ i.e. $\mathrm{nc}$ minus twice the number of combinations of type $\mathrm{c} 1+\mathrm{c} 2$.

$\mathrm{np}+\mathrm{p}$ is equal to $\mathrm{nTC}-(\mathrm{nc}+\mathrm{c})-(\mathrm{np}+\mathrm{c})$

The relation between these three components for the range of even numbers mentioned above is presented in the following table:-

\section{For SADN 8//2:}

\begin{tabular}{|c|c|c|c|c|c|c|}
\hline $\mathbf{2 k}$ & NC & NP & NTC & NCC & NCP & NPP \\
\hline 242 & 15 & 25 & 20 & 3 & 9 & 8 \\
\hline
\end{tabular}

22 [Section 12] 


\begin{tabular}{|c|c|c|c|c|c|c|}
\hline 962 & 83 & 77 & 80 & 19 & 45 & 16 \\
\hline 1682 & 153 & 127 & 140 & 37 & 79 & 24 \\
\hline 2402 & 225 & 175 & 200 & 60 & 105 & 35 \\
\hline 3122 & 304 & 216 & 260 & 88 & 128 & 44 \\
\hline 3842 & 378 & 262 & 320 & 107 & 164 & 49 \\
\hline 4562 & 457 & 303 & 380 & 129 & 199 & 52 \\
\hline 5282 & 535 & 345 & 440 & 155 & 225 & 60 \\
\hline 6002 & 616 & 384 & 500 & 177 & 262 & 61 \\
\hline 6722 & 691 & 429 & 560 & 200 & 291 & 69 \\
\hline 7442 & 775 & 465 & 620 & 229 & 317 & 74 \\
\hline 8162 & 858 & 502 & 680 & 283 & 292 & 105 \\
\hline 8882 & 934 & 546 & 740 & 282 & 370 & 88 \\
\hline 9602 & 1015 & 585 & 800 & 292 & 431 & 77 \\
\hline 10322 & 1095 & 625 & 860 & 334 & 427 & 99 \\
\hline
\end{tabular}

Table 12.10: Relation between components of TC for even numbers of type SADN 8//2

For SADN 4//8:

\begin{tabular}{|c|c|c|c|c|c|c|}
\hline $\mathbf{2 k}$ & NC & NP & NTC & NCC & NCP & NPP \\
\hline 238 & 14 & 26 & 20 & 4 & 6 & 10 \\
\hline 958 & 76 & 84 & 80 & 18 & 40 & 22 \\
\hline 1678 & 145 & 135 & 140 & 36 & 73 & 31 \\
\hline 2398 & 220 & 180 & 200 & 58 & 104 & 38 \\
\hline 3118 & 293 & 227 & 260 & 74 & 145 & 41 \\
\hline 3838 & 371 & 269 & 320 & 109 & 153 & 58 \\
\hline 4558 & 446 & 314 & 380 & 125 & 196 & 59 \\
\hline 5278 & 526 & 354 & 440 & 171 & 184 & 85 \\
\hline 5998 & 602 & 398 & 500 & 174 & 254 & 72 \\
\hline 6718 & 684 & 436 & 560 & 203 & 278 & 79 \\
\hline 7438 & 764 & 476 & 620 & 226 & 312 & 82 \\
\hline 8158 & 839 & 521 & 680 & 246 & 347 & 87 \\
\hline 8878 & 921 & 559 & 740 & 275 & 371 & 94 \\
\hline 9598 & 1001 & 599 & 800 & 298 & 405 & 97 \\
\hline 10318 & 1080 & 640 & 860 & 359 & 362 & 139 \\
\hline
\end{tabular}

Table 12.11: Relation between components of TC for even numbers of type SADN 4//8

For SADN 6//0:

\begin{tabular}{|c|c|c|c|c|c|c|}
\hline $\mathbf{2 k}$ & NC & NP & NTC & NCC & NCP & NPP \\
\hline 240 & 29 & 51 & 40 & 8 & 13 & 19 \\
\hline
\end{tabular}




\begin{tabular}{|c|c|c|c|c|c|c|}
\hline 960 & 159 & 161 & 160 & 44 & 71 & 45 \\
\hline 1680 & 298 & 262 & 280 & 101 & 96 & 83 \\
\hline 2400 & 444 & 356 & 400 & 135 & 174 & 91 \\
\hline 3120 & 597 & 443 & 520 & 195 & 207 & 118 \\
\hline 3840 & 749 & 531 & 640 & 237 & 275 & 128 \\
\hline 4560 & 904 & 616 & 760 & 291 & 322 & 147 \\
\hline 5280 & 1061 & 699 & 880 & 357 & 347 & 176 \\
\hline 6000 & 1218 & 782 & 1000 & 396 & 426 & 178 \\
\hline 6720 & 1374 & 866 & 1120 & 494 & 386 & 240 \\
\hline 7440 & 1539 & 941 & 1240 & 509 & 521 & 210 \\
\hline 8160 & 1698 & 1022 & 1360 & 576 & 546 & 238 \\
\hline 8880 & 1855 & 1105 & 1480 & 631 & 593 & 256 \\
\hline 9600 & 2017 & 1183 & 1600 & 678 & 661 & 261 \\
\hline 10320 & 2176 & 1264 & 1720 & 733 & 710 & 277 \\
\hline
\end{tabular}

Table 12.12: Relation between components of TC for even numbers of type SADN 6//0

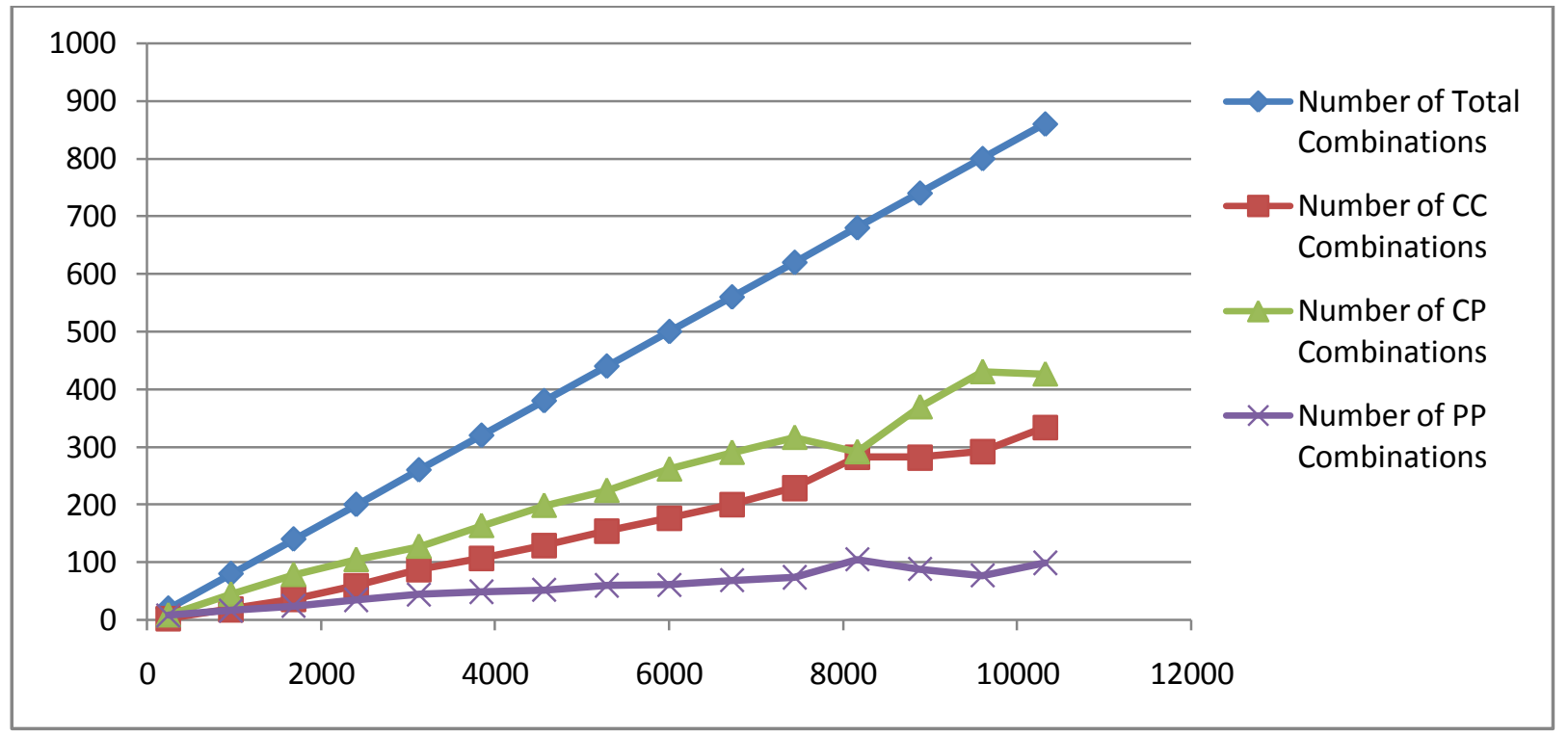

Graph 12.4: Depiction of number of total combinations, number of $\mathrm{c} 1+\mathrm{c} 2$ combinations, number of $c+p$ combinations and number of $p 1+p 2$ combinations for even numbers of SADN8//2 


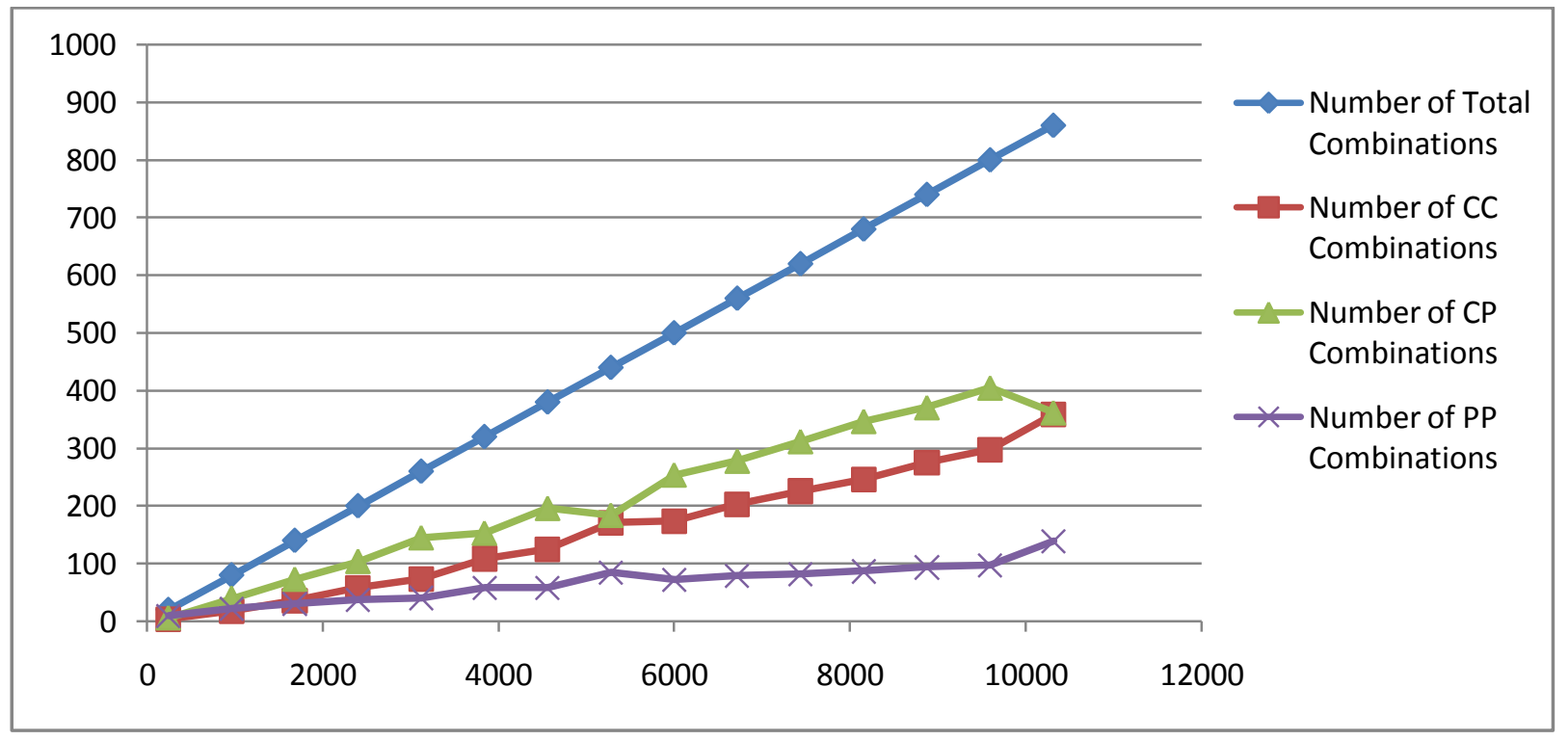

Graph 12.5: Depiction of number of total combinations, number of $\mathrm{c} 1+\mathrm{c} 2$ combinations, number of $c+p$ combinations and number of $p 1+p 2$ combinations for even numbers of SADN6//8

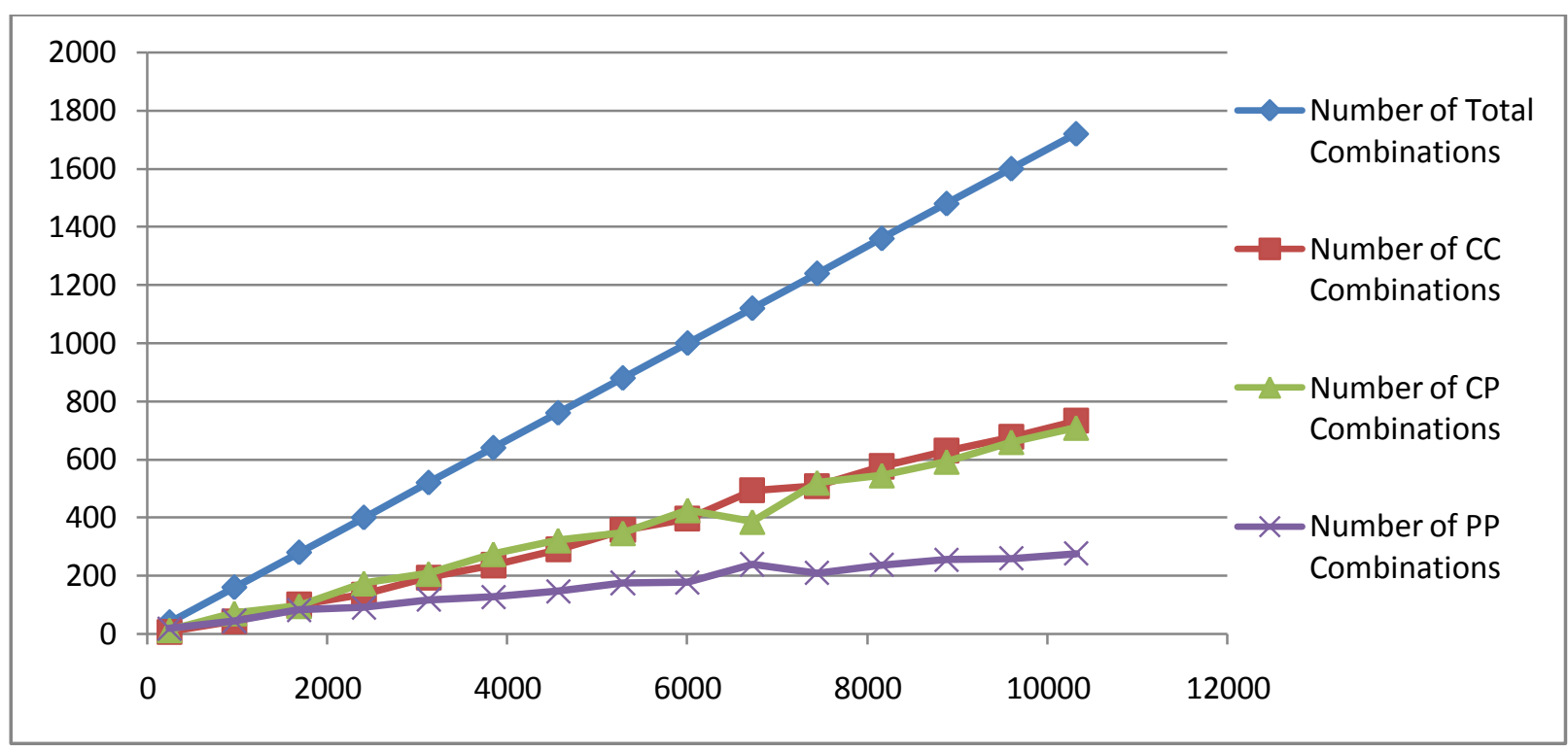

Graph 12.6: Depiction of number of total combinations, number of $\mathrm{c} 1+\mathrm{c} 2$ combinations, number of $c+p$ combinations and number of $p 1+p 2$ combinations for even numbers of SADN4//0

It is deduced from above tables 12.10-12.12 and graphs $12.4-12.6$ that the number of pp combinations (i.e. $\mathrm{p} 1+\mathrm{p} 2$ combinations) steadily increases over the given range of even numbers. Here again it is important to note that the behaviour of actual and minimum $\mathrm{c} 1+\mathrm{c} 2$ observed in the above range of numbers can be observed across any range of even numbers lying anywhere on the number line. Therefore the divergence between these two functions would be continuous and increasing, which implies that number of $\mathrm{p} 1+\mathrm{p} 2$ combinations would correspondingly and continuously increase over the number line. 


\section{3}

\section{Conclusion}

\section{Conclusion: Implications of the above analysis for the Goldbach conjecture}

The much celebrated Goldbach conjecture states that all even numbers can be expressed as summation of two prime numbers i.e. $2 \mathrm{k}=\mathrm{p} 1+\mathrm{p} 2$ where $\mathrm{p} 1$ and $\mathrm{p} 2$ are both prime numbers. Threads of the above discussion lead us to the following broad conceptual framework:-

SADN of any natural number, odd or even, may range from 1 to 9 , while SADN of prime numbers can be $1,2,4,5,7$ or 8 . Odd numbers, primes or composites, that are of $6 n-1$ type are of SADN $(5,2,8)$ and occur in a cyclic order infinitely along the number line while primes or composites of $6 n+1$ type are of $\operatorname{SADN}(7,4,1)$ and occur in a cyclic order infinitely along the number line. This allows us to classify odd numbers into three series- S1, S5 and S3 series- of which the S3 series comprises only of composite numbers while the S1 and S5 series comprise of both prime and composite numbers.

If we consider the possible SADN of prime numbers that add upto a particular even number we find that prime combinations that add upto even numbers of $\operatorname{SADN}(5,2,8)$ can be found on the $\mathrm{S} 1$ series of odd numbers. Prime combinations for even numbers of SADN $(7,4,1)$ can be found on the S5 series while prime combinations for even numbers of SADN $(3,6,9)$ can be found such that one component lies on the S1 series while the other component lies on the $\mathrm{S} 5$ series. We define this as the relevant series for even numbers in that relevant series for $2 \mathrm{k}$ of SADN $(5,2,8)$ is the $\mathrm{S} 1$ series, for $2 \mathrm{k}$ of $\operatorname{SADN}(7,4,1)$ is the S5 series and that for $2 \mathrm{k}$ of SADN $(3,6,9)$ are both the S1 and S5 series. Thereafter we derive the total number of combinations on the relevant series for a given $2 \mathrm{k}$ which would include all elements of the relevant series, either primes or composites, whose value is less than $2 \mathrm{k}$ i.e. all elements on the relevant series whose value is less than $2 \mathrm{k}$ will find a place in one combination or the other. Since these elements can be of either prime or composite in nature, these combinations can be of three types wherein both components of the combination are primes, both components are composites or one component of the combination is prime while the other component is composite i.e. if we denote primes as p1 and p2 and composites as c1 and c2, the three combinations for an even number can be in the nature of:-

i. $\quad \mathrm{p} 1+\mathrm{p} 2$ where both components are prime in nature

ii. $\quad \mathrm{c} 1+\mathrm{c} 2$ where both components are composites in nature

iii. $\mathrm{p} 1+\mathrm{c} 1($ or $\mathrm{p}+\mathrm{c})$ where one component is prime in nature while the other component is composite. 
Based on the relation between total number of acceptable combinations nTC and total number of composites nc, all even numbers can be classified as those where nTC > nc and those where nTC $\leq \mathrm{nc}$. Within these two categories a further classification is where mid-point can be either odd or even and if odd then mid-point may be either prime or composite.

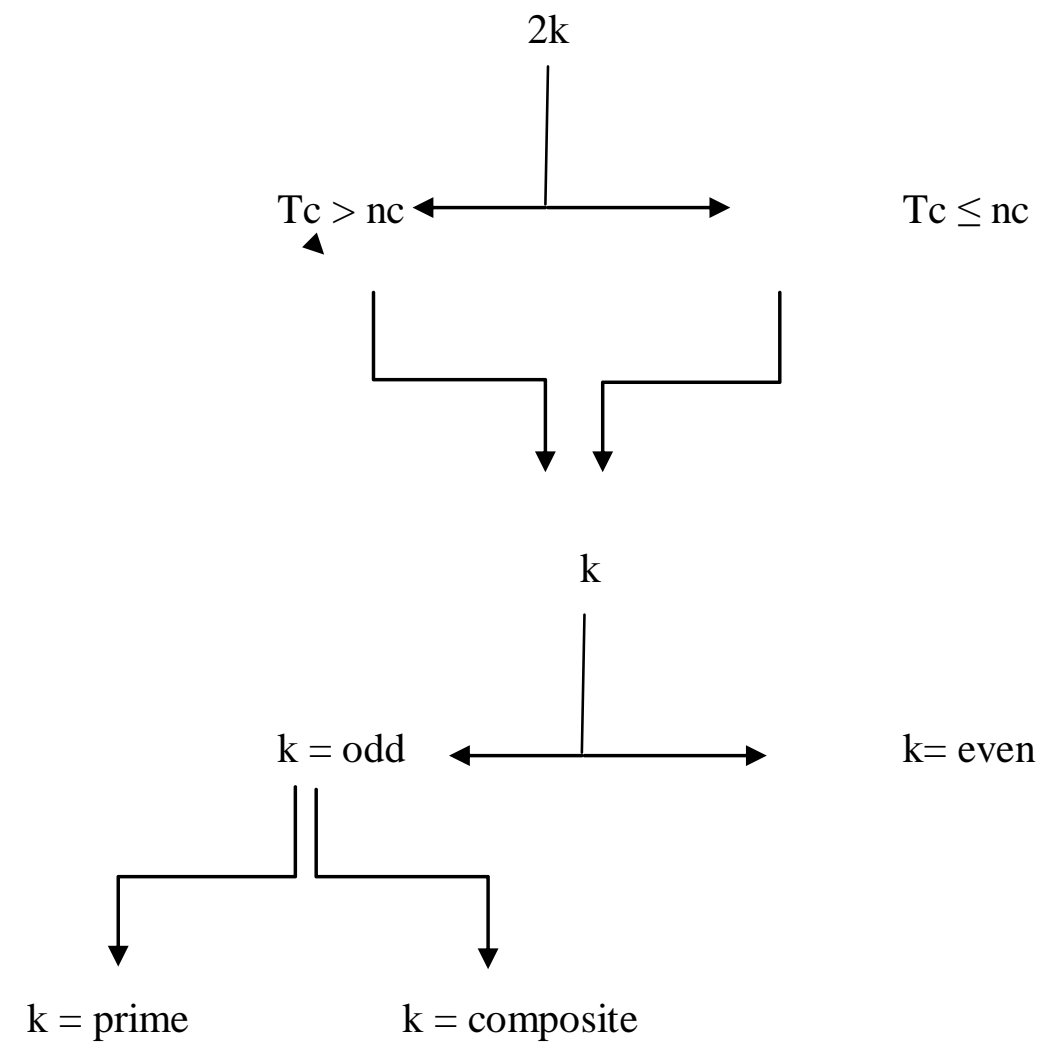

For even numbers where nTC > nc by atleast one, even if all composites are prime-eaters i.e. form part of $\mathrm{p}+\mathrm{c}$ combinations, there would still be atleast one combination of type $\mathrm{p} 1+\mathrm{p} 2$. This is because if nTC $>n c$ then considering $n p=2 n T C-n c, n p>n c$ and the difference between $n p$ and $n c$ would be $2 x(n T C-n c)$. Since prime elements will form part of either $p+c$ or $\mathrm{p} 1+\mathrm{p} 2$ combinations, prime elements remaining after being absorbed by composites to form $\mathrm{p}+\mathrm{c}$ combinations will form $\mathrm{p} 1+\mathrm{p} 2$ combinations i.e. where $\mathrm{nTC}>\mathrm{nc}, \mathrm{np}$ would be $>\mathrm{nc}$ and $n p-n c=2 x(n T C-n c)$

In this case, the maximum possible number of $\mathrm{p}+\mathrm{c}$ combinations would be equal to $\mathrm{nc}$ and number of $\mathrm{p} 1+\mathrm{p} 2$ combinations would be (np-nc)/2. Therefore for even numbers where nTC $>\mathrm{nc}$ by atleast one, it directly follows that $\mathrm{p} 1+\mathrm{p} 2$ combination is existing. For even numbers where midpoint $\mathrm{k}$ is prime, $\mathrm{k}+\mathrm{k}$ will form a combination in which both components of the combination would be prime.

In both the above cases where nTC $>\mathrm{nc}$ and where $\mathrm{k}$ is prime, it directly follows that a prime combination that adds up to the given $2 \mathrm{k}$ is existing and therefore the Goldbach Conjecture holds good in these cases.

In section 12, we have introduced the concepts of actual and minimum $\mathrm{c} 1+\mathrm{c} 2$ and discussed the relation between these two in detail. Actual $\mathrm{c} 1+\mathrm{c} 2$ refers to the total number of $\mathrm{c} 1+\mathrm{c} 2$ 
combinations derived by following the steps discussed in section 11 and broadly includes $\mathrm{c} 1+\mathrm{c} 2$ of following three types:-

i. $\quad \mathrm{c} 1+\mathrm{c} 2$ derived from mid-point $\mathrm{k}$ which is applicable only where $\mathrm{k}$ is a composite number.

ii. $\quad \mathrm{c} 1+\mathrm{c} 2$ derived from last digit of $2 \mathrm{k}$ which would be in the nature of a combination where one component would be a multiple of 5 .

iii. $\quad c 1+c 2$ formed by prime pairs $\mathrm{p} 1 \mathrm{p} 2$ which satisfy the general condition of $2 \mathrm{k} / 6 \mathrm{p} 1 \mathrm{p} 2 \geq$ 1

Minimum $\mathrm{c} 1+\mathrm{c} 2$ refers to the number of $\mathrm{c} 1+\mathrm{c} 2$ that would be identified if all primes would form part of $\mathrm{p}+\mathrm{c}$ combinations and this would be derived as nTC $-\mathrm{np}$ or nc $-\mathrm{Tc}$ or (nc-np)/2

The discussion in section 12 leads us to the solution that though both actual and minimum $\mathrm{c} 1+\mathrm{c} 2$ increase continuously as we move forward along the number line, due to the nature of behaviour of the underlying factors determining the number of actual and minimum $\mathrm{c} 1+\mathrm{c} 2$, the former increases at a rate faster than the latter. Also, at the point at which these functions become relevant in the analysis i.e. where $\mathrm{nTC}=\mathrm{nc}$ and $\mathrm{nTC}<\mathrm{nc}$, actual $\mathrm{c} 1+\mathrm{c} 2$ is found to be greater in number as compared to the latter. These concepts put together lead us to the conclusion that actual $\mathrm{c} 1+\mathrm{c} 2$ is bound to be greater than minimum $\mathrm{c} 1+\mathrm{c} 2$ at the point of relevance and thereafter due to the difference in the rate of increase in the two functions, there would be a continuous divergence between them except of two situations as described with reasons in section 12 . This divergence would be continuous and infinite in nature.

It has also been shown in section 12 that the difference between minimum $\mathrm{c} 1+\mathrm{c} 2$ and actual $\mathrm{c} 1+\mathrm{c} 2$ indicates the number of $\mathrm{p} 1+\mathrm{p} 2$ combinations for a given $2 \mathrm{k}$ i.e.

$\mathrm{np}+\mathrm{p}=$ actual $\mathrm{c}+\mathrm{c}-$ minimum $\mathrm{c}+\mathrm{c}$

considering that the divergence between the actual and minimum $\mathrm{c} 1+\mathrm{c} 2$ functions is continuous and the difference between the two is the number of $\mathrm{p} 1+\mathrm{p} 2$ combinations, it follows that where $\mathrm{nTC} \leq \mathrm{nc}$, due to the gap between minimum $\mathrm{c} 1+\mathrm{c} 2$ and actual $\mathrm{c} 1+\mathrm{c} 2$; $\mathrm{p} 1+\mathrm{p} 2$ combinations would be identified. This confirms the existence of $\mathrm{p} 1+\mathrm{p} 2$ combinations for $2 \mathrm{k}$ where $\mathrm{nTC} \leq \mathrm{nc}$ and therefore proves the Goldbach conjecture for those numbers as well.

Another noteworthy point here is the relation between the nature of $\mathrm{k}$ and the number of $\mathrm{p} 1+\mathrm{p} 2$ combinations i.e. the dependence of number of $\mathrm{p} 1+\mathrm{p} 2$ combinations on whether $\mathrm{k}$ is prime or composite. Watanabe [12] has observed that in case of $2 \mathrm{k}$ if $\mathrm{k}$ is prime, the number of $\mathrm{p} 1+\mathrm{p} 2$ combinations identified would be less as compared to $n p+p$ for $2 \mathrm{k}$ if $\mathrm{k}$ is composite in nature. This condition can be derived from the Venn diagram presented in section 11C.

$\mathrm{c} 1+\mathrm{c} 2$ combinations of all three types exist for numbers where $\mathrm{k}$ is composite in nature while in case of numbers where $\mathrm{k}$ is a prime, $\mathrm{c} 1+\mathrm{c} 2$ combinations of only types 2 and 3 are existing. This is because $\mathrm{c} 1+\mathrm{c} 2$ of type 1 are derived from the composite midpoint $(\mathrm{k})$ by the factors of the midpoint. So when $\mathrm{k}$ is a prime, these $\mathrm{c} 1+\mathrm{c} 2$ combinations would not be identified at all. Further, it is evident from the Venn diagram referred here that there would be some overlap 
between $\mathrm{c} 1+\mathrm{c} 2$ of type 1 with $\mathrm{c} 1+\mathrm{c} 2$ of types 2 and 3 but some $\mathrm{c} 1+\mathrm{c} 2$ of type 1 will be unique in nature.

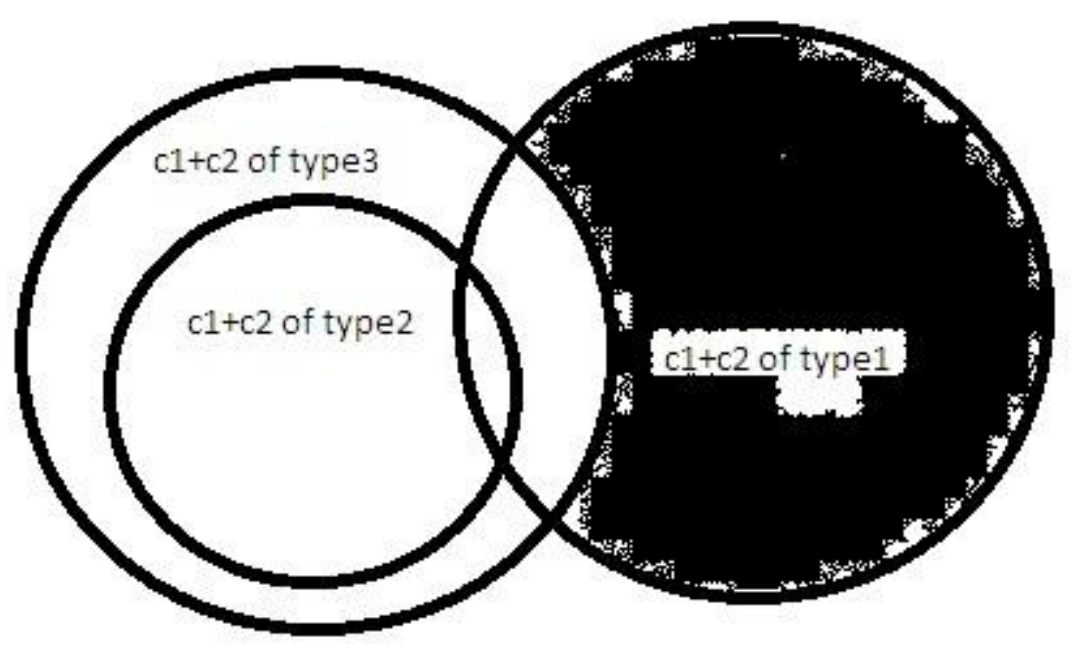

Reproduced here Diagram 11C.1: Venn diagram representing the relation of subset and superset among the c1+c2 combinations of types1, 2 and 3

The shaded portion of $\mathrm{c} 1+\mathrm{c} 2$ of type 1 , in the above venn diagram shows the $\mathrm{c} 1+\mathrm{c} 2$ of type 1 that will not be identified by methods of type 2 or type 3 . Therefore if $\mathrm{k}$ is prime; $\mathrm{c} 1+\mathrm{c} 2$ combinations to the extent of the shaded portion will not be identified and this will cause the overall number of $\mathrm{c} 1+\mathrm{c} 2$ to be less as compared to number of $\mathrm{c} 1+\mathrm{c} 2$ identified for $2 \mathrm{k}$ if $\mathrm{k}$ is composite in nature. As number of composites participating in $\mathrm{c} 1+\mathrm{c} 2$ combinations decreases, the number of $\mathrm{p}+\mathrm{c}$ combinations would correspondingly increase. Due to this reason, number of $\mathrm{p} 1+\mathrm{p} 2$ combinations for $2 \mathrm{k}$ where $\mathrm{k}$ is prime will be less as compared to number of $\mathrm{p} 1+\mathrm{p} 2$ for even number $2 \mathrm{k}$ where $\mathrm{k}$ is composite in nature.

Since even numbers can be of SADN 1 to 9 and the relation between Tc and nc for all even numbers can either be of $\mathrm{Tc}>\mathrm{nc}$ or $\mathrm{Tc} \leq \mathrm{nc}$, the above discussion which shows that the Goldbach conjecture is true for both these categories of even numbers, is totally inclusive of all even numbers in general terms and since analysis of every even number is common in methodology but unique in compilation, this analysis apart from being totally inclusive, is also mutually exclusive in nature.

This proves that the Goldbach conjecture which states that all even numbers can be expressed as atleast one combination of two prime numbers holds true for all even numbers, across all categories possible. Additionally this approach based on conceptual framework of SADN proves that the identification of $p 1+p 2$ combinations which would validate the Goldbach conjecture lies in the identification of $\mathrm{c1}+\mathrm{c} 2$ combinations.

4 [Section13] 


\section{References:}

[1] Goldbach, C.Letter to Euler, Correspondance mathématique et physiquede quelques célèbres géomètres du XVIIIème siècle(Band 1), St.-Pétersbourg 1843, pp. 125-129

[2] Dickson, L. E. "Goldbach's Empirical Theorem: Every Integer is a Sum of Two Primes." In History of the Theory of Numbers, Vol. 1: Divisibility and Primality. New York: Dover, pp. 421-424, 2005.

[3] Pipping, N. "Die Goldbachsche Vermutung und der Goldbach-Vinogradovsche Satz." Acta. Acad. Aboensis, Math. Phys. 11, 4-25, 1938.

[4] Tomás Oliveira e Silva, Siegfried Herzog, and Silvio Pardi, Empirical verification of the even Goldbach conjecture and computation of prime gaps up to $4 \cdot 10^{\wedge} 18$, Mathematics of Computation, vol. 83, no. 288, pp. 2033-2060, July 2014 (published electronically on November 18, 2013).

[5] Hardy, G. H. Ramanujan: Twelve Lectures on Subjects Suggested by His Life and Work, 3rd ed. New York: Chelsea, 1999, pp.19.

[6] Hardy, G. H. and Littlewood, J. E. "Some Problems of 'Partitio Numerorum.' III. On the Expression of a Number as a Sum of Primes." Acta Math. 44, 1-70, 1923.

[7] Hardy, G. H. and Littlewood, J. E. "Some Problems of Partitio Numerorum (V): A Further Contribution to the Study of Goldbach's Problem." Proc. London Math. Soc. Ser. 2 22, 46-56, 1924.

[8] Hardy, G. H. and Wright, E. M. An Introduction to the Theory of Numbers, 5th ed. Oxford, England: Clarendon Press, p. 19, 1979.

[9] Helfgott, H. A. "The Ternary Goldbach Conjecture Is True." Jan. 17, 2014. https://arxiv.org/pdf/1312.7748.pdf.

[10] Pogorzelski, H. A. "Goldbach Conjecture." J. reine angew. Math. 292, 1-12, 1977.

[11] H. Pogorzelski and W. Ryan, Foundations of Semiological Theory of Numbers. Volume O1, General Semiology (2010). Volume O2, Semiological Functions (2010). Volume O3, Foundations of Computability (2010). (Republications of the above Volumes).

[12] Kenneth A. Watanabe, Definitive General Proof of Goldbach's Conjecture; December 6, 2018.

[13] Zeno's paradox of Achilles and Tortoise: Available at http://www.math.utah.edu/ cashen/Teaching/2008SpringCalcII/Zeno.pdf Last accessed on $19^{\text {th }}$ November 2020. 